Otimização de processos acoplados: programação da produção e corte de estoque 

SERVIÇO DE PÓS-GRADUAÇÃO DO ICMC-USP

Data de Depósito:

Assinatura:

\title{
Otimização de processos acoplados: programação da produção e corte de estoque
}

\author{
Carla Taviane Lucke da Silva Ghidini
}

Orientador: Prof. Dr. Marcos Nereu Arenales

Tese apresentada ao Instituto de Ciências Matemáticas e de Computação - ICMC-USP, como parte dos requisitos para obtenção do título de Doutor em Ciências - Ciências de Computação e Matemática Computacional. 

“Ao Edson..." 


\section{Agradecimentos}

Neste momento, quero agradecer as pessoas que de diversas maneiras contribuíram para a realização deste trabalho:

Ao Edson pela companhia, cumplicidade e dedicação durante todo o doutorado.

Aos meus pais Rosimir e Elisabeth pelo carinho e amor.

Aos meus irmãos Alexandre e Roger e cunhadas Valéria e Claudia por acreditarem em mim.

À Mariana, minha sobrinha querida, pelos momentos de descontração e alegria.

Ao professor Marcos Arenales pela orientação, compreensão e simpatia (admirável).

À Selma Arenales pelos conselhos, confiança e amizade.

Aos meus amigos Kelly, Adriana, Douglas, Victor, Daniela (Unicamp), Silvia, Aline, Tamara, Pedro, Claudia, Sheila, Mariá, Guilherme, Marcio, Edilaine, Lana pela amizade, companhia e momentos únicos vividos no doutorado.

Aos professores Franklina, Maristela e Alysson (ICMC - USP), Aurelio (IMECC UNICAMP), Reinaldo (DEP - UFSCar), Socorro e Silvio (Unesp - São José do Rio Preto), Andrea (Unesp - Bauru) pelo apoio e amizade.

Ao pessoal da secretaria de pós-graduação pela colaboração e eficiência.

À FAPESP e ao CNPq pelo apoio financeiro.

A Deus pela minha vida. 


\section{Resumo}

Em diversas indústrias de manufatura (por exemplo, papeleira, moveleira, metalúrgica, têxtil) as decisões do dimensionamento de lotes interagem com outras decisões do planejamento e programação da produção, tais como, a distribuição, o processo de corte, entre outros. Porém, usualmente, essas decisões são tratadas de forma isolada, reduzindo o espaço de soluções e a interdependência entre as decisões, elevando assim os custos totais. Nesta tese, estudamos o processo produtivo de indústrias de móveis de pequeno porte, que consiste em cortar placas grandes disponíveis em estoque para obter diversos tipos de peças que são processadas posteriormente em outros estágios e equipamentos com capacidades limitadas para, finalmente, comporem os produtos demandados. Os problemas de dimensionamento de lotes e corte de estoque são acoplados em um modelo de otimização linear inteiro cujo objetivo é minimizar os custos de produção, estoque de produtos, preparação de máquinas e perda de matéria-prima. Esse modelo mostra o compromisso existente entre antecipar ou não a fabricação de certos produtos aumentando os custos de estoque, mas reduzindo a perda de matéria-prima ao obter melhores combinações entre as peças. O impacto da incerteza da demanda (composta pela carteira de pedidos e mais uma quantidade extra estimada) foi amortizado pela estratégia de horizonte de planejamento rolante e por variáveis de decisão que representam uma produção extra para a demanda esperada no melhor momento, visando a minimização dos custos totais. Dois métodos heurísticos são desenvolvidos para resolver uma simplificação do modelo matemático proposto, o qual possui um alto grau de complexidade. Os experimentos computacionais realizados com exemplares gerados a partir de dados reais coletados em uma indústria de móveis de pequeno porte, uma análise dos resultados, as conclusões e perspectivas para este trabalho são apresentados.

Palavras-chave: Problema de otimização acoplado. Problema de corte bidimensional. Problema de dimensionamento de lotes. 


\section{Abstract}

In the many manufacturing industries (e.g., paper industry, furniture, steel, textile), lot-sizing decisions generally arise together with other decisions of planning production, such as distribution, cutting, scheduling and others. However, usually, these decisions are dealt with separately, which reduce the solution space and break dependence on decisions, increasing the total costs. In this thesis, we study the production process that arises in small scale furniture industries, which consists basically of cutting large plates available in stock into several thicknesses to obtain different types of pieces required to manufacture lots of ordered products. The cutting and drilling machines are possibly bottlenecks and their capacities have to be taken into account. The lot-sizing and cutting stock problems are coupled with each other in a large scale linear integer optimization model, whose objective function consists in minimizing different costs simultaneously, production, inventory, raw material waste and setup costs. The proposed model captures the tradeoff between making inventory and reducing losses. The impact of the uncertainty of the demand, which is composed with ordered and forecasting products) was smoothed down by a rolling horizon strategy and by new decision variables that represent extra production to meet forecasting demands at the best moment, aiming at total cost minimization. Two heuristic methods are proposed to solve relaxation of the mathematical model. Randomly generated instances based on real world life data were used for the computational experiments for empirical analyses of the model and the proposed solution methods.

Keywords: Large scale optimization problem. Integer linear optimization. Two-dimensional cutting stock problem. Lot-sizing problem. 


\section{Índice}

Lista de figuras .......................................................................................................ii

Lista de tabelas .........................................................................................................................................

1 Introdução ................................................................................................................................................1

2 Revisão bibliográfica ............................................................................................................................

2.1 Problema acoplado para um tipo de produto …………………………………………...

2.2 Problema acoplado na indústria de processamento de madeira..........................................

2.3 Problema acoplado na indústria de componentes de cobre ...........................................13

2.4 Problema acoplado na indústria de caminhão.................................................................17

2.5 Problema acoplado na indústria de papel I ................................................................2

2.6 Problema acoplado na indústria de papel II...............................................................22

2.7 Problema acoplado na indústria de correias .............................................................2

2.8 Problema acoplado na indústria de móveis................................................................26

2.9 Problema acoplado na indústria de papel III ...............................................................2

3 Problemas de dimensionamento de lotes e corte de estoque..................................................31

3.1 Problema de dimensionamento de lotes (PDL) …………………………………........ 31

3.1.1 Problema de dimensionamento de lotes mono-estágio .......................................32

3.1.2 Problema de dimensionamento de lotes multi-estágio .........................................35

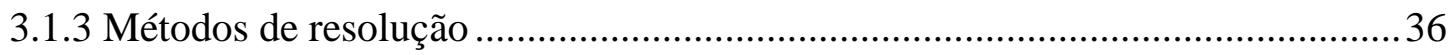

3.2 Problema de corte de estoque (PCE) .........................................................................

3.2.1 Classificação do problema de corte de estoque ..................................................36

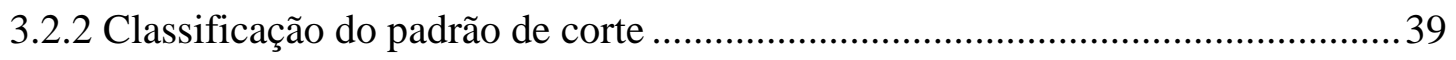


3.2.3 Modelagem matemática do PCE unidimensional e bidimensional.................... 41

3.2.4 Problema de corte de estoque restrito .............................................................. 47

3.2.5 Problema de corte de estoque multiperíodo ...................................................... 48

4. Problema acoplado de dimensionamento de lotes e corte de estoque na indústria de

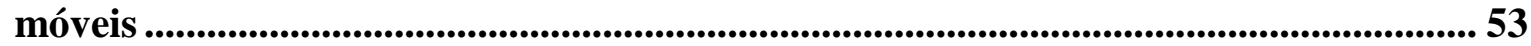

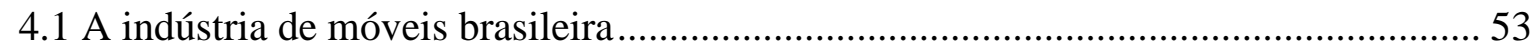

4.2 Programação da produção na indústria de móveis ..................................................... 55

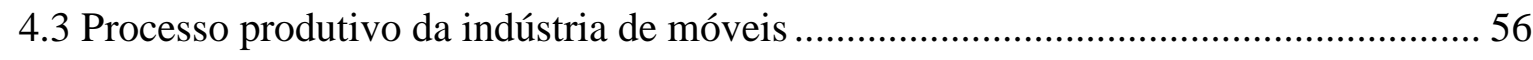

4.4 Problema acoplado na indústria de móveis ................................................................. 59

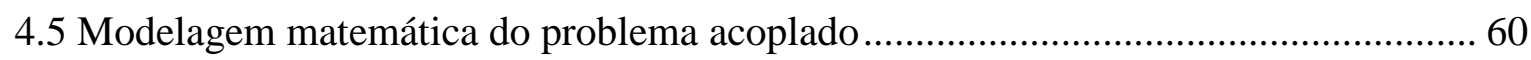

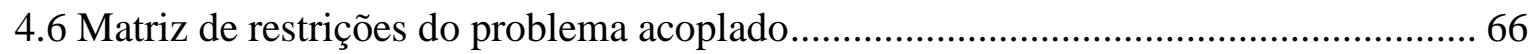

4.7 Dificuldades do modelo matemático do problema acoplado ..................................... 67

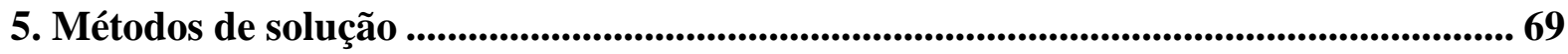

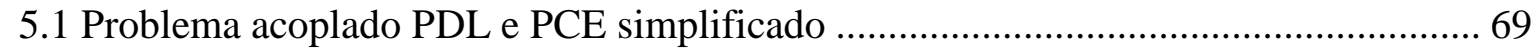

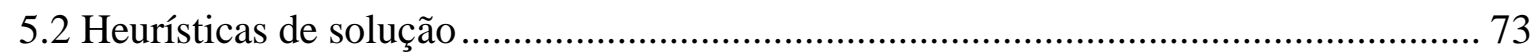

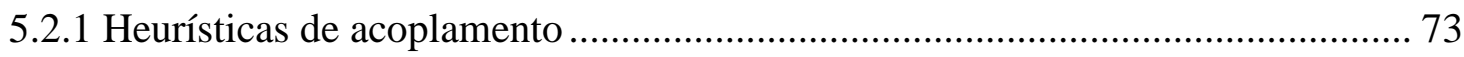

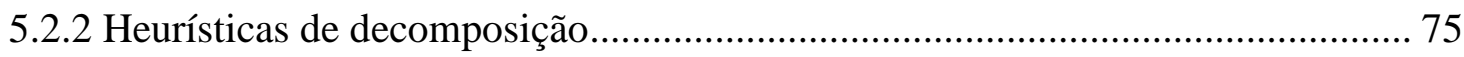

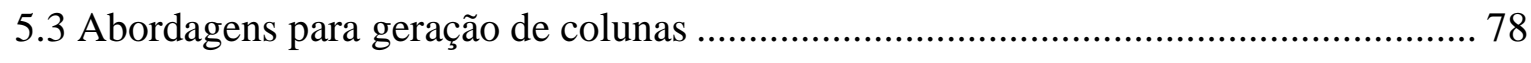

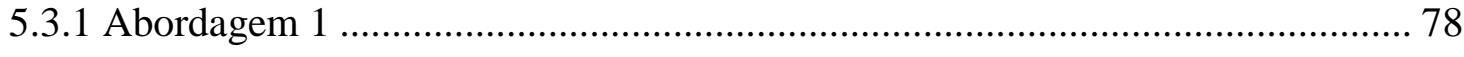

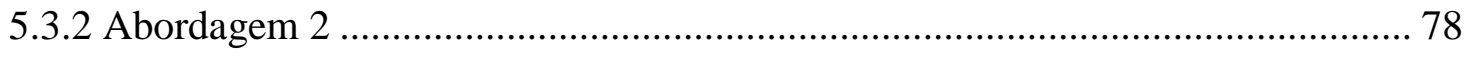

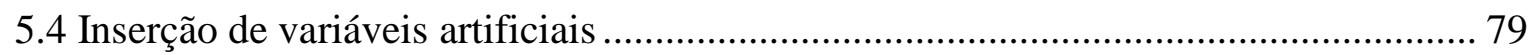

5.5 Heurística de factibilização para a heurística de decomposição ................................... 79

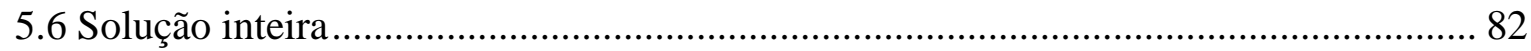

5.6.1 Solução inteira para heurística de decomposição .............................................. 82

5.6.2 Solução inteira para heurística de acoplamento .............................................. 85

5.6.3 Abordagem grafo E/OU para problema de corte bidimensional ........................ 85

6. Experimentos computacionais ........................................................................................................... 89

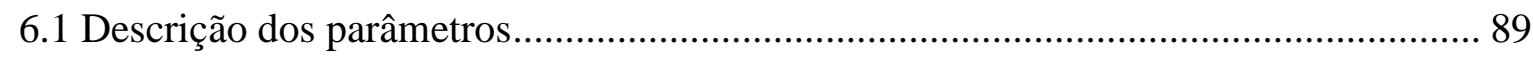

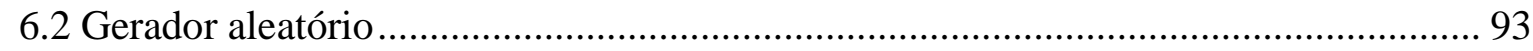

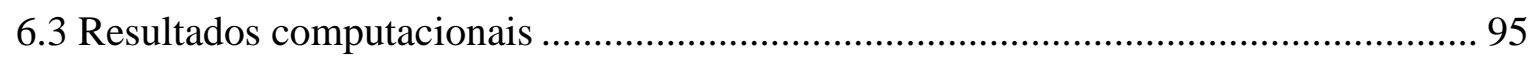


6.3.1 Abordagens 1 e 2 para gerar novas colunas ................................................... 95

6.3.2 Variáveis artificiais nas restrições de acoplamento e de capacidade..................98

6.3.3 Variando parâmetros do modelo proposto.......................................................... 107

6.3.4 Solução para todo o horizonte de planejamento ............................................. 114

6.3.5 Heurística de factibilização ......................................................................... 115

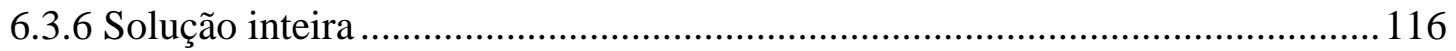

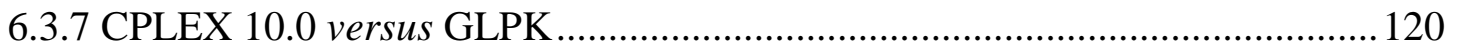

7. Conclusões e perspectivas ...............................................................................................................123

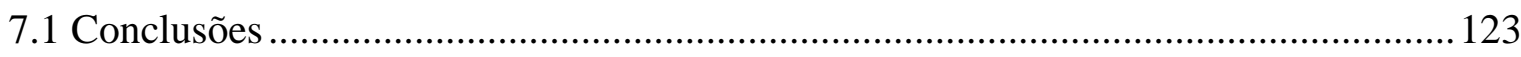

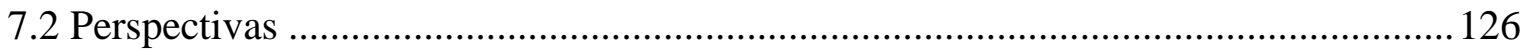

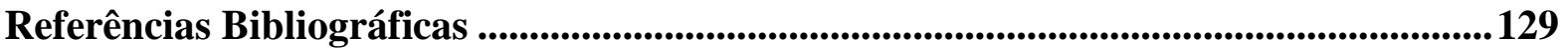




\section{Lista de figuras}

2.1 Solução para o problema da mochila unidimensional …................................................. 9

2.2 Solução para o problema da mochila bidimensional ...................................................... 9

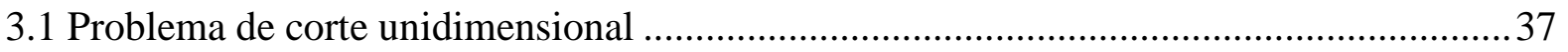

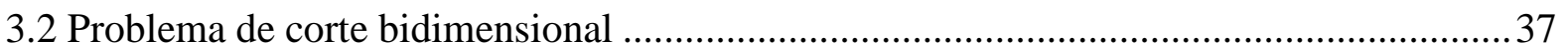

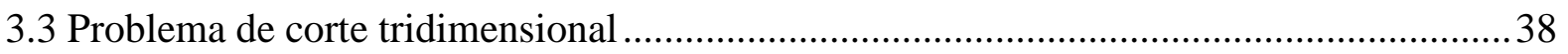

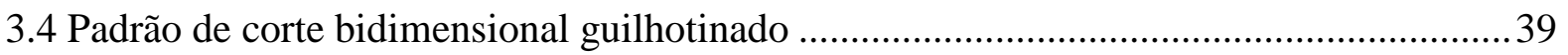

3.5 Padrão de corte bidimensional guilhotinado 3-estágios ....................................................40

3.6 Padrão de corte bidimensional guilhotinado 3-estágios exato ...........................................40

3.7 Padrão de corte bidimensional guilhotinado 2-estágios exato homogêneo........................40

3.8 Padrão de corte bidimensional guilhotinado 2-estágios inexato .......................................47

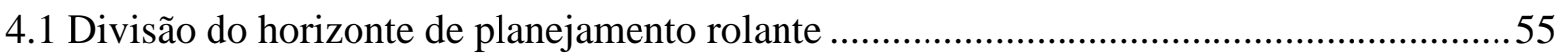

4.2 Processo produtivo simplificado da indústria de móveis .................................................58

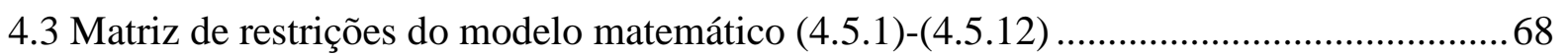

5.1 Matriz de restrições do modelo matemático relaxado (5.1.1)-(5.1.10) ............................ 71

5.2 Possíveis seqüências para a resolução do problema acoplado ..........................................72

5.3 Grafo E/OU com um caminho destacado (a) e o padrão de corte correspondente (b) ......86

6.1 Possíveis sequiências para a resolução do modelo (4.5.1)-(4.5.12) ..................................90

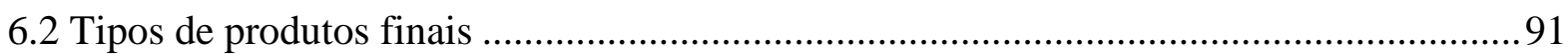

6.3 Comparação do tempo total médio de resolução para demanda baixa............................. 100

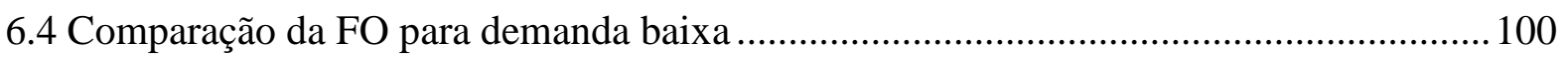

6.5 Comparação do tempo total de resolução para demanda média....................................... 102

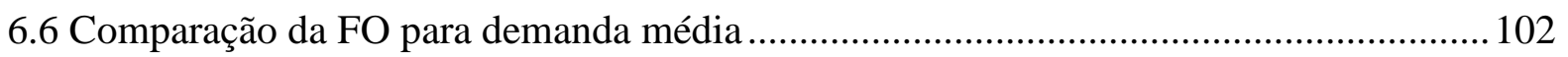

6.7 Comparação do tempo total de resolução para demanda alta.......................................... 104

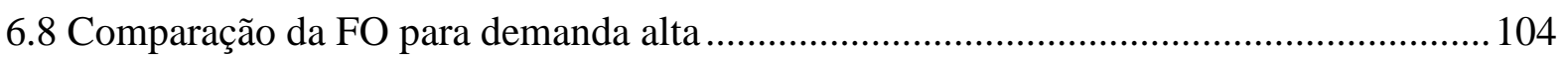

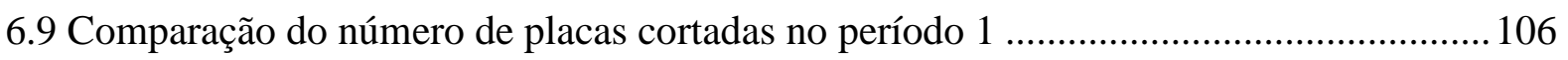


6.10 Comparação do tempo total das soluções inteiras obtidas por HD e HA

6.11 Comparação das perdas nas soluções inteiras obtidas por HD e HA

6.12 Comparação do número de iterações feito pela RAG com HD e HA

6.13 Comparação dos desvios entre as soluções contínuas e inteiras 120

6.14 Comparação do tempo total médio de resolução usando CPLEX 10.0 e GLPK 122 


\section{Lista de tabelas}

6.1 Custos e número de placas cortadas juntas pela serra por espessura..............................91

6.2 Dimensões das peças e estrutura dos produtos finais por espessura ..............................92

6.3 Demandas em carteira e esperada dos produtos no horizonte de planejamento..............93

6.4 Formação das classes de problemas testadas................................................................94

6.5 Comparação do tempo total médio de resolução e número de iterações para demanda baixa

6.6 Comparação do tempo total médio de resolução e número de iterações para demanda média

6.7 Comparação do tempo total médio de resolução e número de iterações para demanda

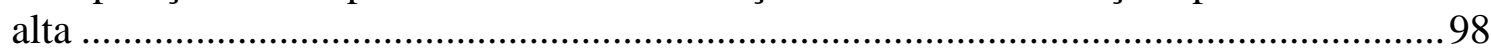

6.8 Comparação do tempo total médio de resolução e valor da FO para demanda baixa ....99

6.9 Comparação do tempo total médio de resolução e valor da FO para demanda média.. 101

6.10 Comparação do tempo total médio de resolução e valor da FO para demanda alta...... 103

6.11 Comparação do número de placas cortadas no período 1 ........................................... 105

6.12 Comparação da programação da produção para o período 1 entre HD e HA ................ 106

6.13 Comparação do número de placas cortadas para HD e HA ao variar a demanda esperada 108

6.14 Comparação da programação da produção para o período 1 ao variar a demanda esperada

6.15 Variação na quantidade de tipos de produtos para demanda média .............................110

6.16 Comparação da perda ocorrida no período 1 ao variar a capacidade de máquina..........112

6.17 Comparação do número de placas cortadas no período 1 ao variar a capacidade de máquina

6.18 Comparação da perda e do número de placas cortadas no período 1 ............................114

6.19 Comparação da solução lote/lote e da HA para o período 1 ........................................ 115

6.20 Comparação da programação da produção do período 1 antes e depois da factibilização 
6.21 Comparação das soluções inteiras obtidas por HD e HA …....................................... 117

6.22 Desvio entre as soluções contínuas e inteiras ............................................................. 119

6.23 Comparação do tempo total médio de resolução usando CPLEX 10.0 e GLPK .......... 121 


\section{Capítulo 1}

\section{Introdução}

O setor de móveis no Brasil vem apresentando, nos últimos anos, um crescimento considerável. O faturamento e as exportações aumentaram, enquanto as importações tiveram uma pequena queda. $\mathrm{O}$ investimento em tecnologia e a adequação do design dos móveis, visando atender consumidores de outros países, possibilitaram um aumento nas exportações e na geração de empregos diretos e indiretos. Mas, apesar desses resultados positivos, o setor ainda sofre com a forte competitividade de países como a China, que consegue se estabelecer como uma grande concorrente com os produtos brasileiros devido, principalmente, aos seus baixos custos de produção. Sendo assim, o setor moveleiro do Brasil precisa tornar-se cada vez mais competitivo no mercado globalizado. Para isto, ações operacionais, que permitem atender à demanda com produtos de qualidade e preços acessíveis têm de ser adotadas. Um exemplo é a redução na perda de matéria-prima durante o processo produtivo, a qual proporciona uma redução no custo de fabricação do produto final sem alterar sua qualidade. Outro exemplo, é a otimização da programação da produção, visando atender sem atrasos, ao menor custo de produção, os pedidos. Ambos problemas, a programação da produção e a redução do desperdício de matéria-prima no processo de corte, de forma acoplada, são o objeto de estudo desta tese.

As indústrias de móveis brasileiras são concentradas em pólos regionais localizados na região Sul, responsável por quase $46 \%$ da produção nacional, na região Sudeste, que fabrica em torno de $40 \%$ da produção nacional, e nas regiões Nordeste, Norte e Centro-Oeste, responsáveis por aproximadamente $7 \%, 4 \%$ e $3 \%$ da produção nacional, respectivamente. Alguns dos pólos mais consolidados e tradicionais são: Bento Gonçalves (RS), São Bento do Sul (SC), Arapongas (PR), Mirassol (SP), Votuporanga (SP) e Grande São Paulo (SP).

Uma parte deste trabalho foi desenvolvida baseada no processo produtivo de uma indústria de móveis de pequeno porte localizada na cidade de Votuporanga, no noroeste do estado de São Paulo, a qual produz somente móveis residenciais, em especial, móveis de dormitórios.

Nas indústrias de móveis, o planejamento e a programação da produção, resumidamente, consistem em determinar quais e quantos produtos finais (dimensionamento de lotes) devem ser produzidos em cada um dos períodos do horizonte de planejamento, de 
forma a atender à demanda, não violar a capacidade de produção e minimizar os custos de produção, preparação de máquina, estoque de produtos e perda de matéria-prima no processo de corte. A quantidade de peças necessária para a confecção dos produtos, em cada período, é obtida com o corte de placas retangulares grandes (objetos) em peças (retângulos menores) utilizando diferentes padrões de corte, os quais são projetados para gerarem a menor perda de material possível.

Em situações reais, geralmente, as indústrias de móveis resolvem os problemas de dimensionamento de lotes e corte de estoque separados, ou seja, inicialmente, são determinadas para cada período do horizonte de planejamento as quantidades de cada tipo de produto final (o tamanho do lote) a serem produzidas. Utilizando essa informação, a quantidade de cada tipo de peça que deve ser cortada é determinada e, então, os melhores padrões de corte são gerados. Entretanto, otimizar os problemas de dimensionamento de lotes e corte de estoque de forma independente pode gerar soluções ruins (ou mesmo inviáveis) do ponto de vista dos altos custos totais obtidos e do aumento do desperdício de material, principalmente, se o corte de matéria-prima for economicamente relevante no processo, isto é, se uma parcela significante do custo do produto final é composto pelo material que foi cortado.

Dessa forma, os problemas de dimensionamento de lotes e corte de estoque devem ser tratados e resolvidos simultaneamente. Porém, a junção destes dois problemas de otimização complexos, leva a um problema de otimização mais difícil de resolver, uma vez que, novas restrições unindo os problemas separados são adicionadas e uma solução ótima global, provavelmente, não será uma simples composição das soluções ótimas dos problemas separados.

O problema de otimização obtido com a união dos problemas de dimensionamento de lotes e corte de estoque chamamos de problema acoplado de dimensionamento de lotes e corte de estoque, ou simplesmente de problema acoplado.

Embora os problemas clássicos de otimização (dimensionamento de lotes e corte de estoque) sejam extensivamente estudados na literatura, ainda são poucos os trabalhos que os consideram acoplados. A relação dos artigos revisados sobre problema acoplado de dimensionamento de lotes e corte de estoque, descritos com detalhes no Capítulo 2, é apresentada a seguir:

- Kantorovich (1939) (traduzido no trabalho de 1960) é, possivelmente, o primeiro trabalho que trata os problemas de dimensionamento de lotes e corte de estoque de forma acoplada. Este fato não é explícito no trabalho, mas pode ser facilmente verificado ao analisar o modelo matemático que Kantorovich propôs para resolver um problema de corte de estoque, o qual possui como variável de decisão o tamanho do lote. Este trabalho foi praticamente ignorado pelos pesquisadores da área.

- Reinders (1992) trabalha com o problema de corte de estoque acoplado ao problema de planejamento e programação da produção de uma companhia alemã de processamento de madeira. Os troncos de árvore devem ser cortados em toras que, posteriormente, são transformadas em placas de diversos tamanhos para serem vendidas. 
- Hendry et al. (1996) consideram o problema de planejamento da produção da fundição de uma indústria de componentes de cobre, cujo processo produtivo, simplesmente, consiste em derreter o cobre, moldar o metal derretido em barras e cortar as barras em itens menores. O objetivo é otimizar os custos da fundição e o tempo de entrega dos pedidos.

- Nonas e Thorstenson $(2000,2008)$ tratam o problema acoplado de dimensionamento de lotes e corte de estoque de uma companhia norueguesa que produz um tipo especial de caminhão basculante. O processo produtivo começa no departamento de aço em que grandes placas de aço são cortadas em partes menores de diferentes formas e tamanhos utilizando diversos padrões de corte. Algumas partes cortadas são furadas e/ou dobradas e todas são estocadas. No trabalho de 2000, é proposto um modelo matemático acoplado com demanda estocástica, função objetivo não linear e restrições lineares e sua versão simplificada é resolvida. No trabalho de 2008, outros métodos de solução foram sugeridos para tentar resolver mais rapidamente o mesmo modelo matemático simplificado com dimensões maiores.

- Respício e Captivo (2002) consideram o sistema de produção de indústria de papel e propõem um modelo matemático inteiro que acopla os problemas de dimensionamento de lotes e corte de estoque. O modelo é resolvido utilizando branch-and-price.

- Menon e Schrage (2002) também trabalham com o processo produtivo da indústria de papel e propõe um modelo matemático inteiro que acopla o problema de corte de estoque e o problema de alocação, o qual é resolvido por um método heurístico baseado no branch-and-price.

- Arbib e Marinelli (2005) apresentam um estudo de caso em uma indústria européia que produz correias de engrenagem. Um modelo matemático inteiro misto que acopla os problemas de dimensionamento de lotes e corte de estoque é desenvolvido, simplificado e resolvido por um procedimento em 2-estágios.

- Gramani e França (2006) tratam o processo produtivo de uma indústria de móveis e propõem um modelo matemático inteiro misto que acopla os problemas de dimensionamento de lotes e corte de estoque. O espaço de soluções é reduzido e o problema é reformulado como a determinação de caminho mínimo, em analogia ao método clássico de Wagner-Whitin (1958).

- Poltroniere et al. (2008) tratam um problema de dimensionamento de lotes e corte de estoque presente na indústria de papel de forma acoplada. Propuseram um modelo matemático de otimização linear inteiro misto, o qual é resolvido por heurísticas baseadas na relaxação lagrangiana da restrição de acoplamento.

Neste trabalho, propomos um modelo de otimização linear inteiro, que captura simultaneamente as relações existentes entre os problemas de dimensionamento de lotes e 
corte de estoque e permite que alguns produtos sejam antecipados e armazenados no estoque. Esta antecipação da produção aumenta os custos de estoque dos produtos finais, mas com o aumento na demanda de peças em um determinado período é possível gerar melhores padrões de corte e diminuir os custos com a perda de matéria-prima.

Embora o modelo matemático proposto tenha sido desenvolvido baseado em uma determinada indústria de móveis de pequeno porte, os principais elementos considerados têm certo grau de generalidade.

Os elementos mais relevantes ao planejamento da produção são:

- Máquinas com capacidades limitadas: a serra e a furadeira possuem limites de capacidade e representam possíveis gargalos do processo produtivo.

- Demanda esperada dos produtos finais: a demanda dos produtos é incerta, pois depende de solicitações de clientes. Para tratar esta característica da demanda, no modelo matemático é utilizada a estratégia de horizonte de planejamento rolante, em que o primeiro período do horizonte é suficientemente detalhado e somente as suas decisões são implementadas. Além disso, a demanda esperada de um determinado produto no horizonte de planejamento é composta pela carteira de pedidos deste produto no horizonte mais uma demanda extra determinada pelo setor de vendas, que pode ser produzida em qualquer momento do horizonte de planejamento e cujo objetivo é atender aos pedidos inesperados. Essa demanda extra é considerada no modelo matemático como um dado fornecido pelo setor de vendas para o horizonte de planejamento e seu atendimento é parcelado por períodos. Tal demanda é representada por variáveis de decisão, as quais determinam o melhor momento, em termos de minimização de custos, para uma produção extra que comporá um estoque de segurança.

\section{Objetivos}

Neste projeto de pesquisa, tratamos o problema acoplado de dimensionamento de lotes e corte de estoque oriundo da indústria de móveis, o qual é ainda pouco explorado na literatura. A constatação de sua relevância em diversas situações práticas demonstra a sua importância e a dificuldade encontrada em resolver os modelos matemáticos que o representa, o que motiva inúmeras pesquisas acadêmicas.

Os objetivos principais deste trabalho consistem em modelar matematicamente o problema acoplado de dimensionamento de lotes e corte de estoque, desenvolver métodos de resolução, que sejam eficientes e capazes de explorar as características do problema, e investigar, capturar e tratar o compromisso existente quando o problema de corte de estoque é resolvido levando em consideração o planejamento da produção para vários períodos do horizonte de planejamento (dimensionamento de lotes). 


\section{Organização do texto}

O Capítulo 2 contém uma revisão bibliográfica de trabalhos que tratam os problemas de programação da produção e corte de estoque de forma acoplada presentes em diferentes tipos de indústria de manufatura, tais como, indústria de papel, móveis, têxtil entre outras.

No Capítulo 3, os problemas de dimensionamento de lotes e corte de estoque são considerados separadamente. A definição, modelagem matemática e alguns métodos clássicos para resolução desses problemas são apresentados.

No Capítulo 4, são descritos o processo produtivo simplificado e algumas características e a programação da produção da indústria de móveis brasileira. São apresentadas a definição do problema, a modelagem matemática e as dificuldades de resolução do modelo matemático do problema acoplado de dimensionamento de lotes e corte de estoque presente na indústria de móveis.

O Capítulo 5 traz a descrição de todos os procedimentos, métodos e técnicas desenvolvidos e utilizados para resolver o modelo matemático proposto para representar o problema acoplado de dimensionamento de lotes e corte de estoque presente nas indústrias de móveis.

O Capítulo 6 trata especificamente dos experimentos computacionais realizados com exemplares gerados aleatoriamente, mas baseados em dados reais coletados de uma indústria de móveis de pequeno porte. Os resultados e análises são apresentados.

O Capítulo 7 contém as conclusões e as perspectivas para trabalhos futuros.

As referências bibliográficas são apresentadas no final deste texto. 


\section{Capítulo 2}

\section{Revisão Bibliográfica}

Este capítulo contém um resumo dos poucos trabalhos que encontramos na literatura sobre os problemas de otimização acoplados de dimensionamento de lotes e corte de estoque, os quais consideram o planejamento e programação da produção de diversos tipos de indústria de manufatura, tais como, indústria de roupas, papel, móveis, caminhões, processamento de madeiras, componentes de cobre e correias de engrenagem.

Em todos os trabalhos revisados os problemas de dimensionamento de lotes e corte de estoque são tratados simultaneamente, ou seja, ao tentar resolver o problema de dimensionamento de lotes, dados e restrições do problema de corte de estoque que interferem diretamente no processo produtivo da indústria são levados em consideração e vice-versa. Esta forma de considerar os clássicos problemas de dimensionamento de lotes e corte de estoque está bastante explícita em alguns trabalhos como, por exemplo, em Gramani e França (2006), Nonas e Thorstenson (2000, 2008) e Poltroniere et al. (2008) e implícita em outros, como nos trabalhos de Kantorovich (1960) e Farley (1988).

\subsection{Problema acoplado para um único tipo de produto}

O trabalho de Kantorovich (1960) (traduzido do trabalho de 1939) é, possivelmente, o primeiro trabalho de otimização linear inteira que particularmente modela os problemas de dimensionamento de lotes e corte de estoque de forma acoplada. Este fato não aparece explicitamente no trabalho, mas pode ser facilmente constatado ao analisar o modelo matemático que Kantorovich propôs para resolver um problema de corte de estoque, o qual possui como variável de decisão o tamanho do lote de um único tipo de produto.

Kantorovich considerou o seguinte problema de corte de estoque para a fabricação de apenas um tipo produto:

Suponha que existem em estoque $K$ tipos de objetos e, de cada tipo, há $q_{k}$ unidades disponíveis. Para produzir uma unidade do produto são requeridos $m$ tipos de itens nas quantidades $P_{1}, P_{2}, \ldots, P_{m}$, os quais devem ser cortados a partir das peças em estoque. $\mathrm{O}$ objetivo é fabricar o maior número de unidades do produto. 
O modelo matemático proposto por Kantorovich para o problema de corte de peças descrito acima é:

$$
\begin{array}{ll}
y_{j k} \geq 0 \text { e inteiros, } j=1, \ldots, N_{k}, & k=1, \ldots, K \\
\sum_{j=1}^{N_{k}} y_{j k}=q_{k}, & k=1, \ldots, K \\
\frac{\sum_{k=1}^{K} \sum_{j=1}^{N_{k}} \alpha_{1 j k} y_{j k}}{P_{1}}=\frac{\sum_{k=1}^{K} \sum_{j=1}^{N_{k}} \alpha_{2 j k} y_{j k}}{P_{2}}=\cdots & =\frac{\sum_{k=1}^{K} \sum_{j=1}^{N_{k}} \alpha_{m j k} y_{j k}}{P_{m}} \leftarrow \text { Maximizar }
\end{array}
$$

em que $N_{k}$ é o número de padrões de corte para o objeto do tipo $k$ e $\alpha_{i j k}$ é o número de itens do tipo $i$ no padrão de corte $j$ do objeto do tipo $k$. As variáveis de decisão do modelo são $\mathrm{y}_{j k}$ (número de objetos do tipo $k$ cortados conforme o padrão de corte $j$ ).

Para reescrever o modelo (2.1.1)-(2.1.3) em notação atual, considere uma nova variável de decisão $x$, que representa a quantidade do único tipo de produto a ser fabricada. Além disso, como a restrição (2.1.2) exige que todo o estoque de objetos seja cortado, modificamos para uma versão mais realista, ou seja, nem todos os objetos precisam ser cortados. Portanto, a nova versão do modelo de Kantorovich pode ser dada por:

$$
\begin{array}{lll}
\operatorname{Max} & x & \\
\text { s.a. } & \sum_{k=1}^{K} \sum_{j=1}^{N_{k}} \alpha_{i j k} y_{j k}=P_{i} x, & \\
& \sum_{j=1}^{N_{k}} y_{j k} \leq q_{k}, & k=1, \ldots, m \\
& y_{j k}, x \geq 0 \text { e inteiros, } j=1, \ldots, K
\end{array}
$$

A função objetivo (2.1.4) consiste em maximizar a quantidade de produtos a ser fabricada. As restrições (2.1.5) asseguram que a quantidade de itens cortados pelos padrões é igual a quantidade de itens necessária para a fabricação dos produtos. As restrições (2.1.6) garantem que o número de objetos cortados não exceda a quantidade estocada e as restrições (2.1.7) são de não negatividade e integralidade das variáveis.

Para $x$ fixo uma demanda por itens fica determinada e as restrições (2.1.5)-(2.1.7) são exatamente as restrições do conhecido modelo de Gilmore e Gomory (1963). Naturalmente, um outro objetivo deve ser definido, por exemplo, minimizar a perda. Esta possibilidade é discutida no trabalho de Kantorovich utilizando um exemplo.

Se o modelo matemático (2.1.4)-(2.1.7) considerasse a variação da demanda do produto ao longo do tempo, seria possível obter um planejamento e programação da produção mais preciso e realista. 


\subsection{Problema acoplado na indústria de processamento de madeira}

Reinders (1992) trabalhou com o problema de corte de estoque acoplado ao problema de planejamento e programação da produção de uma indústria alemã de processamento de madeira. Os níveis operacional e tático de planejamento são considerados.

No nível operacional, o processo produtivo resume-se, basicamente, em dois passos: cortar troncos de árvore em toras e serrar as toras em placas. No primeiro passo, o problema é modelado como um problema da mochila unidimensional (Figura 2.1) e consiste em determinar a melhor maneira de cortar um tronco de árvore em toras de modo a maximizar o valor total do tronco (soma dos valores das partes). No segundo passo, o problema é modelado como um problema da mochila bidimensional (Figura 2.2) e consiste em determinar a melhor forma de serrar uma tora em placas (que podem ser de diferentes tamanhos) e o objetivo é maximizar o valor total da tora (soma dos valores das placas).

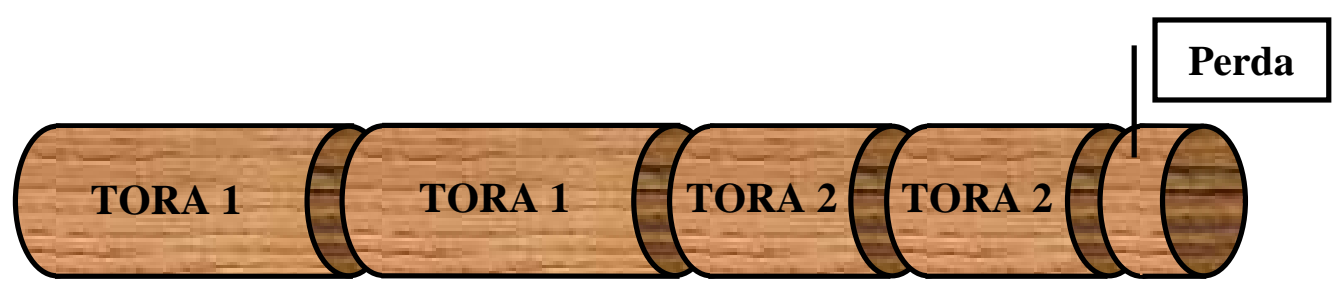

Figura 2.1: Solução para o problema da mochila unidimensional.

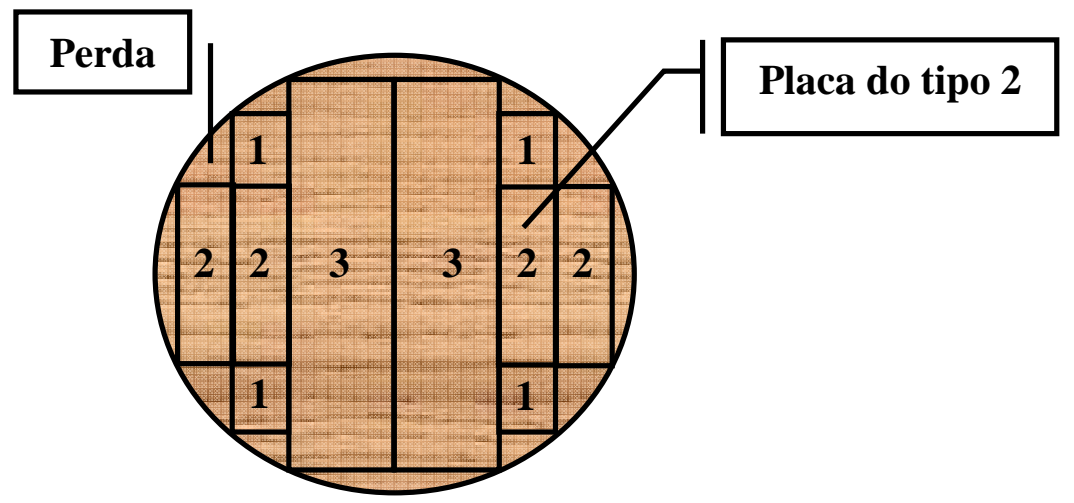

Figura 2.2: Solução para o problema da mochila bidimensional.

A indústria de processamento de madeira tem uma variedade de tipos de tronco de árvore para processar que é dividida em classes. As toras são produzidas e/ou compradas e organizadas em pilhas. $\mathrm{O}$ horizonte de planejamento finito é dividido em períodos (semanas) e horas extras podem ser consideradas. Assim, no nível tático, o problema consiste em determinar de quais tipos e quantos troncos de árvore as toras devem ser feitas, de quais tipos e quantas toras as placas devem ser feitas, em qual semana e durante quais dias, de modo a atender à demanda e antecipá-la se isso for vantajoso, maximizar o valor retornado e a taxa de serviço e minimizar os custos de produção, estoque, mão de obra e toras compradas. Neste momento, os padrões de corte unidimensional e bidimensional (determinados anteriormente) são parâmetros do modelo e a solução obtida é um planejamento da produção multiperíodo. 
Para a modelagem matemática do problema no nível tático são considerados: horizonte de planejamento finito, classes de troncos de árvores (classe: conjunto de troncos de árvores com variações limitadas em suas propriedades), espaço suficiente disponível para armazenar as toras organizadas nas diferentes classes, somente placas anguladas-exatamente (placas com corte inadequado são perdas), toras produzidas e compradas.

A solução inicial do modelo foi interpretada por meio do problema dual e outros padrões de corte foram gerados ajustando os custos baseados na análise das variáveis duais.

A modelagem matemática proposta foi incorporada a um DSS (Decision Support System) e resultou em uma ferramenta para a otimização integrada da companhia.

A notação utilizada no modelo matemático do nível tático é a seguinte:

\section{- Parâmetros}

$N_{a c n}^{t}$ : número de toras do tipo a quando processado um tronco da classe $n$ usando o padrão de corte unidimensional $c$ no período $t$.

$N I_{i s a}^{t}$ : número de produtos finais (placas) do tipo $i$ quando processada uma tora do tipo $a$ usando o padrão de corte bidimensional $s$ no período $t$.

$\mathrm{Nn}$ : número de tipos de classes.

$N p$ : número de tipos de pilhas.

$N a$ : número de toras do tipo $a$.

$\mathrm{Ni}$ : número de produtos finais tipo $i$.

$N s: \quad$ número de padrões de corte bidimensional $s$.

$N t$ : número de períodos $t$.

Nc: $\quad$ número de padrões de corte unidimensional $c$.

$W: \quad$ número de horas de trabalho regular em uma semana.

$B^{t}$ : $\quad$ orçamento para compra de toras no período $t$.

$C P M_{c n}^{t}$ : custo de produção por usar o padrão de corte unidimensional $c$ na matéria-prima da classe $n$ no período $t$.

$C P S_{s a}^{t}$ : custo de produção por usar o padrão de corte bidimensional $s$ na tora tipo $a$ no período $t$.

CEM: custo da hora extra no comércio.

CES: custo da hora extra na serraria.

$V_{s a}^{t}$ : valor de uma tora tipo $a$ no período $t$ cortada no padrão de corte bidimensional $s$.

$V R_{c n}^{t}$ : valor unitário do tronco de árvore da classe $n$ no período $t$ cortado no padrão de corte unidimensional $c$.

$C I_{a}^{t}$ : custo de estoque para a tora tipo $a$ no período $t$.

$\mathrm{CO}_{a}^{t}$ : $\quad$ custo de falta de estoque para a tora tipo $a$ no período $t$.

$C I F_{i}^{t}$ : custo de estoque para o produto final tipo $i$ no período $t$.

$C O F_{i}^{t}$ : custo de falta de estoque para o produto final $i$ no período $t$.

$C I R_{p}^{t}$ : custo de estoque para a matéria-prima da pilha $p$ no período $t$. 
$R_{c n}^{t}$ : tempo (em horas) necessário para processar um tronco de árvore da classe $n$ conforme o padrão de corte unidimensional $c$ no período $t$.

$T_{s a}^{t}$ : $\quad$ tempo (em horas) necessário para processar uma tora tipo $a$ com o padrão de corte bidimensional $s$ no período $t$.

$D A_{a}^{t}$ : demanda da tora tipo $a$ no período $t$.

$D F_{i}^{t}$ : demanda do produto final tipo $i$ no período $t$.

$H R^{t}$ : matéria-prima colhida no período $t$.

$B R^{t}: \quad$ matéria-prima comprada no período $t$.

$\beta_{n}$ : $\quad$ razão da porcentagem da classe $n$ em relação à entrada total de matéria-prima.

$v(a)$ : valor da tora tipo $a$.

$a_{p}: \quad$ primeira classe da pilha $p$.

$z_{p}: \quad$ última classe da pilha $p$.

- Variáveis

$Y_{c n}^{t}$ : freqüência do padrão de corte unidimensional $c$ na tronco da classe $n$ no período $t$.

$X_{s a}^{t}: \quad$ freqüência do padrão de corte bidimensional $s$ na tora tipo $a$ no período $t$.

$Z_{a}^{t}$ : número de toras tipo $a$ compradas no período $t$.

$I R_{p}^{t}$ : estoque de tronco de árvore da pilha $p$ no período $t$.

$I_{a}^{t}$ : estoque da tora tipo $a$ no período $t$.

$I F_{i}^{t}$ : estoque do produto final tipo $i$ no período $t$.

$O_{a}^{t}$ : nível de falta de estoque da tora tipo $a$ no período $t$.

$O F_{i}{ }^{t}$ : nível de falta de estoque do produto final $i$ no período $t$.

$E M^{t}$ : horas extras trabalhadas no comércio na semana $t$.

$U M^{t}$ : horas não utilizadas na semana $t$.

$E S^{t}$ : horas extras trabalhadas na serraria na semana $t$.

$U S^{t}$ : horas não utilizadas na serraria na semana $t$.

$\Phi_{a}$ : $\quad$ variável binária que tem valor 0 se a tora tipo $a$ é processada em placas ou valor 1 se é vendida. 


\section{Modelo matemático}

$$
\begin{aligned}
\operatorname{Max} & \sum_{t=1}^{N_{t}}\left(\sum_{c=1}^{N_{c}} \sum_{n=1}^{N_{n}} V R_{c n}^{t} Y_{c n}^{t}+\sum_{s=1}^{N_{S}} \sum_{a=1}^{N_{a}} V_{s a}^{t} X_{s a}^{t}\right)-\left(\sum_{a=1}^{N_{a}} C I_{a}^{t} I_{a}^{t}+C O_{a}^{t} O_{a}^{t}\right)\left(\sum_{i=1}^{N_{i}} C I F_{i}{ }_{i} I F_{i}{ }^{t}+\operatorname{COF}_{i}{ }^{t} O F_{i}{ }^{t}\right)- \\
& -\left(\text { CEM EM } M^{t}+C E S E S^{t}\right)-\left(\sum_{a=1}^{N_{a}} v(a) Z_{a}^{t}+\sum_{p=1}^{N_{p}} C I R_{p}^{t} I R_{p}^{t}\right)
\end{aligned}
$$

s.a.

$$
\begin{aligned}
& \begin{array}{lrl}
\sum_{c=1}^{N_{c}} \sum_{n=a_{p}}^{z_{p}} Y_{c n}^{t}+I R_{p}^{t}=\sum_{n=a_{p}}^{z_{p}} \beta_{n}\left(H R^{t}+B R^{t}\right)+I R_{p}^{t-1}, & 1 \leq t \leq N t ; & 1 \leq p \leq N_{p} \\
\sum_{c=1}^{N_{c}} \beta_{n} Y_{c n}^{t-1}-\beta_{n+1} Y_{c n}^{t}=0, & a_{p} \leq n \leq z_{p}, \quad 1 \leq t \leq N t, & 1 \leq p \leq N_{p}
\end{array} \\
& \sum_{c=1}^{N_{c}} \sum_{n=1}^{N_{n}} N_{a c n}^{t} Y_{c n}^{t}+I_{a}^{t-1}+O_{a}^{t}+Z_{a}^{t}=\left(1-\Phi_{a}\right) \sum_{s=1}^{N_{s}} X_{s a}^{t}+\Phi_{a} D_{a}^{t}+I_{a}^{t}+O_{a}^{t-1}, \quad 1 \leq t \leq N t, \quad 1 \leq a \leq N a \\
& \sum_{c=1}^{N_{c}} \sum_{n=1}^{N_{n}} R_{c n}^{t} Y_{c n}^{t}-E M^{t}+U M^{t}=W \\
& 1 \leq t \leq N t \\
& \sum_{s=1}^{N_{s}} \sum_{a=1}^{N_{a}} T_{s a}^{t} X_{s a}^{t}-E S^{t}+U S^{t}=W \\
& 1 \leq t \leq N t \\
& \sum_{s=1}^{N_{S}} \sum_{a=1}^{N_{a}} N I_{i s a}^{t} X_{s a}^{t}+I F_{i}^{t-1}+O F_{i}^{t}=D F_{i}^{t}+I F_{i}^{t}+O F_{i}^{t-1} \\
& 1 \leq t \leq N t, \quad 1 \leq i \leq N i \\
& \sum_{a=1}^{N_{a}} v(a) Z_{a}^{t} \leq B^{t}, \\
& \begin{aligned}
& 1 \leq t \leq N t \\
& \forall u= t, c, s, a, n, \quad 1 \leq u \leq N u \\
& \forall u=p, i, t, \quad 1 \leq u \leq N u
\end{aligned} \\
& Y_{c n}^{t}, X_{s a}^{t}, Z_{a}^{t}, I_{a}^{t}, E M^{t}, E S^{t}, O_{a}^{t} \geq 0, \\
& I F_{i}^{t}, O F_{i}^{t}, I R_{p}^{t}, U M^{t}, U S^{t} \geq 0 \text {, }
\end{aligned}
$$

A função objetivo (2.2.1) consiste em maximizar as receitas das placas e toras produzidas e minimizar os custos de estoque, falta de estoque, hora extra e tora compradas. $\mathrm{O}$ conjunto de restrições (2.2.2) é de balanço de estoque da matéria-prima. O estoque inicial de troncos de árvore em uma pilha quando começar o planejamento é $I R_{p}^{0}$. Se o número de pilhas é menor que o número de classes, o conjunto de restrições (2.2.3) ocorre. A decisão de selecionar um tronco de árvore específica fora da classe $n_{1}$ é limitada porque existe uma probabilidade de um tronco de árvore da classe $n_{2}$ ser escolhido, uma vez que ambas as classes estão na pilha de interesse. As restrições (2.2.4) são de balanço de estoque de toras. $\mathrm{O}$ tempo disponível para o corte de troncos de árvores em toras é limitado. O conjunto de restrições (2.2.5) é de capacidade para o corte de troncos em toras. As restrições (2.2.6) são de capacidade da serra para o corte das toras em placas. As restrições (2.2.7) são de balanço de estoque dos produtos finais (placas). O conjunto de restrições (2.2.8) são de limites orçamentários. As restrições (2.2.9) e (2.2.10) são de não negatividade das variáveis. 


\subsection{Problema acoplado na indústria de componentes de cobre}

Hendry et al. (1996) estudaram o problema de planejamento da produção da fundição de uma indústria de componentes de cobre com o objetivo de minimizar os custos e o tempo de entrega dos pedidos.

Simplificadamente, o processo produtivo da fundição pode ser descrito em três passos: derreter o cobre, moldar o metal derretido em barras e cortar as barras em itens menores. No primeiro passo, o problema de planejamento da produção consiste em determinar quando a fornalha deve ser preparada para derreter o cobre e quanto de cobre vai ser derretido. Hora extra no final de semana pode ser considerada. No segundo passo, o metal derretido deve ser moldado em barras de diferentes diâmetros e uma determinada quantia de cobre pode ser armazenada de um dia para outro. O problema de planejamento da produção consiste em determinar quanto de cada diâmetro de barra produzir por dia levando em conta o tempo de preparação para troca de diâmetro e quanto de cobre derreter para ser armazenado. No último passo, existem diversos comprimentos de itens para cada diâmetro da barra e a demanda de cada item é muito variada. O problema de planejamento da produção consiste em decidir quais padrões de corte devem ser utilizados para atender à demanda semanal de forma a minimizar a perda e, consequentemente, o número de barras requerido. A produção das barras leva mais tempo que o processo de corte e, por isso, a capacidade no processo de corte não é considerada.

O problema de planejamento da produção da fundição é representado por dois modelos matemáticos (um para o problema de corte de estoque unidimensional e outro para o problema de dimensionamento de lotes), que são resolvidos consecutivamente por um procedimento em 2-estágios. No primeiro estágio, é determinada uma solução agregada indicando o número total de barras a ser produzida para atender à demanda sobre um dado período de tempo, com o objetivo de minimizar as perdas. A saída deste estágio diz quais os padrões de corte que devem ser usados. No segundo estágio, um planejamento da produção diário é obtido. A solução do primeiro estágio é desagregada para verificar a factibilidade das restrições de capacidade no estágio de produção das barras.

O horizonte de planejamento considerado é de duas semanas e a estratégia de horizonte rolante é utilizada. Assim, a solução obtida é somente para a primeira semana. Um planejamento novo deve ser determinado no início de cada semana.

A notação utilizada no modelo matemático 1 (problema de corte de estoque) é:

\section{- Parâmetros}

$A_{d i j}$ : número de itens de comprimento $i$, diâmetro $d$, no padrão de corte $j$.

$C B_{d}$ : peso do cobre requerido para produzir uma barra de diâmetro $d$, em toneladas.

$D R_{d}$ : número de barras produzidas por lote de diâmetro $d$.

$N_{d i}^{t}$ : número de itens requeridos de comprimento $i$ e diâmetro $d$ na semana $t$.

$C C$ : capacidade máxima de cobre para produção das barras nas 2 semanas.

$C C^{1}$ : capacidade máxima de cobre para produção das barras na semana 1. 


\section{- Variáveis}

$x_{d j}^{t}$ : número de barras de diâmetro $d$, cortadas no padrão $j$, na semana $t$.

$F D_{d}^{t}$ : número de lotes de barras de diâmetro $d$, feito na semana $t$.

$s^{t}$ : capacidade da fornalha não utilizada na semana $t$.

$R_{d i}^{1}$ : $\quad$ produção excedente do item de comprimento $i$ e diâmetro $d$ na semana 1 .

$R_{d i}^{t}$ : $\quad$ produção excedente do item de comprimento $i$ e diâmetro $d$ nas 2 semanas.

\section{Modelo matemático 1}

$$
\begin{aligned}
& \operatorname{Min} \sum_{t} \sum_{d} \sum_{j} x_{d j}^{t} \\
& \text { s.a. } \sum_{t}\left(\sum_{d} C B_{d}\left(\sum_{j} x_{d j}^{t}\right)+s^{t}\right)=C C, \\
& \sum_{d} C B_{d}\left(\sum_{j} x_{d j}^{1}\right)+s^{1}=C C^{1}, \\
& \sum_{j} A_{d i j} x_{d j}^{1}-R_{d i}^{1}=N_{d i}^{1}, \quad \forall d, i \\
& \sum_{t} \sum_{j} A_{d i j} x_{d j}^{t}-R_{d i}=\sum_{t} N_{d i}^{t}, \quad \forall d, i \\
& F D_{d}^{t}=\frac{1}{D R_{d}} \sum_{j} x_{d j}^{t}, \quad \forall d, j \\
& x_{d j}^{t}, F D_{d}^{t}, R_{d i}^{1}, R D_{i} \geq 0 \text { e inteiros, } \forall d, i, t \\
& s^{t} \geq 0, \quad \forall t
\end{aligned}
$$

O objetivo (2.3.1) é minimizar o número de barras usadas. Assim, automaticamente minimizará a perda e, portanto, maximizará a produção de qualquer demanda. A restrição (2.3.2) assegura que a quantidade de cobre derretido usado é menor do que está disponível para as duas semanas. A quantia disponível inclui o que foi estocado na semana anterior. A restrição (2.3.3) é similar, mas somente considera a primeira semana. As restrições (2.3.4) garantem o atendimento à demanda na primeira semana. Similarmente, as restrições (2.3.5) consideram as duas semanas do horizonte de planejamento. As restrições (2.3.6) garantem que um número inteiro de lotes de barras seja produzido. As restrições (2.3.7) são de não negatividade e integralidade das variáveis. As restrições (2.3.8) são de não negatividade das variáveis de capacidade.

No modelo matemático 2 (programação da produção) é utilizada a seguinte notação: 


\section{- Parâmetros}

$W_{m}$ : peso designado para a produção de barras no dia $m$.

$M D_{d}$ : número máximo de lotes de diâmetro $d$ por dia.

$N D_{d}$ : número requerido de lotes de diâmetro $d$ na semana $t$.

$D W_{d}$ : peso de cobre necessário para produzir um lote de diâmetro $d$.

$I C_{1}:$ estoque de cobre derretido armazenado no começo do dia 1.

$T_{d}: \quad$ tempo necessário para produzir um lote de diâmetro $d$ por dia.

$C O$ : tempo necessário para trocar a produção de um diâmetro de barra para outro.

CAP: capacidade de produção de barras diária.

Yld : porcentagem de cobre derretido que pode ser usado.

MS: máximo de toneladas de cobre derretido que pode ser armazenado.

MAX: quantidade máxima diária de cobre que pode ser derretido.

MIN: quantidade mínima diária de cobre que pode ser derretido.

- Variáveis

$M C_{m}$ : peso de cobre derretido no dia $m$.

$Y_{m d}$ : número de lotes de diâmetro $d$ produzido no dia $m$.

$I C_{m}$ : estoque de cobre derretido armazenado no começo do dia $m(m \neq 1)$.

$S_{m}: \quad$ tempo ocioso na produção da barra no dia $m$.

$C_{m}: \quad$ número de diferentes diâmetros de barras produzido no dia $m$.

$M C_{m}^{\prime}$ : variável binária para as restrições (2.3.12) e (2.3.13).

$I D_{m d}$ : variável binária (1 se barras de diâmetro $d$ foram produzidas no dia $m$ e 0 c.c.). 


\section{Modelo matemático 2}

$$
\begin{aligned}
& \operatorname{Min} \sum_{m}\left(W_{m}\left(\sum_{d}\left(Y_{m d} T_{d}\right)+C_{m} C O\right)\right) \\
& \text { s.a. } \quad \sum_{m} Y_{m d}=N D_{d}, \quad \forall d \quad \text { (2.3.10) } \\
& \sum_{d} Y_{m d} D W_{d}+I C_{m+1}=M C_{m} Y l d+I C_{m}, \quad \forall m \\
& I C_{m} \leq M S, \quad \forall m \quad \text { (2.3.12) } \\
& M I N-M C_{m} \leq \operatorname{MAX}\left(1-M C_{m}^{\prime}\right), \quad \forall m \quad \text { (2.3.13) } \\
& M C_{m} \leq M C_{m}^{\prime} M A X, \quad \forall m \quad \text { (2.3.14) } \\
& \sum_{d}\left(Y_{m d} T_{d}\right)+C_{m} C O+S_{m}=C A P, \quad \forall m \quad \text { (2.3.15) } \\
& C_{m}=\sum_{d} I D_{m d}, \quad \forall m \quad \text { (2.3.16) } \\
& Y_{m d} \leq M D_{d} I D_{m d}, \quad \forall m, d \quad(2.3 .17) \\
& Y_{m d} \geq I D_{m d}, \quad \forall m, d \quad(2.3 .18) \\
& M C_{m}, I C_{m}, S_{m} \geq 0, \quad \forall m, d \quad(2.3 .19) \\
& Y_{\text {imd }}, C_{m} \geq 0 \text { e inteiros, } \quad \forall m, d \text { (2.3.20) } \\
& M C_{m}^{\prime}, I D_{m d} \in\{0,1\}, \quad \forall m, d \text { (2.3.21) }
\end{aligned}
$$

O objetivo (2.3.9) é minimizar o tempo total necessário para produzir as barras, incluindo tempo de preparação quando é feita a troca de diâmetro da barra. O peso designado para cada dia é necessário para garantir que o menor número possível de dias seja utilizado. Assim, o menor peso é dado para o primeiro dia e depois os valores aumentam com o tempo. As restrições (2.3.10) garantem que o número total de lotes produzidos nas duas semanas seja igual ao número indicado pela saída do primeiro estágio do procedimento de solução. As restrições (2.3.11) asseguram que o peso total de cobre usado e armazenado para o próximo dia é menor que o cobre derretido no dia em questão mais qualquer sobra do dia anterior. As restrições (2.3.12) asseguram que a quantia estocada de um dia para o outro seja limitada pela capacidade máxima de estoque. As restrições (2.3.13) e (2.3.14) asseguram que o peso de cobre derretido por dia é 0 ou algum valor entre as quantidades mínima e máxima. As restrições (2.3.15) garantem que o tempo total requerido para produzir as barras é menor ou igual a capacidade diária. As restrições (2.3.16) asseguram que o número total de preparações necessárias por dia seja igual ao número de diâmetros usados por dia. As restrições (2.3.17) e (2.3.18) asseguram que as variáveis $I D_{m d}$ quando usada em (2.3.15) sejam 0 ou 1 . As restrições (2.3.19) e (2.3.20) são de não negatividade e integralidade das variáveis. As restrições (2.3.21) definem as variáveis como binárias.

Para resolver o problema do estágio 1 são utilizadas três heurísticas de solução: uma baseada em programação inteira (PI), em que os padrões de corte são selecionados previamente, uma heurística FFD (First Fit Decreasing), em que cada diâmetro de barra é considerado individualmente e uma heurística híbrida que usa a FFD para gerar uma solução inicial e depois tenta melhorá-la. O método baseado na PI apresentou soluções melhores. Para o estágio 2, uma solução ótima do problema é obtida usando programação inteira.

Os resultados dos testes computacionais foram comparados com a solução da indústria e de acordo com os critérios analisados (perda de material e número de vezes que a fornalha é preparada) foram melhores. 


\subsection{Problema acoplado na indústria de caminhão}

Nonas e Thorstenson $(2000,2008)$ tratam do problema acoplado de dimensionamento de lotes e corte de estoque de uma companhia norueguesa, que produz um tipo especial de caminhão basculante.

A maioria das partes de aço que compõem os caminhões é fabricada na própria empresa. O processo produtivo começa no departamento de aço em que grandes placas de aço são cortadas em partes menores de diferentes formas e tamanhos utilizando diversos padrões de corte. Algumas partes cortadas são furadas e/ou dobradas e todas são estocadas. Devido ao tempo de preparação da máquina de corte, placas de mesmo tamanho devem ser cortadas consecutivamente e é desejável utilizar a capacidade total da máquina.

O objetivo é minimizar o custo total do processo de corte composto pelos custos de perda de material, estoque das partes de aço e preparação de máquina para os padrões de corte e para troca de dimensão da placa.

Um modelo matemático com função objetivo não linear (côncava) e restrições lineares é proposto para encontrar um planejamento da produção ótimo. Tal acopla os problemas de dimensionamento de lote e corte de estoque bidimensional com demanda estocástica

Para a modelagem matemática do problema acoplado são consideradas placas de aço de uma única dimensão, a restrição de capacidade não é considerada explicitamente e os padrões de corte são gerados antecipadamente. A notação utilizada no modelo é a seguinte:

\section{- Parâmetros}

M: $\quad$ número total de tipos de produtos.

$N$ : número total de tipos de padrões de corte.

$a_{i j}$ : multiplicidade da parte tipo $j$ no padrão de corte $i$.

$h_{j}: \quad$ custo de estoque por unidade de tempo para a parte de aço tipo $j$.

$K_{i}: \quad$ custo de preparação para utilizar o padrão de corte $i$.

$c$ : $\quad$ custo de uma unidade da placa.

$d_{j}$ : demanda da parte tipo $j$.

$T_{i}: \quad$ tempo de ciclo do padrão de corte $i$.

$B_{i}: \quad$ número suficientemente grande.

\section{- Variáveis}

$x_{i}$ : $\quad$ quantidade requerida de produção do padrão de corte $i$.

$\delta_{i}$ : $\quad$ variável binária ( 1 se $x_{i}>0$ e 0 caso contrário).

$n_{i}$ : freqüência com que o padrão de corte $i$ é produzido. 


\section{Modelo matemático}

$$
\begin{array}{lll}
\text { Min } & c \sum_{i=1}^{N} x_{i}+\sqrt{2\left(K+\sum_{i=1}^{N}\left(K_{i} \delta_{i} / n_{i}\right)\right) \cdot \sum_{i=1}^{N}\left(H_{i} x_{i} n_{i}\right)} & \\
\text { s.a. } & \sum_{i=1}^{N} a_{i j} x_{i} \geq d_{j}, & j=1, \ldots, M \\
& x_{i} \leq B_{i} \delta_{i}, & i=1, \ldots, N \\
& x_{i} \geq 0, & i=1, \ldots, N \\
& n_{i} \geq 1 \mathrm{e} \text { inteiros, } & i=1, \ldots, N \\
& \delta_{i} \in\{0,1\}, & i=1, \ldots, N
\end{array}
$$

O primeiro termo da função objetivo (2.4.1) refere-se ao problema de corte de estoque e é o custo da matéria-prima utilizada no corte e o segundo termo refere-se ao problema de dimensionamento de lotes. O objetivo é minimizar os custos totais, isto é, o custo com a perda de material, o custo de preparação para cada operação iniciada e cada novo padrão de corte utilizado, e o custo de estoque.

O custo de estoque das partes cortadas no padrão $i$ em uma unidade de tempo é $H_{i}=\sum_{j=l}^{M} a_{i j} h_{j}$. Considerando produção instantânea, o custo total de estoque e preparação é

$$
\sum_{i=1}^{N}\left(K_{i} \delta_{i} / T_{i}+H_{i} x_{i} T_{i} / 2\right)
$$

em que $T_{i}=\sqrt{2 K_{i} /\left(H_{i} x_{i}\right)}$, para $x_{i}>0$.

Existe um custo de preparação $K$ toda vez que uma produção é iniciada. Seja $T$ um período de tempo comum entre cada produção consecutiva. Então, $T_{i}=n_{i} T$ e, portanto, o custo total de estoque e preparação é

$$
K / T+\sum_{i=1}^{N}\left(K_{i} \delta_{i} / n_{i} T+H_{i} x_{i} n_{i} T / 2\right)
$$

Substituindo $T$ pela condição de otimalidade, $\sqrt{2\left(K+\sum_{i=1}^{N}\left(K_{i} \delta_{i} / n_{i}\right)\right) / \sum_{i=1}^{N}\left(H_{i} x_{i} n_{i}\right)}$ na expressão acima, obtém-se:

$$
K / T+\sum_{i=1}^{N}\left(K_{i} \delta_{i} / n_{i} T+H_{i} x_{i} n_{i} T / 2\right)=\sqrt{2\left(K+\sum_{i=1}^{N}\left(K_{i} \delta_{i} / n_{i}\right)\right) \cdot \sum_{i=1}^{N}\left(H_{i} x_{i} n_{i}\right)} .
$$

O conjunto de restrições (2.4.2) garante que as demandas das partes de aço são satisfeitas. As restrições (2.4.3) e (2.4.6) asseguram que existe um custo de preparação para cada tipo de padrão de corte utilizado. Os conjuntos de restrições (2.4.4) e (2.4.5) asseguram que a demanda para cada padrão de corte $i$ é não negativa e que cada padrão é produzido um número inteiro de vezes. 
Em Nonas e Thorstenson (2000), para resolver uma simplificação do modelo (2.4.1)(2.4.6), que não considera custo de preparação por operação em cada período do horizonte de planejamento, foram utilizados: dois métodos de solução global (método de classificação de ponto extremo de Murty (1968) e uma versão adaptada deste método) e três algoritmos de busca local (o primeiro busca todos os pontos extremos em uma vizinhança da solução ótima do problema de corte de estoque e, o segundo e o terceiro buscam somente uma pequena parte destes pontos utilizando critérios diferentes). Os padrões de corte são gerados antecipadamente utilizando um algoritmo baseado em busca simples em árvore. A heurística seqüencial proposta por Haessler (1971), em que o problema de corte de estoque é resolvido no primeiro passo e o problema de dimensionamento de lotes é resolvido no segundo passo, também foi considerada.

De acordo com os testes computacionais, o método de Murty obteve bons resultados e melhores que a versão adaptada. Somente problemas com até 50 padrões de corte diferentes foram resolvidos na otimalidade. Os três algoritmos de busca local apresentaram bons resultados, sendo que os dois últimos tiveram tempo de solução próximos e muito menor. $\mathrm{O}$ tempo médio do algoritmo 1 chegou a ser aproximadamente 37 vezes maior que o algoritmo 3 em um conjunto de problemas. $\mathrm{O}$ algoritmo busca simples em árvore apresentou soluções melhores que a heurística seqüencial, mas quando o número de padrões de corte gerado tornase muito grande, ocorrem problemas de alocação de memória.

Nonas e Thorstenson (2008), outros métodos de solução foram propostos para tentar resolver mais rapidamente o mesmo modelo matemático simplificado com dimensões maiores e também resolver o problema de corte de estoque generalizado representado pelo seguinte modelo matemático (2.4.7)-(2.4.11):

$$
\begin{array}{lll}
\text { Min } & c \sum_{i=1}^{N} x_{i}-\text { const }_{r m}+\sum_{i=1}^{N} K \delta_{i} & \\
\text { s.a. } & \sum_{i=1}^{N} a_{i j} x_{i} \geq d_{j}, & j=1, \ldots, M \\
& \sum_{j=1}^{M} a_{i j} \text { size }_{j} \leq \text { size }_{r m}, & i=1, \ldots, N, \\
& x_{i}, a_{i j} \geq 0 \text { e inteiros, } & i=1, \ldots, N, \quad j=1, \ldots, M \\
& \delta_{i} \in\{0,1\}, & i=1, \ldots, N,
\end{array}
$$

em que,

size $j$ : tamanho da parte tipo $j$.

size $_{r m}: \quad$ tamanho da matéria-prima.

const $_{r m}:$ custo constante das partes demandadas dado por: $c \sum_{j=1}^{M} d_{j} \frac{\text { size }_{j}}{\text { size }_{r m}}$.

Um novo procedimento de geração de colunas, denominado CGSP, que inclui características das heurísticas de busca simples em árvore e seqüencial e uma extensão deste procedimento, o CGSP+, que permite cortar peças em excesso, foram propostos. 
Os novos procedimentos geram soluções que são em média melhores que as soluções obtidas pela heurística de busca simples em árvore em termos de função objetivo e tempo de resolução. Por causa de uma classificação melhor dos padrões de corte e níveis de seleção mais apertados para perda e utilidade, o CGSP tem um tempo de resolução muito menor permitindo a resolução de problemas com dimensões maiores. O desempenho dos procedimentos CGSP e CGSP+ foram comparados com o procedimento de Haessler (1971) e seus resultados foram melhores, em média, para todos os exemplares testados.

Os experimentos mostraram que os resultados obtidos com os métodos propostos ao resolver o problema de corte de estoque generalizado são satisfatórios quando comparados com outros procedimentos propostos na literatura.

\subsection{Problema acoplado na indústria de papel I}

Respício e Captivo (2002) consideram o sistema de produção da indústria de papel e propõem um modelo de otimização linear inteiro que acopla os problemas de dimensionamento de lotes e corte de estoque, o qual é resolvido utilizando um algoritmo branch-and-price.

O processo produtivo da indústria de papel começa com fabricação de bobinas grandes de papel, denominadas de bobinas mestres, de diferentes famílias, as quais serão, posteriormente, cortadas em bobinas menores para obter os itens demandados. A capacidade de produção é limitada e não é suficiente para atender à demanda, levando a prazos de entrega grandes. Estoques iniciais são considerados para contornar a falta de capacidade e o planejamento da produção deve incorporar as decisões do processo de corte. O objetivo é obter um planejamento da produção que permite estabelecer tempos de entrega precisos e determina as quantidades de bobinas grandes a serem produzidas em cada período do horizonte de planejamento.

Neste trabalho, a formulação clássica do problema de corte de estoque de Gilmore e Gomory (1961) é estendida considerando demanda acumulada e as respectivas restrições de atendimento à demanda. Restrições de capacidade limitando o tempo de processamento total de bobinas mestres produzidas e cortadas em cada período do horizonte de planejamento são introduzidas. Tempos no processo de corte não são relevantes e, por isso, não são considerados. Variáveis de estoque inicial (variáveis artificiais) com custos altos são utilizadas para garantir a factibilidade do modelo e determinar a falta de capacidade.

Um modelo de otimização linear inteiro é proposto e resolvido usando um algoritmo branch-and-price. Limites inferiores para o ótimo do problema linear (PL) são obtidos utilizando procedimentos apropriados. Quando a solução do PL mestre não é inteira, a ramificação é feita adicionando explicitamente uma restrição no PL restrito atual. São utilizadas duas regras de ramificação. A estrutura do problema mestre muda e os valores ótimos para as variáveis duais associados às restrições adicionadas são considerados na função objetivo do subproblema de geração de coluna. Os padrões de corte iniciais são obtidos usando a heurística Best Fit Decreasing.

O algoritmo foi testado com pequenos e poucos exemplos obtidos a partir de dados reais e o número máximo de nós da árvore branch\&bound fixado em 20000.

A notação utilizada no modelo é a seguinte: 


\section{- Parâmetros}

$m: \quad$ número de tipos de itens.

$c_{t}$ : $\quad$ capacidade de produção disponível no período $t$.

$h_{i}$ : $\quad$ custo de estoque inicial unitário do item tipo $i$.

$F$ : $\quad$ quantidade de famílias.

$F(i)$ : família do item tipo $i$.

$b_{f}$ : tempo (em horas) de processar uma bobina mestre da família $f$.

$q_{i j t}$ : número de vezes que o item tipo $i$ é cortado no padrão de corte $j$ no período $t$.

$d_{i t}$ : demanda acumulada do item $i$ no período $t$.

\section{- Variáveis}

$I_{i}: \quad$ estoque inicial do item tipo $i$.

$x_{j f t}$ : número de bobinas mestre da família $f$ cortado no padrão de corte $j$ no período $t$.

\section{Modelo matemático}

$$
\begin{array}{lll}
\text { Min } & \sum_{i}\left(h_{i} I_{i}\right)+\sum_{t} \sum_{f} \sum_{j} x_{j f t} & \\
\text { s.a. } & \sum_{k=1}^{t} \sum_{j} q_{i j k} x_{j F(i) k}+I_{i} \geq d_{i t}, & \forall i, t \neq T \\
& \sum_{k=1}^{T} \sum_{j} q_{i j k} x_{j F(i) k}+I_{i}=d_{i T}, & \forall i \\
& \sum_{f} \sum_{j} b_{f} x_{j f t} \leq c_{t}, & \forall t \\
& x_{j f t} \geq 0 \text { e inteiros, } & \forall j, f, t \\
& I_{i} \geq 0 \text { e inteiros, } & \forall i
\end{array}
$$

A função objetivo (2.5.1) consiste em minimizar os custos de estoques iniciais e o número total de bobinas mestres cortadas no horizonte de planejamento. As restrições de atendimento à demanda (2.5.2) garantem que a demanda acumulada seja satisfeita pela produção acumulada ou pelos níveis de estoque inicial. Não haverá estoque no final do horizonte devido às restrições (2.5.3), as quais asseguram que a demanda acumulada no último período seja atendida exatamente. O modelo (2.5.1)-(2.5.6) expressa a integração de um conjunto de problemas de corte de estoque menores, um para cada família e cada período. As restrições (2.5.4) acoplam os problemas de corte de estoque menores do mesmo período. As restrições de atendimento à demanda (2.5.2) e (2.5.3) estabelecem as conexões sobre o tempo, devido ao manuseio da produção acumulada e dos estoques iniciais.

A solução do modelo (2.5.1)-(2.5.6), $\left(x_{j f t}^{*}, I_{i}^{*}\right)$, permite calcular o número de bobinas mestre da família $f$ a serem cortadas no período $t$, que é dado por: $\sum_{j} x_{j f t}^{*}$, expressando as quantidades a serem produzidas de cada família em cada período. 


\subsection{Problema acoplado na indústria de papel II}

Menon e Schrage (2002) abordam a programação da produção de uma indústria de papel e propõe um modelo de otimização inteiro que acopla o problema de corte de estoque e o problema de designação com máquinas idênticas, o qual é resolvido por um método heurístico baseado em branch-and-price.

O papel, geralmente, é fabricado em bobinas grandes que, posteriormente, são cortadas em bobinas menores (itens finais) de diferentes larguras. Um pedido consiste de uma lista de larguras dos itens finais e demandas correspondentes. Cada pedido deve ser alocado a uma das máquinas, que possuem capacidade limitada e problemas de corte de estoque (um para cada máquina) devem ser resolvidos para encontrar a forma mais econômica de cortar a matéria-prima (bobinas grandes) para obter os itens finais com o objetivo de minimizar custos de produção.

O modelo acoplado proposto para representar o problema da indústria de papel não considera a variação da demanda ao longo do tempo e possui uma estrutura dual-angular. Segundo o autor, o problema é muito grande para ser resolvido usando métodos convencionais como, por exemplo, o branch-and-bound. Além disso, máquinas idênticas induzem a simetria, o que intensifica ainda mais a dificuldade de resolução do modelo.

A notação utilizada no modelo acoplado proposto é a seguinte:

\section{- Parâmetros}

$c_{k}: \quad$ custo de preparação da máquina tipo $k$.

$u_{k}$ : número máximo de vezes que a máquina tipo $k$ pode ser usada.

$a_{i j k}: \quad$ multiplicidade da largura $i$ no padrão de corte $j$ na máquina tipo $k$.

$d_{i m}$ : demanda da largura $i$ no pedido $m$.

\section{- Variáveis}

$x_{j k}$ : quantidade de vezes que o padrão de corte $j$ é usado na máquina tipo $k$.

$y_{m k}$ : variável binária que indica o uso ou não da máquina tipo $k\left(y_{m k}=1\right.$ se o pedido $m$ é alocado para a máquina tipo $k$ e $y_{m k}=0$ caso contrário).

\section{Modelo matemático}

$$
\begin{array}{lll}
\text { Min } & \sum_{j} \sum_{k} c_{k} x_{j k} & \\
\text { s.a. } & \sum_{k} x_{j k} \leq u_{k}, & \forall k \\
& \sum_{j} a_{i j k} x_{j k} \geq \sum_{m} d_{i m} y_{m k}, & \forall i, k \\
& \sum_{k} y_{m k}=1, & \forall m \\
& y_{m k} \in\{0,1\}, & \forall m, k \\
& x_{j k} \geq 0 \text { e inteiros, }, & \forall j, k
\end{array}
$$


A função objetivo (2.6.1) consiste em minimizar o custo de preparação. As restrições (2.6.2) asseguram que a produção não excederá as capacidades das máquinas. As restrições (2.6.3) garantem o atendimento às demandas das larguras. As restrições (2.6.4) garantem que cada pedido é designado a somente uma máquina. As restrições (2.6.5) definem as variáveis de alocação como binárias. As restrições (2.6.6) são de não negatividade e integralidade das variáveis do corte.

Dados os valores das variáveis $y$, o modelo (2.6.1)-(2.6.6) decompõe-se em vários subproblemas de corte de estoque sendo um para cada máquina tipo $k$. Sendo assim, a idéia é ramificar nas variáveis $y$ até atingir um nó em que tenham valores binários factíveis. Neste nó, os subproblemas de corte podem ser resolvidos separadamente usando branch-and-price ou os métodos de Dyckhoff (1990) ou Vanderbeck (1994). A dificuldade com esta abordagem é a necessidade de resolver os subproblemas como programas inteiros. Logo, é importante reduzir ao máximo o número de vezes em que os subproblemas são resolvidos.

A abordagem proposta utiliza vários limitantes inferiores para a relaxação linear que podem ser facilmente calculados e usados para formular um problema mestre relaxado. Quando estes limitantes são próximos do valor-objetivo dos subproblemas, o problema mestre relaxado fornece um limitante apertado para o problema original.

Sejam:

$v_{k}=\sum_{j} x_{j k}:$ número estimado de vezes que a máquina tipo $k$ pode ser usada.

$L B_{l k}: l$-ésimo limite inferior para a máquina tipo $k$.

O modelo matemático para o problema mestre relaxado é o seguinte:

$$
\begin{array}{llll}
\text { Min } & \sum_{j} \sum_{k} c_{k} v_{k} & & (2.6 .7) \\
\text { s.a. } & v_{k} \leq u_{k}, & \forall k & (2.6 .8) \\
& v_{k} \geq L B_{l k}, & \forall l, k & (2.6 .9) \\
& \sum_{k} y_{m k}=1, & \forall m & (2.6 .10) \\
& v_{k} \geq 0, & \forall k & (2.6 .11) \\
& y_{m k} \in\{0,1\}, & \forall m, k & (2.6 .12)
\end{array}
$$

Nos testes computacionais, primeiro são calculados alguns limitantes para poucos subproblemas de corte de estoque (12 exemplares) e uma máquina e demonstrado que tais limitantes são apertados. Depois, são aplicadas variantes da abordagem de solução ao problema com múltiplas máquinas da indústria de papel.

A abordagem se mostrou eficiente em relação à qualidade das soluções e o tempo de resolução. Enquanto os limites são razoavelmente bons, usar esta abordagem no branch-andbound economiza esforço computacional, pois uma boa solução inteira é obtida, permitindo fazer podas mais cedo. Além disso, a abordagem fornece cortes válidos para o problema original, os quais se forem incorporados ao problema quando usar o branch-and-bound, melhores valores para o PL resolvido em cada nó podem ser obtidos. O autor conclui que estes cortes podem levar à infactibilidade em alguns nós, reduzindo o número de ramificações. 


\subsection{Problema acoplado na indústria de correias}

Arbib e Marinelli (2005) apresentam um estudo de caso em uma indústria européia que produz correias de engrenagem. Um modelo de otimização inteiro misto que acopla os problemas de dimensionamento de lotes e corte de estoque foi desenvolvido.

A produção de uma correia é realizada preparando um cilindro de nylon emborrachado com altura constante e circunferência adequada e cortando-o em um determinado número de correias de engrenagem idênticas. Os cilindros são feitos de tiras, cortadas de uma bobina de largura $w$ por uma máquina equipada com duas facas paralelas que podem ser posicionadas em qualquer ponto do intervalo $[0, w]$ para cortar até 3 tiras de mesmo comprimento e larguras distintas. Se a largura é igual à circunferência de um tipo de correia demandado, os dois lados opostos da tira são costurados juntos ao longo do comprimento para obter a correia cilíndrica correspondente. Caso contrário, a tira é descartada (se a largura é menor que um tamanho mínimo) ou utilizada por costurá-la com uma outra tira.

A idéia de utilização de sobras consiste em adicionar à carteira de pedidos tiras auxiliares não demandadas, que unidas a outras tiras formam itens demandados e enriquecem os padrões de corte factíveis, levando à redução na perda de material.

Um modelo de otimização linear para o problema de corte, com opção de combinação, é proposto, o qual é revisado para aumentar a habilidade em combinação e para considerar também o nível de produção das partes finais e o nível de estoque de sobras. Uma extensão do modelo revisado para planejamento a médio prazo, que considera custos de produção dependentes do material (perda, estoque e transporte) é, finalmente, apresentada. Tal extensão possui variáveis de decisão inteiras e é de difícil solução. Porém, admite uma decomposição natural em um problema de dimensionamento de lotes de único item não capacitado e um problema de corte de estoque.

Os níveis de decisão operacional e tático são acoplados no modelo considerando dois tipos de variáveis. No nível operacional, as decisões ocorrem no corte, utilização de sobras e estoque de tiras e, no nível tático, as decisões são na manutenção e transporte do estoque.

Para a modelagem matemática do problema sejam:

A: lista de pedidos na forma: $\mathrm{A}=\left\{w_{1} \mathrm{x} r_{1}, \ldots, w_{p} \mathrm{x} r_{p}\right\}$ em que $w_{i}$ é a largura e $r_{i}$ é a demanda da parte tipo $i$.

$S: \quad$ conjunto das partes não demandadas produzidas nos padrões de corte cujas larguras são maiores que $w_{\min }$ e que podem ser combinadas para formar partes demandadas. $S$ também contém uma parte fictícia de largura 0 .

$B$ : lista estendida contendo as tiras auxiliares com largura maior que $w_{\min }$, as quais complementam os elementos de $S$ para formar os itens demandados. Cada elemento de $B$ ou é uma parte da lista original ou é uma tira a ser combinada a partes não demandadas produzidas no corte $(B \supseteq A)$.

Os parâmetros e variáveis usados no modelo matemático são: 


\section{- Parâmetros}

T: $\quad$ número de períodos do horizonte de planejamento.

$C$ : $\quad$ número máximo de cilindros que podem ser cortados por dia.

$L$ : $\quad$ tamanho máximo da área para estoque diário.

$w_{i}$ : largura da $i$-ésima parte de $B$.

$B_{h}$ : conjunto dos pares $(i, j)$ de $B$ com larguras $w_{i}$ e $w_{j}$ tais que $w_{i}+w_{j}=w_{h}$ e $i \leq j$. Este conjunto também inclui os pares $(0, j)$ para $j \in A$ (partes sem combinação).

$n$ : $\quad$ número de padrões de corte.

$a_{i}^{k}$ : número de tiras tipo $i$ produzido pelo padrão de corte $k$.

$r_{h}^{t}$ : número de partes tipo $h$ demandado no dia $t$.

\section{- Variáveis}

$x_{k}^{t}: \quad$ frequência do padrão de corte $k$ no dia $t$.

$y_{i}^{t}$ : número de tiras tipo $i$ estocado no final do dia $t$.

$z_{i j}^{t}$ : número de tiras tipo $i$ combinado com uma tira tipo $j$ no dia $t$ para obter um tipo de parte de $A$.

\section{Modelo matemático}

$$
\begin{aligned}
& \operatorname{Min} \sum_{t=1}^{T} \sum_{k=1}^{n} x_{k}^{t} \\
& \text { s.a. } \quad \sum_{(i, j) \in B_{h}} z_{i j}^{t} \geq r_{h}^{t}, \quad \forall h \in A, \quad 1 \leq t \leq T \text { (2.7.2) } \\
& \sum_{k=1}^{n} a_{i}^{k} x_{k}^{t}+y_{i}^{t-1}=\sum_{h \in A}\left(\sum_{(i, j) \in B_{h}: j \leq i} z_{i j}^{t}+\sum_{(i, j) \in B_{h}: i \leq j} z_{i j}^{t}\right)+y_{i}^{t}, \quad i \in B: w_{i} \neq 0, \quad 1 \leq t \leq T \quad \text { (2.7.3) } \\
& \sum_{k=1}^{n} x_{k}^{t} \leq C \\
& 1 \leq t \leq T \\
& \sum_{i \in B: w_{i} \neq 0} y_{i}^{t} \leq L \\
& 1 \leq t \leq T \\
& x_{k}^{t} \geq 0 \text { e inteiros, } \\
& 1 \leq k \leq n \text {, } \\
& \forall i, j:(i, j) \in B_{h}, \quad 1 \leq t \leq T \\
& i \in B \text {, } \\
& 1 \leq t \leq T
\end{aligned}
$$

A função objetivo (2.7.1) consiste em minimizar a perda de material no corte, minimizando a freqüência dos padrões de corte. As restrições (2.7.2) junto com (2.7.7) garantem o atendimento à demanda do dia $t$. As restrições (2.7.3) são as restrições de balanço de estoque dos itens demandados. As restrições (2.7.4) garantem que a capacidade de produção não será violada. As restrições (2.7.5) asseguram que a quantidade a ser estocada não excede o tamanho da área para armazenagem. As restrições (2.7.6), (2.7.7) e (2.7.8) são as restrições de não negatividade e integralidade das variáveis. 
Um procedimento de solução em dois passos é utilizado para reduzir significativamente o número de preparações e combinações. Os resultados dos testes computacionais realizados com dados reais mostraram os benefícios que podem ser obtidos ao controlar o estoque de sobras, acoplando aspectos de planejamento com detalhes do processo produtivo, de forma a melhorar características do dimensionamento de lotes.

\subsection{Problema acoplado na indústria de móveis}

Gramani e França (2006) consideram o processo produtivo de uma indústria de móveis e apresentam um modelo de otimização linear inteiro misto para representar o problema acoplado de dimensionamento de lotes e corte de estoque, o qual é resolvido heuristicamente por uma abordagem análoga ao método de Wagner-Whitin (1958).

$\mathrm{O}$ processo produtivo da indústria de móveis, resumidamente, consiste em cortar placas retangulares disponíveis em estoque conforme diferentes padrões de corte para obter os diversos tipos de peças (itens) que compõem os produtos demandados. A máquina usada no processo de corte tem capacidade limitada. Neste trabalho, somente um tamanho de placa é considerado e o horizonte de planejamento finito é dividido em períodos. As decisões do planejamento consistem em determinar a quantidade de produtos finais a ser produzida em cada período do horizonte de planejamento de forma a atender à demanda, não violar a capacidade de máquina e minimizar os custos de produção, preparação, estoque de peças e número de placas cortadas.

No modelo matemático (programação da produção) é utilizada a seguinte notação:

\section{- Parâmetros}

T: $\quad$ número de períodos do horizonte de planejamento.

$P: \quad$ número de tipos de peças a serem cortadas.

$N: \quad$ número de diferentes padrões de corte para a placa $L x W$.

$M: \quad$ número de tipos de produtos finais.

$c_{i t}$ : custo do produto final tipo $i$ no período $t$.

$c p: \quad$ custo unitário da placa $L \times W$.

$h_{i t}$ : custo de estoque do produto final tipo $i$ no período $t$.

$d_{i t}$ : demanda do produto final tipo $i$ no período $t$.

$r_{p i}$ : número de peças do tipo $p$ necessárias para formar uma unidade do produto final tipo

$i$.

$v_{j}$ : tempo gasto para cortar uma placa no padrão de corte $j$.

$c_{t}$ : $\quad$ capacidade de serra (em horas) no período $t$.

$s_{i t}$ : $\quad$ custo de preparação para manufaturar o produto final tipo $i$ no período $t$.

$a_{p j}$ : número de peças tipo $p$ no padrão de corte $j$.

Q: $\quad$ número suficientemente grande. 


\section{- Variáveis}

$x_{i t}$ : quantidade do produto final tipo $i$ fabricado no período $t$.

$I_{i t}$ : $\quad$ quantidade do produto final tipo $i$ estocada no período $t$.

$y_{j t}: \quad$ quantidade de placas cortadas usando o padrão de corte $j$ no período $t$.

$z_{i t}: \quad$ variável binária $\left(z_{i t}=1\right.$ se $x_{i t}>0$ ou $z_{i t}=0$, caso contrário).

\section{Modelo Matemático}

$$
\begin{aligned}
& \operatorname{Min} \sum_{i=1}^{M} \sum_{t=1}^{T}\left(c_{i t} x_{i t}+h_{i t} I_{i t}+s_{i t} z_{i t}\right)+\sum_{j=1}^{N} \sum_{t=1}^{T} c p y_{j t} \\
& \text { s.a. } \quad x_{i t}+I_{i(t-1)}-I_{i t}=d_{i t}, \quad i=1, \ldots, M, \quad t=1, \ldots, T \\
& \sum_{j=1}^{N} a_{p j} y_{j t} \geq \sum_{i=1}^{M} r_{p i} x_{i t}, \quad \quad p=1, \ldots, P, \quad t=1, \ldots, T \\
& \sum_{j=1}^{N} v_{j} y_{j t} \leq c_{t} \\
& x_{i t} \leq Q z_{i t} \\
& x_{i t}, I_{i t} \geq 0 \text {, } \\
& y_{j t} \geq 0 \text { e inteiros, } \\
& z_{i t} \in\{0,1\}
\end{aligned}
$$

A função objetivo (2.8.1) consiste em minimizar os custos de produção, estoque, preparação de máquinas e placas cortadas. As restrições (2.8.2) são de balanço de estoque de produtos finais. As restrições (2.8.3) junto com $x_{i t}, I_{i t}$ e $y_{j t} \geq 0 \forall i, j, t$ são de atendimento à demanda de peças. Estas restrições acoplam os dois problemas. Nas equações (2.8.4) temos as restrições de capacidade da serra. As restrições (2.8.5) são as restrições de preparação de máquinas. As restrições (2.8.6) são de não negatividade das variáveis $x$ e $I$. As restrições (2.8.7) são restrições de integralidade e não-negatividade das variáveis $y$. As restrições (2.8.8) definem as variáveis $z$ como binárias.

O modelo matemático (2.8.1)-(2.8.8), por ser de difícil resolução, é simplificado de forma que são consideradas apenas as restrições referentes às peças, excluindo as restrições referentes aos produtos finais. No método heurístico de solução proposto, este modelo é representado como um problema de caminho mínimo em redes em que cada período do horizonte de planejamento é representado por um nó e a cada arco da rede é associado um problema de corte de estoque capacitado, em que toda a demanda do período correspondente ao nó destino é antecipada para o período do nó origem do arco. Após a resolução de todos os problemas de corte a rede é construída e, então, resta apenas resolver um problema clássico de caminho mínimo para obter a solução desejada.

Os resultados computacionais obtidos pelo método proposto foram comparados com os resultados obtidos resolvendo os problemas de forma separada (primeiro é resolvido o problema de dimensionamento de lotes e depois o problema de corte de estoque). Os testes com problemas de tamanhos reais mostraram um ganho significativo com a heurística de caminho mínimo. A qualidade das soluções foi verificada comparando-as com as soluções ótimas de poucos e pequenos exemplares resolvidos pelo pacote comercial AMPL/CPLEX. 


\subsection{Problema acoplado na indústria de papel III}

Poltroniere et al. (2008) abordam o problema de dimensionamento de lotes e corte de estoque presentes na indústria de papel de forma acoplada e propõem um modelo de otimização linear inteiro misto, o qual é resolvido heuristicamente.

O processo produtivo da indústria de papel pode ser descrito da seguinte forma: inicialmente, bobinas-jumbo de papel (objetos) são produzidas em diversas máquinas paralelas com capacidades limitadas. Em seguida, estas bobinas vão para o setor de rebobinamento e cortes longitudinais são feitos para obter bobinas menores (intermediárias) de larguras dadas, as quais seguem para o setor de acabamento. Parte das bobinas intermediárias é embalada para atender uma demanda específica e as restantes são cortadas conforme diferentes padrões de corte para obter os diferentes tipos de itens finais demandados, tais como, resmas de papel tipo A4, carta, entre outros.

Para a modelagem matemática do problema, o horizonte de planejamento finito é dividido em períodos, as bobinas-jumbo são simbolicamente divididas em bobinas menores idênticas (contendo uma única gramatura de papel e de mesmo peso), denominadas bobinasmestre e a demanda dos itens finais é agregada por gramatura e período.

As decisões de planejamento da produção consistem em determinar quais e quantas bobinas-mestre (definidas por gramatura e comprimento) devem ser produzidas em cada período do horizonte de planejamento, de forma a atender à carteira de pedidos, evitar atrasos e estoques indesejados e minimizar os custos de produção, preparação, estoque e perda de material.

No modelo matemático é usada a seguinte notação:

\section{- Parâmetros}

T: $\quad$ número de períodos no horizonte de planejamento.

$K$ : $\quad$ número de gramaturas.

$M: \quad$ número de máquinas disponíveis.

$N_{m}$ : número de diferentes padrões de corte para a bobina-mestre produzida na máquina $m$.

$N f$ : número de tipos de produtos finais.

$\{1, \ldots, N f\}=S(1) \cup S(2) \cup \ldots \cup S(K)$, em que $\mathrm{S}(k)=\{i$ : o item tipo $i$ tem gramatura $k\}$.

$c_{k m t}$ : custo de produção de uma bobina-mestre de gramatura $k$ na máquina $m$ no período $t$.

$h_{k t}$ : custo/t de estoque de bobinas-mestre de gramatura $k$ no final do período $t$.

$s_{k m t}$ : $\quad$ custo de preparação da máquina $m$ para produzir a bobina-mestre de gramatura $k$ no período $t$.

$c p_{k t}: \quad$ custo/cm de perda de papel de gramatura $k$ no processo de corte no período $t$.

$\sigma_{i t}: \quad$ custo/t de estoque de itens finais tipo $i$ no período $t$.

$C_{m t}: \quad$ capacidade (em t) da máquina $m$ no período $t$.

$d_{k t}$ : vetor da demanda de itens finais de gramatura $k$ no período $t$, cuja dimensão é $|S(k)|$.

( $d_{i k t}$ é a demanda do item tipo $i$ de gramatura $k$ no período $t$ ). 
$\rho_{k}$ : peso específico (peso por $\mathrm{cm}$ da largura da bobina) de uma bobina-mestre de gramatura $k$.

$\eta_{i k}$ : $\quad$ peso do item final tipo $i$ de gramatura $k$ (o peso do item final tipo $i$ de gramatura $k$ e largura $l_{i}$ é dado por $\eta_{i k}=\rho_{k} l_{i}$ ).

$D_{k t}$ : demanda (t) de papel da gramatura $k$ no período $t$.

$b_{k m}$ : peso de uma bobina-mestre de gramatura $k$ produzida na máquina $m\left(b_{k m}=L_{m} \rho_{k}\right)$.

$f_{k m}$ : $\quad$ peso do papel desperdiçado na preparação da máquina $m$ para a produção da bobinamestre de gramatura $k$.

$a_{j m}$ : vetor associado ao padrão de corte $j$ utilizado para cortar a bobina-mestre de largura

$L_{m}$. A coordenada $i$ deste vetor define o número de itens do tipo $i$ cortados no padrão de corte $j$ para a bobina-mestre de largura $L_{m}$.

$p_{j m}$ : perda de papel $(\mathrm{em} \mathrm{cm})$ no padrão de corte $j$ utilizado para cortar a bobina-mestre de largura $L_{m}$.

$Q$ : número suficientemente grande (escolhido de acordo com os dados do problema de modo a torná-lo mais restrito).

\section{- Variáveis}

$x_{k m t}$ : quantidade de bobinas-mestre de gramatura $k$ produzidas na máquina $m$ no período $t$.

$w_{k m t}$ : quantidade de bobinas-mestre de gramatura $k$ produzidas na máquina $m$ estocadas no período $t$.

$z_{k m t}$ : variável binária que indica a produção ou não da bobina-mestre de gramatura $k$ na máquina $m$ no período $t$.

$y_{k m t}^{j}$ : quantidade de bobinas-mestre de gramatura $k$ produzida na máquina $m$ e cortada usando o padrão de corte $j$ no período $t$.

$e_{k t}$ : vetor que contém em cada coordenada a quantidade de itens finais de gramatura $k$ estocados no final do período $t$. Sua dimensão é $|S(k)|$.

\section{Observação:}

O parâmetro $D_{k t}$ que representa a quantidade total de papel tipo $k$ que deve estar disponível no período $t$, não é um dado do problema, pois depende da perda que ocorre durante o processo de corte. Por definição, deve ser: $D_{k t}=\sum_{i \in S(k)} \eta_{i k} d_{i k t}+$ perda . Como a perda é desconhecida, inicialmente é introduzido um novo parâmetro $\theta$, o qual é uma estimativa para a perda. Por outro lado, o parâmetro $D_{k t}$ pode ser expresso em termos das variáveis que determinam o número de bobinas-mestre tipo $k$ que deve ser cortado no período $t$, isto é, $D_{k t}=\sum_{m=1}^{M} \sum_{j=1}^{N_{m}} b_{k m} y_{k m t}^{j}$. 


\section{Modelo Matemático}

$$
\begin{array}{ll}
\text { Min } \sum_{t=1}^{T} \sum_{m=1 k=1}^{M} \sum_{k m t}^{K}\left(c_{k m t} x_{k t}+h_{k t} b_{k m} w_{k m t}+s_{k m t} z_{k m t}\right)+\sum_{t=1}^{T} \sum_{k=1}^{K} c p_{k t}\left(\sum_{m=1}^{M} \sum_{j=1}^{N m} p_{j m} y_{k m t}^{j}\right) & +\sum_{t=1}^{T} \sum_{k=1 i \in S(k)}^{K} \sum_{i t} \eta_{i k} e_{i k t} \\
\text { s.a. } \quad \sum_{m=1}^{M}\left(b_{k m} x_{k m t}+b_{k m} w_{k m(t-1)}-b_{k m} w_{k m t}\right)=D_{k t}, & \forall k, t \\
\sum_{k=1}^{K}\left(b_{k m} x_{k m t}+f_{k m} z_{k m t}\right) \leq C_{m t}, & \forall m, t \\
\sum_{m=1}^{M} \sum_{j=1}^{N_{m}} a_{j m} y_{k m t}^{j}+e_{k(t-1)}-e_{k t}=d_{k t}, & \forall k, t \\
\sum_{j=1}^{N m} y_{k m t}^{j}=x_{k m t}+w_{k m(t-1)}-w_{k m t}, & \forall k, m, t \\
x_{k m t} \leq Q z_{k m t}, & \forall k, m, t \\
w_{k m 0}=0, \quad e_{k 0}=0, & \forall k, m, t \\
x_{k m t} \geq 0, w_{k m t} \geq 0, e_{k t} \geq 0, & \forall k, m, t \\
z_{k m t} \in\{0,1\}, & \forall k, m, t \\
y_{k m t}^{j} \geq 0 \text { e inteiros, } & \forall j, k, m, t
\end{array}
$$

A função objetivo (2.9.1) consiste em minimizar os custos de produção, preparação, estoque de bobinas e itens e perda de material. As restrições (2.9.2) e (2.9.2) garantem o atendimento à demanda de papel por período. As restrições (2.9.3) são de capacidade de produção. O conjunto de restrições (2.9.4) junto com $e_{k t} \geq 0$ é de balanço de estoques de itens finais e assegura que a demanda de itens finais será atendida. As restrições (2.9.5) são de acoplamento e garantem que a quantidade de bobinas-mestre cortadas no período deve ser igual à quantidade de bobinas-mestre disponíveis neste período. As restrições (2.9.6) são de preparação, ou seja, se existe produção de bobinas-mestre de gramatura $k$ na máquina $m$ $\left(x_{k m t}>0\right)$ ao longo do período $t$, então $z_{i t}=1$, caso contrário $z_{i t}=0$. As restrições (2.9.7) definem os estoques iniciais de todos os tipos de itens são nulos. As restrições (2.9.8) são de não-negatividade das variáveis $x, w$ e $e$. As restrições (2.9.9) definem as variáveis $z$ como binárias. As restrições (2.9.10) são de não-negatividade e integralidade das variáveis $y$.

Para resolver o modelo matemático (2.9.1)-(2.9.10) proposto são desenvolvidas duas heurísticas baseadas na relaxação lagrangiana das restrições de acoplamento. A primeira heurística chamada lote-corte, em cada iteração, resolve, inicialmente, o problema de dimensionamento de lotes, determinando a quantidade de bobinas-mestre a ser produzida em cada período do horizonte de planejamento para atender à demanda e, em seguida, resolve o problema de corte de estoque utilizando as bobinas-mestre produzidas. A outra heurística, denominada corte-lote, resolve o problema de corte admitindo que as quantidades de bobinasmestre são ilimitadas e, a seguir, determina um plano de produção para gerar as bobinasjumbo necessárias. Entretanto, o plano de produção inicial pode gerar estoques e preparações indesejáveis e, portanto, deve ser revisado.

De acordo com os resultados obtidos nos experimentos computacionais realizados com o intuito de comparar ambas heurísticas, a heurística corte-lote apresentou um melhor desempenho que a heurística lote-corte. 


\section{Capítulo 3}

\section{Problemas de dimensionamento de lotes e corte de estoque}

Neste capítulo, os problemas de dimensionamento de lotes e corte de estoque são tratados de forma independente. Por serem problemas de otimização combinatória bastante complexos, é importante revisá-los isoladamente, antes de tratá-los de maneira acoplada, que é o objetivo principal deste trabalho. Não é objetivo deste capítulo uma revisão abrangente e aprofundada de tais problemas, focalizamos alguns problemas que fornecem os elementos necessários para o estudo dos próximos capítulos.

A Seção 3.1 refere-se somente ao problema de dimensionamento de lotes. A definição do problema, características que permitem classificá-lo, alguns modelos matemáticos e comentários sobre métodos de resolução são dados.

A Seção 3.2 trata especificamente do problema de corte de estoque. Definições, classificações, modelagem matemática e métodos de solução para os casos unidimensional, bidimensional e multiperíodo do problema são apresentados.

\subsection{Problemas de dimensionamento de lotes (PDL)}

Em poucas palavras podemos dizer que o problema de dimensionamento de lotes (PDL) consiste em determinar as quantidades a serem produzidas de todos os itens demandados em cada um dos períodos do horizonte de planejamento com o objetivo de minimizar os custos totais de produção, estoque e preparação de máquina sem violar a capacidade de produção disponível e ainda atender à demanda dos produtos.

Algumas características influenciam na classificação, modelagem matemática e complexidade do problema de dimensionamento de lotes, tais como: tipo de horizonte de planejamento (pode ser finito ou infinito, contínuo ou discreto e rolante ${ }^{4}$ ), número de estágios (mono-estágio ${ }^{5}$ ou multi-estágio ${ }^{6}$ ), número de tipos de itens (pode ser produzido um único

\footnotetext{
${ }^{4}$ Horizonte rolante é adequado quando existem incertezas nos dados de períodos futuros.

${ }^{5}$ Mono-estágio quando os itens a serem produzidos são independentes, isto é, a produção de um item final não depende da produção de outros itens.
} 
tipo de item ou múltiplos tipos de itens), restrições de capacidade (os recursos disponíveis para a produção dos itens finais podem ser ilimitados ou limitados), tipos de demanda (determinística ou probabilística, ou ainda, estática ou dinâmica), preparação para produção (a existência ou não de custos e tempos necessários a preparação da produção de um determinado item), estoque de itens, entre outros.

\subsubsection{Problema de dimensionamento de lotes mono-estágio}

O problema de dimensionamento de lotes mais simples é mono-estágio e considera a produção de um único tipo de item, com demanda fixa, sem limitações de capacidade ao longo dos períodos do horizonte de planejamento finito, sem preparação de máquina e cujo objetivo é minimizar os custos de produção e estoque dos itens. Neste caso, o tempo e os custos de preparação são irrelevantes, pois são considerados baixos em relação aos custos de produção e estoque.

Se considerarmos o mesmo problema descrito acima, mas com produção de múltiplos tipos de itens e custos de preparação, o problema de dimensionamento de lotes torna-se um problema inteiro-misto e pode ser modelado conforme a seguir.

Sejam $T$ o número de períodos do horizonte de planejamento finito e $M$ o número de diferentes tipos de itens finais demandados.

Os índices, os parâmetros e as variáveis utilizados no modelo matemático são:

\section{- Índices}

$t=1, \ldots, T: \quad$ período do horizonte de planejamento.

$i=1, \ldots, M$ : tipo de item.

\section{- Parâmetros}

$c_{i t}$ : custo de produção do item tipo $i$ no período $t$.

$h_{i t}$ : custo de estoque do item tipo $i$ no período $t$.

$s_{i t}$ : custo de preparação do item tipo $i$ no período $t$.

$d_{i t}$ : demanda do item tipo $i$ no período $t$.

$Q$ : limitante superior para a variável $x_{i t}$ (ou um número suficientemente grande).

\section{- Variáveis}

$x_{i t}$ : quantidade a ser produzida do item tipo $i$ no período $t$.

$I_{i t}$ : quantidade a ser estocada do item tipo $i$ no período $t$.

$z_{i t}$ : variável binária que indica a produção $\left(z_{i t}=1\right)$ ou não $\left(z_{i t}=0\right)$ do item tipo $i$ no período $t$.

\footnotetext{
${ }^{6}$ Multi-estágio quando a produção de um item final depende da produção de um ou mais itens.
} 


\section{Modelo Matemático}

$$
\begin{aligned}
& \operatorname{Min} \sum_{i=1}^{T} \sum_{i=1}^{M}\left(c_{i t} x_{i t}+h_{i t} I_{i t}+s_{i t} z_{i t}\right) \\
& \text { s.a. } \quad x_{i t}+I_{i, t-1}-I_{i t}=d_{i t}, \quad i=1, \ldots, M, \quad t=1, \ldots, T \\
& x_{i t} \leq Q z_{i t}, \quad i=1, \ldots, M, t=1, \ldots, T \\
& x_{i t}, I_{i t} \geq 0, \quad i=1, \ldots, M, t=1, \ldots, T \\
& z_{i t} \in\{0,1\}, \quad i=1, \ldots, M, t=1, \ldots, T
\end{aligned}
$$

A função objetivo (3.1.1), a ser minimizada, consiste na soma dos custos de produção, estoque e preparação dos $M$ tipos de itens ao longo dos $T$ períodos. O primeiro conjunto de restrições (3.1.2) descreve o balanço de estoque de todos os tipos de itens em todos os períodos. Estas restrições junto com (3.1.4), $I_{i t} \geq 0$, garantem que as demandas de todos os tipos de itens em todos os períodos são satisfeitas. As restrições (3.1.3) indicam se vai haver produção do item no período $\left(z_{i t}=1\right)$ ou não $\left(z_{i t}=0\right)$ e asseguram que ocorrerá produção somente se a preparação da máquina for feita. As restrições (3.1.4) garantem que as variáveis de produção são não-negativas e as restrições (3.1.5) definem as variáveis de preparação como binárias.

Observe que a obtenção de uma solução factível para este problema é trivial (por exemplo, $x_{i t}=d_{i t}$ : solução lote-por-lote). Existem muitas heurísticas para este problema, que buscam equilibrar os custos de estoque e os custos de preparação. Note que se pode antecipar a produção de um ou mais períodos e, com isto, diminuir os custos de preparação, em contrapartida aumentando os custos de estoque. A investigação de todas as possibilidades de antecipação permite representar o problema (3.1.1)-(3.1.5) como um problema de caminho mínimo, numa rede sem ciclos, que pode ser facilmente resolvido, o que constitui no método de Wagner-Whitin (1958).

Considerando que a quantidade de recursos disponível para a produção seja limitada, o modelo matemático para o problema de dimensionamento de lotes mono-estágio, com múltiplos tipos de itens, restrições de capacidade e tempo de preparação, é o seguinte:

\section{Modelo Matemático}

$$
\begin{aligned}
& \operatorname{Min} \sum_{t=1}^{T} \sum_{i=1}^{M}\left(c_{i t} x_{i t}+h_{i t} I_{i t}+s_{i t} z_{i t}\right) \\
& \text { s.a. } \quad x_{i t}+I_{i, t-1}-I_{i t}=d_{i t}, \quad i=1, \ldots, M, \quad t=1, \ldots, T \\
& \sum_{i=1}^{M}\left(v_{i} x_{i t}+f_{i} z_{i t}\right) \leq \operatorname{Cap}_{t}, \quad t=1, \ldots, T \\
& x_{i t} \leq Q z_{i t}, \quad i=1, \ldots, M, t=1, \ldots, T \\
& x_{i t}, I_{i t} \geq 0, \quad i=1, \ldots, M, t=1, \ldots, T \\
& z_{i t} \in\{0,1\}, \quad i=1, \ldots, M, \quad t=1, \ldots, T
\end{aligned}
$$

em que 
$f_{i}$ : $\quad$ tempo de preparação para a produção de itens tipo $i$.

$v_{i:} \quad$ tempo necessário para produzir uma unidade do item tipo $i$.

$\mathrm{Cap}_{t}$ : tempo disponível de máquina no período $t$.

Sem perda de generalidade os estoques iniciais são considerados nulos, ou seja, $I_{i 0}=0$, para $i=1, \ldots, M$.

Os modelos (3.1.1)-(3.1.5) e (3.1.6)-(3.1.11) diferem apenas pelas restrições (3.1.8), as quais representam as limitações de capacidade de recurso (no caso, tempo de máquina disponível) e garantem que o tempo gasto para produzir todos os tipos de itens nos períodos e preparar as máquinas para a produção não exceda o tempo total disponível.

Note agora que soluções factíveis, tipo lote-por-lote ou antecipações integrais na produção de demandas podem não ser factíveis, violando as restrições (3.1.8) e torna este problema NP-completo (Bitran e Yanasse, 1982), grosso modo, a obtenção de uma solução factível é um problema difícil.

A extensão deste modelo para várias máquinas pode ser obtida por considerar as restrições (3.1.8) como

$$
\sum_{i=1}^{M}\left(v_{i k} x_{i t}+f_{i k} z_{i k t}\right) \leq C a p_{k t}, \quad \forall k, t
$$

em que

$f_{i k}$ : tempo de preparação para a produção de itens tipo $i$ na máquina $k$.

$v_{i k}$ : tempo necessário para produzir uma unidade do item tipo $i$ na máquina $k$.

$C_{a p}$ : tempo disponível da máquina $k$ no período $t$.

$z_{i k t}$ : variável binária (indica a produção ou não do item tipo $i$ na máquina $k$ no período $t$ ).

O modelo (3.1.6)-(3.1.11) também pode ser estendido por considerar a produção do item tipo $i$ em máquinas alternativas. Para isto, deve-se considerar:

$x_{i k t}$ : $\quad$ quantidade produzida de itens tipo $i$ na máquina $k$ no período $t$.

$\sum_{k} x_{i t}:$ quantidade total de itens tipo $i$ produzido no período $t$.

Outras extensões de relaxação do modelo (3.1.6)-(3.1.11), como o não atendimento à demanda (estoque negativo), ou a flexibilização da capacidade (horas-extras), podem ser facilmente incorporadas. Tais "relaxações" são muitas vezes necessárias na prática, pois métodos de solução tipicamente heurísticos podem não encontrar soluções factíveis devido às restrições de capacidade. Veremos no Capítulo 6, como tais relaxações são violadas no problema acoplado da indústria de móveis. 


\subsubsection{Problema de dimensionamento de lotes multi-estágio}

Nos problemas de dimensionamento de lotes multi-estágio, a fabricação de um produto (item final) depende da produção de um ou mais itens componentes. Neste caso, as restrições de atendimento à demanda são alteradas para incorporar a demanda dependente composta pelos sucessores do item a ser produzido.

O modelo matemático para o problema de dimensionamento de lotes multi-estágio, com múltiplos tipos de itens, restrições de capacidade e preparação de máquinas é o seguinte:

\section{Modelo Matemático}

$$
\begin{array}{lll}
\text { Min } & \sum_{t=1}^{T} \sum_{i=1}^{M}\left(c_{i t} x_{i t}+h_{i t} I_{i t}+s_{i t} z_{i t}\right) & \\
\text { S.a. } & x_{i t}+I_{i, t-1}-I_{i t}=d_{i t}+\sum_{j \in S(i)} a_{i j} x_{j t}, & i=1, \ldots, M, t=1, \ldots, T \\
& \sum_{i=1}^{M}\left(v_{i} x_{i t}+f_{i t} z_{i t}\right) \leq C a p_{t}, & i=1, \ldots, M, t=1, \ldots, T \\
& x_{i t} \leq Q z_{i t}, & i=1, \ldots, M, t=1, \ldots, T \\
& x_{i t}, I_{i t} \geq 0, & i=1, \ldots, M, t=1, \ldots, T \\
& z_{i t} \in\{0,1\}, & i=1, \ldots, M, t=1, \ldots, T
\end{array}
$$

em que

$a_{i j}$ : $\quad$ quantidade de itens tipo $i$ necessária para compor uma unidade do item tipo $j$.

$\mathrm{S}(i)$ : conjunto dos itens sucessores imediatos do item tipo $i$, isto é, $\mathbf{S}(i)=\left\{j: a_{i j}>0\right\}$.

Note que à demanda externa $d_{i t}$, agora é acrescentada a demanda interna por componentes $\sum_{j \in S(i)} a_{i j} x_{j}$.

As extensões discutidas para o modelo anterior são válidas também para o modelo (3.1.12)-(3.1.17).

As restrições de atendimento à demanda (3.1.13) do modelo matemático (3.1.12)-(3.1.17) para o caso multi-estágio garantem que a quantidade a ser produzida do item final tipo $i$, no período $t$, mais a quantidade estocada no período anterior deste tipo de item menos o que vai ser estocado no final do período têm que ser igual à quantidade demandada do item tipo $i$ no período $t$ mais a demanda deste tipo de item necessária para compor os seus tipos de itens sucessores e a quantidade estocada no final do período. Isto vale para todo $i$ e $t$. 


\subsubsection{Métodos de resolução}

Conforme já observado anteriormente, o problema (3.1.1)-(3.1.5) pode ser facilmente resolvido e é um problema-chave no desenvolvimento de métodos de solução para os demais modelos. O modelo (3.1.6)-(3.1.11) (com restrição de capacidade) pode ser resolvido por uma seqüência de problemas do tipo (3.1.1)-(3.1.5) quando abordado com as técnicas de geração de colunas ou relaxação lagrangiana. Tipicamente, heurísticas de factibilização (transferências de itens entre períodos, para a eliminação de violações das restrições de capacidade) são utilizadas com bastante sucesso (soluções de boa qualidade em baixo tempo computacional são obtidas).

O problema (3.1.12)-(3.1.17), que tem uma interdependência entre os tipos de itens nas restrições de balanço de estoque, pode ser reformulado por uma mudança de variável, chamada de estoque total (ou estoque de escalão), isto é, somam-se todos os tipos de itens, inclusive aqueles presentes em seus sucessores. Com esta reformulação e a relaxação lagrangiana, pode-se decompor o problema numa seqüência de problemas do tipo (3.1.1)-(3.1.5).

Naturalmente, existem muitas estratégias heurísticas eficientes para a resolução destes problemas. Para mais detalhes sobre problemas de dimensionamento de lotes mono-estágio veja Bahl et al. (1987), Karimi et al. (2003) e Brahimi et al. (2006) e sobre problemas de dimensionamento de lotes multi-estágio veja Billington et al. (1983), Maes et al. (1991) e Santos (2000).

\subsection{Problema de corte de estoque (PCE)}

O problema de corte de estoque, simplesmente, consiste em cortar objetos grandes disponíveis em estoque para produzir um conjunto de itens menores, visando atender à demanda de tais itens e satisfazer algum critério de otimização, como por exemplo, minimizar a perda de material, ou o custo dos objetos cortados.

\subsubsection{Classificação do problema de corte de estoque}

Os problemas de corte de estoque são classificados de acordo com as dimensões que são relevantes do objeto a ser cortado da seguinte forma:

\section{- Problema de corte unidimensional}

O problema de corte é unidimensional quando apenas uma dimensão (comprimento) do objeto a ser cortado é relevante no processo de corte. Este tipo de problema aparece, por exemplo, nas indústrias de papel, aço, em que bobinas grandes são cortadas em bobinas com comprimentos menores e mesmo diâmetro.

Algumas restrições podem surgir do processo de corte, tais como, número de facas, compartimentação de itens, entre outras. 
A Figura 3.1 ilustra o problema de corte unidimensional.

\section{Objeto}

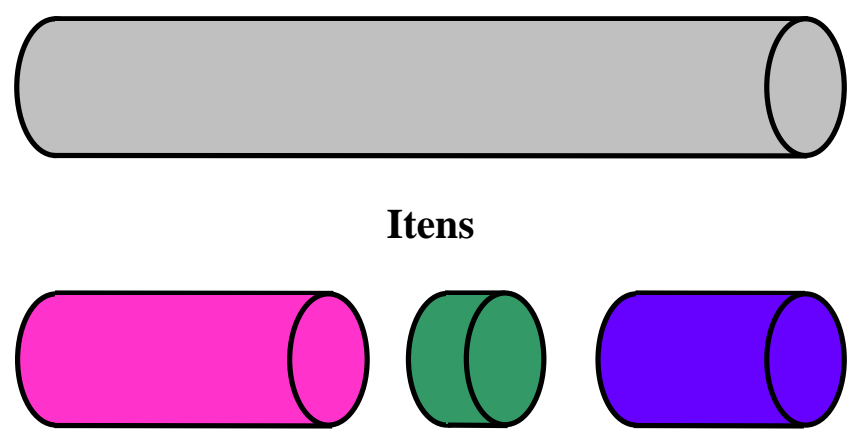

Solução

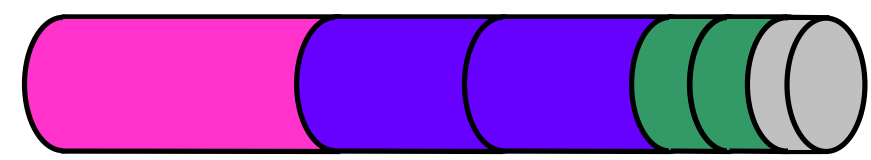

Figura 3.1: Problema de corte unidimensional.

\section{- Problema de corte bidimensional}

Dizemos que o problema de corte é bidimensional quando duas dimensões (comprimento e largura) do objeto a ser cortado são relevantes no processo de corte. Encontramos este tipo de problema nas indústrias de móveis, metalúrgica, de esquadrias de alumínio, entre outras, em que placas retangulares grandes são cortadas em peças retangulares menores (itens), as quais, geralmente, compõem produtos demandados.

\section{Objeto}

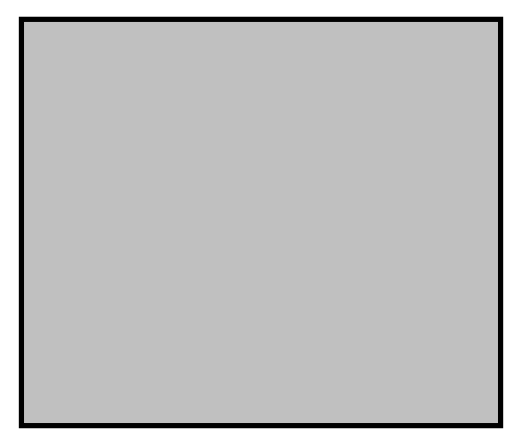

Itens

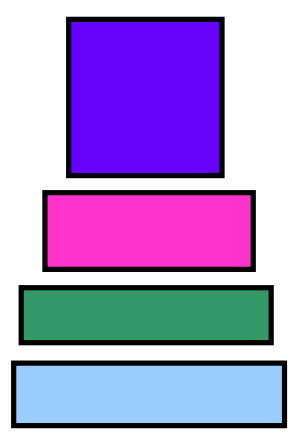

Solução

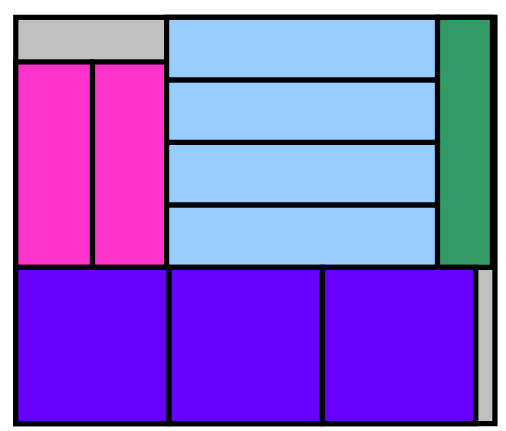

Figura 3.2: Problema de corte bidimensional.

Várias restrições surgem no processo de corte, como por exemplo, o tipo de corte usado, a limitação no número de itens, o número máximo de tipos de itens, o número máximo de estágios, entre outras. Veja na Seção 3.2.2 diversos tipos de padrões de corte classificados conforme tais restrições. 


\section{- Problema de corte tridimensional}

O problema de corte tridimensional é assim chamado porque três dimensões (comprimento, largura e altura) do objeto a ser cortado são relevantes no processo de corte. Este problema aparece, por exemplo, em indústrias de colchões e travesseiros.

Objeto

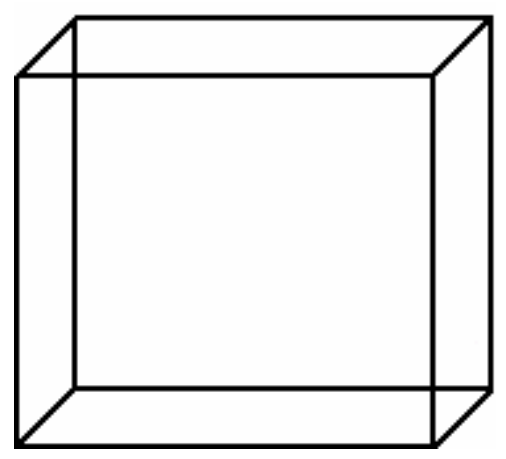

Itens

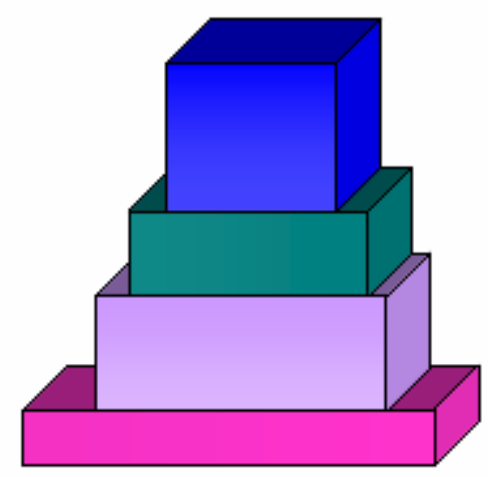

Solução

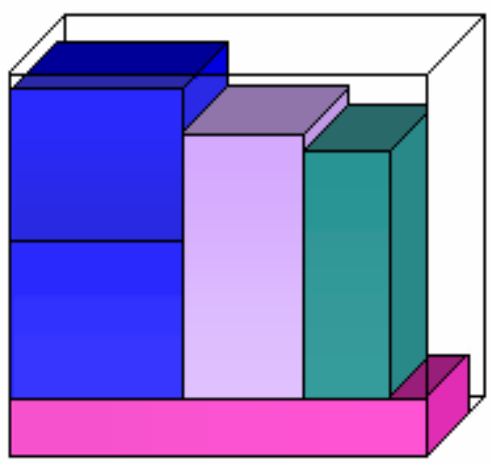

Figura 3.3: Problema de corte tridimensional.

Existem ainda mais algumas classificações para os problemas de corte de estoque com relação às dimensões relevantes dos objetos estocados que são:

- Problema de corte 1.5 unidimensional: é um problema de corte bidimensional com uma das dimensões variável (por exemplo, largura fixa e comprimento suficientemente grande).

- Problema de corte 2.5 dimensional: é um problema de corte tridimensional com uma das dimensões variável (por exemplo, largura e comprimento fixos e altura suficientemente grande).

- Problema de corte multidimensional: é o problema em que mais de três dimensões do objeto a ser cortado são relevantes no processo de corte. Este problema surge quando a produção de um item requer simultaneamente diferentes recursos independentes e limitados.

\section{- Problema de empacotamento}

O problema inverso ao problema de corte é o problema de empacotamento, o qual consiste em colocar (empacotar) dentro de um objeto grande, vários objetos menores. Este tipo de problema surge quando, por exemplo, contêineres ou caminhões precisam ser 
carregados. O problema de empacotamento também pode ser classificado conforme suas dimensões relevantes.

Uma característica comum do problema de corte de estoque é que a demanda de cada tipo de item é grande e a quantidade de diferentes tipos de itens é relativamente pequena. Além disso, os objetos em estoque podem ser de um único tipo ou de vários tipos. Cada tipo de objeto em estoque pode estar disponível em grande quantidade ou não, ou seja, pode haver ou não limitação de estoque.

\subsubsection{Classificação do padrão de corte}

Definição: Padrão de corte é a maneira como um objeto em estoque deve ser cortado para produzir os itens demandados.

Considerando $m$ o número de tipos de itens demandados, a um padrão de corte $j$ é associado um vetor $m$-dimensional $a_{j}$, em que cada coordenada $\alpha_{i j}$ define a quantidade de itens do tipo $i$ presentes no padrão:

$$
a_{j}=\left(\alpha_{1 j}, \alpha_{2 j}, \ldots, \alpha_{m j}\right)^{\mathrm{T}} .
$$

Além das dimensões relevantes do objeto, os padrões de corte podem ser classificados de acordo com o tipo de corte usado, a limitação no número de itens, o número de estágios, entre outros. A seguir, descrevemos os tipos de padrões de corte considerados neste trabalho.

- Padrão de corte guilhotinado: quando todos os cortes realizados no objeto para obter os itens são guilhotinados. Um corte guilhotinado é o corte feito paralelamente a um dos lados do objeto e por toda sua extensão.

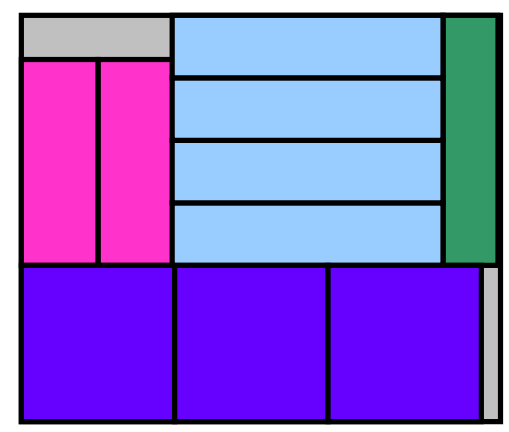

Figura 3.4: Padrão de corte bidimensional guilhotinado. 
- Padrão de corte $n$-estágios: quando são feitas $n$-1 rotações de $90^{\circ}$ no objeto durante o corte do padrão.

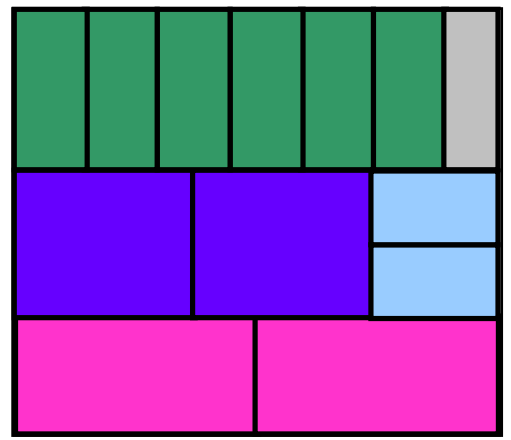

Figura 3.5: Padrão de corte bidimensional guilhotinado 3-estágios.

- Padrão de corte restrito: quando existe uma limitação nas quantidades de cada tipo de item que compõe o padrão de corte.

- Padrão de corte exato: quando os itens obtidos no final do corte do padrão não precisam ser aparados.

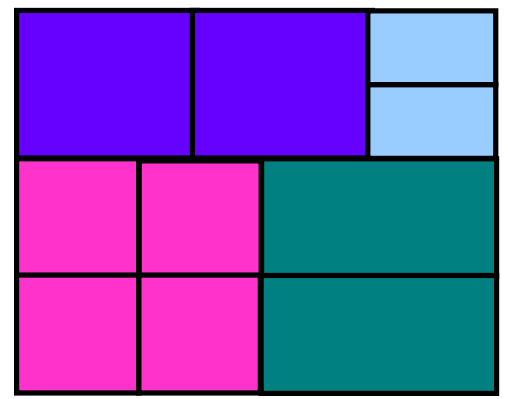

Figura 3.6: Padrão de corte bidimensional guilhotinado 3-estágios exato.

- Padrão de corte homogêneo: quando o padrão de corte é composto por um único tipo de item.

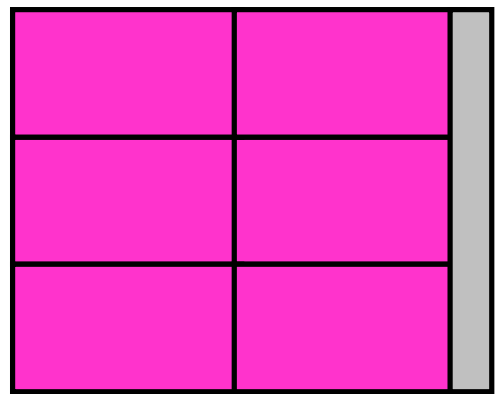

Figura 3.7: Padrão de corte bidimensional guilhotinado 2-estágios exato homogêneo. 


\subsubsection{Modelagem matemática do PCE unidimensional e bidimensional}

\subsubsection{Problema de corte de estoque unidimensional}

Considere que estão disponíveis em estoque $K$ tipos de objetos (barras de aço, bobinas de papel, entre outros) de comprimentos $L_{k}, k=1, \ldots, K$ e em quantidades limitadas $e_{k}$, $k=1, \ldots, K$. O problema de corte de estoque unidimensional consiste em determinar a melhor maneira de cortar os $K$ tipos de objetos estocados para obter os diversos tipos de itens com comprimentos $l_{i}, i=1, \ldots, m$, segundo diferentes padrões de corte, de modo a atender as demandas dos itens $\left(d_{i}, i=1, \ldots, m\right)$ e otimizar uma função objetivo que pode ser minimizar a perda de matéria-prima ou a quantidade de objetos cortados.

A modelagem matemática do problema de corte de estoque envolve duas etapas: definir todos os possíveis padrões de corte para os objetos estocados e decidir quantas vezes cada padrão de corte será utilizado para atender à demanda. A primeira etapa pode ser realizada independentemente da demanda dos itens.

Seja $N_{k}$ o número de padrões de corte gerados para o objeto tipo $k, k=1, \ldots, K$.

Os índices, os parâmetros e as variáveis utilizados no modelo matemático do problema de corte de estoque unidimensional com vários tipos de objetos em estoque e em quantidades limitadas são:

\section{- Índices}

$k=1, \ldots, K: \quad$ tipo de objeto.

$i=1, \ldots, m: \quad$ tipo de item.

$j=1, \ldots, N_{k}$ : padrão de corte unidimensional.

\section{- Parâmetros}

$c_{j k}$ : perda de material no padrão de corte $j$ no objeto tipo $k$.

$a_{i j k}$ : número de itens tipo $i$ no padrão de corte $j$ do objeto tipo $k$.

$d_{i}$ : demanda do item tipo $i$.

$e_{k}$ : disponibilidade em estoque do objeto tipo $k$.

\section{- Variáveis}

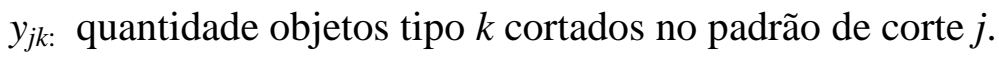




$$
\begin{array}{llr}
\text { Min } & \sum_{k=1}^{K} \sum_{j=1}^{N_{k}} c_{j k} y_{j k} & \\
\text { s.a. } & \sum_{k=1}^{K} \sum_{j=1}^{N_{k}} a_{i j k} y_{j k}=d_{i}, & \\
& \sum_{j=1}^{N_{k}} y_{j k} \leq e_{k}, & k=1, \ldots, M \\
& y_{j k} \geq 0 \quad \mathrm{e} \text { inteiros, } & j=1, \ldots, K \\
& &
\end{array}
$$

A função objetivo (3.2.1) consiste em minimizar a perda de matéria-prima. A perda do objeto tipo $k$ no padrão de corte $j$ é calculada por: $c_{j k}=L_{k}-\left(\alpha_{1 j k} l_{1}+\alpha_{2 j k} l_{2}+\ldots+\alpha_{m j k} l_{m}\right)^{\mathrm{T}}$.

As restrições (3.2.2) garantem que a demanda de todos os tipos de itens será atendida. As restrições (3.2.3) asseguram que a quantidade de cada tipo de objeto que será cortado para atender à demanda de todos os tipos de itens é no máximo igual à quantidade de cada tipo de objeto disponíveis em estoque. As restrições (3.2.4) são de não negatividade e integralidade das variáveis.

\section{Observações}

1. Sem perda de generalidade, pode-se adotar $c_{j k}=1, j=1, \ldots, N_{k}$ e $k=1, \ldots, K$. Neste caso, a função custo corresponde a minimizar o número de objetos cortados.

2. Cada padrão de corte $a_{j k}$ para o objeto tipo $k$ deve satisfazer as seguintes restrições do problema da mochila:

$$
\begin{aligned}
& l_{1} \alpha_{1 j k}+l_{2} \alpha_{2 j k}+\ldots+l_{m} \alpha_{m j k} \leq L_{k}, \\
& \alpha_{i j k} \geq 0 \text { e inteiros, } i=1, \ldots ., m, j=1, \ldots, N_{k}, k=1, \ldots, K
\end{aligned}
$$

3. Outras restrições do processo de corte podem ser incluídas em (3.2.5), por exemplo, a limitação no número de facas.

4. Este tipo de problema ocorre em indústrias nas quais os objetos ou são adquiridos com antecedência e estocados, ou podem ser produzidos, mas a capacidade de produção é limitada.

\subsubsection{Método de resolução}

Existem dois fatores que contribuem para tornar a resolução do modelo matemático (3.2.1)-(3.2.4) para o problema de corte de estoque unidimensional impraticável: a restrição de integralidade sobre as variáveis (quantas vezes cada padrão de corte será utilizado) e o 
número grande de variáveis (uma variável para cada padrão), podendo em problemas práticos ser da ordem de centenas de milhares. Mas, tal modelo apresenta uma estrutura particular que permite trabalhar com estas variáveis implicitamente.

Se a restrição de integralidade das variáveis for relaxada, o problema pode ser resolvido pelo método simplex desenvolvido por Dantzig em 1947, mas a dificuldade em relação ao grande número de variáveis continua existindo. Para tratá-la, Gilmore e Gomory (1961) propõem uma modificação no método simplex incorporando a técnica de geração de colunas da seguinte forma: a cada iteração do método simplex, um dos passos consiste em procurar por uma nova coluna para entrar na base que melhore o valor da função objetivo. Ao invés de examinar um número grande de colunas (todos os possíveis padrões de corte para cada tipo de objeto) para determinar a de menor custo relativo, uma nova coluna é gerada resolvendo um problema auxiliar (subproblema). Considerando que o critério de Dantizg está sendo usado para determinar o menor custo relativo, o subproblema a ser resolvido para o objeto do tipo $k$ é o seguinte:

$$
c_{r k}-\pi^{T} a_{r k}=\min \left\{c_{j k}-\pi^{T} a_{j k}, j=1, \ldots, N_{k}\right\}
$$

sendo $\pi$ o vetor multiplicador simplex de uma determinada iteração.

Considerando que a função objetivo a ser minimizada seja o número total de objetos cortados (ou seja, $c_{j k}=1$ ) e como uma coluna $a_{k}=\left(\alpha_{1 k} \alpha_{2 k} \ldots \alpha_{m k}\right)^{\mathrm{T}}$ corresponde a um padrão de corte para o objeto $k$ então (3.2.6) pode ser reescrita na forma:

$$
\begin{array}{ll}
g\left(a_{k}\right)= & \operatorname{Max} \sum_{i=1}^{m} \pi_{i} \alpha_{i k} \\
\text { s.a. } & \sum_{i=1}^{m} l_{i} \alpha_{i k} \leq L_{k}, \\
& \alpha_{i k} \geq 0 \quad \text { e inteiros, } i=1, \ldots, m
\end{array}
$$

Se o menor dos custos relativos considerando todos os tipos de objetos for nãonegativo, a solução atual do problema relaxado é ótima, caso contrário, uma nova coluna entrará na base e o procedimento continua.

O problema auxiliar (3.2.7)-(3.2.9), que consiste em cortar um único tipo de objeto em estoque, é um problema da mochila e por ser um problema de programação inteira, métodos de enumeração implícita e programação dinâmica podem ser utilizados para resolvê-lo.

\section{Observação}

No modelo (3.2.1)-(3.2.4), a solução homogênea, geralmente usada como solução básica inicial, pode ser infactível e, neste caso, a fase I do método simplex deve ser aplicada.

A seguir, apresentamos o algoritmo do método simplex com geração de colunas para resolver o problema de corte de estoque unidimensional relaxado. 


\section{Algoritmo}

1. $\{$ Fase I $\}$

Determine uma matriz básica inicial $B$.

Faça: Pare $=$ Falso e it $=1$.

2. $\{$ Fase II $\}$

Enquanto Pare $=$ Falso, faça:

2.1 Determine a solução básica atual: $B y_{B}=d$.

2.2 Determine a solução dual: $B^{T} \pi=c_{B}$.

2.3 Resolva $K$ problemas da mochila (um para cada tipo de objeto) na forma (3.2.7)-(3.2.9).

Encontre $r$ tal que $g\left(a_{r}\right)=\min \left\{g\left(a_{k}\right), k=1, \ldots, K\right\}$ e obtenha a nova coluna $a_{r}$.

2.4 \{Teste de otimalidade\}

Se $\left(1-\mathrm{g}\left(a_{r}\right)\right) \geq 0$ então Pare $=$ Verdadeiro (Solução atual é ótima).

Senão, determine as coordenadas básicas da direção simplex: $B z=-a_{r}$.

2.5 Determinação do tamanho do passo $\}$

Encontre $l$ tal que: $-\frac{y_{l}}{z_{l}}=\min \left\{-\frac{y_{B_{i}}}{z_{i}}, z_{i}<0, i=1, \ldots, m\right\}$.

\subsection{AAtualização\}}

Atualize a base $B$ substituindo a $l$-ésima coluna por $a_{r}$ obtido em 2.3.

Faça: $i t=i t+1$.

A partir da solução ótima do problema relaxado, que, geralmente, não é inteira, uma solução inteira para o problema de corte de estoque original pode ser determinada, utilizando um dos procedimentos heurísticos desenvolvidos por vários pesquisadores na área, tais como, Poldi e Arenales (2008), Wäscher e Gau (1996), Pinto (1999), Hinxman (1980), Stadtler (1990), entre outros.

\subsubsection{Problema de corte de estoque bidimensional}

O problema de corte de estoque bidimensional consiste em determinar a quantidade de cada tipo de placa retangular (objeto) estocada, disponíveis em quantidades limitadas, a ser cortada para a produção de vários tipos de itens menores (peças) com demandas préestabelecidas a serem atendidas ao menor custo possível. 
As etapas da modelagem matemática e o modelo matemático descrito na Seção 3.2.3.1 para o problema de corte unidimensional são válidos para o problema de corte bidimensional. A única diferença é que agora os padrões de corte são bidimensionais e, consequentemente, a técnica usada para gerá-los é outra.

Neste trabalho, consideramos um único tamanho de placa $(L x W)$ disponível em estoque e somente padrões de corte bidimensional guilhotinado 2-estágios exatos, pois o problema de corte bidimensional que surge em indústrias de móveis, tipicamente, requer este tipo de padrão de corte.

O método simplex com geração de colunas também pode ser utilizado para resolver os modelos matemáticos do problema de corte bidimensional relaxado, porém o subproblema gerador de colunas (padrões de corte bidimensional) é outro. No final, alguma heurística deve ser aplicada à solução contínua para determinar uma solução inteira para o problema original. No Capítulo 5, é descrita a heurística utilizada para a obtenção de uma solução inteira para o problema de corte bidimensional.

$\mathrm{Na}$ literatura existem várias abordagens exatas, aproximadas ou heurísticas para a construção de padrões de corte bidimensional, por exemplo, os trabalhos de Gilmore e Gomory (1965), Herz (1972), Wang (1983), Oliveira e Ferreira (1990), Morabito e Arenales (1996), Hifi e Zissimopoulos (1996), Vianna (2000), entre outros.

A seguir, apresentamos em detalhes uma das abordagens adotadas para geração de padrões de corte bidimensional guihotinado 2-estágios exato. A outra abordagem em grafo E/OU (Morabito e Arenales (1996)) usada para gerar padrões de corte bidimensional 2-estágios exatos restritos está descrita no Capítulo 5.

\subsubsection{Abordagem exata para o problema de corte bidimensional guilhotinado 2-estágios}

Considere uma placa retangular com dimensões $L x W$ que deve ser cortada para produzir $m$ tipos de itens menores. A cada item tipo $i$, com dimensões $l_{i} \mathrm{x} w_{i}$, está associado um valor de utilidade $v_{i}, i=1, \ldots, m$. O vetor $a=\left(\alpha_{1}, \alpha_{2}, \ldots, \alpha_{m}\right)^{\mathrm{T}}$ é o vetor associado a um padrão de corte para a placa $L \times W$ em que $\alpha_{i}$ é o número de itens tipo $i$ no padrão de corte $a$.

O melhor padrão de corte bidimensional guilhotinado 2-estágios exato é obtido realizando dois passos principais: (i) definir as melhores faixas $L \times w_{i}$ que poderão compor o melhor padrão de corte para a placa $L x W$ resolvendo vários problemas da mochila (um para cada largura dos itens) e (ii) definir quantas vezes cada faixa deve ser utilizada no padrão de corte resolvendo mais um problema da mochila. Vejamos cada passo detalhadamente:

\section{(i) Definir as melhores faixas para compor o padrão}

Seja $W_{u}=\left\{i \mid w_{i}=w_{u}\right\}$ o conjunto dos itens que podem ser cortados em uma faixa $L \times w_{u}$. As faixas são definidas somente para larguras diferentes, isto é, se $w_{1}=w_{2}$ então, apenas a faixa $L \times w_{1}$ é necessária. Supondo que temos $r$ larguras diferentes entre si então são consideradas apenas as $r$ faixas $L \times w_{1}, L \times w_{2}, \ldots, L \times w_{r}$. 
Cada faixa deve ser cortada para a produção dos itens demandados de maneira que se obtenha o maior valor de utilidade. Logo, para cada faixa $L x w_{u}, u=1, \ldots, r$, tem que ser resolvido o seguinte problema da mochila:

$$
\begin{array}{ll}
V_{u}= & \operatorname{Max} \sum_{i \in W_{u}} v_{i} \gamma_{i u} \\
\text { s.a. } & \sum_{i=\in W_{i}} l_{i} \gamma_{i u} \leq L, \\
& \gamma_{i u} \geq 0 \text { e inteiros, } i=1, \ldots, m
\end{array}
$$

em que $\gamma_{i u}$ é o número de itens tipo $i$ na faixa $L x w_{u}$.

A resolução dos $r$ problemas da mochila fornece os valores de utilidade para cada faixa $\left(V_{u}, u=1, \ldots, r\right)$ e quais itens devem ser cortados, ou seja, definem as melhores faixas que poderão compor o padrão de corte bidimensional.

\section{(ii) Determinar quantas vezes cada faixa deve ser utilizada no padrão bidimensional.}

Para determinar quais e quantas vezes cada faixa vai ser usada no padrão de corte é preciso resolver um outro problema da mochila, considerando as larguras $w_{u}$ de cada faixa $u$ para $u=1, \ldots, r$ e a largura $W$ da placa, que é o seguinte:

$$
\begin{array}{ll}
V= & \operatorname{Max} \sum_{u=1}^{r} V_{u} \beta_{u} \\
\text { s.a. } & \sum_{u=1}^{r} w_{u} \beta_{u} \leq W, \\
& \beta_{u} \geq 0 \text { e inteiros, } u=1, \ldots, r
\end{array}
$$

em que $\beta_{u}$ é o número de faixas do tipo $u$ no padrão de corte.

Logo, o vetor associado ao padrão de corte bidimensional 2-estágios exato obtido pelo procedimento acima é representado por:

$$
a=\left(\begin{array}{c}
\alpha_{1}=\sum_{u=1}^{r} \beta_{u} \gamma_{1 u} \\
\vdots \\
\alpha_{m}=\sum_{u=1}^{r} \beta_{u} \gamma_{m u}
\end{array}\right)
$$

Este procedimento produz padrões de corte bidimensional em 2-estágios, sendo que no primeiro são feitos cortes horizontais para produzir as faixas $L \times w_{u}$ e no segundo, os cortes são 
verticais nas faixas para produzir os itens. Além disso, os padrões de corte também são exatos, pois não necessitam de apara final. Caso a apara final seja permitida, ou seja, padrões de corte inexato também são aceitos, o mesmo procedimento pode ser usado, mas o conjunto $W_{u}$ deve ser redefinido para $W_{u}=\left\{i \mid w_{i} \leq w_{u}\right\}$. A Figura 3.8, a seguir, ilustra um padrão de corte bidimensional 2-estágios inexato.

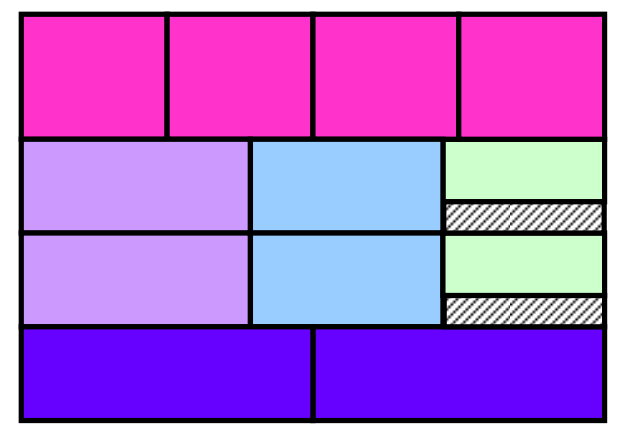

Figura 3.8: Padrão de corte bidimensional guilhotinado 2-estágios inexato.

\section{Observação}

Para produzir padrões de corte guilhotinado 2-estágios, de modo que o primeiro estágio seja formado por cortes verticais, basta produzir faixas $l_{u} \mathrm{x} W$ e redefinir o conjunto de itens que podem ser cortados nessa faixa como $L_{u}=\left\{i \mid l_{i}=l_{u}\right\}$ e aplicar o procedimento descrito acima com as devidas substituições nos problemas (3.2.10)-(3.2.12) e (3.2.13)(3.2.15).

\subsubsection{Problema de corte de estoque restrito}

O problema de corte de estoque restrito surge em situações com baixa demanda de itens. Dizemos que o problema é restrito quando existe uma limitação na demanda de cada tipo de item. Sendo assim, a quantidade de cada tipo de item que pode compor um padrão de corte também é limitada.

Para que uma coluna $a$ corresponda a um padrão de corte no problema restrito as seguintes restrições devem ser satisfeitas:

$$
\begin{aligned}
& l_{1} \alpha_{1}+l_{2} \alpha_{2}+\ldots+l_{m} \alpha_{m} \leq L \\
& 0 \leq \alpha_{i} \leq d_{i} \quad \mathrm{e} \text { inteiros, } i=1, \ldots ., m
\end{aligned}
$$

No caso restrito, cada coordenada $\alpha_{i}$ do padrão de corte determinado usando a abordagem apresentada em 3.2.3.4, que é não linear, deve satisfazer:

$$
0 \leq \alpha_{i}=\sum_{u=1}^{r} \beta_{u} \gamma_{i u} \leq d_{i}, i=1, \ldots, m
$$

No Capítulo 5, é descrita a abordagem em grafo E/OU utilizada para gerar padrões de corte bidimensional guilhotinado 2-estágios exatos e restritos. 


\subsubsection{Problema de corte multiperíodo}

O problema de corte de estoque multiperíodo é uma extensão do problema de corte de estoque e aparece no planejamento e programação da produção de algumas indústrias de manufatura, tais como, indústria de papel, móveis, esquadrias de alumínio, entre outras. Este problema consiste em determinar como os objetos estocados devem ser cortados para atender as demandas de vários tipos de itens em diversos períodos de um horizonte de planejamento, permitindo antecipar ou não a produção de certos itens. Neste caso, existem vários problemas de corte que são interdependentes e, com isso, novas combinações entre os itens (padrões de corte) podem ser consideradas, pois um item que não é demandado em um período pode ser antecipado se sua combinação com os demais itens faz diminuir a perda de matéria-prima e desde que haja disponibilidade de objetos em estoque e capacidade de produção. Esta mesma lógica é empregada nos problemas de dimensionamento de lotes e será estendida, no Capítulo 4, quando parte da demanda em um horizonte de planejamento é conhecida e parte é esperada, não em um período, mas durante todo o horizonte de planejamento. $\mathrm{O}$ estoque dos objetos não utilizados em um período fica disponível no próximo, juntamente com os novos objetos adquiridos ou fabricados pela indústria. A função objetivo a ser minimizada pondera a perda de matéria-prima e os custos de estoque de itens e objetos.

A seguir, apresentamos a definição e o modelo matemático para o problema de corte multiperíodo nos casos unidimensional, bidimensional e com restrições de capacidade, propostos em Poldi (2007).

\subsubsection{Problema de corte multiperíodo unidimensional}

Considere um horizonte de planejamento finito, dividido em $T$ períodos e suponha que estão disponíveis em estoque $K$ tipos de objetos (barras, bobinas, placas, entre outros) de comprimento $L_{k}, k=1, \ldots, K$ e nas quantidades $e_{k t}$, para $k=1, \ldots, K$ e $t=1, \ldots, T$. A cada período $t$, um conjunto de $m$ tipos de itens de comprimentos $l_{\mathrm{i}}, i=1, \ldots, m$ deve ser cortado nas quantidades $d_{i t}, i=1, \ldots, m, t=1, \ldots, T$. O problema de corte de estoque multiperíodo unidimensional consiste em determinar as quantidades de itens demandados a serem produzidas, a partir do corte dos objetos disponíveis em estoque, em cada um dos períodos do horizonte de planejamento, de modo a atender à demanda sem atrasos e otimizar uma certa função objetivo, que pode ser, por exemplo, minimizar a perda de matéria-prima e os custos de estoque.

Os índices, parâmetros e variáveis utilizados no modelo matemático do problema de corte multiperíodo unidimensional descrito acima são:

\section{- Índices}

$t=1, \ldots, T: \quad$ período do horizonte de planejamento.

$k=1, \ldots, K: \quad$ tipo de objeto disponível em estoque.

$j=1, \ldots, N_{k}$ : padrão de corte.

$i=1, \ldots, m: \quad$ tipo de item. 


\section{- Parâmetros}

$L_{k}: \quad$ comprimento do objeto tipo $k$.

$e_{k t}: \quad$ quantidade produzida/comprada de objetos tipo $k$ no período $t$.

$l_{i}$ : $\quad$ comprimento do item tipo $i$.

$d_{i t}$ : quantidade demandada do item tipo $i$ no período $t\left(d_{t}\right.$ vetor cujas componentes são $\left.d_{i t}\right)$.

$c p_{j k t}$ : custo de cortar o objeto tipo $k$ no padrão de corte $j$ no período $t$.

$c r_{i t}$ : custo de estoque do item tipo $i$ no período $t$.

$c s_{k t}: \quad$ custo de estoque do objeto tipo $k$ no período $t$.

$a_{i j k t}$ : quantidade do item tipo $i$ no padrão de corte $j$ do objeto tipo $k$ no período $t$ ( $a_{j k t}$ vetor cujas componentes são $a_{i j k t}$ ).

\section{- Variáveis}

$y_{j k t}$ : quantidade do objeto tipo $k$ cortada no padrão de corte $j$ no período $t$.

$r_{i t}$ : quantidade do item tipo $i$ antecipada para o período $t\left(r_{t}\right.$ vetor cujas componentes são $\left.r_{i t}\right)$.

$s_{k t}$ : quantidade do objeto tipo $k$ que sobram no final do período $t$.

\section{Modelo matemático}

$$
\begin{aligned}
& \operatorname{Min} \sum_{t=1}^{T}\left(\sum_{k=1}^{K} \sum_{j=1}^{N_{k}} c p_{j k t} y_{j k t}+\sum_{j=1}^{N_{K}} c r_{j t} r_{j t}+\sum_{k=1}^{K} c s_{k t} s_{k t}\right) \\
& \text { s.a. } \sum_{k=1}^{K} \sum_{j=1}^{N_{k}} a_{j k t} y_{j k t}+r_{t-1}-r_{t}=d_{t}, \quad t=1, \ldots, T \\
& \sum_{j=1}^{N_{K}} y_{j k t}-s_{k t-1}+s_{k t}=e_{k t}, \quad k=1, \ldots, K, \quad t=1, \ldots, T \\
& y_{j k t} \geq 0 \text { e inteiros, } r_{i t}, s_{k t} \geq 0, \quad j=1, \ldots, N_{k}, \quad k=1, \ldots, K, \quad t=1, \ldots, T
\end{aligned}
$$

A função objetivo (3.2.18) minimiza a soma dos custos das perdas de material de todos os tipos de objetos, em todos os períodos e dos custos de estocar itens e objetos. A antecipação do corte de alguns tipos de itens pode aumentar os custos com o estoque de itens $\left(c r_{i t}\right)$, mas por outro lado, pode permitir uma melhor combinação dos itens, o que minimiza a perda de material. As restrições (3.2.19) são de balanço de estoque de itens e junto com as restrições (3.2.21) asseguram que a demanda de todos os tipos de itens em todos os períodos seja atendida. $\mathrm{O}$ conjunto de restrições (3.2.20) garante que a disponibilidade de objetos em estoque em cada período não seja ultrapassada. As restrições (3.2.21) são de não negatividade e integralidade das variáveis. Os objetos disponíveis em estoque que não foram utilizados em um dado período $t$ são somados aos objetos que estarão disponíveis em estoque no próximo período $t+1$, porém um custo de estoque $c s_{k t}$ é contabilizado na função objetivo. Ao 
considerar os custos de estoque nulos, a tendência é de que a produção de itens seja antecipada, que, por sua vez, é limitada pela disponibilidade dos objetos em estoque no período, eliminando a possibilidade de toda a produção ocorrer no primeiro período do horizonte de planejamento. As restrições (3.2.21) são de não negatividade de todas variáveis e integralidade das variáveis referentes à frequiência do uso dos padrões de corte.

O modelo (3.2.18)-(3.2.21) possui $T(m+K)$ restrições e $T K\left(\sum_{k=1}^{K} N_{k}+2 m\right)$ variáveis. Em situações práticas tal modelo pode conter centenas de restrições e milhões de variáveis. A matriz de restrições deste modelo é bem estruturada e bastante esparsa.

\subsubsection{Problema de corte multiperíodo bidimensional}

O modelo matemático (3.2.18)-(3.2.21) para o problema de corte de estoque multiperíodo unidimensional pode ser utilizado para representar o problema de corte multiperíodo bidimensional, uma vez que a diferença entre estes problemas é a forma dos objetos e itens. Restringimos nosso estudo ao caso bidimensional, em que os objetos são placas retangulares e os itens são peças retangulares. Além disso, restringimos aos cortes guilhotinados em 2-estágios. Portanto, as colunas $a_{j k t}$ nas restrições (3.2.19), ao invés de obedecerem restrições do tipo (3.2.5), devem satisfazer a seqüência de problemas do tipo (3.2.10)-(3.2.12) e (3.2.13)-(3.2.15), ou (3.2.16) no caso restrito.

\subsubsection{Problema de corte multiperíodo com restrições de capacidade}

O problema de corte de estoque multiperíodo pode apresentar restrições adicionais. Uma das mais frequientes é a restrição de capacidade de máquina. Ao acrescentar as restrições de capacidade no problema o modelo matemático para esta nova situação é o seguinte:

\section{Modelo matemático}

$$
\begin{array}{lrl}
\text { Min } & \sum_{t=1}^{T}\left(\sum_{k=1}^{K} \sum_{j=1}^{N_{k}} c p_{j k t} y_{j k t}+\sum_{j=1}^{N_{k}} c r_{j t} r_{j t}+\sum_{k=1}^{K} c s_{k t} s_{k t}\right) & \\
\text { S.a. } & \sum_{k=1}^{K} \sum_{j=1}^{N_{k}} a_{j k t} y_{j k t}+r_{t-1}-r_{t}=d_{t}, & \\
& \sum_{j=1}^{N_{k}} y_{j k t}-s_{k t-1}+s_{k t}=e_{k t}, & \\
& \sum_{k=1}^{K} \sum_{j=1}^{N_{k}} b_{j k t} y_{j k t} \leq C a p_{t}, & \\
& y_{j k t} \geq 0 \text { e inteiros, }, r_{j t}, s_{k t} \geq 0, \quad j=1, \ldots, K, N_{k}, \quad k=1, \ldots, K, & t=1, \ldots, T \\
& t=1, \ldots, T
\end{array}
$$

em que 
$b_{j k t}:$ recurso necessário (tempo de corte) para cortar o padrão de corte $j$ associado ao objeto tipo $k$ no período $t$.

$\mathrm{Cap}_{t}$ : capacidade de corte disponível no período $t$.

A função objetivo (3.2.22) e as restrições (3.2.23), (3.2.24) e (3.2.26) são conforme descritas anteriormente. $\mathrm{O}$ conjunto de restrições (3.2.25) garante que a quantidade de recurso utilizado em cada período do horizonte de planejamento não seja maior que a capacidade disponível de recurso por período.

\subsubsection{Método de resolução}

Os modelos matemáticos (3.2.18)-(3.2.21) e (3.2.22)-(3.2.26) possuem as mesmas dificuldades do modelo apresentado na Seção 3.2.3.1 que são: a integralidade das variáveis e o grande número de variáveis. Novamente, para contornar tais dificuldades, a condição de integralidade sobre as variáveis $y_{j k t}$ é relaxada e os modelos de otimização linear resultantes podem ser resolvidos pelo método simplex com geração de colunas, o qual fornece uma solução ótima contínua para o problema de corte de estoque multiperíodo.

A relaxação linear, em geral, fornece uma boa aproximação para o problema inteiro. Porém, alguma técnica de arredondamento deve ser utilizada para obter uma solução inteira para o problema original. Procedimentos heurísticos para obtenção de soluções inteiras podem ser encontrados em Poldi (2007), Poldi e Arenales (2008), Wäscher e Gau (1996), Stadtler (1990), entre outros. 


\section{Capítulo 4}

\section{Problema acoplado de dimensionamento de lotes e corte de estoque na indústria de móveis}

O problema acoplado de dimensionamento de lotes e corte de estoque presente em diversos tipos de indústrias de manufatura ainda é pouco explorado na literatura, mas a constatação da sua importância em situações reais o caracteriza como um problema relevante e não trivial e, por isso, deve ser estudado.

Neste capítulo, algumas características, a programação da produção e o processo produtivo simplificado da indústria de móveis brasileira são descritos (seções 4.1, 4.2 e 4.3, respectivamente). A Seção 4.4 traz uma definição para o problema acoplado de dimensionamento de lotes e corte de estoque presente na indústria de móveis. A Seção 4.5 contém o modelo matemático proposto para o problema acoplado e sua descrição detalhada. $\mathrm{Na}$ Seção 4.6, as dificuldades de resolução do modelo matemático são apresentadas.

\subsection{A indústria de móveis brasileira}

No Brasil, a indústria de móveis utiliza vários tipos de matéria-prima para manufaturar diversos tipos de produtos, tais como, móveis residenciais, de escritórios e institucionais (escolas, hotéis, consultórios, hospitais, entre outros) nas proporções de 60\%, 25\% e 15\%, respectivamente, empregando tecnologias variadas (Figueiredo, 2006).

As matérias-primas que predominam no setor moveleiro são: madeira, metal e plástico. A maior parte da produção nacional é feita com madeira maciça e/ou placas grandes de compensado, aglomerado e $\mathrm{MDF}^{7}$ (Medium Density Fiberboard) (Figueiredo, 2006).

\footnotetext{
7 O MDF é feito com fibras de madeira aglutinadas com resinas sintéticas por temperatura e pressão e têm consistência similar à da madeira.
} 
Os móveis de madeira podem ser classificados em dois tipos: retilíneos e torneados. Os retilíneos são móveis lisos, possuem formas retas e simples e são feitos com os três tipos de placas citados acima. Os torneados são móveis que possuem detalhes de acabamento mais sofisticados, misturando formas retas e curvilíneas, e cuja matéria-prima principal é a madeira maciça, mas podendo incluir também placas de MDF.

Neste trabalho, tratamos de móveis residenciais, especificamente, móveis de dormitório, retilíneos e feitos com placas de MDF. A definição e modelagem matemática do problema acoplado e o processo produtivo simplificado, apresentados nas próximas seções, foram feitos baseados em informações e dados coletados de uma indústria de móveis de pequeno porte, situada em Votuporanga, que fabrica em torno de 25 tipos de móveis residenciais, cuja maioria são móveis de dormitórios (camas, cômodas, criados e armários com $3,4,5$ e 6 portas) e cada tipo é produzido em cinco cores diferentes: mogno, marfim, cerejeira, tabaco e branco.

$\mathrm{Na}$ prática, a demanda dos móveis (produtos finais) é estocástica, uma vez que, a qualquer momento pode surgir algum evento não previsto fazendo-a variar. Dessa forma, no setor moveleiro tem-se uma demanda esperada dos produtos. Para tratar esta característica da demanda no modelo matemático determinístico proposto para representar o problema acoplado de dimensionamento de lotes e corte de estoque na indústria de móveis, são combinadas duas estratégias: uma estratégia é o horizonte de planejamento rolante e a outra estratégia é representar a demanda esperada dos produtos no horizonte de planejamento como a soma da demanda em carteira mais uma demanda extra, que é, simplesmente, uma expectativa de vendas para todo o horizonte de planejamento, determinada pelo gerente de produção baseado, por exemplo, em previsão de demandas, e sua experiência profissional e bom senso. Em outras palavras, a demanda extra é associada a uma manufatura extra de produto ao longo do horizonte de planejamento, para atender uma demanda inesperada de tais produtos.

Uma forma alternativa de lidar com a estocasticidade da demanda é trabalhar com estoques de segurança que requer informações mais detalhadas, período a período, do gerente de produção, e induz à produção de itens para o estoque, enfraquecendo a oportunidade da produção de um item particular que melhor combine com outros itens de produção necessária para atender a uma demanda em carteira. Naturalmente, a produção extra de um item consiste em estoque de segurança.

A demanda extra é representada, no modelo matemático proposto, por uma variável de decisão, dita de oportunidade, a qual informa em quais períodos e em que quantidades a produção extra deve ser manufaturada, de modo que melhor combinem com os produtos já programados da demanda em carteira, na tentativa de reduzir os custos totais de produção.

A estratégia de horizonte de planejamento rolante consiste em dividir o primeiro dos períodos em que o horizonte de planejamento finito é dividido, em um determinado número de subperíodos. Dessa forma, as decisões referentes ao primeiro período são bem detalhadas e nos demais períodos as decisões são agregadas. Somente a solução relativa ao primeiro período é implementada. Depois disso, os dados devem ser atualizados, o horizonte de planejamento é rolado, ou seja, o segundo período passa a ser o primeiro, o terceiro período o segundo e, assim sucessivamente, até o último período ser agora o penúltimo e mais um período é considerado, passando a ser o último e, então, o problema é novamente resolvido.

A Figura 4.1 ilustra a divisão do horizonte de planejamento rolante. 


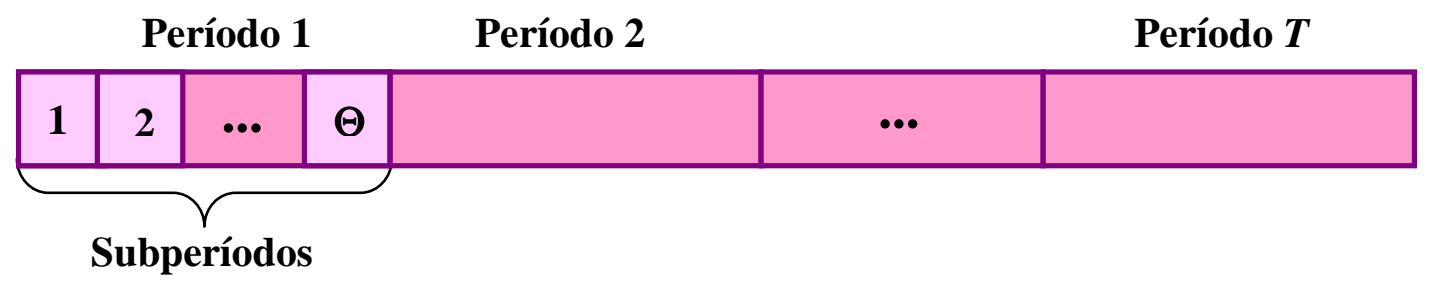

Figura 4.1: Divisão do horizonte de planejamento rolante.

\subsection{Programação da produção na indústria de móveis}

A programação da produção na indústria de móveis envolve 3 passos principais: o primeiro passo consiste em definir, para um horizonte de planejamento finito, as quantidades que serão produzidas e as datas de entrega dos produtos demandados. O segundo passo consiste em converter a demanda dos produtos em demanda de peças. Vale ressaltar, que um mesmo tipo de peça pode ser utilizado em diferentes tipos de produtos. Por exemplo, um armário (produto) pode ter o mesmo tamanho de gaveta que uma cômoda (produto) e, portanto, as peças que compõem as gavetas são iguais para os dois tipos de produtos, ou então, o armário de 3 portas (produto) pode utilizar um mesmo tamanho de porta (peça) que o armário de 5 portas (produto). $\mathrm{O}$ terceiro passo consiste em decidir a quantidade de produtos a ser produzida (tamanho do lote) em cada um dos períodos do horizonte de planejamento, objetivando minimizar os custos totais do processo produtivo.

O gerente de produção é a pessoa responsável por decidir os tamanhos dos lotes a serem produzidos no horizonte de planejamento. Esta tomada de decisão é feita baseada em informações concretas, tais como, dados sobre as vendas (carteira de pedidos), a quantidade de produtos disponíveis em estoque e as quantidades mínima e máxima de cada tipo de produto que precisa manter em estoque e, na sua experiência adquirida, que permite considerar a produção de uma demanda extra de cada tipo de produto para atender pedidos de última hora (neste momento a estocasticidade da demanda é considerada).

No setor de móveis, existe uma sazonalidade na demanda fazendo com que a produção de alguns tipos de móveis aumente em até $50 \%$ no final do ano. Isto explica a grande diferença no tamanho dos lotes para as demandas baixa e alta. Para não ter que mudar o quadro de funcionários no período de baixa demanda, uma saída adotada é dar férias coletivas. Isto é mais vantajoso do que ter um custo adicional com a qualificação de novos funcionários durante o período de demanda alta.

A seqüência da fabricação de todos os tipos de produtos é decidida previamente pelo gerente de produção, mas pode ser modificada com a chegada de alguns pedidos imprevistos importantes. 


\subsection{Processo produtivo da indústria de móveis}

O processo produtivo da indústria de móveis envolve diversas etapas e tipos de equipamentos. De maneira simplificada, este processo pode ser descrito pelas seguintes etapas:

\section{- Corte}

O processo de corte é a etapa inicial de produção e consiste na resolução de um problema de corte de estoque bidimensional, em que os objetos estocados (placas retangulares com dimensões e espessuras fixas) são cortados em diversos tipos de peças, segundo diferentes padrões de corte, os quais compõem os produtos demandados.

O corte das placas pode ser feito em dois setores: primário e secundário. No setor primário, os objetos são cortados em uma máquina de serrar que é operada manualmente e pode cortar simultaneamente várias placas. A espessura máxima que a máquina permite cortar é $60 \mathrm{~mm}$ e os cortes realizados são do tipo guilhotinado. A máquina de serrar precisa ser preparada em dois momentos distintos: quando a serra precisa ser trocada (isso é feito duas vezes ao dia) e quando há mudança de padrões de corte.

A máquina de serrar é um dos possíveis gargalos da linha de produção e, para tentar agilizar o processo de corte, a capacidade total de corte é sempre utilizada, peças muito pequenas são cortadas de forma agrupada para depois serem separadas, o corte das duas últimas peças de uma determinada faixa do padrão de corte é feito junto com o corte de uma nova faixa e, eventualmente, peças de outro produto são cortadas antecipadamente.

No setor de corte secundário, composto por um conjunto de serras menores, algumas peças cortadas no setor primário são aparadas e os retângulos que foram cortados de forma agrupada são separados. Neste setor, também são feitos os vincos para o encaixe das peças quando o móvel é montado.

\section{- Furação}

O setor de furação é composto por furadeiras, manual ou automática, sendo que a maior parte do serviço é feita na furadeira automática. Praticamente todas as peças, exceto as de $3 \mathrm{~mm}$ de espessura, passam por este setor.

A furadeira automática tem capacidade para furar peças com até $45 \mathrm{~mm}$ de espessura e $1,15 \mathrm{~m}$ de largura e fura uma peça de cada vez, pois os furos não são todos vazados. O tempo de preparação desta máquina demora entre 10 e 15 minutos e os ajustes são feitos manualmente. A velocidade para furar as peças é de aproximadamente 5 segundos por peça independente do tamanho, forma e espessura, pois com uma velocidade maior corre-se o risco de danos e aumenta a perda com matéria-prima.

O setor de furação também é um possível gargalo da produção e para agilizar o processo neste setor, evitando perda de tempo com preparações (troca de brocas) uma seqüência para furar as peças, com relação às espessuras, é adotada. Se num determinado lote, 
peças são furadas em ordem crescente de espessura, então, no próximo lote, as peças devem ser furadas na ordem inversa.

\section{- Montagem}

Depois de cortadas e furadas, as peças vão para o setor de montagem, o qual é composto por diferentes tipos de máquinas, tais como, lixadora, prensa, máquina de colar bordas de acabamento (em algumas peças são coladas bordas de acabamento nas quatro laterais), entre outras. Neste setor, todas as peças são montadas e preparadas para a próxima etapa de produção que é a pintura e acabamento.

\section{- Pintura e acabamento}

O setor de pintura UV (ultravioleta) e acabamento é composto por um conjunto de máquinas que lixam, pintam e secam as peças. Estas máquinas operam interligadas e não têm restrições em relação à espessura e ao tamanho das peças.

Nesta etapa do processo produtivo, diversos passos têm de ser realizados até que as peças fiquem prontas para serem embaladas. Resumidamente, os passos são os seguintes: lixamento das peças, pintura com a cor de fundo (comum para todas as cores de móveis) e com a cor definitiva, secagem das peças na estufa e aplicação de verniz (se o móvel for brilhante) ou de outra substância (se o móvel é acetinado) para dar o acabamento final.

O tempo de preparação das máquinas para pintura e acabamento varia de acordo com a cor do móvel, ou seja, mudar de uma cor clara para outra mais escura é mais rápido que mudar da cor escura para a mais clara. Além disso, algumas cores são brilhantes, como mogno e marfim, e são utilizados os dois últimos rolos do conjunto de máquinas para passar o verniz nas peças pintadas com estas cores. Assim, quando a mudança de cor é feita entre essas duas cores, o tempo de preparação é, relativamente, mais curto, pois não é preciso mexer nos dois últimos rolos, apenas naqueles que são utilizados para dar a cor às peças. Já a cor branca, que é fosca, precisa usar os dois últimos rolos com tinta branca para dar o acabamento das peças e, consequentemente, qualquer mudança dessa cor para as demais, terá um tempo de preparação maior.

\section{- Embalagem e estocagem}

No setor de embalagem e estocagem acontece a etapa final do processo produtivo da indústria de móveis, que consiste em fazer uma última vistoria nas peças acabadas que compõem os produtos demandados e embalar estas peças com os devidos acessórios, tais como, parafusos, puxadores, dobradiças, entre outros. Depois de embalados em caixas adequadas e devidamente identificados, os produtos são estocados até a data de entrega.

A Figura 4.2 ilustra as etapas do processo produtivo simplificado da indústria de móveis. As fotos utilizadas foram tiradas de uma indústria de móveis de pequeno porte situada em Votuporanga, interior do estado de São Paulo. 


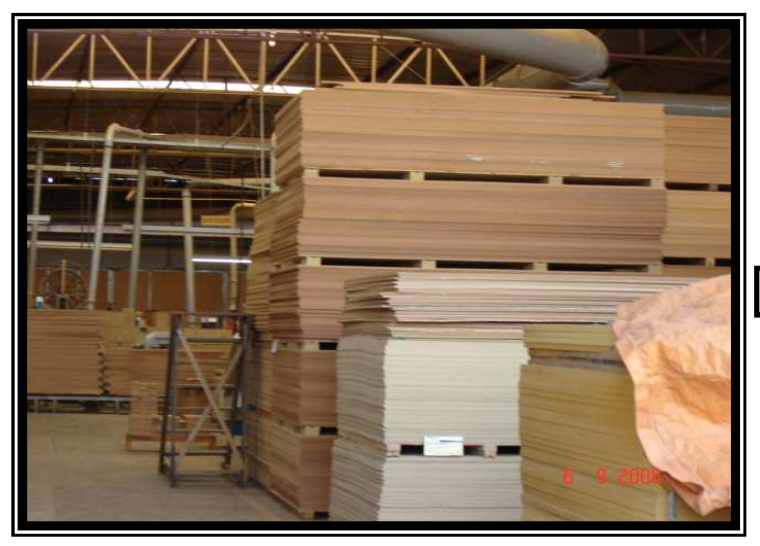

ESTOQUE DE PLACAS

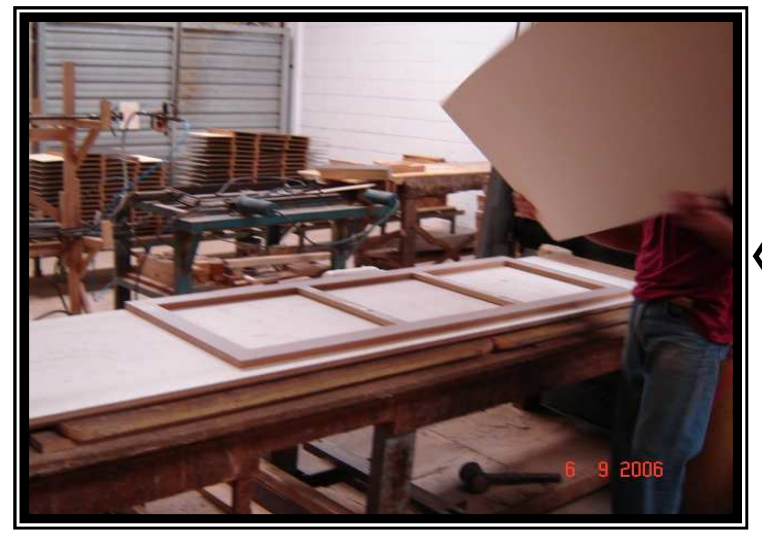

MONTAGEM
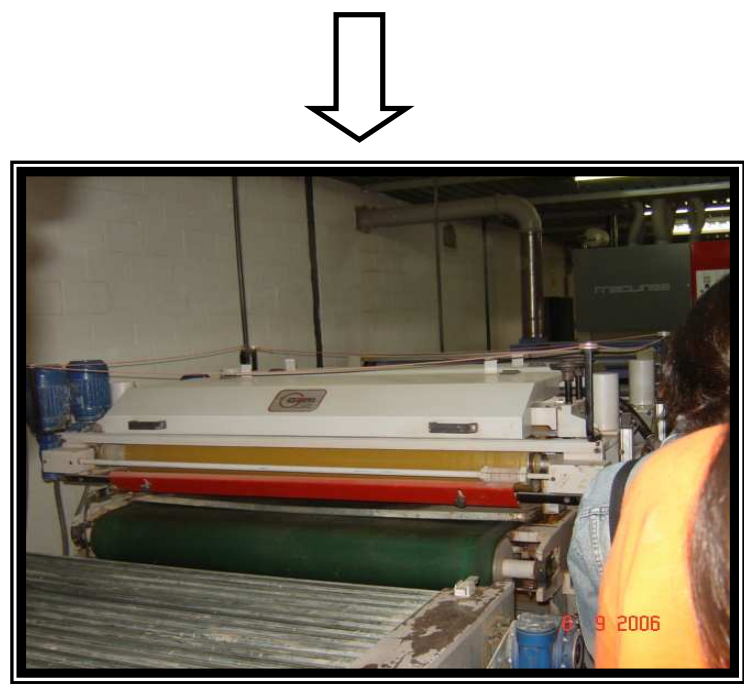

PINTURA E ACABAMENTO

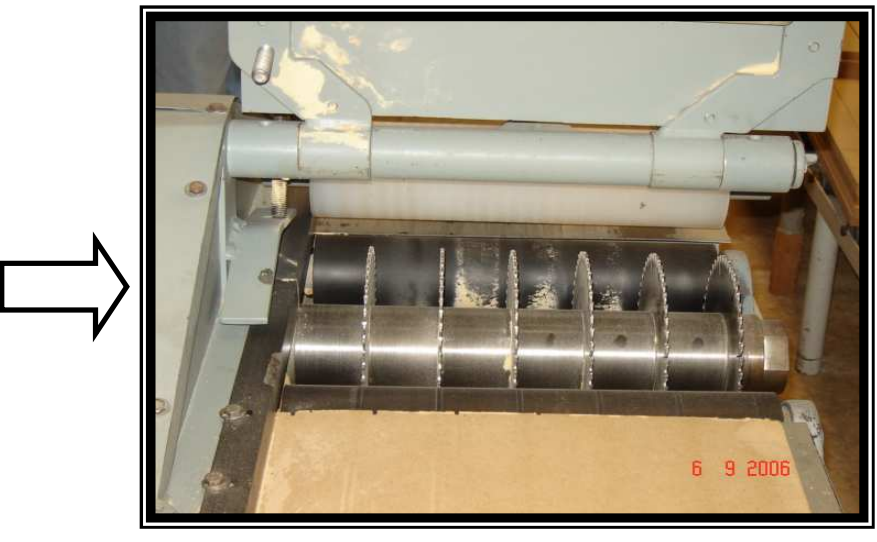

CORTE
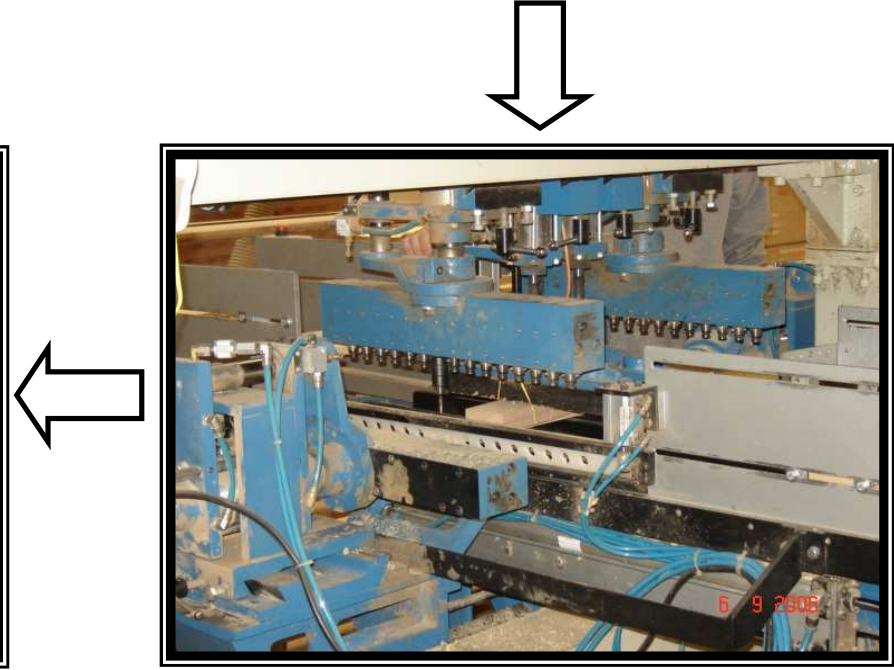

FURAÇÃO

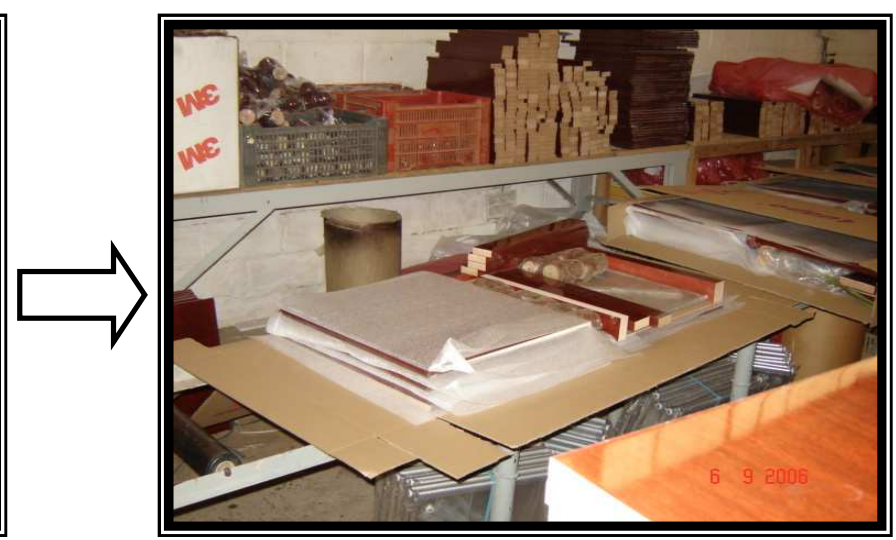

EMBALAGEM E ESTOCAGEM

Figura 4.2: Processo produtivo simplificado da indústria de móveis. 


\subsection{Problema acoplado na indústria de móveis}

Considere um horizonte de planejamento finito dividido em períodos e o primeiro período dividido em subperíodos. Neste trabalho, o horizonte de planejamento representa um mês, o período uma semana e o subperíodo um dia.

A matéria-prima utilizada no processo produtivo é composta de placas retangulares de MDF (objetos) caracterizadas pela dimensão e espessura e disponíveis em quantidade suficiente para atender à demanda esperada de todos os tipos de produtos. Sem perda de generalidade, são considerados objetos com única dimensão $L \times W$ ( $L$ : comprimento e $W$ : largura), espessuras variadas e custo fixo para cada tipo de espessura.

Simplificadamente, o processo produtivo da indústria de móveis resume-se em duas etapas: a primeira etapa consiste em resolver um problema de corte de estoque bidimensional com restrições de capacidade (PCE_BR) e a segunda etapa consiste em resolver um problema de dimensionamento de lotes com múltiplos itens e restrições de capacidade (PDL_R).

Na etapa do PCE_BR, os objetos são cortados utilizando diferentes padrões de corte bidimensional para obter diversos tipos de peças, as quais compõem os produtos demandados. Cada padrão de corte bidimensional demora um certo tempo para ser cortado. A serra, que é um possível gargalo do processo produtivo da indústria de móveis, possui um limite de capacidade a ser respeitado em todos os períodos e subperíodos do horizonte de planejamento. Um custo é associado à preparação da serra, que pode ser diferente para cada tipo de padrão de corte.

Assim como a serra, a furadeira também é um possível gargalo do processo produtivo e possui um limite de capacidade nos períodos e subperíodos que não pode ser violado durante o horizonte de planejamento. As peças são furadas uma de cada vez em um tempo fixo.

Devido à estratégia de horizonte rolante adotada, o detalhamento da etapa do corte é considerado somente no primeiro período do horizonte de planejamento, em todos os subperíodos. Terminado o primeiro período, o horizonte é rolado, o segundo período passa a ser o primeiro, os dados são atualizados e o mesmo modelo é resolvido novamente.

$\mathrm{Na}$ etapa do PDL_R, são determinadas as quantidades a serem produzidas e estocadas, de todos os tipos de produtos, em cada um dos períodos do horizonte de planejamento, de modo a atender às demandas em carteira e esperada dos produtos, sem violar as restrições de capacidade.

Existe um custo associado à manufatura dos produtos em todos os períodos, determinado em função da matéria-prima (número de placas) utilizada para compor uma unidade do produto, um outro custo associado ao estoque dos produtos no final de cada período para atendimento da demanda em carteira, calculado em função do custo de produção e um custo de estoque da produção da demanda extra, o qual é dado em função do custo de estoque.

No PDL_R, também são consideradas restrições de capacidade relacionadas à serra e à furadeira a partir do segundo período do horizonte de planejamento. No período 1, tais restrições são detalhadas por subperíodo, com o detalhamento das decisões de corte.

O custo total do processo produtivo é a soma dos custos de produção, estoque dos produtos para a demanda em carteira ou extra, custos dos objetos cortados e preparação da serra. 
O objetivo do problema acoplado na indústria de móveis é obter um planejamento e programação da produção com custo total de produção mínimo.

\subsection{Modelagem matemática do problema acoplado}

O modelo matemático que propomos, a seguir, conserva o compromisso entre antecipar ou não a produção de certos produtos para atender à demanda (parte em carteira e parte prevista) a fim de minimizar o custo total do processo produtivo.

Sejam:

T: $\quad$ número de períodos do horizonte de planejamento.

$S: \quad$ número de tipos de espessuras para a placa de dimensões $L x W$.

$N^{e}$ : número de diferentes padrões de corte para a placa de espessura $e$.

$M$ : número de tipos de produtos.

$\Theta: \quad$ número de subperíodos em que o período 1 é subdividido.

$P^{e}$ : número de tipos de peças de espessura $e$.

$P$ : $\quad$ número total de tipos de peças, nas $S$ espessuras, que compõem os produtos, ou seja, $P=P^{1}+\ldots+P^{S}$.

Os índices, parâmetros e variáveis utilizados no modelo matemático são:

\section{- Índices}

$t=1, \ldots, T: \quad$ período do horizonte de planejamento.

$e=1, \ldots, S: \quad$ tipo de espessura para a placa $L \times W$.

$j=1, \ldots, N^{e}$ : padrão de corte para a placa de espessura $e$.

$i=1, \ldots, M: \quad$ tipo de produto.

$\tau=1, \ldots, \Theta: \quad$ subperíodo do primeiro período.

$p=1, \ldots, P^{e}:$ tipo de peça de espessura $e$ que compõe os produtos.

\section{- Parâmetros}

$c_{i t}$ : $\quad$ custo de manufaturar o produto tipo $i$ no período $t$.

$c p^{e}: \quad$ custo por unidade da placa de espessura $e$.

$h_{i t}$ : $\quad$ custo de estoque por unidade do produto tipo $i$ no final do período $t$, para atender à demanda em carteira. 
$f_{i t}$ : $\quad$ custo de estoque por unidade do produto tipo $i$ no final do período $t$ para atender à demanda extra.

$d_{i t}$ : demanda em carteira do produto tipo $i$ no período $t$.

$r_{p i}^{e}$ : $\quad$ quantidade de peças do tipo $p$ e espessura $e$ requerida por unidade do produto tipo $i$.

$t c_{i}$ : tempo gasto para cortar todas as peças que compõem uma unidade do produto tipo $i$.

$t f_{i}$ : tempo gasto para furar todas as peças que compõem uma unidade do produto tipo $i$.

$v_{j}^{e}$ : tempo gasto para cortar uma placa de espessura $e$ conforme o padrão de corte $j$.

$b_{p}^{e}: \quad$ tempo gasto para furar uma peça do tipo $p$ e espessura $e$.

$c s_{j \tau}^{e}$ : custo de preparação da serra para cortar uma placa de espessura $e$ conforme o padrão de corte $j$ no subperíodo $\tau$.

$\operatorname{cap}_{\tau}$ : disponibilidade da serra (em horas) no subperíodo $\tau$.

CapS $_{t}$ : disponibilidade da serra (em horas) no período $t$.

$\operatorname{capF}_{i}$ : disponibilidade da furadeira (em horas) no subperíodo $\tau$.

$\mathrm{CapF}_{t}$ : disponibilidade da furadeira (em horas) no período $t$.

$a_{p j \tau}^{e}$ : quantidade de peças do tipo $p$ no padrão de corte $j$ para a placa de espessura $e$ no subperíodo $\tau$.

$D_{i}$ : $\quad$ demanda esperada do produto tipo $i$ no horizonte de planejamento.

Q: $\quad$ quantidade máxima de peças que podem ser cortadas no período 1.

\section{- Variáveis}

$x_{i t}$ : quantidade do produto tipo $i$ a ser manufaturada no período $t$.

$E_{i t}$ : parcela da demanda extra do produto tipo $i$ manufaturada no período $t$.

$I_{i t}$ : quantidade do produto tipo $i$ estocada no final do período $t$ para atender à demanda em carteira.

$y_{j \tau}^{e}$ : quantidade de placas de espessura $e$ cortada conforme o padrão de corte $j$ no subperíodo $\tau$.

$z_{j \tau}^{e}$ : variável binária de preparação (indica a utilização ou não da serra para cortar a placa de espessura $e$ conforme o padrão de corte $j$ no subperíodo $\tau$, ou seja, $z_{j \tau}^{e}=1$ se $y_{j \tau}^{e}>0$ ou $z_{j \tau}^{e}=0$ caso contrário). 


\section{Modelo Matemático}

$$
\begin{aligned}
& \operatorname{Min} \sum_{i=1}^{M} \sum_{t=1}^{T}\left(c_{i t} x_{i t}+h_{i t} I_{i t}+f_{i t} E_{i t}\right)+\sum_{\tau=1}^{\Theta} \sum_{e=1}^{S} \sum_{j=1}^{N e}\left(c p^{e} y_{j \tau}^{e}+c s_{j \tau}^{e} z_{j \tau}^{e}\right) \\
& \text { s.a. } x_{i t}+I_{i(t-1)}-I_{i t}=d_{i t}+E_{i t} \text {, } \\
& \sum_{t=1}^{T}\left(d_{i t}+E_{i t}\right)=D_{i} \text {, } \\
& \sum_{i=1}^{M} t c_{i} x_{i t} \leq \operatorname{CapS}_{t}, \\
& \sum_{i=1}^{M} t f_{i} x_{i t} \leq \operatorname{CapF}_{t} \text {, } \\
& \sum_{j=1}^{N^{e}} \sum_{\tau=1}^{\Theta} a_{p j \tau}^{e} y_{j \tau}^{e}=\sum_{i=1}^{M} r_{p i}^{e} x_{i 1} \text {, } \\
& \sum_{e=1}^{S} \sum_{j=1}^{N e} v_{j}^{e} y_{j \tau}^{e} \leq \operatorname{cap}_{\tau} \\
& i=1, \ldots, M, \quad t=1, \ldots, T \\
& i=1, \ldots . M \\
& t=2, \ldots, T \\
& t=2, \ldots, T \\
& p=1, \ldots, P^{e}, e=1, \ldots, S \\
& \tau=1, \ldots, \Theta \\
& \sum_{e=1}^{S} \sum_{j=1}^{N^{e}} \sum_{p=1}^{P e} b_{p}^{e} a_{p j \tau}^{e} y_{j \tau}^{e} \leq c a p F_{\tau} \text {, } \\
& \tau=1, \ldots, \Theta \\
& y_{j \tau}^{e} \leq Q z_{j \tau}^{e} \text {, } \\
& x_{i t}, I_{i t}, E_{i t} \geq 0 \text { e inteiros, } \\
& y_{j \tau}^{e} \geq 0 \quad \text { einteiros, } \\
& z_{j \tau}^{e} \in\{0,1\} \text {, }
\end{aligned}
$$

- Função objetivo (4.5.1): a função objetivo do modelo matemático (4.5.1)-(4.5.12) consiste em minimizar o custo total do processo produtivo composto pela soma dos custos de produção da demanda esperada $\left(c_{i t}\right)$, do estoque de produtos da demanda em carteira $\left(h_{i t}\right)$, do estoque de produtos da demanda extra $\left(f_{i t}\right)$, das placas cortadas $\left(c p^{e}\right)$ e de preparação de máquina (serra) para o corte $\left(c s_{j \tau}^{e}\right)$.

- Restrições de atendimento à demanda dos produtos finais (4.5.2): estas restrições junto com as restrições (4.5.10) asseguram que as quantidades disponíveis de todos os tipos de produtos são suficientes para atender as demandas em carteira e extra em todos os períodos, ou seja, a quantidade manufaturada do produto tipo $i$ no período $t$ somada à quantidade estocada no período anterior deste produto, menos a quantidade que será estocada (não-negativa) desse produto no final do período atual tem que ser igual à soma da demanda em carteira mais a parcela de atendimento no período $t$ da demanda extra do produto $i$. Sem perder a generalidade, os estoques iniciais de todos os tipos de produtos são considerados nulos.

- Restrições da demanda esperada (4.5.3): esse conjunto de restrições garante que a demanda esperada de todos os tipos de produtos para o horizonte de planejamento seja exatamente a soma em todos os períodos da demanda em carteira e das parcelas de atendimento da demanda extra. 
- Restrições de capacidade da serra para os períodos agregados (4.5.4): tais restrições evitam que uma quantidade muito grande de todos produtos seja planejada para ser manufaturada a partir do segundo período do horizonte de planejamento, o que poderia levar a infactibilidade no corte para esses períodos. Com estas restrições, o tempo total gasto para cortar as peças que compõem os produtos demandados não excederá a capacidade da serra nos períodos de 2 a $T$. Para calcular $t c_{i}$, foi estimado o tempo médio $t \bar{c}$ para cortar qualquer tipo de peça de qualquer espessura. Assim, $t c_{i}$ é dado por:

$$
t c_{i}=t \bar{c} \sum_{e=1}^{S} \sum_{p=1}^{P^{e}} r_{p i}^{e}
$$

- Restrições de capacidade da furadeira para os períodos agregados (4.5.5): análogo à serra, a furadeira também tem um limite de capacidade a ser respeitada nos períodos de 2 a $T$. Assim, estas restrições garantem que o tempo gasto para furar todas as peças que compõem todos produtos demandados no período $t$ não exceda a capacidade da furadeira deste período. O tempo $t f_{i}$ gasto para furar todas as peças que compõem uma unidade do produto $i$ é calculado da seguinte forma:

$$
t f_{i}=\sum_{e=1}^{S} \sum_{p=1}^{p^{e}} b_{p}^{e} r_{p i}^{e}
$$

- Restrições de acoplamento e atendimento à demanda de peças (4.5.6): estas restrições asseguram que a demanda de todos os tipos de peças requerida no primeiro período do horizonte de planejamento seja satisfeita, ou seja, a quantidade de peças de todos os tipos e espessuras cortadas em todos os subperíodos do primeiro período tem de ser igual à quantidade de peças de todos os tipos e espessuras necessárias para compor todos os produtos que serão manufaturados no primeiro período. Tais restrições acoplam os problemas de dimensionamento de lotes e corte de estoque, pois incluem as variáveis $x_{i 1}$ do PDL e as variáveis $y_{j \tau}^{e}$ do PCE, as quais definem o tamanho dos lotes no período 1 e a quantidade de placas cortadas em cada subperíodo do período 1 , respectivamente.

- Restrições de capacidade da serra nos subperíodos (4.5.7): este conjunto de restrições garante que o tempo gasto para cortar as placas de todas as espessuras utilizando diversos padrões de corte não exceda o tempo total disponível da serra para cada subperíodo do primeiro período.

- Restrições de capacidade da furadeira nos subperíodos (4.5.8): a furadeira considerada fura uma única peça por vez. Estas restrições asseguram que o tempo total gasto para furar todas as peças cortadas em um dado subperíodo não exceda o tempo total disponível da furadeira nesse subperíodo. 
- Restrições de preparação de máquina (4.5.9): estas restrições estão relacionadas à preparação da serra no processo de corte quando ocorre a troca de padrão de corte. O tempo gasto com a preparação é penalizado na função objetivo na forma de custo. Se alguma placa de espessura $e$ é cortada conforme o padrão de corte $j$ no subperíodo $\tau$, então $z_{j \tau}^{e}=1$, caso contrário, $z_{j \tau}^{e}=0$.

- Restrições de não negatividade e integralidade das variáveis (4.5.10) e (4.5.11): estes conjuntos de restrições definem as variáveis de produção, de estoques e de placas cortadas como valores não-negativos e inteiros.

- Restrições para as variáveis binárias (4.5.12): estas restrições definem as variáveis de preparação $\left(z_{j \tau}^{e}\right)$ como binárias.

\section{Observações}

1. Note que as restrições (4.5.6) não consideram a variável de estoque para as peças, isso porque na indústria considerada não é possível estocar todas as peças separadamente devido à falta de espaço físico e também pela dificuldade operacional. Obviamente, o estoque de peças (componentes dos produtos finais) pode ser considerado sem dificuldades, conforme o modelo proposto por Gramani e França (2006). Além desta, existem outras diferenças entre o modelo de otimização que propomos para indústria de móveis e o modelo proposto por Gramani e França (2006), tais como: consideramos horizonte de planejamento rolante, restrição de capacidade para a furadeira, variáveis de oportunidade para tratar a demanda esperada, o custo de preparação da serra no problema de corte de estoque, placas de diversas espessuras, entre outras.

2. A perda inerente à serra é em média de $4 \mathrm{~mm}$ e, sem perda de generalidade, supomos que as dimensões das peças e das placas já tenham sido aumentadas por este valor, ou seja,

$$
l_{i}=l_{i}+\sigma, \quad w_{i}=w_{i}+\sigma, \quad L=L+\sigma \quad \text { e } \quad W=W+\sigma,
$$

em que $\sigma$ é a perda com a serra (Gilmore e Gomory, 1965).

3. Na função objetivo, o custo da matéria-prima no processo de corte é contabilizado apenas no primeiro período, assim, somamos uma estimativa do custo de placas necessárias por produto ao custo de produção para os períodos 2 a $T$.

4. Na restrição (4.5.7) a serra pode cortar, ao mesmo tempo, uma certa quantidade de placas $(q)$, dependendo da espessura $e$, que chamamos de lote de placas. O tempo gasto para 
cortar uma placa é dado por: $v_{j}=\frac{\bar{v}_{j}}{q}$, em que $\bar{v}_{j}$ é o tempo médio do ciclo ${ }^{8}$ da serra para cortar um lote de placas no padrão de corte $j$. Na prática, a indústria observada corta em média 50 lotes de placas por subperíodo (dia).

5. Com a produção das parcelas de atendimento à demanda extra (variável de oportunidade), um nível maior de estoque dos produtos finais é gerado, porém este estoque difere do estoque convencional $I_{i t}$ formado apenas pela demanda em carteira. $\mathrm{O}$ exemplo, a seguir, pode ilustrar este fato e justificar o motivo pelo qual as parcelas de atendimento à demanda extra não foram consideradas como estoque convencional, o que, geralmente, é feito nos trabalhos dessa área.

\section{Exemplo}

Considere um horizonte de planejamento com 2 períodos, 1 tipo de produto com as demandas em carteira $d_{11}=10$ e $d_{12}=10$ e a demanda esperada $D_{1}=30$ e a variável $E_{1 t}$ como a parcela para atendimento à demanda extra do produto 1 no período $t$.

Substituindo os dados deste exemplo nas restrições de atendimento à demanda dos produtos finais (4.5.2) e da demanda esperada (4.5.3) do modelo matemático para o problema acoplado obtemos:

$$
\begin{cases}x_{i t}+I_{i(t-1)}-I_{i t}=d_{i t}+E_{i t}, & i=1, \quad t=1,2 \\ \sum_{t=1}^{2}\left(d_{i t}+E_{i t}\right)=D_{i} & i=1 .\end{cases}
$$

$\mathrm{Ou}$, mais detalhadamente,

$$
\left\{\begin{array}{l}
x_{11}+I_{10}-I_{11}=d_{11}+E_{11} \\
x_{12}+I_{11}-I_{12}=d_{12}+E_{12} \\
d_{11}+d_{12}+E_{11}+E_{12}=D_{1}
\end{array}\right.
$$

Substituindo-se os dados, segue:

$$
\left\{\begin{array}{l}
x_{11}-I_{11}=10+E_{11} \\
x_{12}+I_{11}-I_{12}=10+E_{12} \\
10+10+E_{11}+E_{12}=30
\end{array}\right.
$$

\footnotetext{
${ }^{8}$ Ciclo da serra é um conjunto de operações realizadas para cortar uma ou mais placas conforme um determinado padrão de corte, desde pegar as placas até obter as peças cortadas.
} 
Em (4.5.15) temos um sistema linear com 3 equações e 5 incógnitas. Uma solução para este sistema pode ser $x_{11}=20, x_{12}=10, I_{11}=0, I_{12}=0, E_{11}=10$ e $E_{12}=0$.

A meta de manufaturar 30 unidades do produto 1 no horizonte de planejamento (20 para a demanda em carteira e 10 para a demanda extra) foi atingida. Rolando o horizonte, o segundo período passa a ser o primeiro, os dados são atualizados e, eventualmente, a demanda em carteira pode ser atendida pelos produtos em estoque no período correspondente. Obviamente, a parcela de atendimento à demanda extra $E_{11}=10$, ocorrida no período 1 poderia ter sido postergada para o período 2, já que não há demanda em carteira. Entretanto, a combinação das peças (componentes do produto) em uma quantidade maior pode ser conveniente para a redução de perdas no processo de corte (e, consequentemente, do número de placas cortadas). Esta conveniência não trivial para o gerente de produção, é analisada no modelo pelas variáveis de oportunidade $E_{i t}$.

Considere, agora, somente as variáveis de estoque convencional $I_{i t}$ substituindo as variáveis $E_{i t}$ por $I_{i t}$ nas restrições (4.5.3). As restrições (4.5.2) e (4.5.3) tornam-se:

$$
\left\{\begin{array}{l}
x_{11}+I_{10}=d_{11}+I_{11} \\
x_{12}+I_{11}=d_{12}+I_{12} \\
d_{11}+I_{11}+d_{12}+I_{12}=D_{1}
\end{array}\right.
$$

Substituindo os dados do exemplo e a solução anterior em (4.5.16) temos:

$$
\left\{\begin{array}{l}
20+0=10+10 \\
0+10=10+0 \\
10+10+10+0=30
\end{array}\right.
$$

Neste caso, $x_{12}=0$, as restrições são satisfeitas, porém a meta de produzir 30 unidades do produto 1 no horizonte de planejamento não é atingida, pois são produzidas apenas 20 unidades.

\subsection{Matriz de restrições do problema acoplado}

A Figura 4.3 ilustra a matriz de restrições do modelo matemático (4.5.1)-(4.5.12) do problema de otimização acoplado na indústria de móveis, que contém os seguintes vetores:

- tc: vetor cujas componentes são $t c_{i}$ e dimensão é $M$.

- tf : vetor cujas componentes são $t f_{i}$ e dimensão é $M$.

- $\mathrm{R}^{e}$ : matriz formada por $M$ colunas de dimensão $P^{e}$. Cada coluna $i$ contém as quantidades $r_{p i}^{e}$. 
- $\quad \mathrm{A}_{\tau}^{e}$ : matriz formada por $N^{e}$ colunas de dimensões $P^{e}$. Cada coluna $j$ contém um padrão de corte $\left(a_{j \tau}^{e}\right)$ para a placa de espessura $e$ no subperíodo $\tau$.

- $v^{e}$ : vetor cujas componentes são $v_{j}^{e}$ e dimensão é $P^{e}$.

- $\quad \mathrm{b}^{e}: \quad$ vetor cujas componentes são $b_{p}^{e}$ e dimensão é $P^{e}$.

- QI: matriz diagonal, cujos elementos Q.

Observe que a matriz de restrições é bastante esparsa e composta por blocos que possuem um alto grau de esparsidade e pouco acoplamento. Isto indica que a exploração destas características pode produzir bons resultados em termos de eficiência computacional.

A ordem da matriz cresce, consideravelmente, com o aumento no número de tipos de peças, espessuras, produtos finais, períodos e subperíodos e, consequentemente, o grau de esparsidade será ainda maior.

\subsection{Dificuldades do modelo matemático do problema acoplado}

O modelo matemático (4.5.1)-(4.5.12) proposto para representar o problema acoplado da indústria de móveis apresenta algumas dificuldades para sua resolução, que são:

- integralidade das variáveis.

- variáveis binárias de preparação no processo de corte;

- grande quantidade de padrões de corte bidimensional que podem ser considerados.

Por causa destas dificuldades, na prática, as indústrias resolvem os problemas de dimensionamento de lotes e corte de estoque separadamente. Mesmo obtendo a solução ótima para os dois problemas e agregando suas soluções, o compromisso entre os custos de produção e o processo de corte é perdido e, provavelmente, infactibilidades serão encontradas, uma vez que, a quantidade de peças necessárias para compor os produtos programados para serem manufaturados em cada um dos períodos do horizonte de planejamento pode ser maior que as capacidades da serra e da furadeira disponíveis para cortar e furar tais peças. Porém, se os problemas forem resolvidos de forma acoplada, a antecipação da fabricação de certos lotes de produtos ou a produção das parcelas da demanda extra, poderá ocorrer, se for vantajoso, uma melhor utilização das máquinas será possível, períodos com limites de capacidade ultrapassados serão evitados e ainda, a perda de matéria-prima no processo de corte poderá diminuir, pois novas e melhores combinações entre as peças nos padrões de corte bidimensionais serão possíveis.

No capítulo seguinte, é mostrado como tratar tais dificuldades e são propostos métodos heurísticos para a resolução do problema acoplado na indústria de móveis. 


\begin{tabular}{|c|c|c|c|c|c|c|c|c|c|c|c|c|c|c|c|c|c|c|c|c|c|c|c|}
\hline & $\mathbf{x}_{1}$ & $\ldots$ & $\mathbf{x}_{T}$ & $I_{1}$ & ... & $\mathbf{I}_{T}$ & $\mathbf{E}_{1}$ & ... & $\mathbf{E}_{T}$ & $\mathbf{y}_{1}^{1}$ & ... & $\mathbf{y}_{\Theta}^{1}$ & $\ldots$ & $\mathbf{y}_{1}^{S}$ & ... & $\mathbf{y}_{\Theta}^{S}$ & $z_{1}^{1}$ & ... & $\mathbf{z}_{\Theta}^{1}$ & $\ldots$ & $\mathbf{z}_{1}^{S}$ & $\ldots$ & $\mathbf{z}_{\Theta}^{S}$ \\
\hline$t=1$ & I & $\ldots$ & 0 & -I & $\ldots$ & 0 & -I & $\ldots$ & 0 & 0 & $\ldots$ & 0 & $\ldots$ & 0 & $\ldots$ & 0 & 0 & $\ldots$ & 0 & $\ldots$ & 0 & $\ldots$ & 0 \\
\hline$t=2$ & 0 & $\ldots$ & 0 & I & $\ldots$ & 0 & 0 & $\ldots$ & 0 & 0 & $\ldots$ & 0 & $\ldots$ & 0 & $\ldots$ & 0 & 0 & $\ldots$ & 0 & $\ldots$ & 0 & $\ldots$ & 0 \\
\hline$\ldots$ & $\ldots$ & $\ldots$ & $\ldots$ & $\ldots$ & $\ldots$ & $\ldots$ & $\ldots$ & $\ldots$ & $\ldots$ & $\ldots$ & $\ldots$ & $\ldots$ & $\ldots$ & $\ldots$ & $\ldots$ & $\ldots$ & $\ldots$ & $\ldots$ & $\ldots$ & $\ldots$ & $\ldots$ & $\ldots$ & $\ldots$ \\
\hline \multirow[t]{2}{*}{$t=T$} & 0 & $\ldots$ & I & 0 & $\ldots$ & $-\mathrm{I}$ & 0 & $\ldots$ & $-\mathrm{I}$ & 0 & $\ldots$ & 0 & & 0 & $\ldots$ & 0 & 0 & $\ldots$ & 0 & & 0 & $\ldots$ & 0 \\
\hline & 0 & $\ldots$ & 0 & 0 & $\ldots$ & 0 & I & $\ldots$ & I & 0 & $\ldots$ & 0 & $\ldots$ & 0 & $\ldots$ & 0 & 0 & $\ldots$ & 0 & $\ldots$ & 0 & $\ldots$ & 0 \\
\hline$t=2$ & tc & $\ldots$ & 0 & 0 & $\ldots$ & 0 & 0 & $\ldots$ & 0 & 0 & $\ldots$ & 0 & $\ldots$ & 0 & $\ldots$ & 0 & 0 & $\ldots$ & 0 & $\ldots$ & 0 & $\ldots$ & 0 \\
\hline$t=3$ & 0 & $\ldots$ & 0 & 0 & $\ldots$ & 0 & 0 & $\ldots$ & 0 & 0 & $\ldots$ & 0 & $\ldots$ & 0 & $\ldots$ & 0 & 0 & $\ldots$ & 0 & $\ldots$ & 0 & $\ldots$ & 0 \\
\hline$\ldots$ & $\ldots$ & $\ldots$ & $\ldots$ & $\ldots$ & $\ldots$ & $\ldots$ & $\ldots$ & $\ldots$ & $\ldots$ & $\ldots$ & $\ldots$ & $\ldots$ & $\ldots$ & $\ldots$ & $\ldots$ & $\ldots$ & $\ldots$ & $\ldots$ & $\ldots$ & $\ldots$ & $\ldots$ & $\ldots$ & $\ldots$ \\
\hline$t=T$ & 0 & $\ldots$ & tc & 0 & $\ldots$ & 0 & 0 & $\ldots$ & 0 & 0 & $\ldots$ & 0 & $\ldots$ & 0 & $\ldots$ & 0 & 0 & $\ldots$ & 0 & $\ldots$ & 0 & $\ldots$ & 0 \\
\hline$t=2$ & $\mathrm{tf}$ & $\ldots$ & 0 & 0 & $\ldots$ & 0 & 0 & $\ldots$ & 0 & 0 & $\ldots$ & 0 & $\ldots$ & 0 & $\ldots$ & 0 & 0 & $\ldots$ & 0 & $\ldots$ & 0 & $\ldots$ & 0 \\
\hline$t=3$ & 0 & $\ldots$ & 0 & 0 & $\ldots$ & 0 & 0 & $\ldots$ & 0 & 0 & $\ldots$ & 0 & $\ldots$ & 0 & $\ldots$ & 0 & 0 & $\ldots$ & 0 & $\ldots$ & 0 & $\ldots$ & 0 \\
\hline$\ldots$ & $\ldots$ & $\ldots$ & $\ldots$ & $\ldots$ & $\ldots$ & $\ldots$ & $\ldots$ & $\ldots$ & $\ldots$ & $\ldots$ & $\ldots$ & $\ldots$ & $\ldots$ & $\ldots$ & $\ldots$ & $\ldots$ & $\ldots$ & $\ldots$ & $\ldots$ & $\ldots$ & $\ldots$ & $\ldots$ & $\ldots$ \\
\hline$t=T$ & 0 & $\ldots$ & $\mathrm{tf}$ & 0 & $\ldots$ & 0 & 0 & $\ldots$ & 0 & 0 & $\ldots$ & 0 & $\ldots$ & 0 & $\ldots$ & 0 & 0 & $\ldots$ & 0 & $\ldots$ & 0 & $\ldots$ & 0 \\
\hline$e=1$ & $-\mathrm{R}^{1}$ & $\ldots$ & 0 & 0 & $\ldots$ & 0 & 0 & $\ldots$ & 0 & $A_{1}^{1}$ & $\ldots$ & $\mathrm{A}_{\Theta}^{1}$ & $\ldots$ & 0 & $\ldots$ & 0 & 0 & $\ldots$ & 0 & $\ldots$ & 0 & $\ldots$ & 0 \\
\hline$e=2$ & $-\mathrm{R}^{2}$ & $\ldots$ & 0 & 0 & $\ldots$ & 0 & 0 & $\ldots$ & 0 & 0 & $\ldots$ & 0 & $\ldots$ & 0 & $\ldots$ & 0 & 0 & $\ldots$ & 0 & $\ldots$ & 0 & $\ldots$ & 0 \\
\hline$\ldots$ & $\ldots$ & $\ldots$ & $\ldots$ & $\ldots$ & $\ldots$ & $\ldots$ & $\ldots$ & $\ldots$ & $\ldots$ & $\ldots$ & $\ldots$ & $\ldots$ & $\ldots$ & $\ldots$ & $\ldots$ & $\ldots$ & $\ldots$ & $\ldots$ & $\ldots$ & $\ldots$ & $\ldots$ & $\ldots$ & $\ldots$ \\
\hline$e=S$ & $-\mathrm{R}^{S}$ & $\ldots$ & 0 & 0 & $\ldots$ & 0 & 0 & $\ldots$ & 0 & 0 & $\ldots$ & 0 & $\ldots$ & $\mathrm{A}_{1}^{S}$ & $\ldots$ & $\mathrm{A}_{\Theta}^{S}$ & 0 & $\ldots$ & 0 & $\ldots$ & 0 & $\ldots$ & 0 \\
\hline$\tau=1$ & 0 & $\ldots$ & 0 & 0 & $\ldots$ & 0 & 0 & $\ldots$ & 0 & $v^{1}$ & $\ldots$ & 0 & $\ldots$ & $v^{S}$ & $\ldots$ & 0 & 0 & $\ldots$ & 0 & $\ldots$ & 0 & $\ldots$ & 0 \\
\hline$\tau=2$ & 0 & $\ldots$ & 0 & 0 & $\ldots$ & 0 & 0 & $\ldots$ & 0 & 0 & $\ldots$ & 0 & $\ldots$ & 0 & $\ldots$ & 0 & 0 & $\ldots$ & 0 & $\ldots$ & 0 & $\ldots$ & 0 \\
\hline ... & $\ldots$ & $\ldots$ & $\ldots$ & $\ldots$ & $\ldots$ & $\ldots$ & $\ldots$ & $\ldots$ & $\ldots$ & $\ldots$ & $\ldots$ & $\ldots$ & $\ldots$ & $\ldots$ & $\ldots$ & $\ldots$ & $\ldots$ & $\ldots$ & $\ldots$ & $\ldots$ & $\ldots$ & $\ldots$ & $\ldots$ \\
\hline$\tau=\Theta$ & 0 & $\ldots$ & 0 & 0 & $\ldots$ & 0 & 0 & $\ldots$ & 0 & 0 & $\ldots$ & $\mathrm{v}^{1}$ & $\ldots$ & 0 & $\ldots$ & $\mathbf{v}^{S}$ & 0 & $\ldots$ & 0 & $\ldots$ & 0 & $\ldots$ & 0 \\
\hline$\tau=1$ & 0 & $\ldots$ & 0 & 0 & $\ldots$ & 0 & 0 & $\ldots$ & 0 & $\mathrm{~b}^{1}$ & $\ldots$ & 0 & $\ldots$ & $\mathrm{b}^{S}$ & $\ldots$ & 0 & 0 & $\ldots$ & 0 & $\ldots$ & 0 & $\ldots$ & 0 \\
\hline$\tau=2$ & 0 & $\ldots$ & 0 & 0 & $\ldots$ & 0 & 0 & $\ldots$ & 0 & 0 & $\ldots$ & 0 & $\ldots$ & & $\ldots$ & 0 & 0 & $\ldots$ & 0 & $\ldots$ & 0 & $\ldots$ & 0 \\
\hline$\ldots$ & $\ldots$ & $\ldots$ & $\ldots$ & $\ldots$ & $\ldots$ & $\ldots$ & $\ldots$ & $\ldots$ & $\ldots$ & $\ldots$ & $\ldots$ & $\ldots$ & $\ldots$ & $\ldots$ & $\ldots$ & $\ldots$ & $\ldots$ & $\ldots$ & $\ldots$ & $\ldots$ & $\ldots$ & $\ldots$ & $\ldots$ \\
\hline$\tau=\Theta$ & 0 & $\ldots$ & 0 & 0 & $\ldots$ & 0 & 0 & $\ldots$ & 0 & 0 & $\ldots$ & $b^{1}$ & $\ldots$ & 0 & $\ldots$ & $\mathrm{b}^{S}$ & 0 & $\ldots$ & 0 & $\ldots$ & 0 & $\ldots$ & 0 \\
\hline$\tau=1$ & 0 & $\ldots$ & 0 & 0 & $\ldots$ & 0 & 0 & $\ldots$ & 0 & I & $\ldots$ & 0 & $\ldots$ & I & $\ldots$ & 0 & $-\mathrm{QI}$ & $\ldots$ & 0 & $\ldots$ & -QI & $\ldots$ & 0 \\
\hline$\tau=2$ & 0 & $\ldots$ & 0 & 0 & $\ldots$ & 0 & 0 & $\ldots$ & 0 & 0 & $\ldots$ & 0 & $\ldots$ & & $\ldots$ & 0 & 0 & $\ldots$ & 0 & $\ldots$ & & $\ldots$ & 0 \\
\hline ... & $\ldots$ & $\ldots$ & $\ldots$ & $\ldots$ & $\ldots$ & $\ldots$ & $\ldots$ & $\ldots$ & $\ldots$ & $\ldots$ & $\ldots$ & $\ldots$ & $\ldots$ & $\ldots$ & $\ldots$ & $\ldots$ & $\ldots$ & $\ldots$ & $\ldots$ & $\ldots$ & $\ldots$ & $\ldots$ & $\ldots$ \\
\hline$\tau=\Theta$ & 0 & $\ldots$ & 0 & 0 & $\ldots$ & 0 & 0 & $\ldots$ & 0 & 0 & $\ldots$ & I & $\ldots$ & 0 & $\ldots$ & I & 0 & $\ldots$ & -QI & $\ldots$ & 0 & $\ldots$ & -QI \\
\hline
\end{tabular}

Figura 4.3: Matriz de restrições do modelo matemático (4.5.1)-(4.5.12). 


\section{Capítulo 5}

\section{Métodos de Solução}

Este capítulo traz a descrição de todos os procedimentos, métodos e técnicas desenvolvidos e utilizados para resolver o modelo matemático (4.5.1)-(4.5.12) proposto para representar um problema acoplado de dimensionamento de lotes e corte de estoque presente em indústrias de móveis.

Na Seção 5.1, é feita uma simplificação do problema original e, então, um modelo matemático relaxado (de otimização linear) é obtido. Para resolver o novo modelo são desenvolvidas duas heurísticas (acoplamento e decomposição) baseadas no método simplex com geração de colunas, que são apresentadas na Seção 5.2. A Seção 5.3 contém duas abordagens para gerar novas colunas a serem inseridas no modelo. A Seção 5.4 trata das variáveis artificiais introduzidas no modelo matemático. Na Seção 5.5 é apresentada uma heurística de factibilização desenvolvida para a heurística de decomposição. A última seção deste capítulo, Seção 5.6, contém dois procedimentos adotados para obter uma solução inteira para o problema acoplado e descreve a abordagem grafo E/OU para determinar padrões de corte bidimensional guilhotinado 2-estágios exatos restritos usados nestes procedimentos.

\subsection{Problema acoplado PDL e PCE simplificado}

Conforme descrito no Capítulo 4, o modelo matemático (4.5.1)-(4.5.12) do problema acoplado de dimensionamento de lotes e corte de estoque apresenta três principais dificuldades (integralidade das variáveis, variáveis binárias de preparação de máquina e grande quantidade de padrões de corte bidimensionais que podem ser considerados) que o torna de difícil resolução. Estas dificuldades são tratadas realizando uma simplificação do problema e utilizando um método de solução adequado para resolver o novo modelo.

Para simplificar o problema, considere as alterações:

- Relaxar a integralidade das variáveis.

- Desconsiderar os custos de preparação da serra no processo de corte. 
Ao remover os custos de preparação, as variáveis binárias e as restrições de preparação de máquina são eliminadas do modelo matemático. Porém, o tempo de preparação da serra não é totalmente desconsiderado, uma vez que um valor estimado (calculado com base no número de ciclos da serra diário, em torno de 50/dia, e no tempo gasto para trocar a serra 2 vezes ao dia, demora em torno de 30 minutos cada troca) é descontado nas capacidades da serra por subperíodo e período.

Além disso, com a relaxação da integralidade das variáveis de decisão passamos a ter um modelo matemático de otimização linear, o que facilita a resolução do problema na forma acoplada. Mas, a dificuldade com relação à enorme quantidade de padrões de corte bidimensionais a ser considerada (variáveis do problema de corte) continua existindo.

O modelo matemático após as simplificações é o seguinte:

\section{Modelo matemático}

$$
\begin{aligned}
& \operatorname{Min} \sum_{i=1}^{M} \sum_{t=1}^{T}\left(c_{i t} x_{i t}+h_{i t} I_{i t}+f_{i t} E_{i t}\right)+\sum_{\tau=1}^{\Theta} \sum_{e=1}^{S} \sum_{j=1}^{N^{e}}\left(c p^{e} y_{j \tau}^{e}\right) \\
& \text { s.a. } x_{i t}+I_{i(t-1)}-I_{i t}=d_{i t}+E_{i t} \text {, } \\
& \begin{aligned}
i & =1, \ldots, M, \quad t=1, \ldots, T \\
i & =1, \ldots . M, \\
t & =2, \ldots, T, \\
t & =2, \ldots, T, \\
p & =1, \ldots, P e, \quad e=1, \ldots, S \\
\tau & =1, \ldots, \Theta, \\
\tau & =1, \ldots, \Theta, \quad \\
i & =1, \ldots, M, \quad t=1, \ldots, T \\
j=1, \ldots, N^{e}, & e=1, \ldots, S, \quad \tau=1, \ldots, \Theta
\end{aligned} \\
& \sum_{t=1}^{T}\left(d_{i t}+E_{i t}\right)=D_{i} \text {, } \\
& \sum_{i=1}^{M} t c_{i} x_{i t} \leq \operatorname{CapS}_{t} \text {, } \\
& \sum_{i=1}^{M} t f_{i} x_{i t} \leq \mathrm{CapF}_{t}, \\
& \sum_{j=1}^{N^{e}} \sum_{\tau=1}^{\Theta} a_{p j \tau}^{e} y_{j \tau}^{e}=\sum_{i=1}^{M} r_{p i}^{e} x_{i 1} \text {, } \\
& \sum_{e=1}^{S} \sum_{j=1}^{N e} v_{j}^{e} y_{j \tau}^{e} \leq \operatorname{capS}_{\tau} \\
& \sum_{e=1}^{S} \sum_{j=1}^{N^{e}} \sum_{p=1}^{P e} b_{p}^{e} a_{p j \tau}^{e} y_{j \tau}^{e} \leq c a p F_{\tau} \\
& x_{i t}, I_{i t}, E_{i t} \geq 0 \text {, } \\
& y_{j \tau}^{e} \geq 0 \text {, }
\end{aligned}
$$

O modelo matemático (5.1.1)-(5.1.10) é adequado para representar situações em que os custos de preparação não são relevantes e a demanda dos produtos é alta (neste caso, o erro para arredondamento torna-se irrelevante).

Vale ressaltar que, embora as restrições de preparação não sejam mais consideradas, o problema acoplado ainda conserva o compromisso entre os custos de estoque dos produtos e das placas cortadas, que aparece quando os problemas de dimensionamento de lotes e corte de estoque são tratados juntos, ou seja, ainda é necessário verificar se é vantajoso ou não antecipar a produção da demanda em carteira e da demanda extra dos produtos finais, aumentando os custos de estoque e diminuindo a perda de matéria-prima com um melhor arranjo das peças nas placas.

A Figura 5.1, a seguir, ilustra a matriz de restrições do modelo matemático relaxado (5.1.1)-(5.1.10). 


\begin{tabular}{|c|c|c|c|c|c|c|c|c|c|c|c|c|c|c|c|c|}
\hline & $\mathbf{x}_{1}$ & ... & $\mathbf{x}_{T}$ & $\mathbf{I}_{1}$ & ... & $\mathbf{I}_{T}$ & $\mathbf{E}_{1}$ & ... & $\mathbf{E}_{T}$ & $\mathbf{y}_{1}^{1}$ & $\ldots$ & $\mathbf{y}_{\Theta}^{1}$ & $\cdots$ & $\mathbf{y}_{1}^{S}$ & $\ldots$ & $\mathbf{y}_{\Theta}^{S}$ \\
\hline$t=1$ & I & $\ldots$ & 0 & $-\mathrm{I}$ & $\ldots$ & 0 & -I & $\ldots$ & 0 & 0 & $\ldots$ & 0 & $\ldots$ & 0 & $\ldots$ & 0 \\
\hline$t=2$ & 0 & $\ldots$ & 0 & I & $\ldots$ & 0 & 0 & $\ldots$ & 0 & 0 & $\ldots$ & 0 & $\ldots$ & 0 & $\ldots$ & 0 \\
\hline ... & $\ldots$ & $\ldots$ & ... & $\cdots$ & $\ldots$ & $\ldots$ & $\ldots$ & $\ldots$ & $\ldots$ & $\ldots$ & $\ldots$ & ... & $\ldots$ & $\ldots$ & $\ldots$ & $\ldots$ \\
\hline \multirow[t]{2}{*}{$t=T$} & 0 & $\ldots$ & I & 0 & $\ldots$ & $-\mathrm{I}$ & 0 & $\ldots$ & $-\mathrm{I}$ & 0 & $\ldots$ & 0 & & 0 & $\ldots$ & 0 \\
\hline & 0 & $\ldots$ & 0 & 0 & $\ldots$ & 0 & $\mathrm{I}$ & $\ldots$ & $\mathrm{I}$ & 0 & $\ldots$ & 0 & $\ldots$ & 0 & $\ldots$ & 0 \\
\hline$t=2$ & tc & $\ldots$ & 0 & 0 & $\ldots$ & 0 & 0 & $\ldots$ & 0 & 0 & $\ldots$ & 0 & $\ldots$ & 0 & $\ldots$ & 0 \\
\hline$t=\mathbf{3}$ & 0 & $\ldots$ & 0 & 0 & $\ldots$ & 0 & 0 & $\ldots$ & 0 & 0 & $\ldots$ & 0 & $\ldots$ & 0 & $\ldots$ & 0 \\
\hline$\ldots$ & $\ldots$ & $\ldots$ & $\ldots$ & $\ldots$ & $\ldots$ & $\ldots$ & $\ldots$ & $\ldots$ & $\ldots$ & $\ldots$ & $\ldots$ & $\ldots$ & $\ldots$ & $\ldots$ & $\ldots$ & $\ldots$ \\
\hline$t=T$ & 0 & $\ldots$ & tc & 0 & $\ldots$ & 0 & 0 & $\ldots$ & 0 & 0 & $\ldots$ & 0 & $\ldots$ & 0 & $\ldots$ & 0 \\
\hline$t=2$ & tf & $\ldots$ & 0 & 0 & $\ldots$ & 0 & 0 & $\ldots$ & 0 & 0 & $\ldots$ & 0 & $\ldots$ & 0 & $\ldots$ & 0 \\
\hline$t=\mathbf{3}$ & 0 & $\ldots$ & 0 & 0 & $\ldots$ & 0 & 0 & $\ldots$ & 0 & 0 & $\ldots$ & 0 & $\ldots$ & 0 & $\ldots$ & 0 \\
\hline ... & $\ldots$ & $\ldots$ & $\ldots$ & $\ldots$ & $\ldots$ & $\ldots$ & $\ldots$ & $\ldots$ & $\ldots$ & $\ldots$ & $\ldots$ & $\ldots$ & $\ldots$ & $\ldots$ & $\ldots$ & $\ldots$ \\
\hline$t=T$ & 0 & $\ldots$ & $\mathrm{tf}$ & 0 & $\ldots$ & 0 & 0 & $\ldots$ & 0 & 0 & $\ldots$ & 0 & $\ldots$ & 0 & $\ldots$ & 0 \\
\hline$e=1$ & $-\mathrm{R}^{1}$ & $\cdots$ & 0 & 0 & $\ldots$ & 0 & 0 & $\ldots$ & 0 & $\mathrm{~A}_{1}^{1}$ & $\ldots$ & $A_{\Theta}^{1}$ & $\ldots$ & 0 & $\ldots$ & 0 \\
\hline$e=2$ & $-\mathrm{R}^{2}$ & $\cdots$ & 0 & 0 & $\ldots$ & 0 & 0 & $\ldots$ & 0 & 0 & $\ldots$ & 0 & $\cdots$ & 0 & $\ldots$ & 0 \\
\hline .. & $\ldots$ & $\cdots$ & $\ldots$ & $\cdots$ & $\cdots$ & $\ldots$ & $\ldots$ & $\cdots$ & $\ldots$ & $\ldots$ & $\ldots$ & $\ldots$ & $\ldots$ & $\ldots$ & $\ldots$ & $\ldots$ \\
\hline$e=S$ & $-\mathrm{R}^{S}$ & $\cdots$ & 0 & 0 & $\cdots$ & 0 & 0 & $\cdots$ & 0 & 0 & $\cdots$ & 0 & $\cdots$ & $\mathrm{A}_{1}^{S}$ & $\ldots$ & $\mathrm{A}_{\Theta}^{S}$ \\
\hline$\tau=\mathbf{1}$ & 0 & $\ldots$ & 0 & 0 & $\ldots$ & 0 & 0 & $\ldots$ & 0 & $v^{1}$ & $\ldots$ & 0 & $\ldots$ & $v^{S}$ & $\ldots$ & 0 \\
\hline$\tau=2$ & 0 & $\ldots$ & 0 & 0 & $\ldots$ & 0 & 0 & $\ldots$ & 0 & 0 & $\ldots$ & 0 & $\ldots$ & 0 & $\ldots$ & 0 \\
\hline ... & $\ldots$ & $\ldots$ & $\ldots$ & $\ldots$ & $\ldots$ & $\ldots$ & $\ldots$ & $\ldots$ & $\ldots$ & $\ldots$ & $\ldots$ & ... & $\ldots$ & $\ldots$ & $\ldots$ & $\ldots$ \\
\hline$\tau=\Theta$ & 0 & $\ldots$ & 0 & 0 & $\ldots$ & 0 & 0 & $\ldots$ & 0 & 0 & $\ldots$ & $v^{1}$ & $\ldots$ & 0 & $\ldots$ & $\mathrm{v}^{S}$ \\
\hline$\tau=1$ & 0 & $\ldots$ & 0 & 0 & $\ldots$ & 0 & 0 & $\ldots$ & 0 & $\mathrm{~b}^{1}$ & $\ldots$ & 0 & $\ldots$ & $b^{S}$ & $\ldots$ & 0 \\
\hline$\tau=2$ & 0 & $\ldots$ & 0 & 0 & $\ldots$ & 0 & 0 & $\ldots$ & 0 & 0 & $\ldots$ & 0 & $\ldots$ & & $\ldots$ & 0 \\
\hline$\cdots$ & $\ldots$ & $\cdots$ & $\ldots$ & $\ldots$ & $\ldots$ & $\ldots$ & $\cdots$ & $\ldots$ & $\ldots$ & $\ldots$ & $\cdots$ & $\ldots$ & $\cdots$ & $\ldots$ & $\ldots$ & $\ldots$ \\
\hline$\tau=\Theta$ & 0 & $\ldots$ & 0 & 0 & $\ldots$ & 0 & 0 & $\ldots$ & 0 & 0 & $\ldots$ & $b^{1}$ & $\ldots$ & 0 & $\ldots$ & $\mathrm{b}^{S}$ \\
\hline
\end{tabular}

Figura 5.1: Matriz de restrições do modelo matemático relaxado (5.1.1)-(5.1.10).

As submatrizes $\mathrm{A}_{\tau}^{e}$ têm $N^{e}$ colunas contendo padrões de corte bidimensional guilhotinado 2-estágios exatos para a placa de espessura $e$ no subperíodo $\tau$. Por exemplo, a submatriz $\mathrm{A}_{1}^{1}$ tem a seguinte forma:

$$
\mathrm{A}_{1}^{1}=\left[\begin{array}{cccc}
a_{111}^{1} & a_{121}^{1} & \ldots & a_{1 N^{1} 1}^{1} \\
a_{211}^{1} & a_{221}^{1} & \ldots & a_{2 N^{1} 1}^{1} \\
\vdots & \vdots & \ddots & \vdots \\
a_{P^{1} 11}^{1} & a_{P^{1} 21}^{1} & \ldots & a_{P^{1} N^{1} 1}^{1}
\end{array}\right]
$$

Figura 5.2: Submatriz de padrões de corte para $e=2$ e $\tau=1$.

Para determinar uma solução do modelo matemático relaxado são propostos dois métodos heurísticos, baseados no método simplex com geração de colunas, o qual permite resolver problemas de otimização linear com um número grande de variáveis, pois poucas colunas são armazenadas e as demais são consideradas implicitamente.

A Figura 5.2 mostra todos os passos, métodos e técnicas utilizados para resolver o problema acoplado de dimensionamento de lotes e corte de estoque na indústria de móveis, partindo do modelo matemático relaxado (5.1.1)-(5.1.10) até a obtenção de uma solução inteira. 


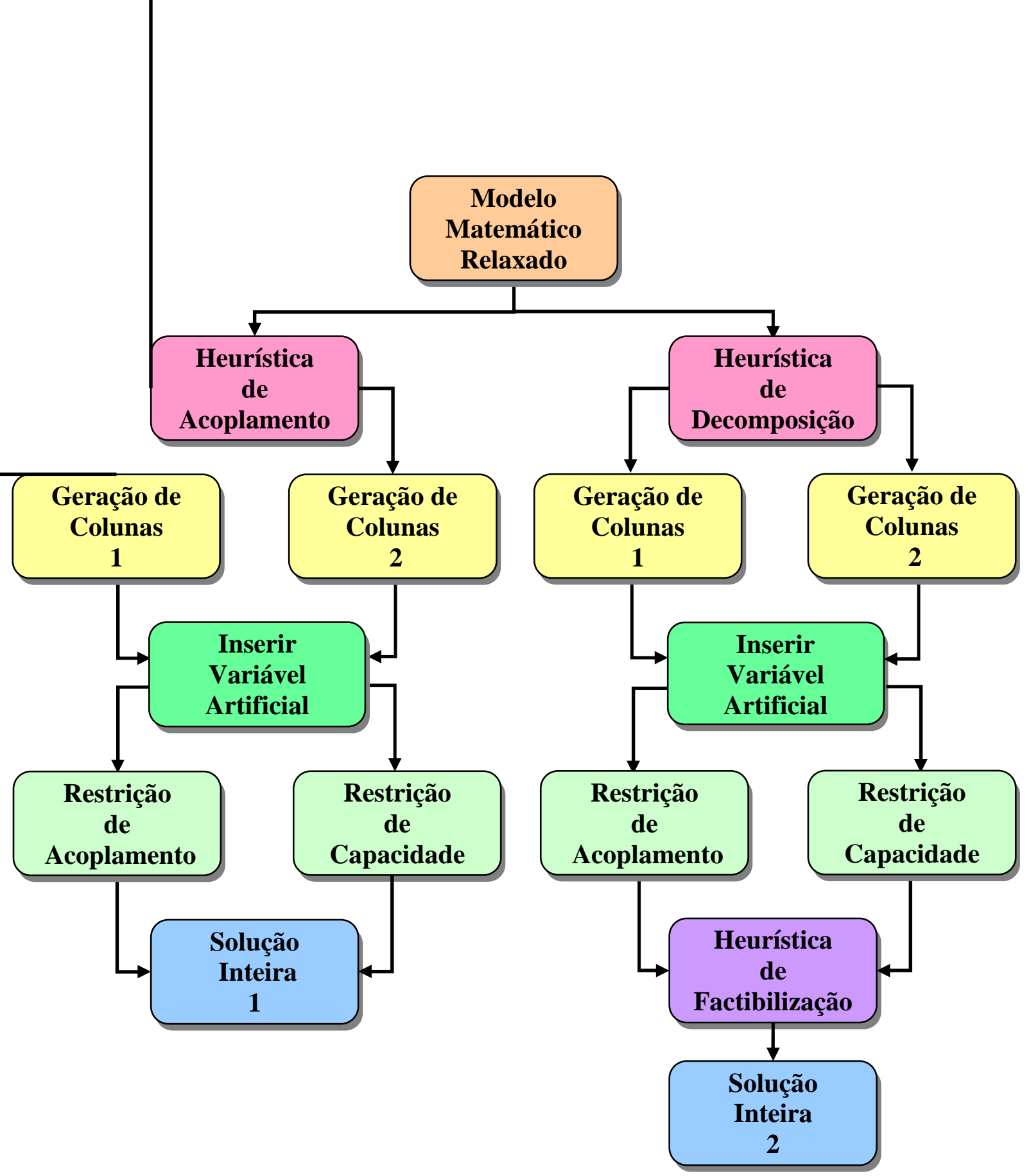

Figura 5.2: Possíveis sequiências para a resolução do problema acoplado.

Para resolver o modelo matemático de otimização linear (relaxado) são utilizadas a heurística de acoplamento, que resolve o modelo acoplado (5.1.1)-(5.1.10) e a heurística de decomposição, que separa o modelo acoplado em dois modelos menores, sendo um para o problema de dimensionamento de lotes e outro para o problema de corte de estoque e os resolve por um procedimento em 2-estágios. Ambas heurísticas são baseadas no método simplex com geração de colunas. Para determinar as novas colunas compostas por padrões de corte bidimensional e por tempos necessários para cortar e furar as peças obtidas em tais padrões são consideradas duas abordagens, que estão detalhadas na Seção 5.3.

Com o intuito de tratar possíveis infactibilidades dos problemas são acrescentadas variáveis artificiais em algumas restrições do modelo matemático relaxado, as quais permitem interpretar o quanto se tem de infactibilidade e o que representam na prática. Mais detalhes sobre isto são dados na Seção 5.4. 
$\mathrm{Na}$ heurística de decomposição, primeiramente, é resolvido o problema de dimensionamento de lotes, depois a solução do primeiro período é transformada em demandas de peças e, em seguida, o problema de corte de estoque é resolvido. Com este procedimento, pode acontecer do problema de corte de estoque ser infactível, devido à alta demanda de peças para o primeiro período determinada pelo problema de dimensionamento de lotes. Neste caso, uma heurística de factibilização é aplicada para tratar a infactibilidade.

Com a aplicação das heurísticas de acoplamento e de decomposição obtemos soluções factíveis para o problema acoplado relaxado (problema de otimização linear), as quais são contínuas. Para determinar soluções inteiras para o problema são propostos dois procedimentos adaptados para ambas heurísticas de solução (acoplamento e decomposição).

Nas seções seguintes estão descritas as heurísticas de solução, abordagens de geração de colunas e todos os procedimentos desenvolvidos e utilizados para a resolução do problema acoplado de dimensionamento de lotes e corte de estoque na indústria de móveis.

\subsection{Heurísticas de solução}

As duas heurísticas apresentadas nesta seção foram desenvolvidas para obter uma solução do problema acoplado simplificado, que consiste em um problema de otimização linear com um número grande de variáveis (milhares). Nestas heurísticas, o método primal simplex com a técnica de geração de colunas (descrito em detalhes no Capítulo 3 Seção 3.2.3.2) é usado para resolver os problemas de otimização linear. A cada iteração de ambas heurísticas, novos padrões de corte bidimensional são gerados ao resolver diversos subproblemas de corte bidimensional para construir novas colunas que poderão ser inseridas no problema.

\subsubsection{Heurística de acoplamento}

A heurística de acoplamento consiste em resolver os problemas de dimensionamento de lotes e corte de estoque juntos aplicando o método simplex com geração de colunas ao modelo matemático (5.1.1)-(5.1.10). Em cada iteração desta heurística é resolvido um problema mestre restrito contendo apenas alguns dos padrões de corte e vários subproblemas de corte para gerar novos padrões de corte bidimensional guilhotinado 2-estágios exatos irrestritos $^{11}$, os quais irão compor novas colunas candidatas a serem inseridas no problema mestre. Ao resolver o problema mestre, o vetor multiplicador simplex $\pi$ é obtido, o qual fará parte da função objetivo do problema de corte (subproblema) resolvido para determinar um novo padrão de corte conforme 5.2.1.

O problema mestre restrito inicial é composto por somente padrões de corte bidimensional homogêneos. Os subproblemas resolvidos para obter novos padrões de corte para cada tipo de espessura e cada subperíodo, são problemas de corte bidimensional guilhotinado 2-estágios exatos irrestritos (PCE_Bi) com a seguinte forma:

\footnotetext{
${ }^{11}$ Padrão de corte é dito irrestrito quando não há limitação no número de itens que podem compor o padrão de corte.
} 


$$
\begin{aligned}
& g\left(a_{\tau}^{e}\right)=\operatorname{Max} \sum_{p=1}^{P^{e}}\left(c p^{e} l_{p} w_{p}+\pi_{(M T+M+2 T-2+p)}+b_{p}^{e} \pi_{(M T+M+2 T-2+P+\Theta+\tau)}\right) \cdot a_{p \tau}^{e} \\
& \text { s.a. } \quad\left(\begin{array}{c}
a_{1 \tau}^{e} \\
\vdots \\
a_{P^{e} \tau}^{e}
\end{array}\right): \begin{array}{l}
\text { padrão de corte bidimensional guilhotinado 2-estágios } \\
\text { exato para a placa } L x W \text { de espessura } e .
\end{array}
\end{aligned}
$$

em que $(M T+M+2 T-2+p)$ é a posição da coordenada do vetor $\pi$ referente a peça do tipo $p$ e $(M T+M+2 T-2+P+\Theta+\tau)$ é a posição da coordenada do vetor $\pi$ referente ao tempo de furar as peças que compõe o padrão de corte no subperíodo $\tau$.

$\mathrm{O}$ algoritmo, a seguir, descreve todos os passos da heurística de acoplamento.

\section{Algoritmo}

\section{1. $\{$ Inicialização $\}$}

Construa o problema mestre restrito inicial contendo somente padrões de corte bidimensional guilhotinado 2-estágios exatos homogêneos, sendo um para cada tipo de peça, cada espessura e por subperíodo.

Faça: Pare $=$ Falso .

2. $\{$ Passo principal $\}$

Enquanto Pare = Falso faça:

2.1 Resolva o problema mestre restrito e obtenha a solução ótima dual.

2.2 Para $e=1, \ldots, S$ e $\tau=1, \ldots, \Theta$

Resolva o problema de corte (5.2.1) e calcule o custo relativo das novas colunas candidatas a serem inseridas no modelo (5.1.1)-(5.1.10) da seguinte forma:

$$
\begin{aligned}
& \hat{c} r_{\tau}^{e}=c r_{\tau}^{e}-\pi^{\mathrm{T}} \bar{a}_{\tau}^{e}= \\
& =c p^{e} \cdot L \cdot W-v^{e} \pi_{(P+\tau)}-\sum_{p=1}^{P^{e}}\left(c p^{e} l_{p} w_{p}+\pi_{(M T+M+2 T-2+p)}+b_{p}^{e} \pi_{(M T+M+2 T-2+P+\Theta+\tau)}\right) \cdot a_{p \tau}^{e} .
\end{aligned}
$$

2.3 Teste de otimalidade $\}$

Se todos os custos relativos das novas colunas são não negativos, a solução atual é ótima para a relaxação linear do problema, então Pare $=$ Verdadeiro.

Senão, construa as novas colunas para o modelo (5.1.1)-(5.1.10) com custo relativo negativo e adicione-as ao problema mestre (aumentando seu número de variáveis) e volte ao Passo 2.1. 


\section{Observações}

1. No Passo 2.2 do algoritmo, é usada a abordagem descrita na Seção 3.2.3.4 para obter os novos padrões de corte bidimensional guilhotinado 2-estágios exatos irrestritos.

2. Para a construção de novas colunas para o modelo (5.1.1)-(5.1.10) no Passo 2.3, exemplificamos a seguir:

Suponha que no Passo 2.2, o problema (5.2.1) tenha sido resolvido para o subperíodo 1 e espessura 2, resultando no padrão de corte:

$$
a_{1}^{2}=\left(\begin{array}{llll}
a_{11}^{2} & a_{21}^{2} & \ldots & a_{P^{2} 1}^{2}
\end{array}\right)^{\mathrm{T}}
$$

com custo relativo negativo, ou seja,

$$
\hat{c} r_{1}^{2}=c p^{2} \cdot L \cdot W-v^{2} \pi_{(P+1)}-\sum_{p=1}^{P^{1}}\left(c p^{2} l_{p} w_{p}+\pi_{(M T+M+2 T-2+p)}+b_{p}^{2} \pi_{(M T+M+2 T-2+P+\Theta+1)}\right) \cdot a_{p 1}^{2}<0 \text {. }
$$

A coluna correspondente a este padrão de corte é a seguinte:

$$
\begin{aligned}
& \begin{array}{lllllllll}
M T & M & T-1 & T-1 & P^{1} & P^{2} & P^{S} & \Theta & \Theta
\end{array}
\end{aligned}
$$

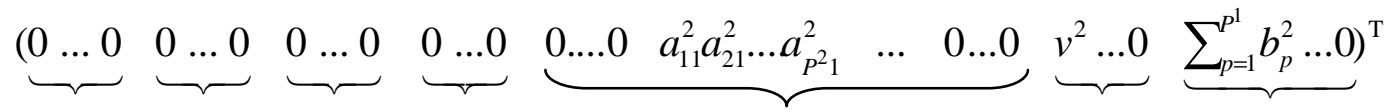

$$
\begin{aligned}
& \text { (5.1.2) (5.1.3) (5.1.4) (5.1.5) }
\end{aligned}
$$

\subsubsection{Heurística de decomposição}

A heurística de decomposição, como o próprio nome diz, consiste em: decompor o problema acoplado em dois subproblemas (dimensionamento de lotes com múltiplos itens e capacitado e corte de estoque bidimensional), resolver primeiro o problema de dimensionamento de lotes (PDL_R), em seguida, calcular a demanda de peças necessária para a produção do primeiro período do horizonte de planejamento determinada ao resolver o PDL_R e, finalmente, resolver o problema de corte bidimensional (PCE_Bi). Caso o problema de corte seja infactível, a produção do primeiro período do dimensionamento de lotes é modificada até que a infactibilidade do corte desapareça. Para isto, é aplicada a heurística de factibilização descrita na Seção 5.5.

A seguir, estão os modelos matemáticos dos dois subproblemas: 


\section{Modelo matemático para o PDL_R}

$$
\begin{array}{lll}
\text { Min } & \sum_{i=1}^{M} \sum_{t=1}^{T}\left(c_{i t} x_{i t}+h_{i t} I_{i t}+f_{i t} E_{i t}\right) & \\
\text { s.a. } & x_{i t}+I_{i(t-1)}-I_{i t}=d_{i t}+E_{i t}, & i=1, \ldots, M, \quad t=1, \ldots, T \\
& \sum_{t=1}^{T}\left(d_{i t}+E_{i t}\right)=D_{i}, & i=1, \ldots . M, \\
& \sum_{i=1}^{M} t c_{i} x_{i t} \leq \operatorname{CapS}_{t}, & t=1, \ldots, T, \quad e=1, \ldots, S \\
& \sum_{i=1}^{M} t f_{i} x_{i t} \leq \text {CapF}_{t}, & t=1, \ldots, T, \\
& x_{i t}, I_{i t}, E_{i t} \geq 0 \text { e inteiros, } & i=1, \ldots, M, \quad t=1, \ldots, T
\end{array}
$$

Observe que no modelo matemático (5.2.3)-(5.2.8) do PDL_R são acrescentadas as restrições de capacidade da serra e furadeira para o primeiro período do horizonte de planejamento, as quais são omitidas no modelo matemático acoplado, uma vez que, as restrições de capacidade da serra e furadeira em todos os subperíodos do primeiro período no problema de corte de estoque estão detalhadas em termos de variáveis de corte. Além disso, todas as variáveis de decisão do PDL_R são consideradas como inteiras. Isto é possível porque a dimensão de tais problemas é fixa e pequena (da ordem de centenas), permitindo obter uma solução exata para estes problemas com o auxílio de softwares de otimização, que os resolvem de maneira eficiente.

\section{Modelo matemático para o PCE_Bi}

$$
\begin{array}{lll}
\operatorname{Min} & \sum_{\tau=1}^{\Theta} \sum_{e=1}^{S} \sum_{j=1}^{N^{e}}\left(c p_{j}^{e} y_{j \tau}^{e}\right) & \\
\text { s.a. } & \sum_{j=1}^{N e} \sum_{\tau=1}^{\Theta} a_{p j \tau}^{e} y_{j \tau}^{e}=\sum_{i=1}^{M} r_{p i}^{e} x_{i 1}, \quad p=1, \ldots, P^{e}, e=1, \ldots, S \\
& \sum_{e=1}^{S} \sum_{j=1}^{N e} v_{j}^{e} y_{j \tau}^{e} \leq c a p S_{\tau}, & \tau=1, \ldots, \Theta \\
& \sum_{e=1}^{S} \sum_{j=1}^{N e} \sum_{p=1}^{N e} b_{p}^{e} a_{p j \tau}^{e} y_{j \tau}^{e} \leq c a p F_{\tau}, \quad \tau=1, \ldots, \Theta \\
& y_{j \tau}^{e} \geq 0, & j=1, \ldots, N^{e}, \quad \tau=1, \ldots, \Theta, e=1, \ldots, S
\end{array}
$$

No modelo matemático (5.2.9)-(5.2.13) do PCE_Bi a demanda de peças para o primeiro período do horizonte de planejamento, dada por: $\sum_{i=1}^{M} r_{p i}^{e} x_{i 1}$, é um parâmetro do problema calculado após a resolução do PDL_R. 


\section{Algoritmo}

1. $\{$ Inicialização $\}$

Construa o problema de dimensionamento de lotes e o problema de corte mestre restrito inicial contendo somente padrões de corte homogêneos, sendo um para cada tipo de peça, para cada espessura e por subperíodo.

Faça: Pare $=$ Falso .

2. $\{$ Passo principal $\}$

2.1 Resolva o PDL_R e obtenha $x_{i 1}, i=1, \ldots, M$.

Enquanto Pare $=$ Falso faça:

2.2 Determine a demanda de peças do primeiro período do horizonte de planejamento de acordo com a solução do PDL_R

2.3 Resolva o PCE_Bi usando o método simplex com geração de colunas, conforme a heurística de acoplamento descrita na seção anterior com as respectivas adaptações.

2.4 Se o PCE é factível Pare = Verdadeiro. (Uma solução para o problema acoplado relaxado foi obtida).

Senão, aplique uma heurística de factibilização.

Se a solução foi factibilizada, volte ao Passo 2.2.

Senão, Pare = Verdadeiro. (Não foi possível encontrar uma solução factível para o problema).

\section{Observações}

1. No Passo 2.2 do algoritmo, é utilizada a abordagem descrita na Seção 3.2.3.1 para gerar os novos padrões de corte bidimensional guilhotinado 2-estágios exatos irrestritos, os quais compõem as colunas a serem inseridas no problema de corte mestre.

2. Novamente considere o subperíodo 1 e a espessura 2. Uma nova coluna gerada para o problema de corte mestre pela heurística de decomposição tem a seguinte forma:

$$
\begin{array}{ccccc}
P^{1} & P^{2} & P^{S} & \Theta & \Theta \\
(\underbrace{0 \ldots 0} \quad a_{11}^{2} a_{21}^{2} \ldots a_{P^{2} 1}^{2} & \ldots & 0 \ldots 0 & \underbrace{v^{2} \ldots 0} \underbrace{\sum_{p=1}^{P^{1}} b_{p}^{2} \ldots 0})^{\mathrm{T}}
\end{array}
$$

3. No Passo 2.3, é aplicada a heurística de factibilização descrita na Seção 5.5. 


\subsection{Abordagens para geração de colunas}

Nesta seção, são propostas duas abordagens para determinar novas colunas candidatas a serem inseridas nos problemas mestres restritos tanto da heurística de acoplamento (no modelo matemático acoplado relaxado (5.1.1)-(5.1.10)) quanto da heurística de decomposição (no modelo matemático do problema PCE_Bi (5.2.9)-(5.2.13)), as quais diferem, basicamente, na resolução do subproblema (5.2.1).

\subsubsection{Abordagem 1}

Em cada iteração do passo principal da heurística de acoplamento aplicada ao modelo matemático acoplado (5.1.1)-(5.1.10) ou ao modelo matemático do PCE_Bi (5.2.9)-(5.2.13) é gerado um padrão de corte bidimensional guilhotinado 2-estágios exato irrestrito para cada espessura e cada subperíodo, resolvendo subproblemas de corte bidimensional na forma (5.2.1) pela abordagem descrita na Seção 3.2.3.1.

Uma nova coluna com cada padrão de corte e os respectivos tempos de serra e de furadeira deste padrão é criada conforme (5.2.2) ou (5.2.14).

Todas as colunas novas com custos relativos negativos são inseridas na matriz de restrições do modelo matemático do problema mestre restrito. O número total de padrões de corte gerados e o número máximo de colunas novas inseridas por iteração é $S \Theta$.

\subsubsection{Abordagem 2}

A idéia principal desta abordagem é construir, em cada iteração da heurística de acoplamento ou de decomposição, novas colunas para mais de um subperíodo utilizando um mesmo padrão de corte bidimensional. Com isso, a quantidade de subproblemas de corte bidimensional resolvidos por iteração pode diminuir.

Como o padrão de corte gerado para a placa de espessura $e$ é um padrão válido para a produção de peças de espessura $e$ para todos os demais subperíodos (naturalmente, pode não ser ótimo, pois a função objetivo depende dos subperíodos) então pode-se construir colunas para os demais subperíodos a partir do padrão de corte obtido para um subperíodo particular, conforme (5.2.2) ou (5.2.14). Se tais colunas (cada qual associada a um subperíodo) têm custos relativos negativos, então o subproblema de corte (5.2.1) não é resolvido e a solução aproximada, conforme descrita anteriormente, é adotada.

Veremos nos experimentos computacionais apresentados no Capítulo 6 que esta estratégia simples reduz o tempo de solução dos problemas. 


\subsection{Inserção de variáveis artificiais}

Antes de resolver os modelos matemáticos (5.1.1)-(5.1.10) e (5.2.9)-(5.2.13) são inseridas variáveis artificiais nas restrições de acoplamento (5.1.6) ou (5.2.10) e nas restrições de capacidade da serra (5.1.7) ou (5.2.11) e da furadeira (5.1.8) ou (5.2.12), referentes ao problema de corte de estoque bidimensional. Tais variáveis artificiais são penalizadas na função objetivo dos respectivos modelos por um valor suficientemente grande.

No caso da heurística de acoplamento, as variáveis artificiais positivas indicam que o problema original é infactível, pois o modelo (5.1.1)-(5.1.10) é uma relaxação do problema original. Entretanto, a heurística de decomposição usa a estratégia relaxa-e-fixa, de modo que as restrições de corte são relaxadas e as variáveis de produção fixadas de forma gulosa. Caso o problema (5.2.9)-(5.2.13) não seja factível (variáveis artificiais positivas), as variáveis de produção são alteradas heuristicamente (Seção 5.5) e, assim, não é possível afirmar que variáveis artificiais positivas indicam infactibilidade do problema. Os experimentos computacionais revelam que, para os dados utilizados, sempre foi possível factibilizar uma determinada solução quando o problema era factível.

Dependendo do tipo de restrição em que as variáveis artificiais são incorporadas temse uma interpretação para a infactibilidade do problema:

- Variáveis artificiais nas restrições de acoplamento com valores positivos significam que o total de peças cortadas em todos os subperíodos do primeiro período não são suficientes para compor os produtos que devem ser manufaturados no primeiro período do horizonte de planejamento.

- Variáveis artificiais nas restrições de capacidade da serra ou da furadeira com valores positivos nos subperíodos do primeiro período do horizonte de planejamento mostram que o tempo disponível da serra ou da furadeira por subperiodo não é suficiente para cortar ou furar o total de peças requeridas no primeiro período do horizonte.

\subsection{Heurística de factibilização para a heurística de decomposição}

A heurística de factibilização proposta para tratar a infactibilidade do problema de corte bidimensional quando a heurística de decomposição é aplicada, consiste em: classificar os produtos demandados utilizando algum critério previamente determinado (por exemplo, uma análise das variáveis duais) e reduzir a produção do primeiro período de tais produtos, conforme tal classificação, até eliminar totalmente a infactibilidade do problema de corte, se possível.

Para reduzir a produção do período 1, primeiro olhamos para as variáveis de oportunidade $E_{i l}$, uma vez que a demanda extra pode ser produzida em qualquer período do horizonte de planejamento e depois para as variáveis de estoque $I_{i 1}$.

O algoritmo apresentado, a seguir, descreve todos os passos realizados nesta heurística de factibilização quando as variáveis artificiais são inseridas nas restrições de acoplamento do problema relaxado. 
Seja $x_{p}^{a}$ a variável artificial na restrição de acoplamento referente à peça do tipo $p$.

A classificação dos produtos é feita analisando as variáveis duais e identificando o que acontecerá com o valor da função objetivo ao reduzir em uma unidade a fabricação do produto do tipo $i$ no período 1 . Para isto, é calculada uma estimativa $\left(\delta_{i}\right)$ da redução para cada tipo de produto, em termos das peças, da seguinte forma:

$$
\delta_{i}=\sum_{e=1}^{S} \sum_{p=1}^{p^{e}} \pi_{p}^{e} r_{p i}^{e}, \text { para } i=1, \ldots, M
$$

\section{Algoritmo}

1. $\{$ Inicialização $\}$

\{Classificar os produtos de acordo com as variáveis duais\}

Calcule $\delta_{i}$ para $i=1, \ldots, M$ e ordene-os forma que: $\delta_{1} \leq \delta_{2} \leq \ldots . \leq \delta_{M}$.

Faça: $k=1$ e Pare $=$ Falso.

\{Calcular a infactibilidade inicial do problema $\}$

Calcule: infac $=\sum_{p=1}^{P} x_{p}^{a}$

2. $\{$ Passo principal $\}$

Enquanto $(k \leq M)$ e $($ Pare $=$ Falso $)$

$\{$ Reduzir a produção de acordo com as variáveis $E$ \}

2.1 $\operatorname{Se}\left(E_{k 1}>0\right)$ faça:

$$
x_{k 1}=x_{k 1}-1 \text { e } E_{k 1}=E_{k 1}-1 \text {. }
$$

Recalcule a nova demanda de peças para o período 1 do horizonte de planejamento e resolva o novo problema PCE_Bi (5.2.9)-(5.2.13).

2.2 Se o problema de corte ainda é infactível

Determine a nova infactibilidade do problema: infac_nova $=\sum_{p=1}^{P} x_{p}^{a}$.

Estime $\lambda_{k}$ (quantidade do produto do tipo $k$ que ainda deve ser reduzida para eliminar infactibilidades), conforme:

$$
\lambda_{k}=\left\lceil\frac{\text { infac }}{\text { infac-infac_nova }}\right\rceil
$$


2.3 $\operatorname{Se}\left(E_{k 1} \geq \lambda_{k}\right)$ faça:

$\left\{\right.$ Reduzir $\lambda_{k}$ unidades de $x_{k 1}$ e $\left.E_{k 1}\right\}$

$x_{k 1}=x_{k 1}-\lambda_{k}$ e $E_{k 1}=E_{k 1}-\lambda_{k}$.

Pare $=$ Verdadeiro.$\{$ A infactibilidade já foi eliminada $\}$

Senão faça:

$\left\{\right.$ Reduzir $E_{k 1}$ unidades de $\left.x_{k 1}\right\}$

$x_{k 1}=x_{k 1}-E_{k 1}$ e $E_{k 1}=0$.

$k=k+1$.

3. Se $($ Pare $=$ Falso $)$ faça $k=1$

\{Não foi possível eliminar infactibilidades com a redução das variáveis E\}

Enquanto $(k \leq M)$ e $($ Pare $=$ Falso $)$

$\{$ Reduzir a produção de acordo com as variáveis I\}

3.1 Se $\left(I_{k 1}>0\right)$ faça:

$x_{k 1}=x_{k 1}-1$ e $I_{k 1}=I_{k 1}-1$.

Recalcule a nova demanda de peças para o período 1 do horizonte de planejamento e resolva o novo problema PCE_Bi (5.2.9)-(5.2.13).

3.2 Se o problema de corte é infactível

Determine a nova infactibilidade do problema: infac_nova $=\sum_{p=1}^{P} x_{p}^{a}$.

Estime $\lambda_{k}=\left\lceil\frac{\text { infac }}{\text { infac-infac_nova }}\right\rceil$.

3.3 Se $\left(I_{k 1} \geq \lambda_{k}\right)$ faça:

$\left\{\right.$ Reduzir $\lambda_{k}$ unidades de $x_{k 1}$ e $\left.I_{k 1}\right\}$

$x_{k 1}=x_{k 1}-\lambda_{k}$ e $I_{k 1}=I_{k 1}-\lambda_{k}$.

Pare $=$ Verdadeiro. $\{$ A infactibilidade já foi eliminada $\}$

Senão faça:

$\left\{\right.$ Reduzir $I_{k 1}$ unidades de $\left.x_{k 1}\right\}$

$x_{k 1}=x_{k 1}-I_{k 1}$ e $I_{k 1}=0$.

$k=k+1$.

4. Se $(k>M)$ e Pare $=$ Falso, não foi possível eliminar a infactibilidade do problema. 


\section{Observação}

Pequenas modificações são realizadas na heurística de factibilização para tratar a infactibilidade do problema de corte de estoque quando as variáveis artificiais são inseridas nas restrições de capacidade da serra e da furadeira nos subperíodos do primeiro período do horizonte de planejamento. Tais como:

- A infactibilidade do problema de corte é tratada separadamente para as restrições de capacidade da serra e da furadeira. Primeiro é tratada a infactibilidade da serra e depois da furadeira.

- A classificação dos produtos é feita em função do tempo usado para cortar as placas que compõem cada tipo de produto quando a infactibilidade da serra é tratada e em função do tempo usado para furar as peças que compõem cada tipo de produto quando a infactibilidade da furadeira é considerada. A ordenação dos produtos é feita em ordem crescente em ambos os casos.

\subsection{Solução Inteira}

Após aplicar as heurísticas de acoplamento ou de decomposição para resolver o modelo matemático relaxado (5.1.1)-(5.1.10), em ambos os casos, uma solução factível contínua para o problema acoplado da indústria de móveis é obtida. Para determinar uma solução inteira são propostos dois procedimentos adequados de acordo com a heurística de solução utilizada, os quais estão descritos nas seções seguintes.

\subsubsection{Solução inteira para heurística de decomposição}

$\mathrm{Na}$ heurística de decomposição, o problema de dimensionamento de lotes é resolvido como um problema inteiro e, portanto, suas variáveis já são valores inteiros. Para obter uma solução inteira para o problema de corte bidimensional é proposta uma heurística de arredondamento residual baseada na heurística residual gulosa proposta por Poldi e Arenales (2008) para problemas de corte estoque unidimensional. A heurística é aplicada no modelo matemático do problema de corte de estoque bidimensional (5.2.9)-(5.2.13) com variáveis de decisão não negativas e inteiras.

As heurísticas residuais para problemas de corte consistem em: resolver a relaxação linear do problema de corte residual, determinar uma solução inteira aproximada, atualizar a demanda de peças, resolver novamente a relaxação linear do novo problema de corte residual e, assim sucessivamente, até que a demanda residual seja nula.

Os problemas de corte de estoque residuais relaxados são resolvidos da mesma forma que os problemas de corte de estoque da heurística de decomposição usando o método simplex com geração de colunas.

Para gerar os padrões de corte bidimensional guilhotinado 2-estágios exatos restritos, que comporão as novas colunas candidatas a serem inseridas nos problemas mestres residuais, são resolvidos diversos subproblemas (problemas de corte bidimensionais restritos) utilizando uma abordagem grafo E/OU (Vianna (2000)) descrita em detalhes na Seção 5.6. 
Antes da descrição do algoritmo para obtenção de uma solução inteira factível para o problema de corte bidimensional da indústria de móveis considere as seguintes definições:

Definição: Seja $\bar{y}$ uma solução inteira aproximada para $y$. O vetor $\bar{r}$, cujas componentes são dadas por:

$$
\bar{r}_{p}=\sum_{i=1}^{M} r_{p i}^{e} x_{i 1}-\sum_{j=1}^{N^{e}} \sum_{\tau=1}^{\Theta} a_{p j \tau}^{e} \bar{y}_{j \tau}^{e}
$$

é chamado de vetor da demanda residual.

Os vetores $\bar{s}$ e $\bar{f}$, cujas componentes são calculadas, respectivamente, por:

$$
\bar{S}_{\tau}=c a p S_{\tau}-\sum_{e=1}^{S} \sum_{j=1}^{N^{e}} v_{j}^{e} \bar{y}_{j \tau}^{e} \text { e } \bar{f}_{\tau}=c a p F_{\tau}-\sum_{e=1}^{S} \sum_{j=1}^{N^{e}} \sum_{p=1}^{p^{e}} b_{p}^{e} a_{p j \tau}^{e} \bar{y}_{j \tau}^{e}
$$

são denominados vetores das disponibilidades de recursos para serra e furadeira.

\section{Algoritmo (Heurística residual de arredondamento gulosa)}

1. $\{$ Inicialização $\}$

1.1 Seja $n=P^{1}+\ldots+P^{S}+2 \Theta$ o número total de restrições do problema (5.2.9)-(5.2.13) Faça: $k=1$, e Pare $=$ Falso .

1.2 Calcule: $\bar{r}_{p}^{k}, \bar{s}_{\tau}^{k}$ e $\bar{f}_{\tau}^{k}$ usando a solução ótima do problema de corte de estoque bidimensional relaxado.

1.3 Gere um padrão de corte bidimensional homogêneo para cada tipo de peça, considerando que o número de peças do tipo $p$ é limitado por $\bar{r}_{p}^{k}$ e construa colunas para o problema de corte de estoque residual inicial.

Enquanto Pare $=$ Falso

2. $\{$ Solução ótima contínua $\}$

2.1 Resolva a relaxação linear do problema de corte de estoque residual usando o mesmo procedimento adotado na heurística de decomposição.

Para gerar novos padrões de corte bidimensional guilhotinado 2-estágios exatos restritos resolva os subproblemas restritos aplicando a abordagem grafo E/OU (veja Seção 5.6.3), pois as demandas residuais $\bar{r}_{p}^{k}$ podem ser pequenas. 
2.2 Seja $y^{k}$ a solução ótima contínua do problema de corte de estoque residual. Se $y^{k}$ for uma solução inteira, então Pare $=$ Verdadeiro.

Senão

3. $\{$ Solução inteira aproximada\}

Determine uma solução inteira aproximada $\bar{y}^{k}$ de $y^{k}$ da seguinte forma:

3.1 Ordene o vetor $y^{k}$ em ordem decrescente de forma que: $y_{1}^{k} \geq \ldots \geq y_{n}^{k}$.

Para $i=1, \ldots, n$

3.2 Faça: $\bar{y}_{i}^{k}=\left\lceil y_{i}^{k}\right\rceil$

3.3 Construa o vetor $\bar{y}^{k}=\left(\begin{array}{lllllll}\bar{y}_{1}^{k} & \bar{y}_{2}^{k} & \ldots & \bar{y}_{i}^{k} & 0 & \ldots & 0\end{array}\right)^{\mathrm{T}}$.

3.4 Calcule o novo vetor dos termos independentes do problema de corte de estoque residual.

3.5 Se alguma restrição do problema estiver violada faça: $\bar{y}_{i}^{k}=\bar{y}_{i}^{k}-1$. Repita este passo até que nenhuma restrição seja violada.

\section{4. $\{$ Atualização $\}$}

4.1 Atualize a demanda residual e as disponibilidades de recursos.

$$
\begin{aligned}
& \bar{r}_{p}^{k+1}=\bar{r}_{p}^{k}-\sum_{j=1}^{N^{e}} \sum_{\tau=1}^{\Theta} a_{p j \tau}^{e} \bar{y}_{j \tau}^{e} . \\
& \bar{s}_{\tau}^{k+1}=\bar{s}_{\tau}^{k}-\sum_{e=1}^{S} \sum_{j=1}^{N^{e}} v_{j}^{e} \bar{y}_{j \tau}^{e} . \\
& \bar{f}_{\tau}^{k+1}=\bar{f}_{\tau}^{k}-\sum_{e=1}^{S} \sum_{j=1}^{N^{e}} \sum_{p=1}^{P^{e}} b_{p}^{e} a_{p j \tau}^{e} \bar{y}_{j \tau}^{e} .
\end{aligned}
$$

4.2 Se $\bar{r}^{k+1}=0$ então Pare $=$ Verdadeiro. Uma solução inteira aproximada para o problema de corte de estoque (5.2.9)-(5.2.13) foi obtida $\left(\bar{y}^{k}\right)$.

\subsection{Senão,}

Se $\bar{s}_{\tau}^{k+1}=0$ ou $\bar{f}_{\tau}^{k+1}=0$ então Pare $=$ Verdadeiro. Problema infactível.

Senão, faça $k=k+1$, construa o novo problema de corte de estoque residual restrito composto somente por novos padrões de corte bidimensional guilhotinado 2-estágios exatos homogêneos e volte para o Passo 2. 


\subsubsection{Solução inteira para heurística de acoplamento}

Para obter uma solução inteira para o problema acoplado, após utilizar a heurística de acoplamento no modelo matemático relaxado (5.1.1)-(5.1.10), a heurística residual descrita na seção anterior é aplicada ao problema de corte de estoque residual obtido do problema acoplado relaxado, da seguinte forma:

\section{Passos}

1. Resolva o problema mestre restrito ótimo do modelo matemático do problema acoplado relaxado (5.1.1)-(5.1.10) como um problema inteiro misto fixando as variáveis do PDL_R como inteiras (as colunas das variáveis $y_{j \tau}^{e}$ são contínuas).

2. Armazene a solução inteira do PDL_R e remova as variáveis do PDL_R do modelo matemático relaxado (5.1.1)-(5.1.10).

3. Calcule a demanda de peças do primeiro período do horizonte de planejamento e resolva o problema de corte de estoque, conforme a heurística de decomposição e a heurística residual de arredondamento gulosa.

\subsubsection{Abordagem grafo E/OU para problema de corte bidimensional}

A abordagem grafo E/OU foi proposta por Morabito (1989) para resolver problemas de corte guilhotinado bidimensional irrestrito e não-estagiado. Morabito (1992) estendeu esta abordagem para problemas de corte guilhotinado irrestrito e restrito, considerando as dimensões unidimensional, bidimensional e tridimensional (Morabito e Arenales (1996)). Tal abordagem, também foi generalizada para problemas de corte diversos, incluindo cortes nãoguilhotinados (Arenales e Morabito (1995)) e estendida para diferentes processos de corte em Vianna (2000).

Um grafo E/OU pode ser definido para representar todos os possíveis padrões de corte, em que os nós representam retângulos (no caso do problema de corte bidimensional, com placa e peças retangulares) e os arcos representam cortes. Um arco (corte) estabelece uma relação entre um nó $\mathrm{N}$ do grafo (retângulo), com dois outros nós $\mathrm{N}_{1}$ e $\mathrm{N}_{2}$ (retângulos obtidos após o corte), portanto, um arco-E. Os nós $\mathrm{N}_{1}$ e $\mathrm{N}_{2}$ são chamados sucessores de $\mathrm{N}$ e o nó $\mathrm{N}$ é chamado de predecessor dos nós $\mathrm{N}_{1}$ e $\mathrm{N}_{2}$. Os padrões de corte são gerados examinando-se todas as possibilidades alternativas de corte (daí, arcos-OU) e uma delas é reproduzir o próprio retângulo $\mathrm{N}$ (chamado de corte-0), ao qual nenhum outro corte será feito, indicando o final do processo de corte.

Um corte-0 é representado por um arco ordinário (isto é, aponta para um único nó). $\mathrm{O}$ nó inicial é representado pela placa $(L x W)$ e os nós finais são aqueles originados de um corte0 (sem perda de generalidade, associam-se aos retângulos finais um ou mais itens idênticos). Sem perda de generalidade, os cortes (verticais ou horizontais) podem ser restritos a um conjunto finito, chamado de "conjunto de discretização", formado pelas combinações lineares não-negativas dos tamanhos dos itens (veja Herz (1972) e Morabito e Arenales (1995) para sua construção). A Figura 5.3 ilustra diversas sequiências de corte e, portanto, diversos padrões de corte. Por exemplo, três arcos-OU emergem da raiz, indicando alternativas 
diferentes para se obter três padrões de corte. Um padrão de corte é bem definido seguindo-se uma sequiência de arcos-E (cortes), a partir da raiz (placa inicial) até nós finais (nós após cortes-0). Esta sequiência é chamada de caminho completo e todo padrão de corte tem um caminho completo associado. Um mesmo nó pode pertencer a seqüências diferentes (isto é, retângulos de mesmos tamanhos podem ser obtidos por diferentes seqüências de corte), o que caracteriza um ciclo. O valor de utilidade do padrão de corte é a soma dos valores de utilidade dos nós finais do caminho completo associado.

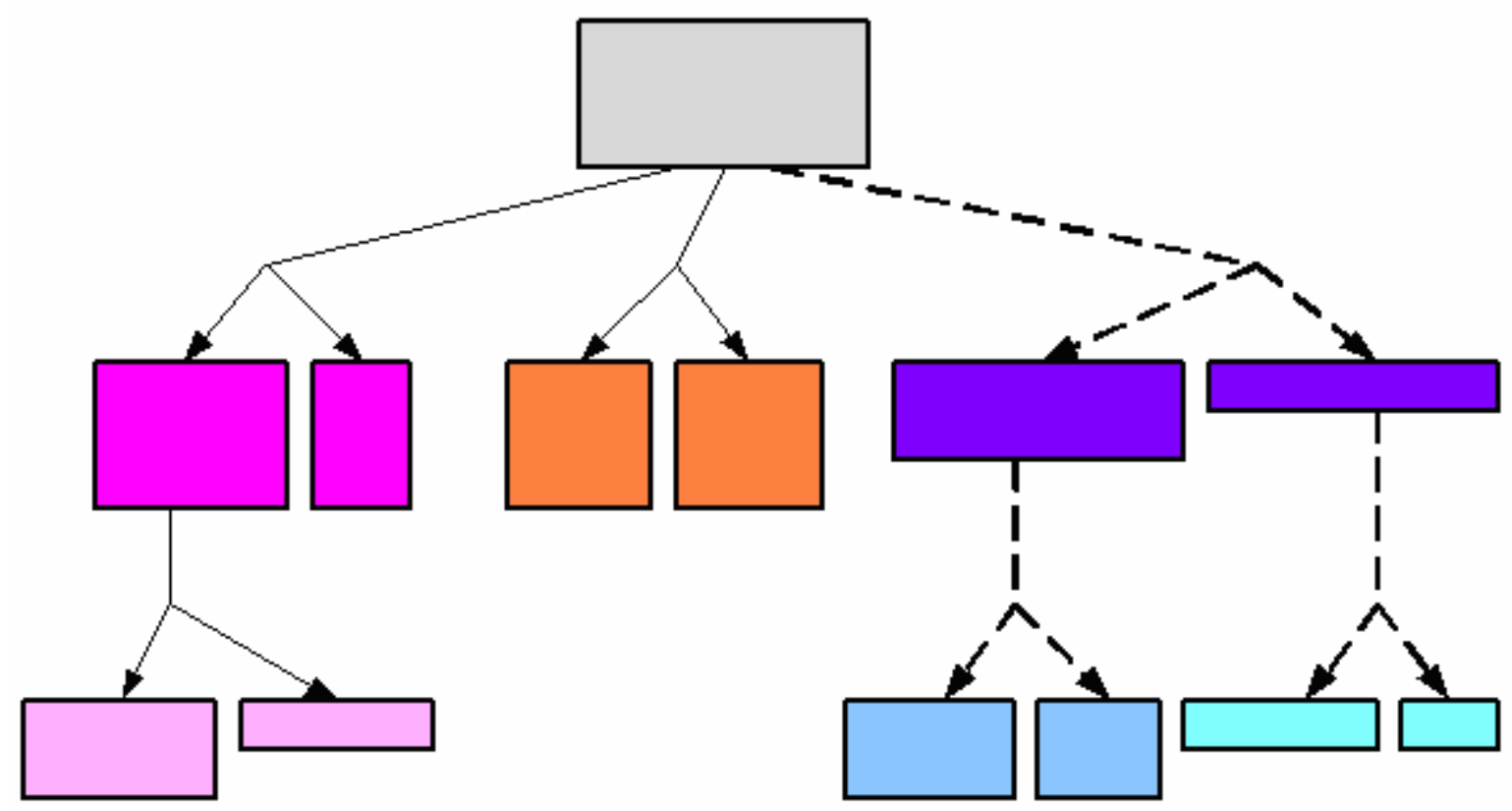

(a)

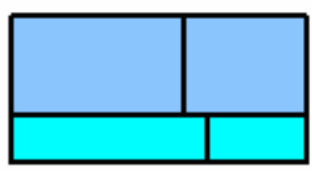

(b)

Figura 5.3: Grafo E/OU com um caminho destacado (a) e o padrão de corte correspondente (b).

O número de possíveis caminhos completos no grafo E/OU (ou seja, o número de padrões de corte) pode ser enorme e computacionalmente impraticável. No caso do problema restrito, a decisão de produzir um item tipo $i$ em um determinado nó do grafo E/OU depende da produção deste item nos demais nós do mesmo caminho. Isto aumenta consideravelmente a dificuldade de resolução e Morabito e Arenales (1996) propõem uma heurística simples para percorrer o grafo E/OU, que consiste em resolver o nó N1 e com a demanda residual resolver o nó N2, e vice-versa. Uma solução para o nó N é então obtida.

Para a resolução do problema de corte é utilizado um método de enumeração implícita, baseado em uma busca no grafo E/OU que descreve o espaço de soluções possíveis. A estratégia de busca combina busca em profundidade (backtracking) com busca informada (hill-climbing). Enumerar explicitamente todos os caminhos do grafo, durante o processo de busca, é, na maioria das vezes, inviável computacionalmente. Mas, as soluções podem ser 
enumeradas implicitamente, ou seja, é possível descartar a expansão de um nó sem perder a solução ótima, usando limitantes.

As duas estratégias de busca podem ser descritas da seguinte forma:

- Backtracking: é uma variação da estratégia de busca em profundidade, que consiste em ramificar os nós gerados mais recentemente.

- Hill-climbing: depois de expandir o nó até uma profundidade pré-determinada, o melhor caminho é escolhido e todos os nós finais, na profundidade pré-determinada, são expandidos. Os demais caminhos são descartados (otimização local).

O uso de limitante na profundidade e da estratégia hill-climbing levam a perda da otimalidade da solução na busca em grafo E/OU.

A seguir, é apresentado o algoritmo que combina as duas estratégias de busca backtracking e hill-climbing.

\section{Algoritmo: BT-HC (Morabito e Arenales, 1996)}

1. $\{$ Inicialização $\}$

Considere: a placa $(L x W)$, as peças $\left(l_{i} \times w_{i}\right), i=1, \ldots, P$ e $M P$ (profundidade máxima permitida na busca backtracking).

Considere o nó raiz como o nó que contém as informações da placa inicial.

\section{2. $\{$ Backtracking $\}$}

Aplique a busca backtracking com profundidade $M P$ a partir do nó raiz.

\section{3. $\{$ Hill-Climbing $\}$}

Selecione o caminho mais promissor (pode-se usar a soma das soluções homogêneas em cada nó final do caminho) e descarte os demais.

Para cada nó final do caminho gerado pela busca backtracking, verifique se é possível expandi-lo. Se for, retorne ao Passo 1, considerando cada um deles como nó raiz.

Na Seção 6.3.6 são apresentados os resultados dos experimentos computacionais feitos com a heurística residual de arredondamento gulosa (RAG) para obter uma solução inteira para o problema acoplado, a qual utiliza esta procedimento de grafo E/OU para gerar novos padrões de corte bidimensional guilhotinado 2-estágios exatos e restritos (a demanda dos itens é pequena e pode limitar a quantidade de itens no padrão). 


\section{Capítulo 6}

\section{Experimentos Computacionais}

Este capítulo contém uma série de experimentos computacionais realizados com os métodos heurísticos desenvolvidos e implementados para resolver o modelo matemático inteiro proposto para representar o problema acoplado de dimensionamento de lotes e corte de estoque da indústria de móveis e uma análise detalhada sobre os resultados obtidos nos testes. Os exemplares utilizados nos experimentos foram baseados em dados reais coletados em uma indústria de móveis de pequeno porte, os quais foram perturbados aleatoriamente.

A Seção 6.1 traz uma descrição dos parâmetros utilizados para gerar os dados. Na Seção 6.2, o gerador aleatório e as classes de exemplares criadas são apresentados. A Seção 6.3 traz os resultados e os comentários dos experimentos computacionais.

Os algoritmos foram implementados no sistema operacional Windows, em linguagem de programação C e os softwares CPLEX 10.0 e GLPK foram utilizados para resolver os problemas de otimização. Os testes foram realizados numa máquina com processador Pentium 4 de $3 \mathrm{GHz}$ e $2.0 \mathrm{~GB}$ de RAM.

A Figura 6.1 mostra a sequiência de passos realizados para resolver o problema acoplado, partindo do modelo de otimização relaxado até a obtenção de uma solução inteira. Os arcos que estão tracejados mostram alternativas que não foram realizadas.

\subsection{Descrição dos parâmetros}

Os parâmetros utilizados para gerar as classes de exemplares testadas nos experimentos computacionais são dados a seguir.

- Número de períodos: $T=4$.

- Número de subperíodos: $\Theta=5$. 


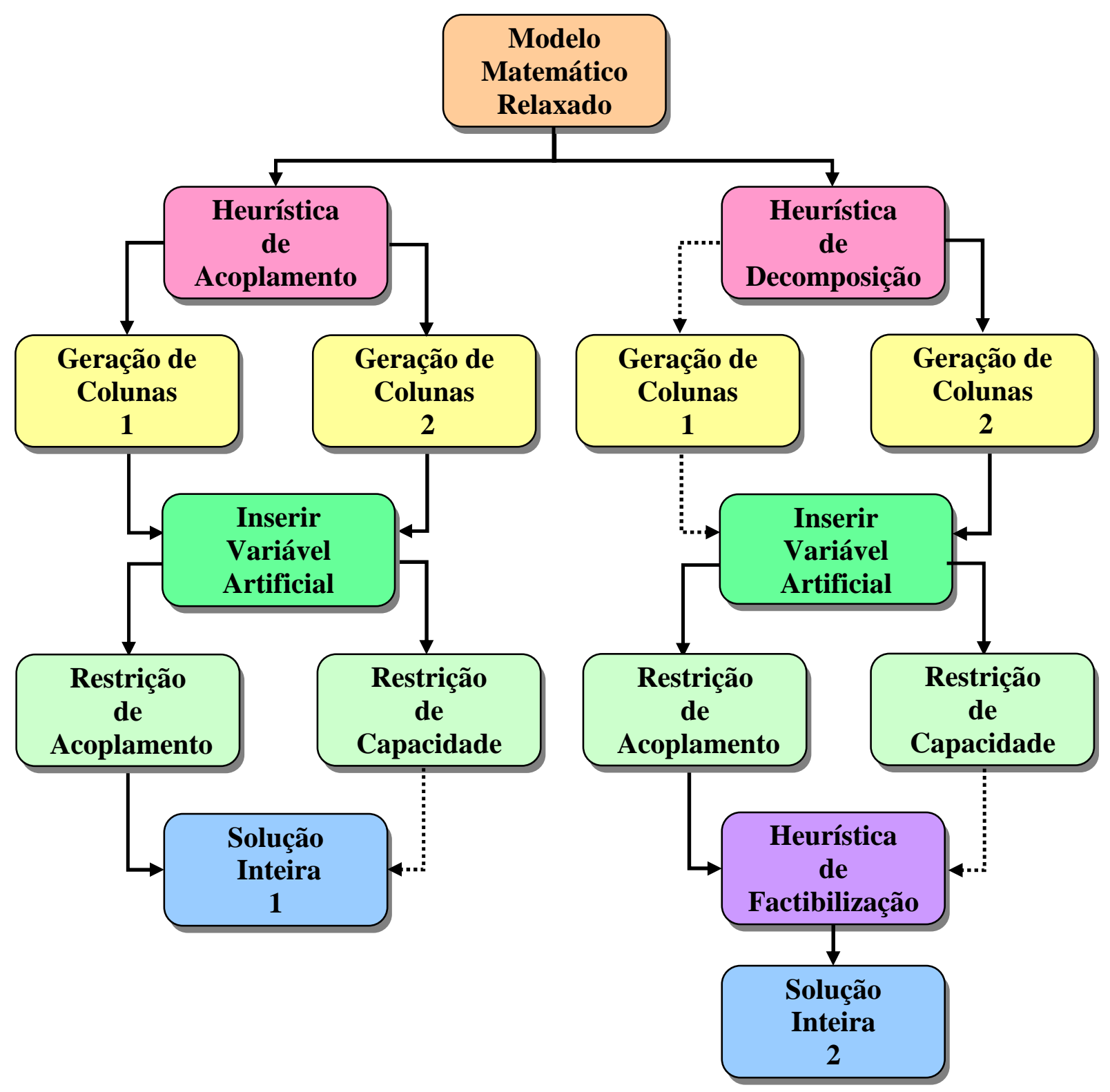

Figura 6.1: Possíveis seqüências para a resolução do modelo (4.5.1)-(4.5.12).

- Dimensões da placa: $L x W=2750 \mathrm{~mm} \times 1830 \mathrm{~mm}$.

- Número de tipos de espessuras: $S=6$.

- Espessuras das placas: $3 \mathrm{~mm}, 9 \mathrm{~mm}, 12 \mathrm{~mm}, 15 \mathrm{~mm}, 20 \mathrm{~mm}$ e $25 \mathrm{~mm}$.

- Números de tipos de produtos demandados: $M=4$

- Tipos de produtos finais: armário de 4 portas, armário de 5 portas, cômoda e criado (veja Figura 6.2). 


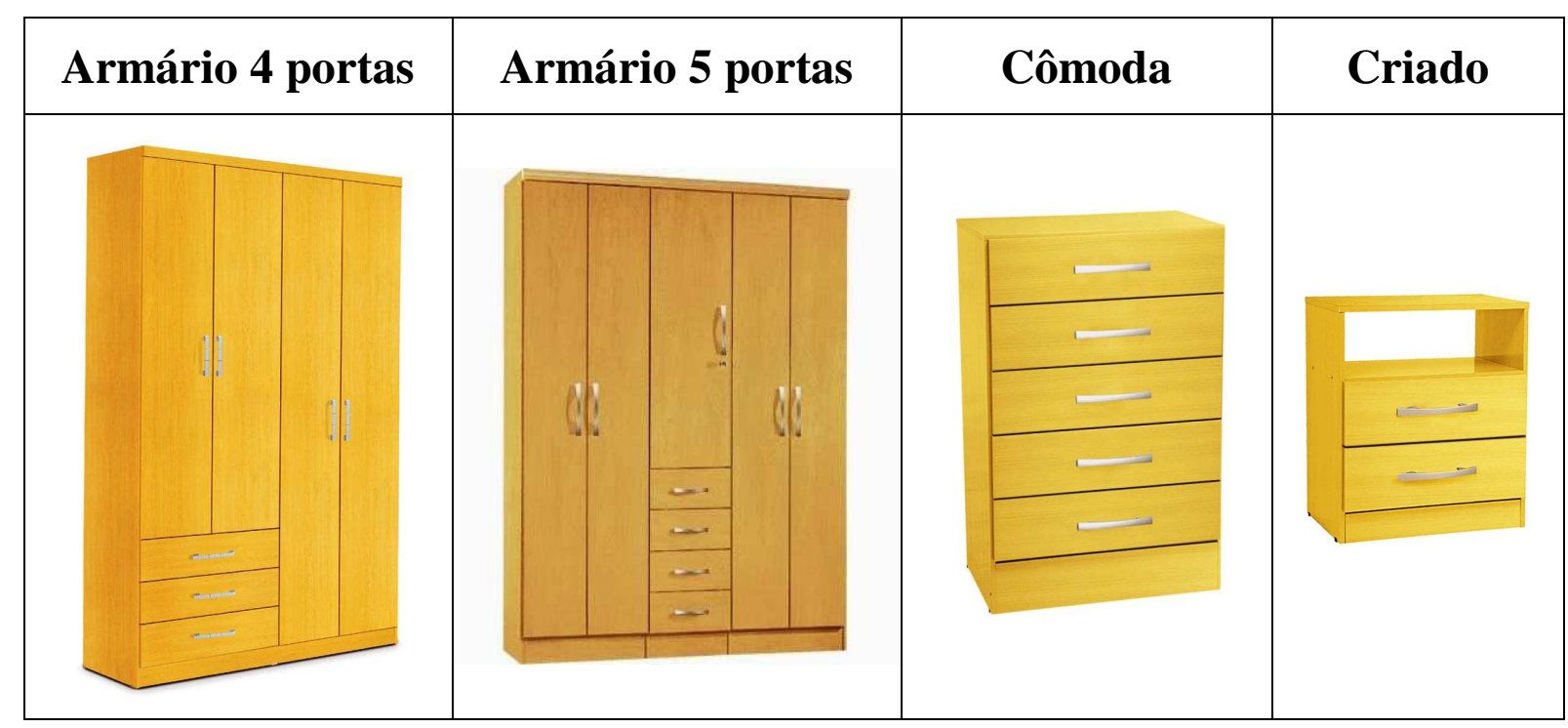

Figura 6.2: Tipos de produtos finais.

- Tempo para furar uma peça: 5 segundos para todos os tipos de peças.

- Tempo para cortar uma placa por espessura: varia no intervalo [24s; 242s].

- Número total de tipos de peças para todas as espessuras: $P=67$.

- Número de tipos de peças por espessura: $P^{1}=16, P^{2}=4, P^{3}=8, P^{4}=24, P^{5}=12, P^{6}=3$.

- Capacidades da serra e da furadeira por subperíodo: 25200 segundos.

- Capacidades da serra e da furadeira por período: 126000 segundos.

- Custos unitários das placas por espessura: Tabela 6.1.

- Quantidade máxima de placas cortadas juntas pela serra por espessura: Tabela 6.1.

\begin{tabular}{|c|c|c|c|c|c|c|}
\hline \multicolumn{7}{|c|}{ Custos e número de placas por espessura } \\
\hline & $\boldsymbol{e}=\mathbf{1}$ & $\boldsymbol{e}=\mathbf{2}$ & $\boldsymbol{e}=\mathbf{3}$ & $\boldsymbol{e}=\mathbf{4}$ & $\boldsymbol{e}=\mathbf{5}$ & $\boldsymbol{e}=\mathbf{6}$ \\
\hline $\boldsymbol{c p}_{\boldsymbol{e}}(\mathbf{R} \mathbf{\$})$ & 23,97 & 47,22 & 61,12 & 72,85 & 98,65 & 138,73 \\
\hline Número de placas & 20 & 6 & 5 & 4 & 3 & 2 \\
\hline
\end{tabular}

Tabela 6.1: Custos e número de placas cortadas juntas pela serra por espessura

- Largura $\left(l_{p}\right)$ e comprimento $\left(w_{p}\right)$ das peças e estrutura dos produtos: Tabela 6.2.

- Custos de fabricação por tipo de produto para o primeiro período $\left(c_{i 1}\right)$ : $\mathrm{R} \$ 259,95$, $\mathrm{R} \$ 212,55, \mathrm{R} \$ 62,67$ e $\mathrm{R} \$ 20,22$.

- Custos de fabricação por tipo de produto a partir do segundo período: $c_{i t}=(1+\gamma) \cdot c_{i 1}$, para $i=1, \ldots, M ; t=2, \ldots, T$ e $\gamma=0,05,0,1$ e 0,15 .

- Custos das variáveis de estoque $\left(I_{i t}\right)$ por tipo de produto e por período: $h_{i t}=h \cdot c_{i t}$, para $i=1, \ldots, M ; t=1, \ldots, T$ e $h=0,0001,0,001,0,01$ e 0,1 .

- Custos das variáveis de oportunidade $\left(E_{i t}\right)$ por tipo de produto e por período: $f_{i t}=\alpha \cdot h_{i t}$, para $i=1, \ldots, M ; t=1, \ldots, T$ e $\alpha=0,5,1$ e 1,5 . 


\begin{tabular}{|c|c|c|c|c|c|c|c|c|c|c|c|c|c|}
\hline \multicolumn{14}{|c|}{ Estrutura dos produtos $\left(r_{p i}^{e}\right)$ e Dimensões das peças } \\
\hline$p$ & $\begin{array}{c}l_{p} \\
(\mathbf{m m})\end{array}$ & $\begin{array}{c}w_{p} \\
(\mathrm{~mm})\end{array}$ & $i=1$ & $i=\mathbf{2}$ & $i=\mathbf{3}$ & $i=4$ & $p$ & $\begin{array}{c}l_{p} \\
(\mathrm{~mm})\end{array}$ & $\begin{array}{c}w_{p} \\
(\mathrm{~mm})\end{array}$ & $i=1$ & $i=\mathbf{2}$ & $i=\mathbf{3}$ & $i=4$ \\
\hline \multicolumn{14}{|c|}{$e=1(3 \mathrm{~mm})$} \\
\hline 1 & 2500 & 565 & 6 & 0 & 0 & 0 & 9 & 710 & 535 & 6 & 0 & 0 & 0 \\
\hline 2 & 647 & 453 & 4 & 0 & 0 & 0 & 10 & 1062 & 530 & 4 & 0 & 0 & 0 \\
\hline 3 & 710 & 454 & 2 & 0 & 6 & 0 & 11 & 388 & 377 & 2 & 0 & 6 & 0 \\
\hline 4 & 454 & 454 & 2 & 2 & 0 & 0 & 12 & 410 & 383 & 2 & 2 & 0 & 0 \\
\hline 5 & 1080 & 454 & 5 & 1 & 0 & 0 & 13 & 445 & 213 & 5 & 1 & 0 & 0 \\
\hline 6 & 530 & 454 & 5 & 4 & 0 & 0 & 14 & 2000 & 565 & 5 & 4 & 0 & 0 \\
\hline 7 & 1050 & 500 & 1 & 4 & 0 & 0 & 15 & 647 & 454 & 1 & 4 & 0 & 0 \\
\hline 8 & 483 & 215 & 2 & 0 & 0 & 0 & 16 & 428 & 454 & 2 & 0 & 0 & 0 \\
\hline \multicolumn{14}{|c|}{$e=2(9 \mathrm{~mm})$} \\
\hline 1 & 510 & 450 & 1 & 1 & 0 & 0 & $\mathbf{3}$ & 433 & 50 & 0 & 0 & 2 & 0 \\
\hline 2 & 630 & 50 & 0 & 0 & 3 & 0 & 4 & 295 & 50 & 0 & 0 & 3 & 0 \\
\hline \multicolumn{14}{|c|}{$e=3(12 \mathrm{~mm})$} \\
\hline 1 & 454 & 180 & 8 & 8 & 6 & 0 & 5 & 454 & 135 & 0 & 0 & 4 & 0 \\
\hline 2 & 635 & 180 & 4 & 4 & 3 & 0 & 6 & 635 & 135 & 0 & 0 & 2 & 0 \\
\hline 3 & 440 & 65 & 0 & 0 & 2 & 0 & 7 & 390 & 110 & 0 & 0 & 0 & 6 \\
\hline 4 & 635 & 50 & 0 & 0 & 1 & 0 & 8 & 370 & 110 & 0 & 0 & 0 & 3 \\
\hline \multicolumn{14}{|c|}{$e=4(15 \mathrm{~mm})$} \\
\hline 1 & 1049 & 452 & 5 & 0 & 0 & 0 & 13 & 1047 & 450 & 0 & 4 & 0 & 0 \\
\hline 2 & 499 & 452 & 5 & 0 & 0 & 0 & 14 & 700 & 200 & 0 & 4 & 0 & 0 \\
\hline 3 & 452 & 429 & 2 & 0 & 0 & 0 & 15 & 490 & 60 & 0 & 2 & 0 & 0 \\
\hline 4 & 1050 & 535 & 2 & 0 & 0 & 0 & 16 & 1060 & 60 & 0 & 1 & 0 & 0 \\
\hline 5 & 535 & 500 & 2 & 0 & 0 & 0 & 17 & 440 & 60 & 0 & 4 & 0 & 0 \\
\hline 6 & 535 & 430 & 2 & 0 & 0 & 0 & 18 & 510 & 60 & 0 & 1 & 0 & 0 \\
\hline 7 & 700 & 212 & 4 & 0 & 0 & 0 & 19 & 970 & 570 & 0 & 0 & 2 & 0 \\
\hline 8 & 1050 & 535 & 0 & 2 & 0 & 0 & 20 & 700 & 75 & 0 & 0 & 1 & 0 \\
\hline 9 & 430 & 535 & 0 & 2 & 0 & 0 & 21 & 700 & 212 & 0 & 0 & 3 & 0 \\
\hline 10 & 500 & 535 & 0 & 2 & 0 & 0 & 22 & 700 & 163 & 0 & 0 & 2 & 0 \\
\hline 11 & 497 & 450 & 0 & 4 & 0 & 0 & 23 & 600 & 440 & 0 & 0 & 0 & 2 \\
\hline 12 & 497 & 450 & 0 & 1 & 0 & 0 & 24 & 450 & 132 & 0 & 0 & 0 & 3 \\
\hline \multicolumn{14}{|c|}{$e=5(20 \mathrm{~mm})$} \\
\hline 1 & 2500 & 60 & 12 & 0 & 0 & 0 & 7 & 430 & 60 & 3 & 0 & 0 & 0 \\
\hline 2 & 445 & 60 & 12 & 0 & 0 & 0 & 8 & 440 & 60 & 4 & 0 & 0 & 0 \\
\hline 3 & 445 & 40 & 26 & 0 & 0 & 0 & 9 & 1060 & 60 & 2 & 0 & 0 & 0 \\
\hline 4 & 490 & 60 & 1 & 0 & 0 & 0 & 10 & 2000 & 60 & 0 & 12 & 0 & 0 \\
\hline 5 & 500 & 60 & 3 & 3 & 0 & 0 & 11 & 444 & 40 & 0 & 22 & 0 & 0 \\
\hline 6 & 1050 & 60 & 5 & 3 & 0 & 0 & 12 & 444 & 60 & 0 & 12 & 0 & 0 \\
\hline \multicolumn{14}{|c|}{$e=6(25 \mathrm{~mm})$} \\
\hline 1 & 430 & 60 & 2 & 0 & 0 & 0 & 3 & 1050 & 60 & 4 & 2 & 0 & 0 \\
\hline 2 & 500 & 60 & 4 & 2 & 0 & 0 & & & & & & & \\
\hline
\end{tabular}

Tabela 6.2: Dimensões das peças e estrutura dos produtos finais por espessura

- Tipos de demanda: baixa, média e alta.

As demandas dos tipos baixa e alta referem-se às carteiras de pedidos dos meses de abril de 2007 e dezembro de 2006, respectivamente, da indústria de móveis em que estes dados foram coletados. A demanda média é a média aritmética das demandas baixa e alta com os valores arredondados para cima. A Tabela 6.3 traz os valores da demanda em carteira por período e por produto e da demanda esperada para todos os tipos de produtos. 


\begin{tabular}{|c|c|c|c|c|c|c|c|c|c|c|c|c|c|c|c|}
\hline & \multicolumn{5}{|c|}{ Baixa } & \multicolumn{5}{|c|}{ Média } & \multicolumn{5}{|c|}{ Alta } \\
\hline & \multicolumn{4}{|c|}{$d_{i t}$} & \multirow{2}{*}{$D_{i}$} & \multicolumn{4}{|c|}{$d_{i t}$} & \multirow{2}{*}{$D_{i}$} & \multicolumn{4}{|c|}{$d_{i t}$} & \multirow{2}{*}{$D_{i}$} \\
\hline & $t=1$ & $t=2$ & $t=3$ & $t=4$ & & $t=1$ & $t=2$ & $t=3$ & $t=4$ & & $t=1$ & $t=2$ & $t=3$ & $t=4$ & \\
\hline$i=1$ & 8 & 31 & 28 & 40 & 147 & 18 & 65 & 24 & 24 & 171 & 27 & 98 & 19 & 7 & 191 \\
\hline$i=2$ & 13 & 38 & 43 & 65 & 199 & 48 & 77 & 38 & 35 & 238 & 82 & 115 & 32 & 4 & 273 \\
\hline$i=3$ & 2 & 3 & 19 & 13 & 137 & 41 & 18 & 12 & 7 & 178 & 80 & 32 & 5 & 1 & 218 \\
\hline$i=4$ & 2 & 0 & 0 & 0 & 32 & 44 & 36 & 10 & 4 & 124 & 85 & 71 & 19 & 7 & 212 \\
\hline
\end{tabular}

Tabela 6.3: Demandas em carteira e esperada dos produtos no horizonte de planejamento

\section{Observações}

- Os valores utilizados para as capacidades das máquinas representam os tempos de máquinas disponíveis por período e subperíodo, considerando que os tempos de preparação das máquinas (serra e furadeira) estão descontados.

- O tempo para cortar uma placa por espessura foi calculado dividindo o tempo médio do ciclo da serra (aproximadamente 540 segundos) pelo número de placas cortadas juntas. Naturalmente, este tempo depende das peças cortadas e do desenho do padrão de corte.

- O custo de produção para o período 1 por tipo de produto é calculado em termos do número de placas necessário para compor uma unidade desse tipo de produto, ou seja,

$$
c_{i 1}=\sum_{e=1}^{S} \frac{c p^{e}}{L \cdot W}\left(\sum_{p=1}^{p e} r_{p i}^{e} \cdot l_{p} \cdot w_{p}\right), \text { para } i=1, \ldots, 4 .
$$

- O valor do custo de produção a partir do segundo período é acrescido em função de $\gamma$, para representar uma estimativa da perda que, provavelmente, ocorrerá no processo de corte.

- O parâmetro $h$ usado no cálculo dos custos de estoque deve variar de acordo com a importância a ser dada ao estoque.

- Uma outra opção para determinar os custos das variáveis de oportunidade é considerar o tempo que a produção da demanda extra ficará em estoque, por exemplo:

$$
\left\{\begin{array}{l}
f_{i t}=\sum_{\rho=1}^{T-1} h_{i \rho} \rho^{-1} \\
f_{i T}=0
\end{array} \text { para } i=1, \ldots, 4 .\right.
$$

No pior caso, a produção extra fica em estoque até o período final e $f_{i t}=\sum_{\rho=1}^{T-1} h_{i \rho}$.

\subsection{Gerador Aleatório}

Utilizando os dados apresentados na seção anterior, para a realização dos testes computacionais são criadas 108 classes de problemas acoplados combinando os seguintes parâmetros: tipo de demanda, $h$ (custo da variável de estoque), $\alpha$ (custo da variável de oportunidade) e $\gamma$ (custo de produção a partir do segundo período).

Para cada classe foram gerados aleatoriamente 20 exemplares variando alguns parâmetros, como por exemplo, o tempo para cortar um determinado padrão, o tempo para furar as peças cortadas em um padrão, entre outros. A formação de cada classe está detalhada na Tabela 6.4. 


\begin{tabular}{|c|c|c|c|c|c|c|c|c|c|c|c|c|c|}
\hline \multicolumn{14}{|c|}{ Classes de problemas } \\
\hline \multirow{2}{*}{ Demanda } & \multirow{2}{*}{$\boldsymbol{h}$} & \multirow{2}{*}{ Classe } & \multicolumn{3}{|c|}{$\gamma=\mathbf{0 , 0 5}$} & \multirow{2}{*}{ Classe } & \multicolumn{3}{|c|}{$\gamma=0,1$} & \multirow{2}{*}{ Classe } & \multicolumn{3}{|c|}{$\gamma=0,15$} \\
\hline & & & $\alpha=\mathbf{0 , 5}$ & $\alpha=1$ & $\alpha=1,5$ & & $\alpha=0,5$ & $\alpha=1$ & $\alpha=1,5$ & & $\alpha=0,5$ & $\alpha=1$ & $\alpha=1,5$ \\
\hline \multirow{12}{*}{ Baixa } & 0,0001 & 1 & $\mathrm{X}$ & & & 37 & $\mathrm{X}$ & & & 73 & $\mathrm{X}$ & & \\
\hline & 0,001 & 2 & $\mathrm{X}$ & & & 38 & $\mathrm{X}$ & & & 74 & $\mathrm{X}$ & & \\
\hline & $\mathbf{0 , 0 1}$ & 3 & $\mathrm{X}$ & & & 39 & $\mathrm{X}$ & & & 75 & $\mathrm{X}$ & & \\
\hline & 0,1 & 4 & $\mathrm{X}$ & & & 40 & $\mathrm{X}$ & & & 76 & $\mathrm{X}$ & & \\
\hline & 0,0001 & 5 & & $\mathrm{X}$ & & 41 & & $\mathrm{X}$ & & 77 & & $\mathrm{X}$ & \\
\hline & 0,001 & 6 & & $\mathrm{X}$ & & 42 & & $\mathrm{X}$ & & 78 & & $\mathrm{X}$ & \\
\hline & $\mathbf{0 , 0 1}$ & 7 & & $\mathrm{X}$ & & 43 & & $\mathrm{X}$ & & 79 & & $\mathrm{X}$ & \\
\hline & 0,1 & 8 & & $\mathrm{X}$ & & 44 & & $\mathrm{X}$ & & 80 & & $\mathrm{X}$ & \\
\hline & 0,0001 & 9 & & & $\mathrm{X}$ & 45 & & & $\mathrm{X}$ & 81 & & & $\mathrm{X}$ \\
\hline & 0,001 & 10 & & & $X$ & 46 & & & $\mathrm{X}$ & 82 & & & $X$ \\
\hline & $\mathbf{0 , 0 1}$ & 11 & & & $\mathrm{X}$ & 47 & & & $\mathrm{X}$ & 83 & & & $X$ \\
\hline & 0,1 & 12 & & & $\mathrm{X}$ & 48 & & & $\mathrm{X}$ & 84 & & & $X$ \\
\hline \multirow{12}{*}{ Média } & 0,0001 & 13 & $\mathrm{X}$ & & & 49 & $\mathrm{X}$ & & & 85 & $\mathrm{X}$ & & \\
\hline & 0,001 & 14 & $\mathrm{X}$ & & & 50 & $X$ & & & 86 & $\mathrm{X}$ & & \\
\hline & 0,01 & 15 & $\mathrm{X}$ & & & 51 & $\mathrm{X}$ & & & 87 & $\mathrm{X}$ & & \\
\hline & 0,1 & 16 & $\mathrm{X}$ & & & 52 & $\mathrm{X}$ & & & 88 & $\mathrm{X}$ & & \\
\hline & 0,0001 & 17 & & $\mathrm{X}$ & & 53 & & $\mathrm{X}$ & & 89 & & $\mathrm{X}$ & \\
\hline & $\mathbf{0 , 0 0 1}$ & 18 & & $\mathrm{X}$ & & 54 & & $\mathrm{X}$ & & 90 & & $X$ & \\
\hline & $\mathbf{0 , 0 1}$ & 19 & & $X$ & & 55 & & $\mathrm{X}$ & & 91 & & $X$ & \\
\hline & 0,1 & 20 & & $\mathrm{X}$ & & 56 & & $\mathrm{X}$ & & 92 & & $\mathrm{X}$ & \\
\hline & 0,0001 & 21 & & & $\mathrm{X}$ & 57 & & & $\mathrm{X}$ & 93 & & & $\mathrm{X}$ \\
\hline & 0,001 & 22 & & & $\mathrm{X}$ & 58 & & & $\mathrm{X}$ & 94 & & & $\mathrm{X}$ \\
\hline & $\mathbf{0 , 0 1}$ & 23 & & & $\mathrm{X}$ & 59 & & & $\mathrm{X}$ & 95 & & & $X$ \\
\hline & 0,1 & 24 & & & $\mathrm{X}$ & 60 & & & $X$ & 96 & & & $X$ \\
\hline \multirow{12}{*}{ Alta } & 0,0001 & 25 & $\mathrm{X}$ & & & 61 & $\mathrm{X}$ & & & 97 & $\mathrm{X}$ & & \\
\hline & $\mathbf{0 , 0 0 1}$ & 26 & $\mathrm{X}$ & & & 62 & $\mathrm{X}$ & & & 98 & $\mathrm{X}$ & & \\
\hline & $\mathbf{0 , 0 1}$ & 27 & $\mathrm{X}$ & & & 63 & $X$ & & & 99 & $X$ & & \\
\hline & $\mathbf{0 , 1}$ & 28 & $\mathrm{X}$ & & & 64 & $X$ & & & 100 & $\mathrm{X}$ & & \\
\hline & 0,0001 & 29 & & $\mathrm{X}$ & & 65 & & $\mathrm{X}$ & & 101 & & $\mathrm{X}$ & \\
\hline & $\mathbf{0 , 0 0 1}$ & 30 & & $\mathrm{X}$ & & 66 & & $X$ & & 102 & & $\mathrm{X}$ & \\
\hline & $\mathbf{0 , 0 1}$ & 31 & & $X$ & & 67 & & $X$ & & 103 & & $\mathrm{X}$ & \\
\hline & $\mathbf{0 , 1}$ & 32 & & $X$ & & 68 & & $X$ & & 104 & & $\mathrm{X}$ & \\
\hline & 0,0001 & 33 & & & $\mathrm{X}$ & 69 & & & $\mathrm{X}$ & 105 & & & $\mathrm{X}$ \\
\hline & $\mathbf{0 , 0 0 1}$ & 34 & & & $\mathrm{X}$ & 70 & & & $\mathrm{X}$ & 106 & & & $\mathrm{X}$ \\
\hline & $\mathbf{0 , 0 1}$ & 35 & & & $\mathrm{X}$ & 71 & & & $X$ & 107 & & & $\mathrm{X}$ \\
\hline & 0,1 & 36 & & & $\mathrm{X}$ & 72 & & & $\mathrm{X}$ & 108 & & & $\mathrm{X}$ \\
\hline
\end{tabular}

Tabela 6.4: Formação das classes de problemas testadas 


\subsection{Resultados Computacionais}

Os resultados obtidos são apresentados em várias seções, cada qual com um objetivo específico. Porém, o objetivo principal ao realizar os testes é identificar as vantagens e desvantagens de cada uma das heurísticas de solução propostas e verificar se os objetivos deste trabalho foram alcançados.

\subsubsection{Abordagens 1 e 2 para gerar novas colunas}

Os primeiros experimentos computacionais foram realizados com o intuito de comparar as duas abordagens (A1 e A2) propostas na Seção 5.3 para obter novas colunas candidatas a serem inseridas nos problemas mestres restritos do modelo de otimização relaxado. Foram resolvidas as 108 classes de exemplares pela heurística de acoplamento (HA) com variáveis artificiais inseridas nas restrições de acoplamento. Os resultados destes testes são os valores médios de cada classe, agrupados conforme o tipo de demanda e apresentados nas Tabelas 6.5, 6.6 e 6.7 para as demandas baixa, média e alta, respectivamente.

A coluna Classe mostra o número da classe. Embora para cada classe já estejam fixados os parâmetros $\alpha, h$ e $\gamma$, especificamos novamente para evidenciar os efeitos sobre as abordagens. A coluna Tempo contém o tempo total médio de resolução em segundos por exemplar para cada classe e cada abordagem. A coluna Iterações fornece o número total médio de iterações (com os valores arredondados), por exemplar, realizadas para encontrar a solução ótima dos problemas relaxados de todas as classes.

Analisando os resultados apresentados nas Tabelas 6.5, 6.6 e 6.7, podemos dizer que, o tempo total médio de resolução, por exemplar de cada classe, foi menor utilizando a abordagem A2 em todas as classes para as demandas baixa, média e alta. No pior caso, a abordagem A2 é aproximadamente $23 \%$ mais rápida, no melhor caso é $51 \%$ mais rápida e em média, esta abordagem é $37 \%$ mais rápida.

Em relação ao número de iterações, os resultados foram muito próximos, porém a abordagem A2 apresentou resultados melhores ou iguais que a abordagem A1, na maioria das classes para todos os tipos de demanda, principalmente, para a demanda baixa. A abordagem 2 chegou a fazer $16 \%$ menos de iterações em alguns casos.

Com estes experimentos, ficou claro que a abordagem 2 para geração de novas colunas para o problema mestre restrito é a mais eficiente e mesmo quando faz mais iterações que a abordagem 1, ainda é mais rápida. Sendo assim, a partir de agora, somente esta abordagem é utilizada nos experimentos.

Não fizemos testes com a heurística de decomposição porque a estrutura dos problemas de corte que são resolvidos e, consequentemente, das colunas novas a serem geradas é a mesma do problema acoplado resolvido pela heurística de acoplamento. 


\begin{tabular}{|c|c|c|c|c|c|c|c|}
\hline \multicolumn{8}{|c|}{ Abordagens para gerar novas colunas - Demanda Baixa } \\
\hline \multirow{2}{*}{ Classes } & \multirow{2}{*}{$\alpha$} & \multirow{2}{*}{$h$} & \multirow{2}{*}{$\gamma$} & \multicolumn{2}{|c|}{ Tempo (s) } & \multicolumn{2}{|c|}{ Iterações } \\
\hline & & & & A1 & A2 & A1 & A2 \\
\hline 1 & \multirow{4}{*}{0,5} & $\mathbf{0 , 0 0 0 1}$ & \multirow{4}{*}{$\mathbf{0 , 0 5}$} & 66,19 & 35,33 & 67 & 56 \\
\hline 2 & & $\mathbf{0 , 0 0 1}$ & & 67,17 & 35,38 & 67 & 56 \\
\hline 3 & & $\mathbf{0 , 0 1}$ & & 66,30 & 35,39 & 67 & 56 \\
\hline 4 & & $\mathbf{0 , 1}$ & & 72,81 & 39,34 & 72 & 62 \\
\hline 5 & \multirow{4}{*}{1} & 0,0001 & \multirow{4}{*}{0,05} & 64,78 & 34,55 & 67 & 56 \\
\hline 6 & & 0,001 & & 64,02 & 34,14 & 67 & 56 \\
\hline 7 & & $\mathbf{0 , 0 1}$ & & 65,30 & 35,16 & 67 & 56 \\
\hline 8 & & $\mathbf{0 , 1}$ & & 72,06 & 38,91 & 72 & 62 \\
\hline 9 & \multirow{4}{*}{1,5} & 0,0001 & \multirow{4}{*}{0,05} & 66,36 & 38,91 & 67 & 56 \\
\hline 10 & & 0,001 & & 66,61 & 35,23 & 67 & 56 \\
\hline 11 & & $\mathbf{0 , 0 1}$ & & 67,39 & 35,83 & 67 & 56 \\
\hline 12 & & 0,1 & & 72,53 & 40,31 & 72 & 62 \\
\hline 37 & \multirow{4}{*}{0,5} & 0,0001 & \multirow{4}{*}{0,1} & 46,58 & 30,81 & 51 & 51 \\
\hline 38 & & 0,001 & & 46,05 & 30,63 & 51 & 51 \\
\hline 39 & & 0,01 & & 45,75 & 30,81 & 51 & 51 \\
\hline 40 & & 0,1 & & 46,67 & 31,33 & 52 & 52 \\
\hline 41 & \multirow{4}{*}{1} & 0,0001 & \multirow{4}{*}{0,1} & 47,38 & 31,34 & 52 & 52 \\
\hline 42 & & 0,001 & & 46,92 & 29,44 & 51 & 51 \\
\hline 43 & & $\mathbf{0 , 0 1}$ & & 47,11 & 29,67 & 51 & 51 \\
\hline 44 & & 0,1 & & 47,55 & 30,22 & 52 & 52 \\
\hline 45 & \multirow{4}{*}{1,5} & 0,0001 & \multirow{4}{*}{0,1} & 47,86 & 30,03 & 51 & 51 \\
\hline 46 & & 0,001 & & 47,34 & 29,34 & 51 & 51 \\
\hline 47 & & 0,01 & & 45,83 & 29,19 & 51 & 51 \\
\hline 48 & & 0,1 & & 46,81 & $\mathbf{3 0 , 0 3}$ & 52 & 52 \\
\hline 73 & \multirow{4}{*}{0,5} & 0,0001 & \multirow{4}{*}{0,15} & 60,36 & 40,00 & 66 & 64 \\
\hline 74 & & $\mathbf{0 , 0 0 1}$ & & 60,78 & 42,25 & 66 & 64 \\
\hline 75 & & 0,01 & & 65,67 & 45,11 & 69 & 67 \\
\hline 76 & & 0,1 & & 65,58 & 46,41 & 69 & 70 \\
\hline 77 & \multirow{4}{*}{1} & 0,0001 & \multirow{4}{*}{0,15} & 60,91 & 41,73 & 65 & 64 \\
\hline 78 & & 0,001 & & 62,11 & 41,53 & 66 & 64 \\
\hline 79 & & $\mathbf{0 , 0 1}$ & & 65,50 & 42,64 & 70 & 66 \\
\hline 80 & & $\mathbf{0 , 1}$ & & 63,27 & 44,20 & 69 & 69 \\
\hline 81 & \multirow{4}{*}{1,5} & 0,0001 & \multirow{4}{*}{0,15} & 60,34 & 40,06 & 66 & 64 \\
\hline 82 & & 0,001 & & 61,34 & 39,70 & 66 & 64 \\
\hline 83 & & 0,01 & & 61,92 & 40,98 & 66 & 66 \\
\hline 84 & & 0,1 & & 65,86 & 44,17 & 69 & 70 \\
\hline
\end{tabular}

Tabela 6.5: Comparação do tempo total médio de resolução e número de iterações para demanda baixa 


\begin{tabular}{|c|c|c|c|c|c|c|c|}
\hline \multicolumn{8}{|c|}{ Abordagens para gerar novas colunas - Demanda Média } \\
\hline \multirow{2}{*}{ Classes } & \multirow{2}{*}{$\alpha$} & \multirow{2}{*}{$\boldsymbol{h}$} & \multirow{2}{*}{$\gamma$} & \multicolumn{2}{|c|}{ Tempo (s) } & \multicolumn{2}{|c|}{ Iterações } \\
\hline & & & & A1 & A2 & A1 & A2 \\
\hline 13 & \multirow{4}{*}{0,5} & $\mathbf{0 , 0 0 0 1}$ & \multirow{4}{*}{$\mathbf{0 , 0 5}$} & 78,38 & 49,77 & 73 & 76 \\
\hline 14 & & $\mathbf{0 , 0 0 1}$ & & 78,66 & 47,72 & 73 & 72 \\
\hline 15 & & $\mathbf{0 , 0 1}$ & & 81,80 & $\mathbf{5 1 , 1 7}$ & 76 & 75 \\
\hline 16 & & $\mathbf{0 , 1}$ & & 73,58 & 46,61 & 71 & 67 \\
\hline 17 & \multirow{4}{*}{1} & 0,0001 & \multirow{4}{*}{0,05} & 76,31 & 51,11 & 73 & 75 \\
\hline 18 & & $\mathbf{0 , 0 0 1}$ & & 77,81 & 51,33 & 73 & 76 \\
\hline 19 & & $\mathbf{0 , 0 1}$ & & 78,92 & 49,63 & 72 & 74 \\
\hline 20 & & 0,1 & & 79,81 & 49,05 & 72 & 71 \\
\hline 21 & \multirow{4}{*}{1,5} & 0,0001 & \multirow{4}{*}{0,05} & 77,77 & 50,95 & 72 & 75 \\
\hline 22 & & $\mathbf{0 , 0 0 1}$ & & 81,66 & 49,91 & 76 & 73 \\
\hline 23 & & 0,01 & & 81,06 & 52,92 & 76 & 76 \\
\hline 24 & & $\mathbf{0 , 1}$ & & 74,16 & 51,20 & 71 & 71 \\
\hline 49 & \multirow{4}{*}{0,5} & 0,0001 & \multirow{4}{*}{0,1} & 60,81 & 36,81 & 64 & 60 \\
\hline 50 & & $\mathbf{0 , 0 0 1}$ & & 61,27 & 36,92 & 64 & 60 \\
\hline 51 & & $\mathbf{0 , 0 1}$ & & 70,56 & 43,03 & 69 & 63 \\
\hline 52 & & 0,1 & & 58,19 & 36,77 & 58 & 57 \\
\hline 53 & \multirow{4}{*}{1} & 0,0001 & \multirow{4}{*}{$\mathbf{0 , 1}$} & 59,92 & 37,58 & 62 & 60 \\
\hline 54 & & $\mathbf{0 , 0 0 1}$ & & 63,14 & 37,17 & 64 & 60 \\
\hline 55 & & $\mathbf{0 , 0 1}$ & & 60,17 & 41,98 & 59 & 63 \\
\hline 56 & & 0,1 & & 58,80 & 32,47 & 58 & 52 \\
\hline 57 & \multirow{4}{*}{1,5} & 0,0001 & \multirow{4}{*}{0,1} & 58,47 & 37,13 & 62 & 60 \\
\hline 58 & & 0,001 & & 63,53 & 36,98 & 65 & 60 \\
\hline 59 & & $\mathbf{0 , 0 1}$ & & 70,36 & 41,03 & 69 & 63 \\
\hline 60 & & $\mathbf{0 , 1}$ & & 57,98 & 31,95 & 58 & 52 \\
\hline 85 & \multirow{4}{*}{0,5} & 0,0001 & \multirow{4}{*}{0,15} & 67,33 & 38,38 & 68 & 60 \\
\hline 86 & & $\mathbf{0 , 0 0 1}$ & & 55,25 & 44,02 & 59 & 67 \\
\hline 87 & & $\mathbf{0 , 0 1}$ & & 63,84 & 44,06 & 67 & 67 \\
\hline 88 & & 0,1 & & 63,39 & 36,48 & 63 & 55 \\
\hline 89 & \multirow{4}{*}{1} & 0,0001 & \multirow{4}{*}{0,15} & 67,05 & 42,44 & 70 & 64 \\
\hline 90 & & $\mathbf{0 , 0 0 1}$ & & 57,19 & 44,27 & 60 & 67 \\
\hline 91 & & $\mathbf{0 , 0 1}$ & & 64,64 & 44,66 & 67 & 67 \\
\hline 92 & & 0,1 & & 61,38 & 35,72 & 60 & 55 \\
\hline 93 & \multirow{4}{*}{1,5} & 0,0001 & \multirow{4}{*}{0,15} & 64,77 & 45,95 & 67 & 70 \\
\hline 94 & & $\mathbf{0 , 0 0 1}$ & & 64,59 & 42,81 & 67 & 67 \\
\hline 95 & & $\mathbf{0 , 0 1}$ & & 54,16 & 41,95 & 59 & 67 \\
\hline 96 & & 0,1 & & 65,23 & 34,83 & 64 & 55 \\
\hline
\end{tabular}

Tabela 6.6: Comparação do tempo total médio de resolução e número de iterações para demanda média 


\begin{tabular}{|c|c|c|c|c|c|c|c|}
\hline \multicolumn{8}{|c|}{ Abordagens para gerar novas colunas - Demanda Alta } \\
\hline \multirow{2}{*}{ Classes } & \multirow{2}{*}{$\alpha$} & \multirow{2}{*}{$\boldsymbol{h}$} & \multirow{2}{*}{$\gamma$} & \multicolumn{2}{|c|}{ Tempo (s) } & \multicolumn{2}{|c|}{ Iterações } \\
\hline & & & & A1 & A2 & A1 & A2 \\
\hline 25 & \multirow{4}{*}{0,5} & 0,0001 & \multirow{4}{*}{$\mathbf{0 , 0 5}$} & 42,64 & 26,86 & 72 & 67 \\
\hline 26 & & $\mathbf{0 , 0 0 1}$ & & 41,92 & 28,88 & 72 & 68 \\
\hline 27 & & $\mathbf{0 , 0 1}$ & & 42,28 & 28,52 & 72 & 72 \\
\hline 28 & & $\mathbf{0 , 1}$ & & 37,44 & 27,28 & 65 & 69 \\
\hline 29 & \multirow{4}{*}{1} & 0,0001 & \multirow{4}{*}{0,05} & 42,03 & 27,94 & 72 & 72 \\
\hline 30 & & $\mathbf{0 , 0 0 1}$ & & 48,42 & 28,55 & 70 & 72 \\
\hline 31 & & $\mathbf{0 , 0 1}$ & & 57,56 & 28,08 & 71 & 71 \\
\hline 32 & & $\mathbf{0 , 1}$ & & 62,45 & $\mathbf{3 0 , 3 0}$ & 68 & 69 \\
\hline 33 & \multirow{4}{*}{1,5} & 0,0001 & \multirow{4}{*}{0,05} & 70,39 & 35,63 & 72 & 70 \\
\hline 34 & & $\mathbf{0 , 0 0 1}$ & & 73,31 & 42,61 & 72 & 74 \\
\hline 35 & & $\mathbf{0 , 0 1}$ & & 74,16 & 44,59 & 70 & 71 \\
\hline 36 & & 0,1 & & 73,48 & 45,83 & 68 & 69 \\
\hline 61 & \multirow{4}{*}{0,5} & 0,0001 & \multirow{4}{*}{0,1} & 77,53 & 47,58 & 71 & 69 \\
\hline 62 & & $\mathbf{0 , 0 0 1}$ & & 79,66 & 52,00 & 72 & 72 \\
\hline 63 & & 0,01 & & 72,98 & 51,17 & 66 & 71 \\
\hline 64 & & 0,1 & & 71,66 & 46,63 & 66 & 66 \\
\hline 65 & \multirow{4}{*}{1} & 0,0001 & \multirow{4}{*}{0,1} & 76,75 & 48,80 & 72 & 68 \\
\hline 66 & & $\mathbf{0 , 0 0 1}$ & & 76,19 & 53,30 & 72 & 72 \\
\hline 67 & & $\mathbf{0 , 0 1}$ & & 88,38 & 53,02 & 81 & 72 \\
\hline 68 & & 0,1 & & 85,08 & 47,23 & 76 & 66 \\
\hline 69 & \multirow{4}{*}{1,5} & 0,0001 & \multirow{4}{*}{0,1} & 77,70 & 52,22 & 71 & 72 \\
\hline 70 & & $\mathbf{0 , 0 0 1}$ & & 79,27 & 43,63 & 72 & 64 \\
\hline 71 & & 0,01 & & 75,97 & 51,20 & 71 & 72 \\
\hline 72 & & 0,1 & & 85,53 & 49,92 & 77 & 66 \\
\hline 97 & \multirow{4}{*}{0,5} & 0,0001 & \multirow{4}{*}{0,15} & 74,97 & 54,22 & 71 & 75 \\
\hline 98 & & $\mathbf{0 , 0 0 1}$ & & 77,55 & 51,20 & 72 & 72 \\
\hline 99 & & $\mathbf{0 , 0 1}$ & & 79,48 & 52,08 & 72 & 72 \\
\hline 100 & & 0,1 & & 73,16 & 59,70 & 66 & 76 \\
\hline 101 & \multirow{4}{*}{1} & 0,0001 & \multirow{4}{*}{0,15} & 78,52 & 46,61 & 72 & 64 \\
\hline 102 & & $\mathbf{0 , 0 0 1}$ & & 70,77 & 52,73 & 67 & 72 \\
\hline 103 & & $\mathbf{0 , 0 1}$ & & 75,67 & 51,50 & 72 & 72 \\
\hline 104 & & $\mathbf{0 , 1}$ & & 78,38 & 46,09 & 72 & 66 \\
\hline 105 & \multirow{4}{*}{1,5} & 0,0001 & \multirow{4}{*}{0,15} & 78,13 & 47,28 & 72 & 67 \\
\hline 106 & & 0,001 & & 77,78 & 50,25 & 72 & 72 \\
\hline 107 & & 0,01 & & 78,16 & 51,47 & 72 & 72 \\
\hline 108 & & 0,1 & & 78,88 & 54,66 & 71 & 74 \\
\hline
\end{tabular}

Tabela 6.7: Comparação do tempo total médio de resolução e número de iterações para demanda alta

\subsubsection{Variáveis artificiais nas restrições de acoplamento e de capacidade}

Nesta seção, são apresentados os resultados obtidos com o intuito de comparar e identificar as diferenças entre as soluções das heurísticas de acoplamento e de decomposição ao inserir variáveis artificiais nas restrições de acoplamento (VA) dos problemas de dimensionamento de lotes e corte de estoque e nas restrições de capacidade (VC) da serra e furadeira nos subperíodos do primeiro período.

Analisando as soluções das abordagens VA e VC para cada tipo de demanda (baixa, média e alta) apresentadas nas Tabelas 6.8 a 6.11 e Figuras 6.3 a 6.9, podemos dizer que o tempo total médio de resolução, por exemplar, foi menor quando as variáveis artificiais estão nas restrições de acoplamento em praticamente todas as classes resolvidas (exceto 3 das 108 
classes testadas) independente da heurística utilizada. Porém, a heurística de decomposição apresentou melhores tempos em aproximadamente $90 \%$ das classes.

O valor da função objetivo (FO) não se alterou ao inserir variáveis artificiais nas restrições de acoplamento ou nas restrições de capacidade para as duas heurísticas. Mas, a solução da heurística de acoplamento foi melhor que a solução da heurística de decomposição em todas as classes resolvidas. Ao aumentar os custos de estoque, o valor da função objetivo tem uma pequena variação como era de se esperar. A maior diferença obtida entre a heurística de decomposição e a heurística de acoplamento foi em torno de 3,8\% e o menor foi em torno de $0,07 \%$.

\begin{tabular}{|c|c|c|c|c|c|c|c|c|c|c|}
\hline \multicolumn{11}{|c|}{ Demanda baixa } \\
\hline \multirow{3}{*}{ Classe } & \multirow{3}{*}{$\alpha$} & \multirow{3}{*}{$\boldsymbol{h}$} & \multirow{3}{*}{$\gamma$} & \multicolumn{4}{|c|}{ Tempo (s) } & \multicolumn{2}{|c|}{ FO $(\mathbf{R} \$)$} & \multirow{3}{*}{$\begin{array}{c}\text { Desvio } \\
(\%)\end{array}$} \\
\hline & & & & \multicolumn{2}{|c|}{ HD } & \multicolumn{2}{|c|}{ HA } & \multirow{2}{*}{$\begin{array}{c}\text { HD } \\
\text { VA e VC }\end{array}$} & \multirow{2}{*}{$\begin{array}{c}\text { HA } \\
\text { VA e VC }\end{array}$} & \\
\hline & & & & VA & $\mathrm{VC}$ & VA & VC & & & \\
\hline 1 & \multirow{4}{*}{0,5} & 0,0001 & \multirow{4}{*}{$\mathbf{0 , 0 5}$} & 28,23 & 46,09 & 39,53 & 40,63 & 97070,02 & 94661,03 & 2,48 \\
\hline 2 & & $\mathbf{0 , 0 0 1}$ & & 30,06 & 38,09 & 39,45 & 40,80 & 97654,19 & 94672,74 & 3,05 \\
\hline 3 & & 0,01 & & 29,38 & 34,30 & 38,84 & 42,02 & 98556,08 & $\mathbf{9 4 7 8 9 , 8 2}$ & 3,82 \\
\hline 4 & & 0,1 & & 36,42 & 45,20 & 41,30 & 44,20 & 98480,04 & 95952,15 & 2,57 \\
\hline 5 & \multirow{4}{*}{1} & 0,0001 & \multirow{4}{*}{0,05} & 29,73 & 46,02 & 38,53 & 40,78 & 97071,32 & 94662,32 & 2,48 \\
\hline 6 & & $\mathbf{0 , 0 0 1}$ & & 30,95 & 38,53 & 37,86 & 40,91 & 97667,09 & 94685,63 & 3,05 \\
\hline 7 & & 0,01 & & 29,98 & 35,36 & 38,81 & 41,88 & 98684,94 & 94918,68 & 3,82 \\
\hline 8 & & 0,1 & & $37, \mathbf{5 0}$ & 45,38 & 41,00 & 44,56 & 99768,75 & 97240,86 & 2,53 \\
\hline 9 & \multirow{4}{*}{1,5} & 0,0001 & \multirow{4}{*}{0,05} & 30,31 & 46,08 & 38,67 & 41,56 & 97072,60 & 94663,61 & 2,48 \\
\hline 10 & & $\mathbf{0 , 0 0 1}$ & & 30,78 & 38,36 & 38,95 & 41,73 & 97679,96 & 94698,51 & 3,05 \\
\hline 11 & & 0,01 & & 30,05 & 35,22 & 39,44 & 41,66 & 98813,82 & 95047,56 & 3,81 \\
\hline 12 & & 0,1 & & 37,27 & 46,05 & 41,83 & 43,94 & 101057,47 & $\mathbf{9 8 5 2 9 , 5 8}$ & 2,50 \\
\hline 37 & \multirow{4}{*}{0,5} & 0,0001 & \multirow{4}{*}{0,1} & 27,20 & 34,81 & 34,06 & 35,39 & 99251,03 & 98832,65 & 0,42 \\
\hline 38 & & $\mathbf{0 , 0 0 1}$ & & 28,05 & 34,97 & 33,97 & 34,97 & 99309,66 & 98844,36 & 0,47 \\
\hline 39 & & 0,01 & & 26,86 & 38,72 & 34,06 & 34,86 & 100341,70 & 98961,45 & 1,38 \\
\hline 40 & & 0,1 & & 38,52 & 49,16 & 35,00 & 36,11 & 103179,92 & 100126,66 & 2,96 \\
\hline 41 & \multirow{4}{*}{1} & $\mathbf{0 , 0 0 0 1}$ & \multirow{4}{*}{0,1} & 38,86 & 49,80 & 35,09 & 35,72 & $\begin{array}{l}103179,92 \\
\end{array}$ & 100126,66 & 2,96 \\
\hline 42 & & $\mathbf{0 , 0 0 1}$ & & 27,83 & 33,67 & 34,25 & 34,06 & 99322,56 & 98857,26 & 0,47 \\
\hline 43 & & 0,01 & & 26,67 & 38,06 & 33,64 & 34,20 & 100470,56 & 99090,31 & 1,37 \\
\hline 44 & & 0,1 & & 38,42 & 49,36 & 34,94 & 35,56 & 104468,63 & 101415,37 & 2,92 \\
\hline 45 & \multirow{4}{*}{1,5} & 0,0001 & \multirow{4}{*}{0,1} & 26,81 & 33,45 & 34,50 & 35,25 & 99253,61 & $\mathbf{9 8 8 3 5 , 2 3}$ & 0,42 \\
\hline 46 & & 0,001 & & 27,31 & 33,41 & 34,27 & 35,19 & 99335,43 & 98870,13 & 0,47 \\
\hline 47 & & 0,01 & & 26,52 & 37,92 & 33,84 & 35,80 & 100599,44 & 99219,19 & 1,37 \\
\hline 48 & & 0,1 & & 37,36 & 48,59 & 34,91 & 36,78 & 105757,35 & 102704,09 & 2,89 \\
\hline 73 & & $\mathbf{0 , 0 0 0 1}$ & & 26,84 & 34,39 & 46,83 & 46,66 & 101423,21 & 101324,55 & 0,10 \\
\hline 74 & & $\mathbf{0 , 0 0 1}$ & 0,15 & 27,92 & 34,06 & 49,13 & 46,44 & 101481,85 & 101376,48 & 0,10 \\
\hline 75 & 0,0 & 0,01 & & 28,38 & 34,69 & 49,17 & 48,81 & 102573,16 & 101895,65 & 0,66 \\
\hline 76 & & 0,1 & & 36,14 & 40,36 & 52,56 & 51,33 & 105242,08 & 103809,18 & 1,36 \\
\hline 77 & & 0,0001 & & 27,20 & 33,36 & 48,19 & 46,69 & 101424,51 & 101325,85 & 0,10 \\
\hline 78 & & $\mathbf{0 , 0 0 1}$ & 0,15 & 27,86 & 33,73 & 47,70 & 47,00 & 101494,74 & 101389,37 & 0,10 \\
\hline 79 & 1 & 0,01 & & 28,58 & 35,00 & 50,59 & 50,88 & 102702,02 & 102024,51 & 0,66 \\
\hline 80 & & 0,1 & & 38,30 & 40,70 & 56,28 & 53,84 & 106530,80 & $\mathbf{1 0 5 0 9 7 , 8 9}$ & 1,35 \\
\hline 81 & & 0,0001 & & 27,45 & 34,14 & 47,48 & 49,95 & 101425,79 & 101327,13 & 0,10 \\
\hline 82 & & 0,001 & 0,15 & 27,23 & 34,44 & 50,06 & 48,77 & 101507,62 & 101402,25 & 0,10 \\
\hline 83 & 1,0 & 0,01 & & 27,72 & 36,23 & 50,38 & 54,02 & 102830,90 & 102153,39 & 0,66 \\
\hline 84 & & 0,1 & & 35,08 & 41,77 & 53,58 & 52,73 & 107819,51 & 106386,61 & 1,33 \\
\hline
\end{tabular}

Tabela 6.8: Comparação do tempo total médio de resolução e valor da FO para demanda baixa 


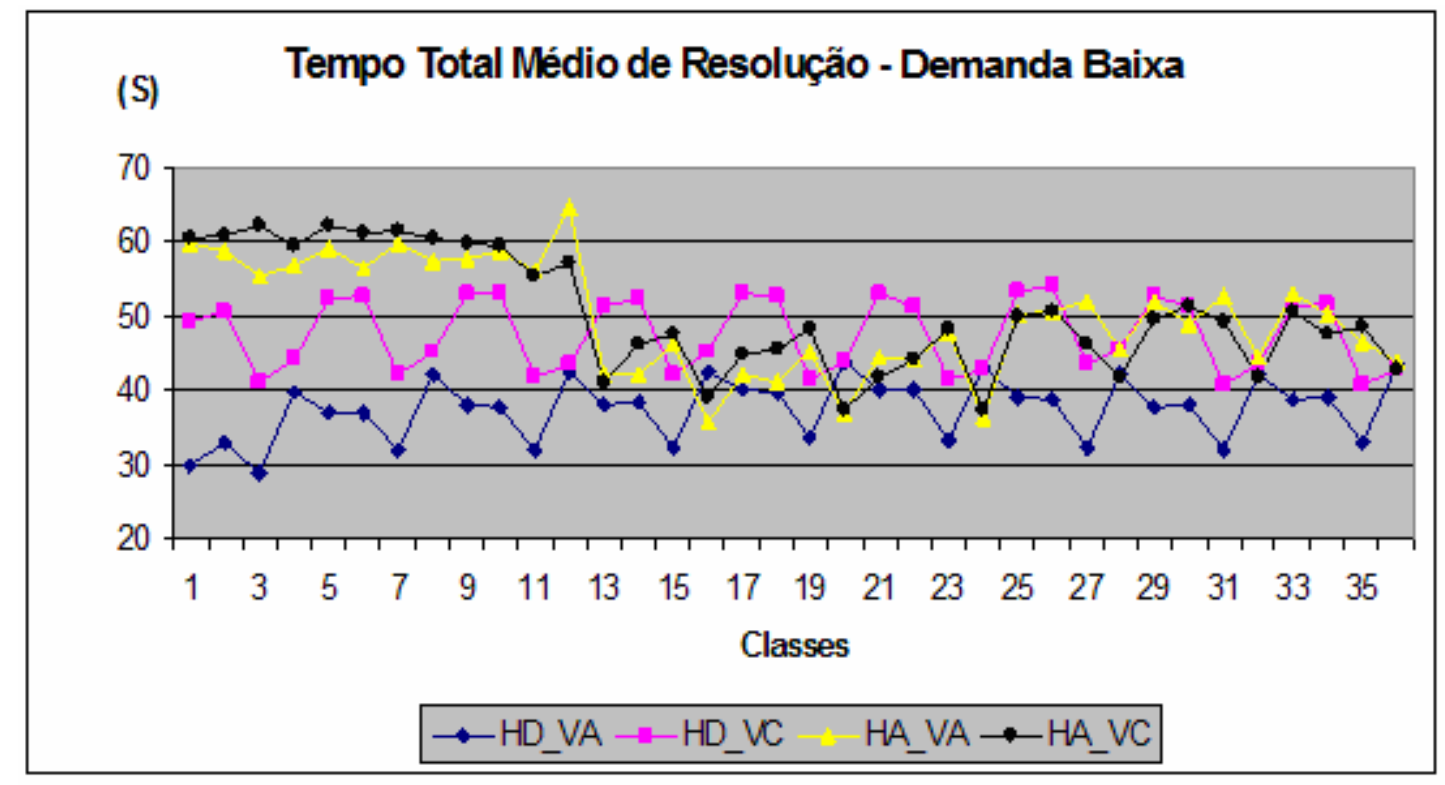

Figura 6.3: Comparação do tempo total médio de resolução para demanda baixa.

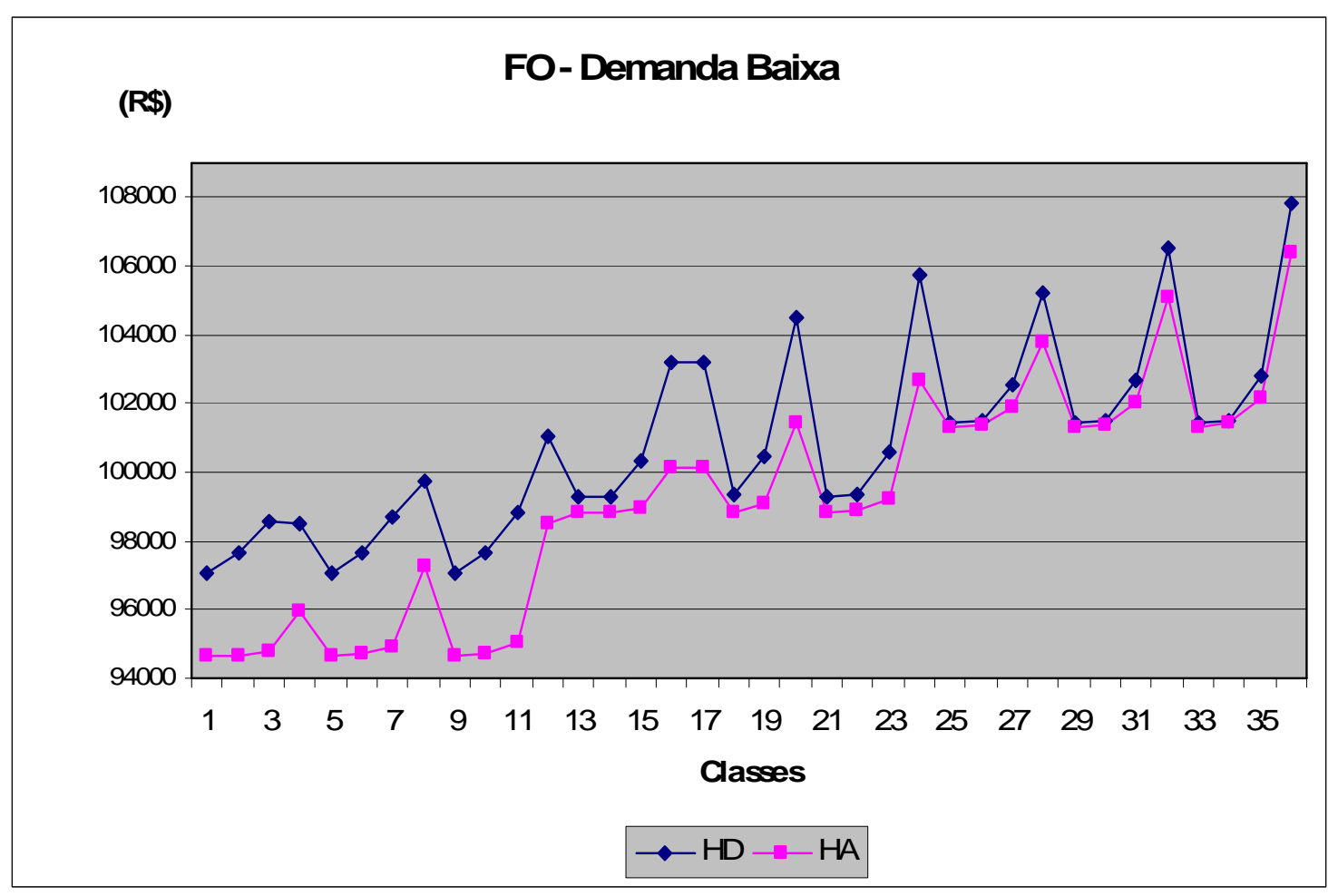

Figura 6.4: Comparação da FO para demanda baixa. 


\begin{tabular}{|c|c|c|c|c|c|c|c|c|c|c|}
\hline \multicolumn{11}{|c|}{ Demanda Média } \\
\hline \multirow{3}{*}{ Classe } & \multirow{3}{*}{$\alpha$} & \multirow{3}{*}{$\boldsymbol{h}$} & \multirow{3}{*}{$\gamma$} & \multicolumn{4}{|c|}{ Tempo (s) } & \multicolumn{2}{|c|}{ FO (R\$) } & \multirow{3}{*}{$\begin{array}{c}\text { Desvio } \\
(\%)\end{array}$} \\
\hline & & & & \multicolumn{2}{|c|}{ HD } & \multicolumn{2}{|c|}{ HA } & \multirow{2}{*}{$\begin{array}{c}\text { HD } \\
\text { VA e VC }\end{array}$} & \multirow{2}{*}{$\frac{\text { HA }}{\text { VA e VC }}$} & \\
\hline & & & & VA & $\mathrm{VC}$ & VA & $\mathrm{VC}$ & & & \\
\hline 13 & \multirow{4}{*}{0,5} & 0,0001 & \multirow{4}{*}{0,05} & 30,00 & 49,14 & 59,78 & 60,63 & 116989,76 & 115698,67 & 1,10 \\
\hline 14 & & 0,001 & & 32,84 & 50,56 & 58,70 & 60,77 & 117015,64 & 115711,51 & 1,11 \\
\hline 15 & & 0,01 & & 28,94 & 41,11 & 55,25 & 62,06 & 117751,34 & 115839,88 & 1,62 \\
\hline 16 & & $\mathbf{0 , 1}$ & & 39,72 & 44,20 & 56,63 & 59,59 & 119524,25 & 117040,30 & 2,08 \\
\hline 17 & \multirow{4}{*}{1} & 0,0001 & \multirow{4}{*}{0,05} & 36,86 & 52,42 & 59,11 & 62,17 & 116991,06 & 115699,97 & 1,10 \\
\hline 18 & & $\mathbf{0 , 0 0 1}$ & & 37,00 & 52,69 & 56,41 & 61,30 & 117028,53 & 115724,41 & 1,11 \\
\hline 19 & & 0,01 & & 31,95 & 42,09 & 59,75 & 61,44 & 117880,20 & 115968,74 & 1,62 \\
\hline 20 & & 0,1 & & 42,02 & 45,11 & 57,39 & 60,41 & 120812,96 & 118329,01 & 2,06 \\
\hline 21 & \multirow{4}{*}{1,5} & 0,0001 & \multirow{4}{*}{0,05} & 37,91 & 52,84 & 57,70 & 59,80 & 116992,34 & 115701,26 & 1,10 \\
\hline 22 & & 0,001 & & $\mathbf{3 7 , 5 8}$ & 53,00 & 58,88 & 59,31 & 117041,41 & 115737,28 & 1,11 \\
\hline 23 & & 0,01 & & 31,91 & 41,92 & 56,20 & 55,38 & 118009,08 & 116097,62 & 1,62 \\
\hline 24 & & $\mathbf{0 , 1}$ & & 42,39 & 43,42 & 64,42 & 57,19 & 122101,68 & 119617,73 & 2,03 \\
\hline 49 & \multirow{4}{*}{0,5} & 0,0001 & \multirow{4}{*}{0,1} & 37,91 & 51,20 & 41,94 & 41,11 & 120195,10 & 120022,18 & 0,14 \\
\hline 50 & & $\mathbf{0 , 0 0 1}$ & & $\mathbf{3 8 , 3 0}$ & 52,25 & 42,02 & 46,25 & 120220,97 & 120046,24 & 0,15 \\
\hline 51 & & 0,01 & & 32,16 & 42,16 & 46,31 & 47,58 & 120973,50 & 120214,98 & 0,63 \\
\hline 52 & & 0,1 & & 42,50 & 45,13 & 35,75 & 39,11 & 122827,84 & 121464,46 & 1,11 \\
\hline 53 & \multirow{4}{*}{1} & $\mathbf{0 , 0 0 0 1}$ & \multirow{4}{*}{0,1} & 40,17 & 53,06 & 42,11 & 44,77 & 120196,40 & 120023,48 & 0,14 \\
\hline 54 & & 0,001 & & 39,84 & 52,55 & 41,11 & 45,59 & 120233,87 & 120059,14 & 0,15 \\
\hline 55 & & 0,01 & & 33,47 & 41,53 & 45,33 & 48,17 & 121102,36 & 120343,84 & 0,63 \\
\hline 56 & & 0,1 & & 43,88 & 43,88 & 36,94 & 37,23 & 124116,56 & 122753,17 & 1,10 \\
\hline 57 & \multirow{4}{*}{1,5} & 0,0001 & \multirow{4}{*}{0,1} & 39,95 & 52,86 & 44,42 & 41,77 & 120197,68 & 120024,77 & 0,14 \\
\hline 58 & & 0,001 & & 40,08 & 51,38 & 44,25 & 44,03 & 120246,75 & 120072,01 & 0,15 \\
\hline 59 & & 0,01 & & 33,17 & 41,41 & 47,77 & 48,30 & 121231,24 & 120472,72 & 0,63 \\
\hline 60 & & $\mathbf{0 , 1}$ & & 43,05 & 42,75 & 36,25 & 37,19 & 125405,28 & 124041,89 & 1,09 \\
\hline 85 & & $\mathbf{0 , 0 0 0 1}$ & & 39,05 & 53,27 & 50,20 & 49,81 & 123400,42 & 123316,32 & 0,07 \\
\hline 86 & & 0,001 & 0,15 & 38,83 & 53,86 & 50,70 & 50,45 & 123426,29 & 123340,38 & 0,07 \\
\hline 87 & 0,5 & 0,01 & & 32,33 & 43,44 & 51,83 & 46,27 & 124195,64 & 123580,91 & 0,49 \\
\hline 88 & & 0,1 & & 42,20 & 45,67 & 45,48 & 41,66 & 126131,42 & 125395,90 & 0,58 \\
\hline 89 & & $\mathbf{0 , 0 0 0 1}$ & & 37,61 & 52,66 & 51,84 & 49,44 & 123401,72 & 123317,62 & 0,07 \\
\hline 90 & & $\mathbf{0 , 0 0 1}$ & 0,15 & 38,05 & 51,36 & 48,89 & 51,28 & 123439,19 & 123353,27 & 0,07 \\
\hline 91 & 1 & 0,01 & & 31,80 & 40,91 & 52,72 & 49,38 & 124324,50 & 123709,76 & 0,49 \\
\hline 92 & & 0,1 & & 41,95 & 43,38 & 44,52 & 41,92 & 127420,14 & 126684,61 & 0,58 \\
\hline 93 & & 0,0001 & & $\mathbf{3 8 , 7 7}$ & 51,23 & 53,11 & 50,52 & 123403,00 & 123318,90 & 0,07 \\
\hline 94 & & 0,001 & 0,15 & 39,03 & 51,52 & 50,44 & 47,69 & 123452,07 & 123366,15 & 0,07 \\
\hline 95 & 1,5 & 0,01 & & 32,92 & 40,77 & 46,66 & 48,48 & 124453,38 & 123838,64 & 0,49 \\
\hline 96 & & 0,1 & & 43,52 & 42,92 & 43,80 & 42,77 & 128708,86 & 127973,33 & 0,57 \\
\hline
\end{tabular}

Tabela 6.9: Comparação do tempo total médio de resolução e valor da FO para demanda média 


\section{(S) \\ Tempo Total Médio de Resolução - Demanda Média}

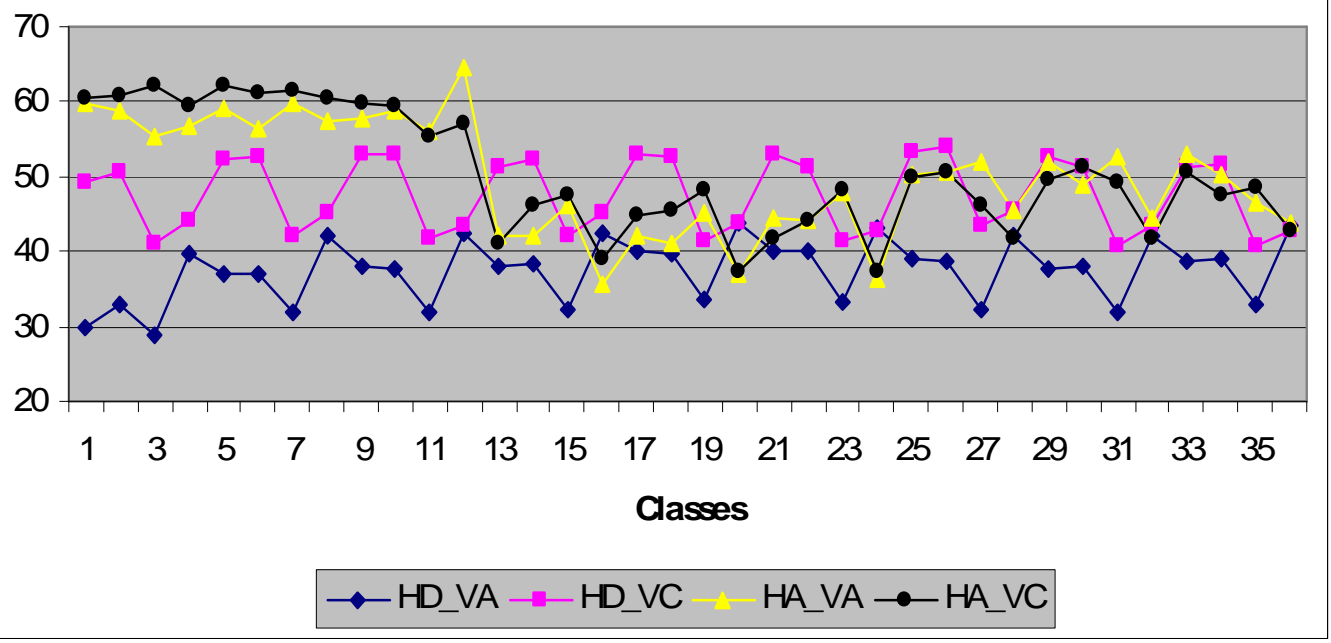

Figura 6.5: Comparação do tempo total médio de resolução para demanda média.

(R\$)

FO- Demanda Média

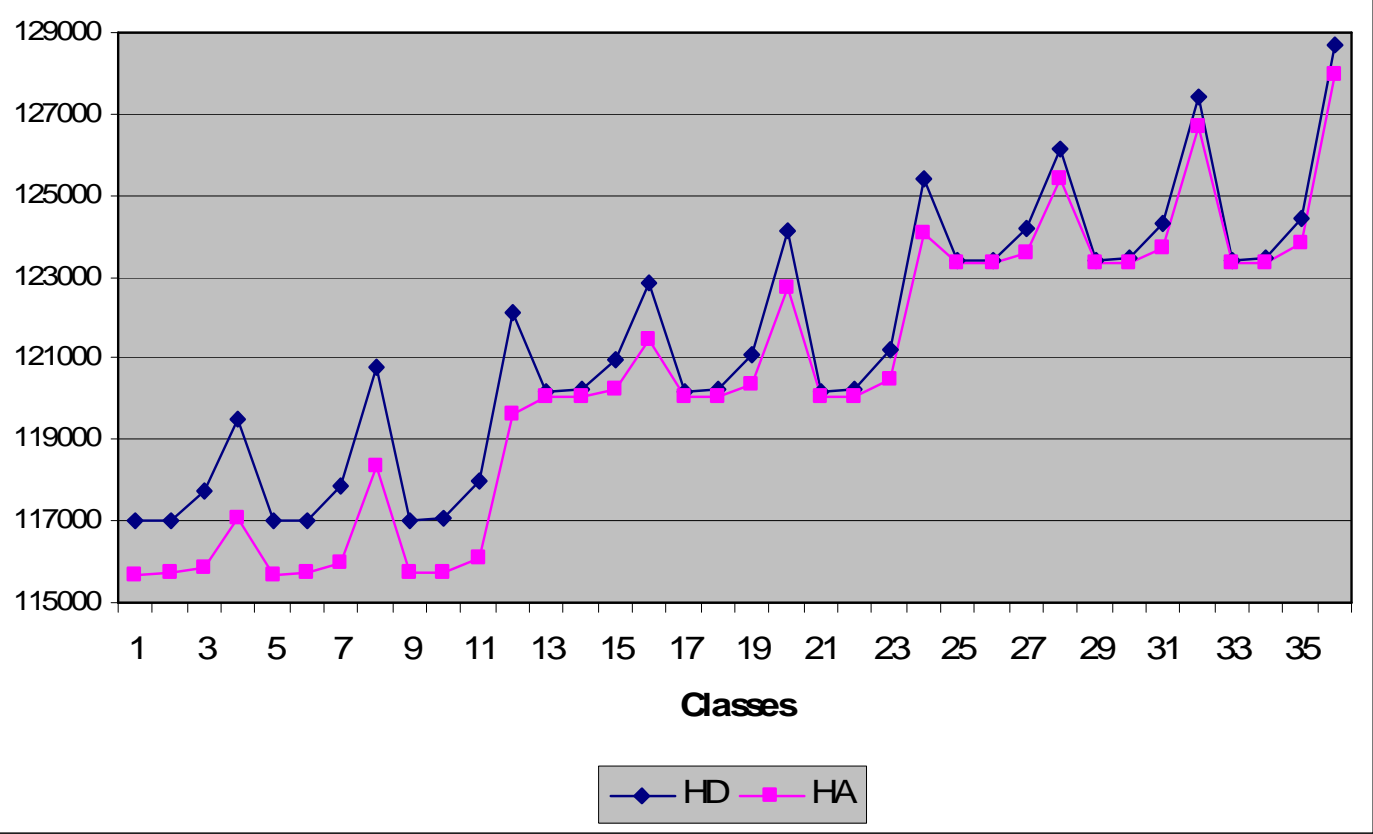

Figura 6.6: Comparação da FO para demanda média. 


\begin{tabular}{|c|c|c|c|c|c|c|c|c|c|c|}
\hline \multicolumn{11}{|c|}{ Demanda Alta } \\
\hline \multirow{3}{*}{ Classe } & \multirow{3}{*}{$\alpha$} & \multirow{3}{*}{$\boldsymbol{h}$} & \multirow{3}{*}{$\gamma$} & \multicolumn{4}{|c|}{ Tempo (s) } & \multicolumn{2}{|c|}{ FO (R\$) } & \multirow{3}{*}{$\begin{array}{c}\text { Desvio } \\
(\%)\end{array}$} \\
\hline & & & & \multicolumn{2}{|c|}{ HD } & \multicolumn{2}{|c|}{ HA } & \multirow{2}{*}{$\begin{array}{c}\text { HD } \\
\text { VA e VC } \\
\end{array}$} & \multirow{2}{*}{$\frac{\text { HA }}{\text { VA e VC }}$} & \\
\hline & & & & VA & $\mathrm{VC}$ & VA & $\mathrm{VC}$ & & & \\
\hline 25 & & $\mathbf{0 , 0 0 0 1}$ & & 17,39 & 21,84 & 32,94 & 29,19 & 135305,66 & 134947,46 & 0,26 \\
\hline 26 & & 0,001 & 0,05 & 16,59 & 21,75 & 40,34 & 28,75 & 135326,16 & 134966,79 & 0,27 \\
\hline 27 & 0,5 & $\mathbf{0 , 0 1}$ & & 16,73 & 21,66 & 46,17 & 28,47 & 135531,05 & 135160,05 & 0,27 \\
\hline 28 & & 0,1 & & 26,67 & 34,69 & 48,33 & 28,70 & 137560,45 & 137060,42 & 0,36 \\
\hline 29 & & 0,0001 & & 16,70 & 21,72 & 54,39 & 35,56 & 135306,96 & 134948,76 & 0,26 \\
\hline 30 & & $\mathbf{0 , 0 0 1}$ & $\mathbf{0 , 0 5}$ & 16,66 & 21,70 & 56,50 & 42,00 & 135339,05 & 134979,68 & 0,27 \\
\hline 31 & 1 & 0,01 & & 16,66 & 22,45 & 56,50 & 48,23 & 135659,91 & 135288,91 & 0,27 \\
\hline 32 & & 0,1 & & 26,70 & 41,34 & 56,72 & 49,14 & 138849,17 & 138349,13 & 0,36 \\
\hline 33 & & 0,0001 & & 17,17 & 31,67 & 58,92 & 55,06 & 135308,25 & 1349 & 0,26 \\
\hline 34 & & 0,001 & 0,05 & 18,94 & 35,64 & 51,77 & 57,17 & 135351,93 & 134992,56 & 0,27 \\
\hline 35 & $1, \mathbf{y}$ & 0,01 & & 21,05 & 40,13 & 59,53 & 58,53 & 135788,79 & 135417,79 & 0,27 \\
\hline 36 & & 0,1 & & 38,44 & 66,33 & 61,00 & 57,33 & 140137,89 & 139637,85 & 0,36 \\
\hline 61 & & 0,0001 & & 39,95 & 52,86 & 44,42 & 41,77 & 139456,13 & 139221,23 & 0,17 \\
\hline 62 & & $\mathbf{0 , 0 0 1}$ & $\mathbf{0 , 1}$ & 40,08 & 51,38 & 44,25 & 44,03 & 139476,63 & & 0,17 \\
\hline 63 & 0,0 & 0,01 & & 33,17 & 41,41 & 47,77 & 48,30 & 139681,52 & 1394 & 0,18 \\
\hline 64 & & 0,1 & & 43,05 & 42,75 & 36,25 & 37,19 & 141793,35 & 141342,12 & 0,32 \\
\hline 65 & & 0,0001 & & 35,38 & 41,48 & 58,84 & 59,2 & 39457,43 & 139222,52 & 0,17 \\
\hline 66 & & 0,001 & 0,1 & 35,30 & 42,73 & 57,23 & 58,88 & 139489,52 & 139253,45 & 0,17 \\
\hline 67 & 1 & $\mathbf{0 , 0 1}$ & & 35,48 & 43,52 & 56,03 & 59,72 & 0,38 & 2,68 & 0,18 \\
\hline 68 & & 0,1 & & 43,19 & 54,67 & 49,53 & 60,98 & 143082,06 & 142630,83 & 0,32 \\
\hline 69 & & 0,0001 & & 34,98 & 44,45 & 57,38 & 61,77 & 8,71 & 139223,81 & 0,17 \\
\hline 70 & 15 & 0,001 & $\mathbf{0 , 1}$ & 34,25 & 44,75 & 58,55 & 62,73 & 139502,40 & 139266,33 & 0,17 \\
\hline 71 & 1,0 & 0,01 & & 34,58 & 44,83 & 58,98 & 62,27 & 139939,26 & 139691,56 & 0,18 \\
\hline 72 & & $\underline{0,1}$ & & 43,02 & 55,45 & 52,84 & 64,61 & 144370,78 & $\mathbf{1 4 3 9 1 9 , 5 5}$ & 0,31 \\
\hline 97 & & 0,0001 & & 36,30 & 42,83 & 63,45 & 63,61 & 143606,58 & 143494,97 & 0,08 \\
\hline 98 & & 0,001 & 0,15 & 36,77 & 42,20 & 62,75 & 61,66 & 7,08 & & 0,08 \\
\hline 99 & 0,3 & 0,01 & & 36,48 & 42,53 & 62,34 & 62,19 & 143831,97 & 143 & 0,09 \\
\hline 100 & & 0,1 & & 41,03 & 49,98 & 61,61 & 55,73 & 145897,21 & 145603,60 & 0,20 \\
\hline 101 & & 0,0001 & & 35,88 & 44,22 & 62,20 & 61,11 & 143607,88 & 143496,27 & 0,08 \\
\hline 102 & & 0,001 & 0,15 & 35,17 & 44,95 & 61,53 & 59,78 & 143639,97 & 143527,2 & 0,08 \\
\hline 103 & 1 & 0,01 & & 35,36 & 44,41 & 62,89 & 60,97 & 143960,83 & 143836,42 & 0,09 \\
\hline 104 & & 0,1 & & 39,28 & 52,06 & 57,81 & 60,70 & 147185,93 & 146892,31 & 0,20 \\
\hline 105 & & $\mathbf{0 , 0 0 0 1}$ & & 35,14 & 45,56 & 63,41 & 61,28 & 143609,16 & 143497,56 & 0,08 \\
\hline 106 & & $\mathbf{0 , 0 0 1}$ & 0,15 & 35,30 & 44,91 & 57,89 & 62,33 & 143652,85 & 143540,08 & 0,08 \\
\hline 107 & 1,2 & 0,01 & & 35,28 & 44,08 & 66,44 & 63,95 & 144089,71 & 143965,30 & 0,09 \\
\hline 108 & & 0,1 & & 39,20 & 49,03 & 61,36 & 63,20 & 148474,65 & 148181,03 & 0,20 \\
\hline
\end{tabular}

Tabela 6.10: Comparação do tempo total médio de resolução e valor da FO para demanda alta 


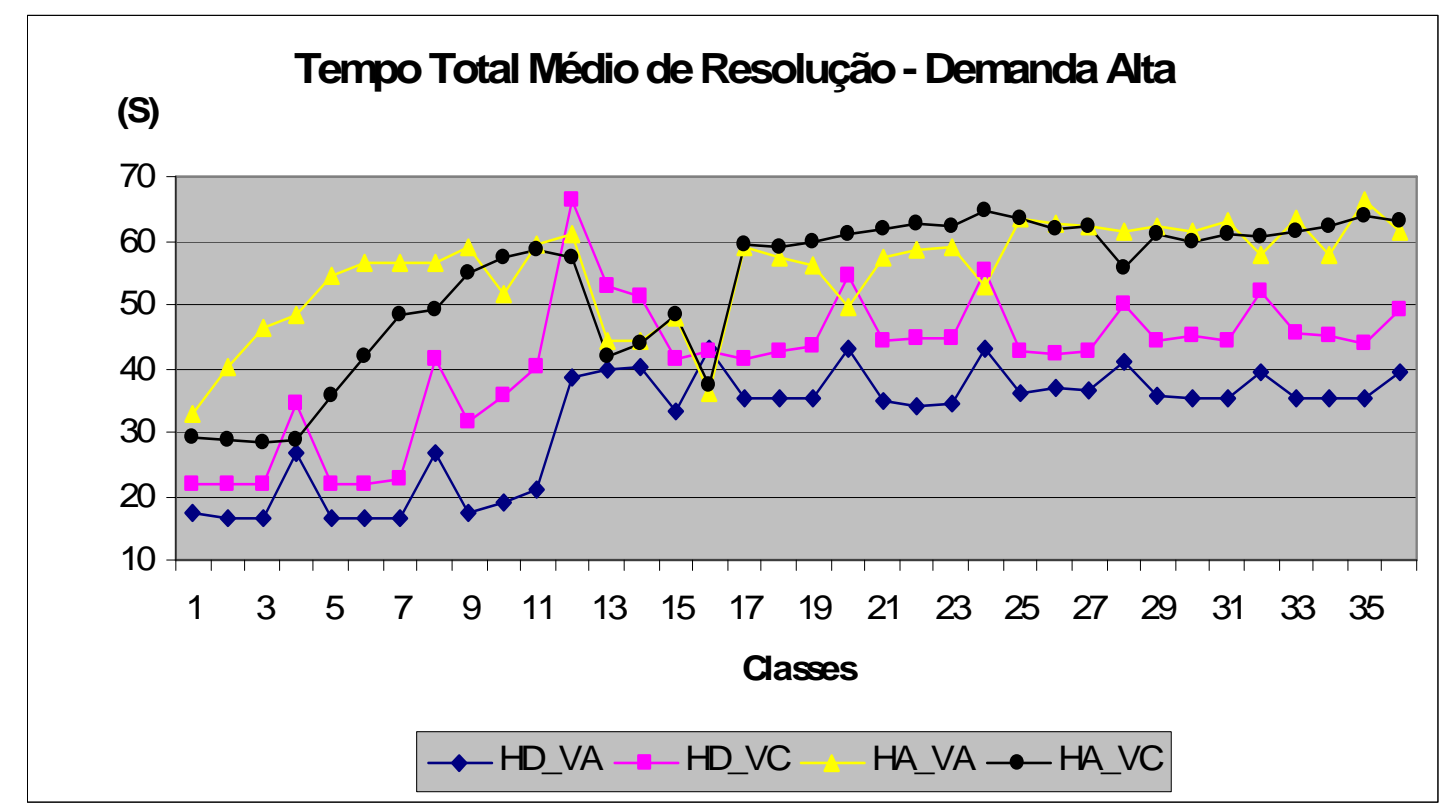

Figura 6.7: Comparação do tempo total médio de resolução para demanda alta.

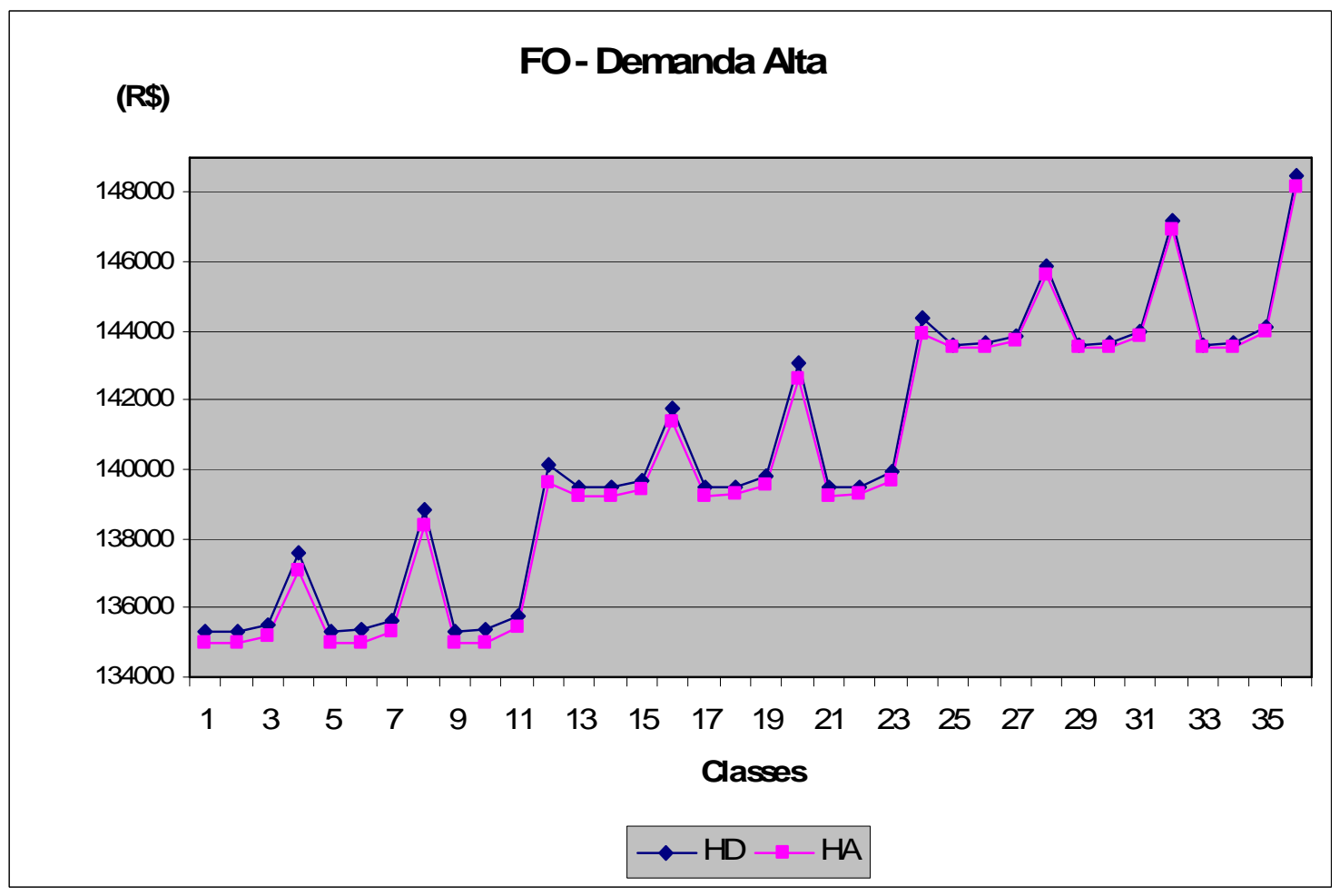

Figura 6.8: Comparação da FO para demanda alta. 


\begin{tabular}{|c|c|c|c|c|c|c|}
\hline \multicolumn{7}{|c|}{ Número de placas cortadas no período 1} \\
\hline \multirow{2}{*}{ Classes } & \multirow[b]{2}{*}{$\alpha$} & \multirow{2}{*}{$\boldsymbol{h}$} & \multirow[b]{2}{*}{$\gamma$} & \multirow{2}{*}{ Demanda } & \multicolumn{2}{|c|}{ VA e VC } \\
\hline & & & & & HD & HA \\
\hline $1,5,9$ & & 0,0001 & & & 1075,62 & 135,46 \\
\hline $2,6,10$ & $0,5,1 \mathrm{e}$ & $\mathbf{0 , 0 0 1}$ & 0,05 & Baixa & 1095,27 & 135,46 \\
\hline $3,7,11$ & 1,5 & $\mathbf{0 , 0 1}$ & & & 1093,85 & 135,46 \\
\hline $4,8,12$ & & $\mathbf{0 , 1}$ & & & 761,23 & 134,21 \\
\hline $13,17,21$ & & $\mathbf{0 , 0 0 0 1}$ & & & 1050,04 & 486,87 \\
\hline $14,18,22$ & $0,5,1 \mathrm{e}$ & $\mathbf{0 , 0 0 1}$ & 0,05 & Média & 1050,04 & 486,87 \\
\hline $15,19,23$ & 1,5 & $\mathbf{0 , 0 1}$ & & & 1068,14 & 486,87 \\
\hline $16,20,24$ & & $\mathbf{0 , 1}$ & & & 1059,10 & 465,68 \\
\hline $25,29,33$ & & 0,0001 & & & 1033,54 & 972,56 \\
\hline $26,30,34$ & $0,5,1 \mathrm{e}$ & 0,001 & 0,05 & Alta & 1033,54 & 972,56 \\
\hline $27,31,35$ & 1,5 & 0,01 & & & 1033,54 & 972,56 \\
\hline $28,32,36$ & & 0,1 & & & 993,19 & 967,94 \\
\hline $37,41,45$ & & $\mathbf{0 , 0 0 0 1}$ & & & 1068,98 & 318,63 \\
\hline $38,42,46$ & $0,5,1 \mathrm{e}$ & $\mathbf{0 , 0 0 1}$ & 0,1 & Baixa & 1079,69 & 318,63 \\
\hline $39,43,47$ & 1,5 & 0,01 & & & 1101,77 & 318,63 \\
\hline $40,44,48$ & & 0,1 & & & 1068,98 & 317,80 \\
\hline $49,53,57$ & & 0,0001 & & & 1050,04 & 1006,18 \\
\hline $50,54,58$ & $0,5,1 \mathrm{e} \mid$ & 0,001 & 0,1 & Média & 1050,04 & 1006,18 \\
\hline $51,55,59$ & 1,5 & 0,01 & & & 1068,14 & 722,90 \\
\hline $52,56,60$ & & 0,1 & & & 1059,10 & 716,98 \\
\hline $61,65,69$ & & 0,0001 & & & 1033,54 & 972,56 \\
\hline $62,66,70$ & $0,5,1 \mathrm{e}$ & 0,001 & 0,1 & Alta & 1033,54 & 972,56 \\
\hline $63,67,71$ & 1,5 & $\mathbf{0 , 0 1}$ & & & 1033,54 & 972,56 \\
\hline $64,68,72$ & & 0,1 & & & 1006,63 & 978,52 \\
\hline $73,77,81$ & & 0,0001 & & & 1079,69 & 1060,83 \\
\hline $74,78,82$ & $0,5,1 \mathrm{e} \mid$ & $\mathbf{0 , 0 0 1}$ & 0,15 & Baixa & 1079,69 & 1060,83 \\
\hline $75,79,83$ & 1,5 & $\mathbf{0 , 0 1}$ & & & 1102,99 & 1060,83 \\
\hline $76,80,84$ & & 0,1 & & & 1058,86 & 387,17 \\
\hline $85,89,93$ & & 0,0001 & & & 1050,04 & 1006,18 \\
\hline $86,90,94$ & $0,5,1 \mathrm{e} \mid$ & $\mathbf{0 , 0 0 1}$ & 0,15 & Média & 1050,04 & 1006,18 \\
\hline $87,91,95$ & 1,5 & 0,01 & & & 1068,14 & 1006,18 \\
\hline $88,92,96$ & & 0,1 & & & 1059,10 & 716,98 \\
\hline $97,101,105$ & & 0,0001 & & & 1033,54 & 972,56 \\
\hline $98,102,106$ & $0,5,1 \mathrm{e}$ & $\mathbf{0 , 0 0 1}$ & 0,15 & Alta & 1033,54 & 972,56 \\
\hline $99,103,107$ & 1,5 & 0,01 & & & 1033,54 & 972,56 \\
\hline $100,104,108$ & & 0,1 & & & 1034,75 & $\mathbf{9 7 8 , 5 2}$ \\
\hline
\end{tabular}

Tabela 6.11: Comparação do número de placas cortadas no período 1

Na Tabela 6.11, cada linha da coluna Classes contém três números que representam três classes que diferem somente no valor usado para $\alpha(0,5,1$ e 1,5$)$ no cálculo dos custos das variáveis de oportunidade. Porém, na solução ótima destas classes o número de placas cortadas é o mesmo.

De acordo com os resultados da Tabela 6.11, ao aumentar os custos das variáveis de estoque e, consequentemente, os custos das variáveis de oportunidade, o número de placas cortadas no período 1 praticamente não se altera. Uma variação acontece somente quando $h=0,1$, ou seja, quando o custo de estoque é $10 \%$ do custo de produção. Além disso, a solução não se modifica com a variação no valor de $\alpha$ (aumento nos custos das variáveis de oportunidade). Porém, com a heurística de acoplamento menos placas são cortadas em todas as classes resolvidas. 


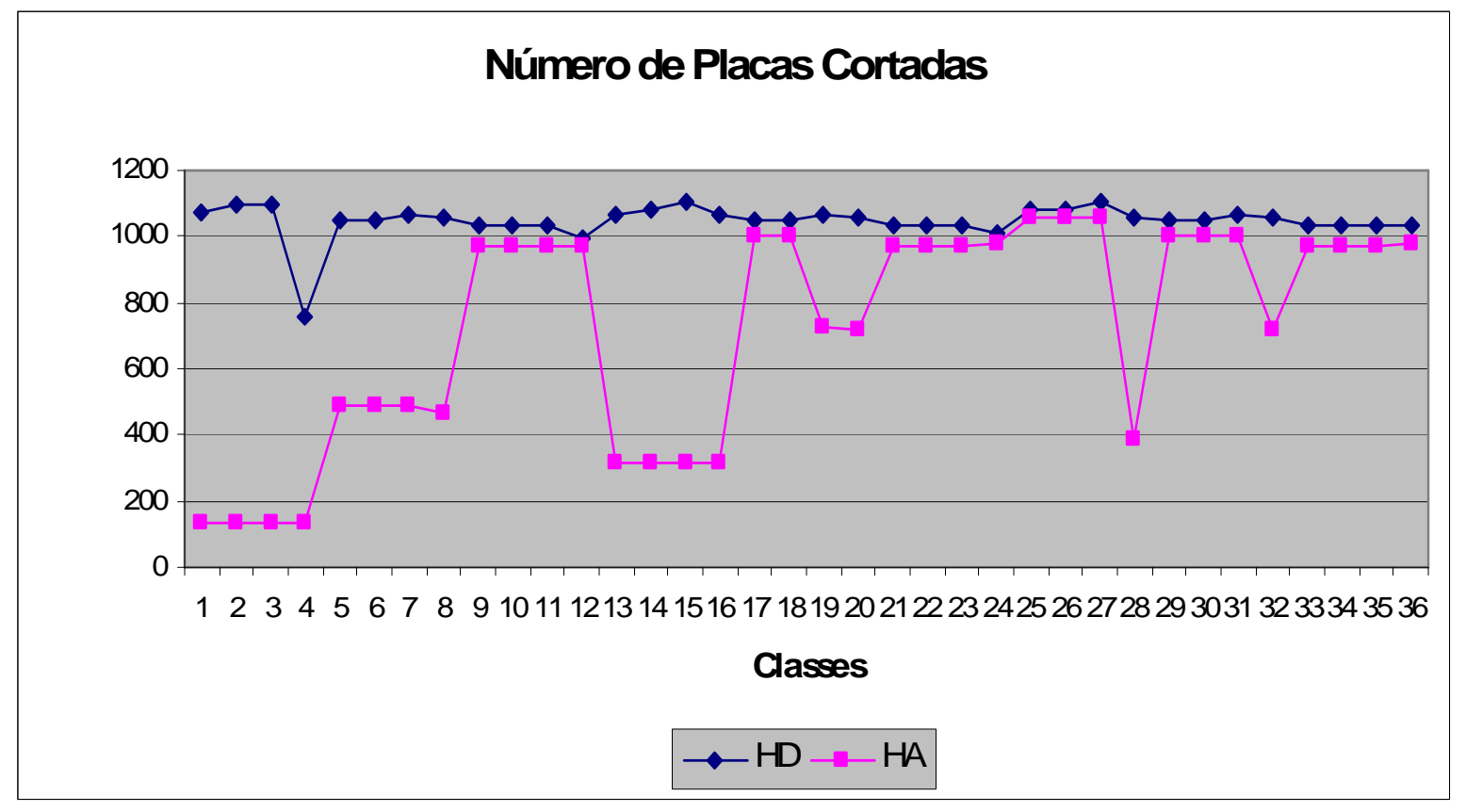

Figura 6.9: Comparação do número de placas cortadas no período 1.

Em geral, considerando os resultados da heurística de acoplamento, ao variar o valor de $\boldsymbol{\gamma}$ fazendo com que o custo de produção a partir do segundo período do horizonte de planejamento seja maior (acrescentando uma estimativa para a perda de matéria-prima no processo de corte), a produção do primeiro período e, consequentemente, o número de placas cortadas neste período, aumentam, ficando bem próximos aos valores obtidos pela heurística de decomposição. Para ilustrar este fato, a Tabela 6.12, a seguir, mostra a programação da produção para um dos exemplares de algumas das classes de problemas com $\alpha=0,5$ e $h=0,0001$ resolvidas pelas heurísticas de decomposição e de acoplamento.

\begin{tabular}{|c|c|c|c|c|c|c|c|c|c|c|c|c|c|c|}
\hline \multicolumn{15}{|c|}{ Programação da produção para o período 1} \\
\hline Classe & Demanda & Heurística & $x_{11}$ & $\mathbf{x}_{21}$ & $x_{31}$ & $x_{41}$ & $I_{11}$ & $I_{21}$ & $I_{31}$ & $\mathbf{I}_{41}$ & $E_{11}$ & $\mathbf{E}_{21}$ & $\mathbf{E}_{31}$ & $\mathbf{E}_{41}$ \\
\hline \multirow{2}{*}{1} & \multirow{2}{*}{ Baixa } & HD & 147 & 37 & 2 & 2 & 99 & 0 & 0 & 0 & 40 & 24 & 0 & 0 \\
\hline & & HA & 8 & 13 & 2 & 35 & 0 & 0 & 0 & 3 & 0 & 0 & 0 & 30 \\
\hline \multirow{2}{*}{13} & \multirow{2}{*}{ Média } & HD & 119 & 48 & 41 & 44 & 61 & 0 & 0 & 0 & 40 & 0 & 0 & 0 \\
\hline & & HA & 18 & 48 & 41 & 124 & 0 & 0 & 0 & 50 & 0 & 0 & 0 & 30 \\
\hline \multirow{2}{*}{25} & \multirow{2}{*}{ Alta } & HD & 71 & 82 & 80 & 85 & 38 & 0 & 0 & 0 & 6 & 0 & 0 & 0 \\
\hline & & HA & 52,8 & 82 & 80 & 85 & 25,8 & 0 & 0 & 81,9 & 0 & 0 & 0 & 30 \\
\hline \multirow{2}{*}{37} & \multirow{2}{*}{ Baixa } & HD & 145 & 40 & 2 & 2 & 97 & 0 & 0 & 0 & 40 & 27 & 0 & 0 \\
\hline & & HA & 39 & 13 & 2 & 35 & 0 & 0 & 0 & 3 & 31 & 0 & 0 & 30 \\
\hline \multirow{2}{*}{49} & \multirow{2}{*}{ Média } & HD & 119 & 48 & 41 & 44 & 61 & 0 & 0 & 0 & 40 & 0 & 0 & 0 \\
\hline & & HA & 105,9 & 48 & 41 & 124 & 47,9 & 0 & 0 & 50 & 40 & 0 & 0 & 30 \\
\hline \multirow[b]{2}{*}{61} & \multirow[b]{2}{*}{ Alta } & HD & 71 & 82 & 80 & 85 & 38 & 0 & 0 & 0 & 6 & 0 & 0 & 0 \\
\hline & & HA & 52,8 & 82 & 80 & 196,9 & 25,8 & 0 & 0 & 81,9 & 0 & 0 & 0 & 30 \\
\hline \multirow{2}{*}{73} & \multirow{2}{*}{ Baixa } & HD & 145 & 40 & 2 & 2 & 97 & 0 & 0 & 0 & 40 & 27 & 0 & 0 \\
\hline & & HA & 135,3 & 45,1 & 2 & 35 & 87,3 & 0 & 0 & 3 & 40 & 32,1 & 0 & 30 \\
\hline \multirow{2}{*}{85} & \multirow{2}{*}{ Média } & HD & 119 & 48 & 41 & 44 & 61 & 0 & 0 & 0 & 40 & 0 & 0 & 0 \\
\hline & & HA & 105,9 & 48 & 41 & 124 & 47,9 & 0 & 0 & 50 & 40 & 0 & 0 & 30 \\
\hline \multirow[b]{2}{*}{97} & \multirow{2}{*}{ Alta } & HD & 71 & 82 & 80 & 85 & 38 & 0 & 0 & 0 & 6 & 0 & 0 & 0 \\
\hline & & HA & 52,8 & 82 & 80 & 196,9 & 25,8 & 0 & 0 & 81,9 & 0 & 0 & 0 & 30 \\
\hline
\end{tabular}

Tabela 6.12: Comparação da programação da produção para o período 1 entre HD e HA 
Com a realização destes testes, foi possível detectar que quando a estimativa da perda a partir do período 2 é muito inferior à perda que realmente ocorrerá, a heurística de acoplamento não antecipa em grandes quantidades a fabricação dos produtos em carteira e da parcela da demanda esperada, apesar de ter capacidade de máquina disponível. Diferentemente da heurística de decomposição, que sempre trabalha no limite da capacidade (Observe os resultados da Tabela 6.12).

Nos próximos testes, consideramos apenas as variáveis artificiais nas restrições de acoplamento. Vale salientar que são introduzidas 67 variáveis artificiais para as restrições de acoplamento e apenas 10 variáveis artificiais para as restrições de capacidade.

\subsubsection{Variando parâmetros do modelo proposto}

Para analisar o comportamento das soluções obtidas pelas heurísticas de acoplamento e decomposição ao alterar alguns dos parâmetros do modelo proposto, fizemos experimentos computacionais modificando um tipo de parâmetro por vez.

\subsubsection{Variação na demanda esperada}

Nestes experimentos, somente o valor da demanda esperada dos produtos para o horizonte de planejamento foi modificado. Primeiro, utilizamos um único valor da demanda extra para todos os tipos de produtos, ou seja, $D_{i}-\sum_{t=1}^{4} d_{i t}=60$, para $i=1, \ldots, 4$. Dessa forma, os produtos 1, 2 e 4 tiveram o valor da demanda esperada aumentado e para o produto 3, o valor diminuiu. Depois, consideramos a demanda extra como sendo a metade do valor utilizado nos testes da seção anterior, ou seja, $D_{1}-\sum_{t=1}^{4} d_{1 t}=20, D_{2}-\sum_{t=1}^{4} d_{2 t}=20$, $D_{3}-\sum_{t=1}^{4} d_{3 t}=50$ e $D_{4}-\sum_{t=1}^{4} d_{4 t}=15$.

Foram resolvidas as 108 classes de problemas e as Tabelas 6.13 e 6.14 apresentam e comparam os resultados para o número de placas cortadas no primeiro período nas soluções ótimas das heurísticas HD e HA. A coluna Menor apresenta os resultados quando a demanda esperada de todos os tipos de produtos foi reduzida, a coluna Anterior contém as soluções obtidas na seção anterior e a coluna Igual traz os resultados quando a demanda extra é igual para todos os tipos de produtos.

Apresentamos somente a solução com relação ao número de placas cortadas no primeiro período, pois tal número fornece uma medida de como a fábrica está funcionando e reflete a quantidade de móveis produzida. 


\begin{tabular}{|c|c|c|c|c|c|c|c|c|c|c|}
\hline \multicolumn{11}{|c|}{ Variação da demanda esperada - Número de placas cortadas no período 1} \\
\hline \multirow[b]{2}{*}{ Classes } & \multirow[b]{2}{*}{$\alpha$} & \multirow[b]{2}{*}{$\boldsymbol{h}$} & \multirow[b]{2}{*}{$\gamma$} & \multirow{2}{*}{ Dem } & \multicolumn{2}{|c|}{ Menor } & \multicolumn{2}{|c|}{ Anterior } & \multicolumn{2}{|c|}{ Igual } \\
\hline & & & & & HD & HA & HD & HA & HD & HA \\
\hline $1,5,9$ & & 0,0001 & & & 1087,13 & 129,18 & 1075,62 & 135,46 & 1073,21 & 148,15 \\
\hline $2,6,10$ & 0,3 & 0,001 & 0,05 & Baixa & 1090,45 & 129,18 & 1095,27 & 135,46 & 1085,41 & 148,15 \\
\hline $3,7,11$ & 15 & $\mathbf{0 , 0 1}$ & & & 1091,41 & 129,18 & 1093,85 & 135,46 & 1102,99 & 148,15 \\
\hline $4,8,12$ & & 0,1 & & & 441,81 & 127,93 & 761,23 & 134,21 & 927,97 & 146,87 \\
\hline $13,17,21$ & & \begin{tabular}{|l|}
0,0001 \\
\end{tabular} & & & 1050,04 & 480,51 & 1050,04 & 486,87 & 1050,04 & 499,70 \\
\hline $14,18,22$ & & 0,001 & 0,05 & Média & 1053,86 & 480,51 & 1050,04 & 486,87 & 1050,04 & 499,70 \\
\hline $15,19,23$ & 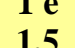 & 0,01 & & & 1058,90 & 480,51 & 1068,14 & 486,87 & 1070,69 & 499,70 \\
\hline $16,20,24$ & & 0,1 & & & 773,52 & $\mathbf{4 5 9 , 5 8}$ & 1059,10 & 465,68 & 1070,69 & 478,39 \\
\hline $25,29,33$ & & 0,0001 & & & 1033,54 & 972,56 & 1033,54 & 972,56 & 1033,85 & 972,56 \\
\hline $26,30,34$ & 0,3, & 0,001 & 0,05 & Alta & 1033,54 & 972,56 & 1033,54 & 972,56 & 1033,85 & 972,56 \\
\hline $27,31,35$ & 10 & $\mathbf{0 , 0 1}$ & & & 1033,54 & 972,56 & 1033,54 & 972,56 & 1034,75 & 972,56 \\
\hline $28,32,36$ & & 0,1 & & & 993,19 & 961,59 & 993,19 & 967,94 & 993,19 & 972,56 \\
\hline $37,41,45$ & & \begin{tabular}{|l|}
0,0001 \\
\end{tabular} & & & 1087,13 & 312,36 & 1068,98 & 318,63 & 1073,21 & 331,21 \\
\hline $38,42,46$ & , , & 0,001 & 0,1 & Baixa & 1087,13 & 312,36 & 1079,69 & 318,63 & 1073,21 & 331,21 \\
\hline $39,43,47$ & & 0,01 & & & 1109,40 & 247,33 & 1101,77 & 318,63 & 1102,99 & 331,21 \\
\hline $40,44,48$ & & 0,1 & & & 838,04 & 246,49 & 1068,98 & 317,80 & 1054,16 & $\mathbf{3 3 0 , 3 7}$ \\
\hline $49,53,57$ & & 0,0001 & & & 1050,04 & 1014,47 & 1050,04 & 1006,18 & 1050,04 & 989,62 \\
\hline $50,54,58$ & $\mathbf{0 , \mathbf { J }}$ & 0,001 & 0,1 & Média & 1050,04 & 1014,47 & 1050,04 & 1006,18 & 1050,04 & 989,62 \\
\hline $51,55,59$ & & $\mathbf{0 , 0 1}$ & & & 1058,90 & $\mathbf{5 9 8 , 5 0}$ & 1068,14 & 722,90 & 1070,69 & 853,69 \\
\hline $52,56,60$ & & 0,1 & & & 1042,28 & 592,56 & 1059,10 & 716,98 & 1070,69 & 847,78 \\
\hline $61,65,69$ & & $0,0,0001$ & & & 1033,54 & 972,56 & 1033,54 & 972,56 & 1033,85 & 972,56 \\
\hline $62,66,70$ & 1, & 0,001 & 0,1 & Alta & 1033,54 & 972,56 & 1033,54 & 972,56 & 1033,85 & 972,56 \\
\hline $63,67,71$ & & $\mathbf{0 , 0 1}$ & & & 1033,54 & 972,56 & 1033,54 & 972,56 & 1033,11 & 972,56 \\
\hline $64,68,72$ & & 0,1 & & & 1006,63 & $\mathbf{9 8 6 , 7 0}$ & 1006,63 & $\mathbf{9 7 8 , 5 2}$ & 1006,63 & 972,56 \\
\hline $73,77,81$ & & 0,0001 & & & 1087,13 & 990,67 & 1079,69 & 1060,83 & 1073,21 & 1043,78 \\
\hline $74,78,82$ & & 0,001 & 0,15 & Baixa & 1087,13 & 990,67 & 1079,69 & 1060,83 & 1073,21 & 1043,78 \\
\hline $75,79,83$ & 10 & 0,01 & & & 1109,40 & 990,67 & 1102,99 & 1060,83 & 1102,99 & 1043,78 \\
\hline $76,80,84$ & & $\mathbf{0 , 1}$ & & & 838,04 & 246,49 & 1058,86 & 387,17 & 1045,93 & 553,88 \\
\hline $85,89,93$ & & 0,0001 & & & 1050,04 & 1014,47 & 1050,04 & 1006,18 & 1050,04 & 989,62 \\
\hline $86,90,94$ & $1 \mathrm{e}$ & $\mathbf{0 , 0 0 1}$ & 0,15 & Média & 1050,04 & 1014,47 & 1050,04 & 1006,18 & 1050,04 & 989,62 \\
\hline $87,91,95$ & & 0,01 & & & 1058,90 & 1014,47 & 1068,14 & 1006,18 & 1070,69 & 989,62 \\
\hline $88,92,96$ & & 0,1 & & & 1044,29 & 592,56 & 1059,10 & 716,98 & 1070,69 & $\mathbf{8 4 7 , 7 8}$ \\
\hline $97,101,105$ & & \begin{tabular}{|l|l|}
0,0001 \\
\end{tabular} & & & 1033,54 & 972,56 & 1033,54 & 972,56 & 1033,85 & 972,56 \\
\hline $98,102,106$ & 0, & $\mathbf{0 , 0 0 1}$ & 0,15 & Alta & 1033,54 & 972,56 & 1033,54 & 972,56 & 1033,85 & 972,56 \\
\hline 99,103,107 & 1. & $\mathbf{0 , 0 1}$ & & & 1033,54 & 972,56 & 1033,54 & 972,56 & 1033,11 & 972,56 \\
\hline $100,104,108$ & & 0,1 & & & 1034,75 & 986,70 & 1034,75 & 978,52 & 1034,75 & 972,56 \\
\hline
\end{tabular}

Tabela 6.13: Comparação do número de placas cortadas para HD e HA ao variar a demanda esperada

De acordo com os resultados, a heurística de acoplamento corta o mesmo número de placas na maioria das classes com demanda alta apesar de variar a demanda esperada de todos os tipos de produtos. Para as demandas baixa e média, o número de placas cortadas é maior ao aumentar o custo de produção a partir do segundo período, porém os valores são próximos.

A heurística de decomposição apresentou resultados muito próximos ou iguais para as demandas baixa, média e alta e mesmo variando a demanda esperada dos produtos a diferença no número de placas cortadas foi pequena.

A Tabela 6.14 mostra a programação da produção do período 1 para um dos exemplares de algumas das classes de problemas com $\alpha=0,5$ e $h=0,0001$ resolvidas pelas heurísticas de decomposição e de acoplamento ao variar a demanda esperada dos produtos. 


\begin{tabular}{|c|c|c|c|c|c|c|c|c|c|c|c|c|c|c|}
\hline \multicolumn{15}{|c|}{ Variação da demanda esperada - Programação da produção para o período 1} \\
\hline Classe & Demanda & Heurística & $\mathbf{x}_{11}$ & $\mathbf{x}_{21}$ & $\mathbf{x}_{31}$ & $\mathbf{x}_{41}$ & $\mathbf{I}_{11}$ & $\mathbf{I}_{21}$ & $\mathbf{I}_{31}$ & $\mathbf{I}_{\mathbf{4 1}}$ & $\mathbf{E}_{11}$ & $\mathbf{E}_{21}$ & $\mathbf{E}_{31}$ & $\mathbf{E}_{41}$ \\
\hline \multirow[t]{6}{*}{ 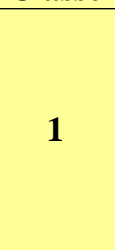 } & \multirow{6}{*}{ Baixa } & \multirow{3}{*}{ HD } & 121 & 61 & 2 & 2 & 99 & 28 & 0 & 0 & 20 & 20 & 0 & 0 \\
\hline & & & 147 & 37 & 2 & 2 & 99 & 0 & 0 & 0 & 40 & 24 & 0 & 0 \\
\hline & & & 167 & 14 & 2 & 2 & 99 & 0 & 0 & 0 & 60 & 1 & 0 & 0 \\
\hline & & \multirow{3}{*}{ HA } & 8 & 13 & 2 & 20 & 0 & 0 & 0 & 3 & 0 & 0 & 0 & 15 \\
\hline & & & 8 & 13 & 2 & 35 & 0 & 0 & 0 & 3 & 0 & 0 & 0 & 30 \\
\hline & & & 8 & 13 & 2 & 65 & 0 & 0 & 0 & 3 & 0 & 0 & 0 & 60 \\
\hline \multirow{6}{*}{13} & \multirow{6}{*}{ Média } & & 119 & 48 & 41 & 44 & 81 & 0 & 0 & 0 & 20 & 0 & 0 & 0 \\
\hline & & HD & 119 & 48 & 41 & 44 & 61 & 0 & 0 & 0 & 40 & 0 & 0 & 0 \\
\hline & & & 119 & 48 & 41 & 44 & 41 & 0 & 0 & 0 & 60 & 0 & 0 & 0 \\
\hline & & & 18 & 48 & 41 & 109 & 0 & 0 & 0 & 50 & 0 & 0 & 0 & 15 \\
\hline & & HA & 18 & 48 & 41 & 124 & 0 & 0 & 0 & 50 & 0 & 0 & 0 & 30 \\
\hline & & & 18 & 48 & 41 & 154 & 0 & 0 & 0 & 50 & 0 & 0 & 0 & 60 \\
\hline \multirow{6}{*}{25} & \multirow{6}{*}{ Alta } & & 71 & 82 & 80 & 85 & 38 & 0 & 0 & 0 & 6 & 0 & 0 & 0 \\
\hline & & HD & 71 & 82 & 80 & 85 & 38 & 0 & 0 & 0 & 6 & 0 & 0 & 0 \\
\hline & & & 71 & 82 & 80 & 86 & 38 & 0 & 0 & 0 & 6 & 0 & 0 & 1 \\
\hline & & & 52,8 & 82 & 80 & 196,9 & 25,8 & 0 & 0 & 96,9 & 0 & 0 & 0 & 15 \\
\hline & & HA & 52,8 & 82 & 80 & 196,9 & 25,8 & 0 & 0 & 81,9 & 0 & 0 & 0 & 30 \\
\hline & & & 52,8 & 82 & 80 & 196,9 & 25,8 & 0 & 0 & 71 & 0 & 0 & 0 & 40,9 \\
\hline \multirow{6}{*}{37} & \multirow{6}{*}{ Baixa } & & 127 & 61 & 2 & 2 & 99 & 28 & 0 & 0 & 20 & 20 & 0 & 0 \\
\hline & & HD & 145 & 40 & 2 & 2 & 97 & 0 & 0 & 0 & 40 & 27 & 0 & 0 \\
\hline & & & 167 & 14 & 2 & 2 & 99 & 0 & 0 & 0 & 60 & 1 & 0 & 0 \\
\hline & & & 39 & 13 & 2 & 20 & 11 & 0 & 0 & 3 & 20 & 0 & 0 & 15 \\
\hline & & HA & 39 & 13 & 2 & 35 & 0 & 0 & 0 & 3 & 31 & 0 & 0 & 30 \\
\hline & & & 39 & 13 & 2 & 65 & 0 & 0 & 0 & 3 & 31 & 0 & 0 & 60 \\
\hline \multirow{6}{*}{49} & \multirow{6}{*}{ Média } & & 119 & 48 & 41 & 44 & 81 & 0 & 0 & 0 & 20 & 0 & 0 & 0 \\
\hline & & HD & 119 & 48 & 41 & 44 & 61 & 0 & 0 & 0 & 40 & 0 & 0 & 0 \\
\hline & & & 119 & 48 & 41 & 44 & 41 & 0 & 0 & 0 & 60 & 0 & 0 & 0 \\
\hline & & & 108,4 & 48 & 41 & 109 & 70,4 & 0 & 0 & 50 & 20 & 0 & 0 & 15 \\
\hline & & HA & 105,9 & 48 & 41 & 124 & 47,9 & 0 & 0 & 50 & 40 & 0 & 0 & 30 \\
\hline & & & 101 & 48 & 41 & 154 & 23 & 0 & 0 & 50 & 60 & 0 & 0 & 60 \\
\hline \multirow{6}{*}{61} & & & 71 & 82 & 80 & 85 & 38 & 0 & 0 & 0 & 6 & 0 & 0 & 0 \\
\hline & & HD & 71 & 82 & 80 & 85 & 38 & 0 & 0 & 0 & 6 & 0 & 0 & 0 \\
\hline & Alta & & 71 & 82 & 80 & 86 & 38 & 0 & 0 & 0 & 6 & 0 & 0 & 1 \\
\hline & Alta & & 52,8 & 82 & 80 & 196,9 & 25,8 & 0 & 0 & 96,9 & 0 & 0 & 0 & 15 \\
\hline & & HA & 52,8 & 82 & 80 & 196,9 & 25,8 & 0 & 0 & 81,9 & 0 & 0 & 0 & 30 \\
\hline & & & 52,8 & 82 & 80 & 196,9 & 25,8 & 0 & 0 & 71 & 0 & 0 & 0 & 40,9 \\
\hline & & & 127 & 61 & 2 & 2 & \begin{tabular}{|l|}
99 \\
\end{tabular} & 28 & 0 & 0 & 20 & 20 & 0 & 0 \\
\hline & & HD & 145 & 40 & 2 & 2 & 97 & 0 & 0 & 0 & 40 & 27 & 0 & 0 \\
\hline & & & 167 & 14 & 2 & 2 & 99 & 0 & 0 & 0 & 60 & 1 & 0 & 0 \\
\hline 73 & Baixa & & 127 & 42,3 & 2 & 20 & 99 & 9,3 & 0 & 3 & 20 & 20 & 0 & 15 \\
\hline & & HA & 135,3 & 45,1 & 2 & 35 & 87,3 & 0 & 0 & 3 & 40 & 32,1 & 0 & 30 \\
\hline & & & 131,5 & 43,8 & 2 & 65 & 63,5 & 0 & 0 & 3 & 60 & 30,8 & 0 & 60 \\
\hline & & & 119 & 48 & 41 & 44 & 81 & 0 & 0 & 0 & 20 & 0 & 0 & 0 \\
\hline & & HD & 119 & 48 & 41 & 44 & 61 & 0 & 0 & 0 & 40 & 0 & 0 & 0 \\
\hline 8 & 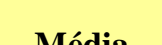 & & 119 & 48 & 41 & 44 & 41 & 0 & 0 & 0 & 60 & 0 & 0 & 0 \\
\hline 03 & vieua & & 108,4 & 48 & 41 & 109 & 70,4 & 0 & 0 & 50 & 20 & 0 & 0 & 15 \\
\hline & & HA & 105,9 & 48 & 41 & 124 & 47,9 & 0 & 0 & 50 & 40 & 0 & 0 & 30 \\
\hline & & & 101 & 48 & 41 & 154 & 23 & 0 & 0 & 50 & 60 & 0 & 0 & 60 \\
\hline & & & 71 & 82 & 80 & 85 & 38 & 0 & 0 & 0 & 6 & 0 & 0 & 0 \\
\hline & & HD & 71 & 82 & 80 & 85 & 38 & 0 & 0 & 0 & 6 & 0 & 0 & 0 \\
\hline 07 & Alts & & 71 & 82 & 80 & 86 & 38 & 0 & 0 & 0 & 6 & 0 & 0 & 1 \\
\hline 91 & Alta & & 52,8 & 82 & 80 & $\begin{array}{l}196,9 \\
\end{array}$ & 25,8 & 0 & 0 & 96,9 & 0 & 0 & 0 & 15 \\
\hline & & HA & 52,8 & 82 & 80 & 196,9 & 25,8 & 0 & 0 & 81,9 & 0 & 0 & 0 & 30 \\
\hline & & & 52,8 & 82 & 80 & 196,9 & 25,8 & 0 & 0 & 71 & 0 & 0 & 0 & 40,9 \\
\hline
\end{tabular}

Tabela 6.14: Comparação da programação da produção para o período 1 ao variar a demanda esperada 
Analisando a Tabela 6.14 vemos que, no caso da demanda baixa, ao diminuir e aumentar a demanda esperada dos produtos a heurística de decomposição fabrica o total da demanda extra dos produtos 1 e 2 conforme antes e aumenta, quando possível, a antecipação destes produtos. Para a demanda média, a produção do primeiro período continua a mesma ao variar a demanda esperada, porém a quantidade de demanda extra produzida no período 1 diminui ou aumenta conforme a demanda esperada e o estoque varia inversamente. Quando a demanda é alta, a programação da produção do período 1 é praticamente a mesma ao variar a demanda esperada. Houve apenas um aumento de uma unidade na fabricação da demanda extra do produto tipo 4. Isto acontece, porque a capacidade disponível já está no limite.

Considerando agora as soluções obtidas pela heurística de acoplamento, podemos dizer que, para as demandas baixa e média, a produção do período 1, a antecipação dos produtos e a produção da demanda extra variaram conforme a demanda esperada. Já a demanda alta, não modificou a produção do período 1 ao variar a demanda esperada, apenas adaptou a quantidade de produtos antecipados e a fabricação da demanda extra conforme a diminuição e o aumento da demanda esperada.

Comparando todas as soluções obtidas pelas duas heurísticas, notamos que na HA a ordem de escolha dos produtos para a fabricação da demanda extra e a formação de estoque é produtos 4, 1, 2 e 3 e na HD a ordem é produtos 1, 2, 4 e 3.

Em geral, podemos dizer que ao variar a demanda esperada de todos os tipos de produtos o comportamento das soluções não apresentou alterações significativas.

\subsubsection{Variação na quantidade de tipos de produtos}

Nestes experimentos, consideramos a mesma capacidade das máquinas (serra e furadeira) em todos os períodos e subperíodos e somente aumentamos a quantidade de tipos de produtos demandados para o mesmo horizonte de planejamento. Foram criadas novas classes de exemplares para demanda média, $h=0,0001, \alpha=0,5$ e $\gamma=0,15$. A demanda dos novos produtos foi gerada aleatoriamente no intervalo $\left[0,8 d_{i t} 1,2 d_{i t}\right]$. Os demais parâmetros foram coletados na indústria de móveis. Os resultados obtidos pelas heurísticas de acoplamento e de decomposição são apresentados na Tabela 6.15.

\begin{tabular}{|c|c|c|c|c|c|c|c|}
\hline \multicolumn{8}{|c|}{ Variação na quantidade de tipos de produtos } \\
\hline Heurística & $\begin{array}{l}\text { Tipos de } \\
\text { Produtos } \\
\end{array}$ & $\begin{array}{c}\text { Tempo } \\
\text { (s) }\end{array}$ & $\begin{array}{c}\text { FO total } \\
(\mathbf{R} \$)\end{array}$ & $\begin{array}{c}\text { FO Lote } \\
\text { (R\$) }\end{array}$ & $\begin{array}{c}\text { FO Corte } \\
(\mathbf{R} \$)\end{array}$ & Placas & $\begin{array}{c}\text { Perda } \\
(\%)\end{array}$ \\
\hline \multirow{6}{*}{ HD } & 5 & 147,47 & 134281,71 & 130655,54 & 3626,17 & 894,21 & 9,92 \\
\hline & 6 & 144,75 & 145336,32 & 141893,50 & 3442,82 & 855,22 & 9,73 \\
\hline & 7 & 202,64 & 148588,43 & 144952,01 & 3636,42 & 887,28 & 9,81 \\
\hline & 8 & 251,84 & 150036,78 & 146435,42 & 3601,35 & 901,06 & 9,62 \\
\hline & 9 & 187,70 & 150238,32 & 146645,94 & 3592,38 & 900,70 & 9,64 \\
\hline & 10 & 273,72 & 153722,01 & 150191,16 & 3530,85 & 918,75 & 9,21 \\
\hline \multirow{6}{*}{ HA } & 5 & 103,80 & 134257,44 & 130752,48 & 3504,95 & 874,17 & 9,81 \\
\hline & 6 & 134,08 & 145294,83 & 141960,37 & 3334,46 & 841,08 & 9,62 \\
\hline & 7 & 153,50 & 148510,68 & 145132,68 & 3378,00 & 848,58 & 9,63 \\
\hline & 8 & 124,24 & 149953,50 & 146619,18 & 3334,32 & 861,82 & 9,31 \\
\hline & 9 & 167,39 & 150162,33 & 146829,56 & 3332,77 & 861,56 & 9,31 \\
\hline & 10 & 198,61 & 153645,59 & 150369,77 & 3275,81 & 880,38 & 9,02 \\
\hline
\end{tabular}

Tabela 6.15: Variação na quantidade de tipos de produtos para demanda média 
Observando os resultados da Tabela 6.15, podemos dizer que a heurística de acoplamento teve um melhor desempenho que a heurística de decomposição, pois o tempo total médio de resolução, a quantidade de placas cortadas, o valor total ótimo da função objetivo, o valor ótimo da função objetivo do problema de corte e a perda total de matériaprima são menores para todas as classes testadas. Além disso, apesar do valor ótimo da função objetivo do problema de dimensionamento de lotes ser menor para a heurística de decomposição, a economia ocorrida no processo de corte ao utilizar um menor número de placas e também ter uma menor perda de matéria-prima, fez com que o valor total ótimo para heurística de acoplamento fosse menor.

A pequena diferença no valor ótimo do problema de dimensionamento de lotes entre as heurísticas se deu pelo fato da heurística de decomposição ter fabricado uma quantidade um pouco maior de produtos no primeiro período, uma vez que o custo de produção a partir do segundo período é maior. Como a HD não enxerga o problema de corte ao resolver o primeiro PDL, então tal heurística tenta produzir o máximo possível de produtos no período 1 sem se preocupar com a quantidade de placas cortadas e a perda de material.

O comportamento das soluções obtidas ao aumentar a quantidade de tipos de produtos foi igual aos experimentos realizados anteriormente com classes de problemas com parâmetros semelhantes, exceto o tempo total de resolução que, curiosamente, foi menor para a heurística de acoplamento.

Após estes testes, podemos dizer que as heurísticas de acoplamento e de decomposição, com os dados utilizados (coletados da indústria), conseguem determinar uma solução factível do problema acoplado para, no máximo, 10 tipos de produtos com demandas médias no horizonte de planejamento de um mês sem ter que aumentar a capacidade das máquinas para os períodos e subperíodos.

\subsubsection{Variação na capacidade das máquinas}

Continuando os experimentos, alteramos a capacidade das máquinas em todos os períodos e subperíodos do horizonte de planejamento em $\pm 20 \%$ dos valores considerados nos testes anteriores.

As colunas Apertada e Folgada da Tabela 6.16 mostram as perdas médias de matériaprima no primeiro período do horizonte de planejamento para todas as classes de problemas resolvidas pelas heurísticas de decomposição e de acoplamento quando as capacidades das máquinas foram diminuídas e aumentadas em $20 \%$, respectivamente. A coluna Normal contém as perdas das heurísticas HD e HA para a capacidade real das máquinas.

Conforme os resultados obtidos nestes testes, ao diminuir a capacidade das máquinas em $20 \%$ as heurísticas HD e HA não encontraram soluções factíveis para todas as classes de exemplares com demanda alta.

Notamos por estes experimentos que as capacidades das máquinas pouco influenciam na perda de matéria-prima (Tabela 6.16) e que o aumento e a diminuição da produção do período 1, que ocorreram ao variar tais capacidades, estão refletidos no número de placas cortadas (Tabela 6.17). Enquanto a heurística de decomposição (HD) usa a capacidade disponível no período 1, a heurística de acoplamento (HA) somente aumenta a produção no primeiro período se a perspectiva de perda for maior para os períodos futuros. Por exemplo, para $\gamma=0,05$ (5\% de perda), o número de placas cortadas não é influenciado pelo aumento de capacidade. Para $\gamma=0,1$ (10\% da perda) boa parte da produção é antecipada para o período 1 
e o custo de estocagem passa a ser inibidor. Para $\gamma=0,15$ (15\% de perda), ambas heurísticas têm comportamentos semelhantes, antecipando a produção, sendo que HA é um pouco mais sensível ao aumento do custo de estocagem.

\begin{tabular}{|c|c|c|c|c|c|c|c|c|c|c|}
\hline \multicolumn{11}{|c|}{ Variação na capacidade de máquina - Perda no período 1 (\%) } \\
\hline \multirow{2}{*}{ Classes } & \multirow{2}{*}{$\alpha$} & \multirow{2}{*}{$\boldsymbol{h}$} & \multirow[b]{2}{*}{$\gamma$} & \multirow{2}{*}{ Demanda } & \multicolumn{2}{|c|}{ Apertada } & \multicolumn{2}{|c|}{ Normal } & \multicolumn{2}{|c|}{ Folgada } \\
\hline & & & & & HD & HA & HD & HÁ & HD & HA \\
\hline $1,5,9$ & & 0,0001 & & & 11,19 & 12,80 & 11,77 & 12,80 & 13,00 & 12,80 \\
\hline $2,6,10$ & 0,5, & $\mathbf{0 , 0 0 1}$ & 0,05 & Baixa & 12,74 & 12,80 & 13,88 & 12,80 & 13,48 & 12,80 \\
\hline $3,7,11$ & 1.5 & $\mathbf{0 , 0 1}$ & & & 14,31 & 12,80 & 15,19 & 12,80 & 14,69 & 12,80 \\
\hline $4,8,12$ & & 0,1 & & & 14,82 & 12,97 & 14,82 & 12,97 & 14,82 & 12,97 \\
\hline $13,17,21$ & & 0,0001 & & & 12,79 & 13,66 & 12,14 & 13,66 & 11,81 & 13,66 \\
\hline $14,18,22$ & 0,5 & $\mathbf{0 , 0 0 1}$ & 0,05 & Média & 12,79 & 13,66 & 12,14 & 13,66 & 12,24 & 13,66 \\
\hline $15,19,23$ & 15 & $\mathbf{0 , 0 1}$ & & & 14,43 & 13,66 & 14,07 & 13,66 & 13,37 & 13,66 \\
\hline $16,20,24$ & & 0,1 & & & 14,45 & 14,44 & 15,33 & 14,44 & 14,45 & 14,44 \\
\hline $25,29,33$ & & 0,0001 & & & - & 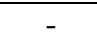 & 13,83 & 13,31 & 13,18 & 13,84 \\
\hline $26,30,34$ & 0,3 & 0,001 & 0,05 & Alta & - & - & 13,83 & 13,31 & 13,18 & 13,84 \\
\hline $27,31,35$ & $1 \mathrm{e}$ & 0,01 & & & - & - & 13,83 & 13,31 & 14,79 & 13,84 \\
\hline $28,32,36$ & & 0,1 & & & - & - & 14,76 & 13,39 & 14,82 & 14,66 \\
\hline $37,41,45$ & & 0,0001 & & & 11,19 & 11,15 & 11,86 & 11,15 & 13,11 & 11,15 \\
\hline $38,42,46$ & 1, & $\mathbf{0 , 0 0 1}$ & 0,1 & Baixa & 11,19 & 11,15 & 11,86 & 11,15 & 13,11 & 11,15 \\
\hline $39,43,47$ & $1 \mathrm{e}$ & $\mathbf{0 , 0 1}$ & & & 14,31 & 11,15 & 14,23 & 11,15 & 14,91 & 11,15 \\
\hline $40,44,48$ & & 0,1 & & & 14,22 & 11,19 & 15,27 & 11,19 & 14,85 & 11,19 \\
\hline $49,53,57$ & & 0,0001 & & & 12,79 & 12,20 & 12,14 & 11,71 & 11,85 & 11,41 \\
\hline $50,54,58$ & 0,5 & $\mathbf{0 , 0 0 1}$ & 0,1 & Média & 12,79 & 12,20 & 12,14 & 11,71 & 11,85 & 11,41 \\
\hline $51,55,59$ & 1 & $\mathbf{0 , 0 1}$ & & & 14,45 & 12,40 & 14,07 & 12,40 & 13,44 & 12,40 \\
\hline $52,56,60$ & & 0,1 & & & 14,45 & 12,54 & 15,33 & 12,54 & 14,39 & 12,54 \\
\hline $61,65,69$ & & 0,0001 & & & - & - & 13,83 & 13,31 & 13,18 & 12,63 \\
\hline $62,66,70$ & 0,3, & $\mathbf{0 , 0 0 1}$ & 0,1 & Alta & - & - & 13,83 & 13,31 & 13,18 & 12,63 \\
\hline $63,67,71$ & $1 \mathrm{e}$ & 0,01 & & & _. & - & 13,83 & 13,31 & 14,82 & 12,93 \\
\hline $64,68,72$ & & 0,1 & & & - & - & 14,89 & 13,35 & 14,82 & 13,11 \\
\hline $73,77,81$ & & 0,0001 & & & 11,90 & 11,62 & 11,86 & 11,68 & 13,11 & 11,70 \\
\hline $74,78,82$ & , & $\mathbf{0 , 0 0 1}$ & 0,15 & Baixa & 11,90 & 11,62 & 11,86 & 11,68 & 13,11 & 11,70 \\
\hline $75,79,83$ & 1 & $\mathbf{0 , 0 1}$ & & & 14,31 & 11,62 & 14,35 & 11,68 & 15,02 & 11,70 \\
\hline $76,80,84$ & & 0,1 & & & 14,39 & 11,32 & 14,44 & 11,32 & 14,85 & 11,32 \\
\hline $85,89,93$ & & 0,0001 & & & 12,79 & 12,20 & 12,14 & 11,71 & 11,85 & 11,41 \\
\hline $86,90,94$ & 0,5, & 0,001 & 0,15 & Média & 12,79 & 12,20 & 12,14 & 11,71 & 11,85 & 11,41 \\
\hline $87,91,95$ & & $\mathbf{0 , 0 1}$ & & & 14,45 & 12,20 & 14,07 & 11,71 & 13,44 & 11,41 \\
\hline $88,92,96$ & & $\mathbf{0 , 1}$ & & & 14,45 & 12,54 & 15,33 & 12,54 & 14,28 & 12,54 \\
\hline 97,101,105 & & 0,0001 & & & 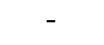 & 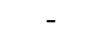 & 13,83 & 13,31 & 13,18 & 12,63 \\
\hline $98,102,106$ & 0,3 & $\mathbf{0 , 0 0 1}$ & 0,15 & Alta & - & - & 13,83 & 13,31 & 13,18 & 12,63 \\
\hline $99,103,107$ & 1.5 & $\mathbf{0 , 0 1}$ & & & - & - & 13,83 & 13,31 & 14,82 & 12,63 \\
\hline $100,104,108$ & & $\mathbf{0 , 1}$ & & & 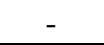 & - & 13,93 & 13,35 & 14,95 & 13,11 \\
\hline
\end{tabular}

Tabela 6.16: Comparação da perda ocorrida no período 1 ao variar a capacidade de máquina 


\begin{tabular}{|c|c|c|c|c|c|c|c|c|c|c|}
\hline \multicolumn{11}{|c|}{ Variação na capacidade de máquina - Número de placas cortadas no período 1} \\
\hline \multirow{2}{*}{ Classes } & \multirow{2}{*}{$\alpha$} & \multirow{2}{*}{$\boldsymbol{h}$} & \multirow[b]{2}{*}{$\boldsymbol{\gamma}$} & \multirow{2}{*}{ Demanda } & \multicolumn{2}{|c|}{ Apertada } & \multicolumn{2}{|c|}{ Normal } & \multicolumn{2}{|c|}{ Folgada } \\
\hline & & & & & HD & HA & HD & HA & HD & HA \\
\hline $1,5,9$ & & 0, & & & 852,62 & 135,46 & 1075,62 & 135,46 & 1303,60 & 135,46 \\
\hline $2,6,10$ & 0,5 & 0,001 & 0,05 & Baixa & 862,61 & 135,46 & 1095,27 & 135,46 & 1310,41 & 135,46 \\
\hline $3,7,11$ & $1 \mathrm{e}$ & $\mathbf{0 , 0 1}$ & & & 875,45 & 135,46 & 1093,85 & 135,46 & 1301,38 & 135,46 \\
\hline $4,8,12$ & & 0,1 & & & 61,23 & 134,21 & 761,23 & 134,21 & 761,23 & 134,21 \\
\hline $13,17,21$ & & 0,0001 & & & 831,08 & 486,87 & 1050,04 & 486,87 & 1257,34 & 486,87 \\
\hline $14,18,22$ & 0,3 & $\mathbf{0 , 0 0 1}$ & 0,05 & Média & 831,08 & 486 & 1050,04 & & 1275,79 & 486,87 \\
\hline $15,19,23$ & 14 & $\mathbf{0 , 0 1}$ & & & 839,48 & 486,87 & 1068,14 & 486,87 & 1274,51 & 486,87 \\
\hline $16,20,24$ & & 0,1 & & & 843,22 & 465,68 & 1059,10 & 465,68 & 1092,94 & 465,68 \\
\hline 25,2 & & 0,0001 & & & 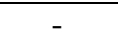 & 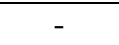 & 103 & & 5,38 & 826,83 \\
\hline 26,3 & & 0,001 & 0,05 & Alta & - & - & 1033,54 & 972,56 & 1245,38 & 826,83 \\
\hline $27,31,35$ & - & 0,01 & & & - & - & 1033,54 & 972,56 & 1258,34 & 826,83 \\
\hline $28,32,36$ & & 0,1 & & & - & 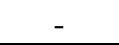 & 993,19 & 967,94 & 1254,98 & 790,23 \\
\hline $37,41,45$ & & 0,0001 & & & 852,62 & 318,63 & 1068,98 & 318,63 & 1308,22 & 318,63 \\
\hline $38,42,46$ & 1, & $\mathbf{0 , 0 0}$ & 0,1 & Baixa & 852,62 & 318,63 & 1079,69 & 318,63 & 1308,22 & 318,63 \\
\hline $39,43,47$ & & 0,01 & & & 875,45 & 318,63 & 1101,77 & 318 & 1329,34 & 318,63 \\
\hline $40,44,48$ & & 0,1 & & & 38,12 & 317 & 106 & & 41 & 317,80 \\
\hline 49,5 & & 0,0001 & & & 831,08 & 786,68 & 105 & 100 & 1,90 & 1217,27 \\
\hline $50,54,58$ & & $\mathbf{0 , 0 0}$ & 0,1 & N & 831,08 & 786,68 & 1050,04 & 100 & 1261,90 & 1217,27 \\
\hline $51,55,59$ & 1 & $\mathbf{0 , 0 1}$ & & & 843,22 & 722,90 & 1068,14 & 722,90 & 1279,56 & 722,90 \\
\hline $52,56,60$ & & 01 & & & 843,22 & 716,98 & 1059,10 & 716,98 & 1235,51 & 716,98 \\
\hline 61,6 & & 0,0001 & & & - & - & & & 38 & 1175,05 \\
\hline 62 , & & & 0,1 & Alta & - & - & 10 & 97 &, 38 & 05 \\
\hline 63,6 & & $\mathbf{0 , 0}$ & & & - & 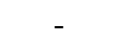 & 103 & 97 &, 81 & 1062,69 \\
\hline 64,6 & & $\mathbf{0}$, & & & - & - & 1006,63 & 978 & 1254,98 & 1051,66 \\
\hline $73,77,81$ & & 0,0001 & & & 852,62 & 837,74 & 1079,69 & 1060,83 & 1308,22 & 1151,10 \\
\hline $74,78,82$ & 1, & $\mathbf{0 , 0 0 1}$ & 0,15 & Baixa & 852,62 & 837,74 & 1079,69 & 1060,83 & 1308,22 & 1151,10 \\
\hline $75,79,83$ & 1 & 0,0 & & & 875 & 837,74 & 110 & 1060,83 & 1330,70 & 1151,10 \\
\hline $76,80,84$ & & 0,1 & & & 831,97 & 387,17 & & & & 387,17 \\
\hline 85,8 & & 0,0001 & & & 831,08 & 786,68 & 1050,04 & 1006,18 & 1261,90 & 1217,27 \\
\hline $86,90,94$ & 0,5 & 0,001 & 0,15 & Média & 831,08 & 786,68 & 1050,04 & 1006,18 & 1261,90 & 1217,27 \\
\hline $87,91,95$ & & $\mathbf{0 , 0}$ & & & 843,22 & 786,68 & 1068,14 & 1006,18 & 1279,56 & 1217,27 \\
\hline $88,92,96$ & & 0,1 & & & 843,22 & 716,98 & 1059,10 & 716,98 & 1246,22 & 716,98 \\
\hline $97,101,105$ & & 0,0001 & & & 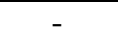 & 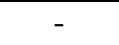 & 1033,54 & 972,56 & 1245,38 & 1175,05 \\
\hline $98,102,106$ & 0,3, & $\mathbf{0 , 0 0}$ & 0,15 & Alta & & - & 1033 & 972,56 & 5,38 & 1175,05 \\
\hline $99,103,107$ & & $\mathbf{0 , 0}$ & & & & - & 1033,54 & 972,56 & 1263,81 & 1175,05 \\
\hline $100,104,108$ & & 0,1 & & & & - & 103 & 978 & 1261 & 105 \\
\hline
\end{tabular}

Tabela 6.17: Comparação do número de placas cortadas no período 1 ao variar a capacidade de máquina

\subsubsection{Variação na estimativa da perda a partir do segundo período}

Em todas as classes de exemplares testadas até o momento, a estimativa da perda acrescentada aos custos de produção a partir do segundo período do horizonte de planejamento foi determinada aleatoriamente e igual para todos os períodos. Decidimos, então, estimá-la de uma forma um pouco mais realista, considerando a perda percentual ocorrida na solução lote-por-lote para esta estimativa. Nestes experimentos, foram resolvidos exemplares de uma classe para cada tipo de demanda (baixa, média e alta) com $h=0,0001$, $\alpha=0,5$ e $\gamma=0,05$ e usando a heurística de acoplamento. Os resultados obtidos são apresentados na Tabela 6.18 .

A coluna Perda lote/lote contém as perdas obtidas a partir do período 2 do horizonte de planejamento na solução lote-por-lote, as quais foram usadas para calcular os custos de 
produção a partir do segundo período e cujas soluções (perdas e placas cortadas) para o período 1 são dadas nas colunas $\boldsymbol{\gamma}=\mathbf{l o t e} / \mathbf{l o t e}$. As colunas $\boldsymbol{\gamma}=\mathbf{0 , 0 5}$ contém as soluções (perdas e placas cortadas) do período 1 com os custos de produção a partir do período 2 calculados com uma estimativa de perda de $5 \%$.

\begin{tabular}{|c|c|c|c|c|c|c|}
\hline \multicolumn{7}{|c|}{ Variação na estimativa da perda } \\
\hline \multirow[t]{2}{*}{ Demanda } & \multirow{2}{*}{$\begin{array}{l}\text { Período } \\
\quad(t)\end{array}$} & \multirow{2}{*}{$\begin{array}{c}\text { Perda lote/lote } \\
(\%)\end{array}$} & \multicolumn{2}{|c|}{$\begin{array}{c}\text { Perda no período } 1 \\
(\%)\end{array}$} & \multicolumn{2}{|c|}{$\begin{array}{l}\text { Placas cortadas } \\
\text { no período } 1\end{array}$} \\
\hline & & & $\gamma=0,05$ & $\gamma=$ lote $/$ lote & $\gamma=\mathbf{0 , 0 5}$ & $\gamma=$ lote/lote \\
\hline \multirow{3}{*}{ Baixa } & 2 & 15 & \multirow{3}{*}{13} & \multirow{3}{*}{8} & \multirow{3}{*}{136} & \multirow{3}{*}{1784} \\
\hline & 3 & 16 & & & & \\
\hline & 4 & 16 & & & & \\
\hline \multirow{3}{*}{ Média } & 2 & 15 & \multirow{3}{*}{14} & \multirow{3}{*}{12} & \multirow{3}{*}{487} & \multirow{3}{*}{1006} \\
\hline & 3 & 14 & & & & \\
\hline & 4 & 15 & & & & \\
\hline \multirow{3}{*}{ Alta } & 2 & 14 & \multirow{3}{*}{13} & \multirow{3}{*}{13} & \multirow{3}{*}{972} & \multirow{3}{*}{972} \\
\hline & 3 & 15 & & & & \\
\hline & 4 & 12 & & & & \\
\hline
\end{tabular}

Tabela 6.18: Comparação da perda e do número de placas cortadas no período 1

Analisando os resultados, vemos que a perda total média de matéria-prima no período 1 , quando os custos de produção para os períodos 2, 3 e 4 foram determinados considerando a perda da solução lote-por-lote, foi bem menor para as classes com demandas baixa (quase $40 \%$ ) e média (em torno de $15 \%$ ) e igual para a classe de demanda alta. Com relação ao número de placas cortadas, para a classe com demanda baixa a solução foi aproximadamente 13 vezes maior, para a demanda média foi em torno de $50 \%$ maior e para a demanda alta foi igual. A solução da classe com demanda alta permaneceu igual ao modificar os custos de produção, pois as capacidades das máquinas no período 1 limitaram a produção deste período, não permitindo seu aumento.

Diante destes resultados, podemos dizer que, como a estimativa de perda de $5 \%$ usada no cálculo dos custos de produção a partir do segundo período era muito pequena diante da realidade, praticamente só a demanda em carteira do período é programada para ser produzida no primeiro período. Ao aumentar esta estimativa de perda, baseado na perda da solução lotepor-lote, adiantar a fabricação de alguns produtos passa a ser vantajoso, a demanda de peças aumenta e a utilização de outros padrões de corte permite reduzir a perda de material.

Este comportamento das soluções considerando as demandas baixa, média e alta também pode ser observado nas soluções apresentadas em experimentos anteriores, nas seções 6.3.2 e 6.3.3.1.

\subsubsection{Solução para todo o horizonte de planejamento}

Nesta seção, apresentamos e comparamos a solução lote-por-lote e a solução obtida pela heurística de acoplamento sem considerar a demanda extra, ou seja, $D_{i}=\sum_{t=1}^{4} d_{i t}$, para $i=1, \ldots, 4$. Resolvemos um exemplar cada tipo de demanda e cada valor de $h$. O horizonte de planejamento foi rolado e as demandas para os novos períodos foram consideradas nulas. 
A Tabela 6.19 contém as soluções do primeiro período para todos os exemplares resolvidos pela HA a solução lote-por-lote deste período.

\begin{tabular}{|c|c|c|c|c|c|c|c|c|}
\hline \multicolumn{9}{|c|}{ Solução para o período 1} \\
\hline \multirow{2}{*}{ Demanda } & \multirow{2}{*}{$h$} & \multirow{2}{*}{$\begin{array}{l}\text { FO Corte } \\
(\mathbf{R} \$)\end{array}$} & \multirow{2}{*}{$\begin{array}{c}\text { Placas } \\
\text { Cortadas }\end{array}$} & \multirow{2}{*}{$\begin{array}{c}\text { Perda } \\
(\%)\end{array}$} & \multicolumn{4}{|c|}{ Estoque período 1} \\
\hline & & & & & $I_{11}$ & $I_{21}$ & $I_{31}$ & $I_{41}$ \\
\hline \multirow{5}{*}{ Baixa } & 0,0001 & 5818,00 & 1132,51 & 9,83 & 99 & 76,86 & 0 & 0 \\
\hline & 0,001 & 5635,38 & 1099,42 & 13,9 & 99 & 71,76 & 0 & 0 \\
\hline & 0,01 & 5635,38 & 1099,42 & 13,9 & 99 & 71,76 & 0 & 0 \\
\hline & 0,1 & 5635,38 & 1099,42 & 13,9 & 99 & 71,76 & 0 & 0 \\
\hline & Lote/lote & 679,49 & 122,56 & 15,48 & - & - & - & - \\
\hline \multirow{5}{*}{ Média } & $\mathbf{0 , 0 0 0 1}$ & 5312,69 & 1098,46 & 9,12 & 105,29 & 0 & 0 & 0 \\
\hline & 0,001 & 5080,51 & 1050,55 & 12,14 & 101,09 & 0 & 0 & 0 \\
\hline & 0,01 & 5080,51 & 1050,55 & 12,14 & 101,09 & 0 & 0 & 0 \\
\hline & 0,1 & 5269,18 & 1056,75 & 12,81 & 89,00 & 14,22 & 0 & 0 \\
\hline & Lote/lote & 2593,67 & 454,25 & 15,22 & - & - & - & - \\
\hline \multirow{5}{*}{ Alta } & 0,0001 & 5529,45 & 1034,68 & 13,82 & 44,19 & 0 & 0 & 0 \\
\hline & 0,001 & 5529,45 & 1034,68 & 13,82 & 44,19 & 0 & 0 & 0 \\
\hline & $\mathbf{0 , 0 1}$ & 5529,45 & 1034,68 & 13,82 & 44,19 & 0 & 0 & 0 \\
\hline & 0,1 & 5529,45 & 1034,68 & 13,82 & 44,19 & 0 & 0 & 0 \\
\hline & Lote/lote & 4477,04 & 775,08 & 15,31 & - & - & - & - \\
\hline
\end{tabular}

Tabela 6.19: Comparação das soluções lote/lote e da HA para o período 1

Analisando a Tabela 6.19, vemos que a perda de material no primeiro período do horizonte de planejamento é menor nas soluções da HA em todos os exemplares resolvidos. Isto ocorreu, por causa da antecipação da fabricação de alguns produtos no primeiro período, permitindo um melhor aproveitamento das placas ao aumentar a demanda de peças e também por utilizar padrões de corte com menor perda. Este fato pode ser verificado observando as quatro últimas colunas da tabela que referem-se ao estoque do primeiro período.

Valores maiores para a função objetivo do problema de corte com a HA eram esperados devido à maior quantidade de produtos fabricados no primeiro período e, consequentemente, uma quantidade maior de placas usadas. As soluções da HA para os exemplares de demanda alta não se modificaram ao variar os custos de estoque por causa da limitação na capacidade, que não permitiu aumentar a quantidade de produtos fabricados no primeiro período ao diminuir o custo de estoque conforme ocorreu com as demandas baixa e média.

Com estes experimentos foi possível constatar mais uma vez que como o problema acoplado permite identificar produtos adequados para serem antecipados levando a uma diminuição na perda de matéria-prima e, consequentemente, reduz os custos totais de produção. Destacamos a diminuição da perda, pois no primeiro período, com o aumento da produção devido à antecipação, o número de placas aumenta na solução do problema acoplado, mas em contra-partida, reduz a perda de material, significando um melhor aproveitamento dos recursos.

\subsubsection{Heurística de factibilização}

Para realizar os experimentos com a heurística de factibilização, aumentamos a capacidade do primeiro período do problema de dimensionamento de lotes em $20 \%$. Na Tabela 6.20, mostramos a programação da produção para o primeiro período do horizonte de 
planejamento antes e depois de aplicar a heurística de factibilização. Somente os resultados para um exemplar de cada uma das classes 1 a 36 são apresentados. Para as demais classes, as soluções foram semelhantes e, por isso, omitidas.

Ao aumentar somente a capacidade das máquinas no período 1 do problema de dimensionamento de lotes, a heurística de decomposição determinou uma programação da produção para tal período, que transformada em demanda de peças a serem cortadas e furadas nos subperíodos, tornou o problema de corte infactível.

\begin{tabular}{|c|c|c|c|c|c|c|c|c|c|c|c|c|c|c|}
\hline \multicolumn{15}{|c|}{ Programação da produção para período 1 - Heurística de factibilização } \\
\hline Exemplares & Demanda & & $\mathbf{x}_{11}$ & $\mathbf{x}_{21}$ & $\mathbf{x}_{31}$ & $\mathbf{x}_{41}$ & $\mathbf{I}_{11}$ & $\mathbf{I}_{21}$ & $\mathbf{I}_{31}$ & $\mathbf{I}_{41}$ & $\mathbf{E}_{11}$ & $\mathbf{E}_{21}$ & $\mathbf{E}_{31}$ & $\mathbf{E}_{41}$ \\
\hline \multirow{4}{*}{$2,6,10$} & \multirow{8}{*}{ Baixa } & Antes & 147 & 79 & 2 & 2 & 99 & 26 & 0 & 0 & 40 & 40 & 0 & 0 \\
\hline & & Depois & 144 & 39 & 2 & 2 & 99 & 26 & 0 & 0 & 37 & 0 & 0 & 0 \\
\hline & & Antes & 137 & 91 & 2 & 2 & 89 & 38 & 0 & 0 & 40 & 40 & 0 & 0 \\
\hline & & Depois & 134 & 51 & 2 & 2 & 89 & 38 & 0 & 0 & 37 & 0 & 0 & 0 \\
\hline \multirow{2}{*}{$3,7,11$} & & Antes & 105 & 91 & 105 & 2 & 57 & 38 & 3 & 0 & 40 & 40 & 100 & 0 \\
\hline & & Depois & 105 & 85 & 5 & 2 & 57 & 38 & 3 & 0 & 40 & 34 & 0 & 0 \\
\hline \multirow{2}{*}{$4,8,12$} & & Antes & 144 & 93 & 3 & 2 & 99 & 80 & 1 & 0 & 40 & 0 & 0 & 0 \\
\hline & & Depois & 53 & 93 & 3 & 2 & 48 & 80 & 1 & 0 & 0 & 0 & 0 & 0 \\
\hline \multirow{2}{*}{$13,17,21$} & \multirow{8}{*}{ Média } & Antes & 154 & 48 & 41 & 44 & 96 & 0 & 0 & 0 & 40 & 0 & 0 & 0 \\
\hline & & Depois & 118 & 48 & 41 & 44 & 96 & 0 & 0 & 0 & 4 & 0 & 0 & 0 \\
\hline \multirow{2}{*}{$14,18,22$} & & Antes & 123 & 85 & 41 & 44 & 65 & 0 & 0 & 0 & 40 & 37 & 0 & 0 \\
\hline & & Depois & 118 & 48 & 41 & 44 & 65 & 0 & 0 & 0 & 35 & 0 & 0 & 0 \\
\hline \multirow{2}{*}{$15,19,23$} & & Antes & 120 & 88 & 41 & 44 & 62 & 0 & 0 & 0 & 40 & 40 & 0 & 0 \\
\hline & & Depois & 119 & 48 & 41 & 44 & 62 & 0 & 0 & 0 & 39 & 0 & 0 & 0 \\
\hline \multirow{2}{*}{$16,20,24$} & & Antes & 58 & 88 & 141 & 74 & 0 & 0 & 0 & 0 & 40 & 40 & 100 & 30 \\
\hline & & Depois & 58 & 88 & 126 & 44 & 0 & 0 & 0 & 0 & 40 & 40 & 85 & 0 \\
\hline \multirow{2}{*}{$25,29,33$} & \multirow{8}{*}{ Alta } & Antes & 106 & 83 & 80 & 85 & 39 & 0 & 0 & 0 & 40 & 1 & 0 & 0 \\
\hline & & Depois & 70 & 82 & 80 & 85 & 39 & 0 & 0 & 0 & 4 & 0 & 0 & 0 \\
\hline \multirow{2}{*}{$26,30,34$} & & Antes & 106 & 83 & 80 & 85 & 39 & 0 & 0 & 0 & 40 & 1 & 0 & 0 \\
\hline & & Depois & 70 & 82 & 80 & 85 & 39 & 0 & 0 & 0 & 4 & 0 & 0 & 0 \\
\hline \multirow{2}{*}{$27,31,35$} & & Antes & 105 & 84 & 80 & 85 & 38 & 0 & 0 & 0 & 40 & 2 & 0 & 0 \\
\hline & & Depois & 70 & 82 & 80 & 85 & 38 & 0 & 0 & 0 & 5 & 0 & 0 & 0 \\
\hline \multirow{2}{*}{$28,32,36$} & & Antes & 65 & 106 & 111 & 156 & 0 & 19 & 31 & 71 & 38 & 5 & 0 & 0 \\
\hline & & Depois & 32 & 101 & 111 & 156 & 0 & 19 & 31 & 71 & 5 & 0 & 0 & 0 \\
\hline
\end{tabular}

Tabela 6.20: Comparação da programação da produção do período 1 antes e depois da factibilização

De acordo com os dados da Tabela 6.20, percebemos que, se há capacidade de máquina disponível, a heurística de decomposição antecipa, o quanto for possível, a fabricação da demanda em carteira de alguns tipos de produtos e aproveita para produzir uma determinada quantidade da demanda extra logo no primeiro período do horizonte de planejamento. Este fato pode ser facilmente observado, analisando, principalmente, os resultados obtidos para as classes com demanda baixa.

\subsubsection{Solução Inteira}

Nesta seção, mostramos os resultados dos experimentos computacionais realizados com as heurísticas de decomposição (HD) e de acoplamento (HA) ao aplicar a heurística residual de arredondamento gulosa (RAG) para obter soluções inteiras para o problema acoplado. Analisamos e comentamos a qualidade das soluções. 
Resolvemos somente um exemplar de cada uma das classes com $\alpha=0,5$, pois para os demais valores de $\alpha$ as soluções contínuas foram iguais. Devido ao grande tempo de resolução, limitamos o número de novas colunas inseridas por iteração da heurística residual de arredondamento gulosa em 3000 colunas. Os resultados obtidos pelas heurísticas de decomposição e acoplamento são comparados e apresentados na Tabela 6.21.

A coluna Desvio mostra a diferença em percentual entre o valor da função objetivo total obtido pela heurística de decomposição e pela heurística de acoplamento.

\begin{tabular}{|c|c|c|c|c|c|c|c|c|c|c|c|}
\hline \multicolumn{12}{|c|}{ Solução Inteira } \\
\hline \multirow[t]{2}{*}{ Exemplar } & \multirow[t]{2}{*}{$\boldsymbol{h}$} & \multirow[t]{2}{*}{$\gamma$} & \multicolumn{2}{|c|}{$\begin{array}{l}\text { Tempo } \\
\text { (s) }\end{array}$} & \multicolumn{2}{|c|}{$\begin{array}{l}\text { FO Total } \\
\text { (R\$) }\end{array}$} & \multicolumn{2}{|c|}{$\begin{array}{c}\text { Perda } \\
(\%)\end{array}$} & \multicolumn{2}{|c|}{$\begin{array}{c}\text { Iterações } \\
\text { da RAG }\end{array}$} & \multirow{2}{*}{$\begin{array}{c}\text { Desvio } \\
(\%)\end{array}$} \\
\hline & & & HD & HA & HD & HA & HD & HA & HD & HA & \\
\hline 1 & \begin{tabular}{|l|}
0,0001 \\
\end{tabular} & \multirow{4}{*}{$\mathbf{0 , 0 5}$} & 7426 & 6149 & 97585,99 & 95118,28 & 11,7 & 14,49 & 6 & 3 & 2,53 \\
\hline 2 & 0,001 & & 11340 & 6125 & 98223,41 & 95129,99 & 13,74 & 14,76 & 6 & 3 & 3,15 \\
\hline 3 & 0,01 & & 12681 & 6563 & Infactível & $\mathbf{9 5 2 7 8 , 2 3}$ & - & 15,16 & - & 3 & . \\
\hline 4 & 0,1 & & 3122 & 3455 & 99379,28 & 96433,63 & 15,36 & 14,45 & 6 & 4 & 2,96 \\
\hline 13 & 0,0001 & \multirow{4}{*}{0,1} & 4953 & 2243 & 117695,44 & 116415,56 & 12,44 & 14,76 & 6 & 5 & 1,09 \\
\hline 14 & 0,001 & & 4988 & 2291 & 117721,32 & 116491,86 & 12,44 & 15,18 & 6 & 5 & 1,04 \\
\hline 15 & $\mathbf{0 , 0 1}$ & & 2918 & 2812 & 118367,80 & 116481,19 & 12,44 & 14,62 & 4 & 4 & 1,59 \\
\hline 16 & 0,1 & & 2673 & 2161 & 120387,93 & 117792,63 & 14,40 & 16,11 & 7 & 4 & 2,16 \\
\hline 25 & 0,0001 & \multirow{4}{*}{0,15} & 2852 & 3086 & 136128,17 & 135923,20 & 14,16 & 14,06 & 5 & 6 & 0,15 \\
\hline 26 & $\mathbf{0 , 0 0 1}$ & & 3200 & 3588 & 136148,67 & 135924,84 & 14,16 & 14,03 & 5 & 6 & 0,16 \\
\hline 27 & $\mathbf{0 , 0 1}$ & & 3177 & 3332 & 136353,56 & 136001,57 & 14,16 & 14,18 & 5 & 4 & 0,26 \\
\hline 28 & 0,1 & & 3325 & 5347 & 138387,64 & 138027,30 & 15,36 & 14,21 & 5 & 4 & 0,26 \\
\hline 37 & 0,0001 & \multirow{4}{*}{0,05} & 9364 & 5631 & Infactível & 99499,50 & - & 12,31 & - & 3 & - \\
\hline 38 & 0,001 & & 8399 & 5651 & Infactível & 99511,21 & - & 12,31 & - & 4 & - \\
\hline 39 & $\mathbf{0 , 0 1}$ & & 11341 & 4536 & 101042,39 & 99605,18 & 14,20 & 12,23 & 6 & 4 & 1,42 \\
\hline 40 & 0,1 & & 7689 & 5194 & 103956,35 & 100556,84 & 15,70 & 11,52 & 5 & 4 & 3,27 \\
\hline 49 & 0,0001 & \multirow{4}{*}{0,1} & 4808 & 4567 & 120900,78 & 120868,35 & 12,44 & 12,55 & 6 & 4 & 0,03 \\
\hline 50 & 0,001 & & 4797 & 3117 & 120926,65 & 120972,63 & 12,44 & 13,48 & 6 & 5 & $-0,04$ \\
\hline 51 & 0,01 & & 2794 & 1909 & 121589,95 & 121049,41 & 14,4 & 13,51 & 4 & 4 & 0,44 \\
\hline 52 & 0,1 & & 2745 & 5255 & 123691,52 & 122134,72 & 15,70 & 14,12 & 7 & 4 & 1,26 \\
\hline 61 & 0,0001 & \multirow{4}{*}{0,15} & 2956 & 3918 & 140278,64 & 140186,27 & 14,16 & 14,23 & 5 & 5 & 0,07 \\
\hline 62 & 0,001 & & 2948 & 3243 & 140299,14 & 140358,40 & 14,16 & 14,17 & 5 & 6 & $-0,04$ \\
\hline 63 & 0,01 & & 2982 & 4311 & 140504,03 & 140251,60 & 14,16 & 14,44 & 5 & 5 & 0,18 \\
\hline 64 & 0,1 & & 4665 & 4165 & 142429,41 & 142295,96 & 15,22 & 12,03 & 4 & 5 & 0,09 \\
\hline 73 & 0,0001 & \multirow{4}{*}{0,05} & 11303 & 2495 & Infactível & 101858,48 & - & 11,81 & - & 5 & - \\
\hline 74 & 0,001 & & 8797 & 3079 & Infactível & 101777,85 & - & 11,92 & - & 5 & - \\
\hline 75 & 0,01 & & 10845 & 1960 & 103162,00 & 102364,36 & 14,26 & 11,62 & 6 & 5 & 0,77 \\
\hline 76 & 0,1 & & 2779 & 5669 & 106088,48 & 104299,09 & 14,82 & 12,70 & 6 & 4 & 1,69 \\
\hline 85 & 0,0001 & \multirow{4}{*}{0,1} & 4762 & 2315 & 124106,10 & 124265,22 & 12,44 & 12,68 & 6 & 4 & $-0,13$ \\
\hline 86 & $\mathbf{0 , 0 0 1}$ & & 4763 & 2799 & 124131,97 & 124293,10 & 12,44 & 12,62 & 6 & 6 & $-0,13$ \\
\hline 87 & 0,01 & & 2782 & 2454 & 124812,09 & 124547,08 & 14,40 & 13,54 & 4 & 4 & 0,21 \\
\hline 88 & 0,1 & & 2533 & 3954 & 126995,10 & 126122,72 & 15,70 & 14,07 & 7 & 4 & 0,69 \\
\hline 97 & 0,0001 & \multirow{4}{*}{0,15} & 2941 & 6888 & 144429,09 & 144458,36 & 14,16 & 14,11 & 5 & 6 & $-0,02$ \\
\hline 98 & $\mathbf{0 , 0 0 1}$ & & 2940 & 2289 & 144449,58 & 144336,13 & 14,16 & 14,02 & 5 & 6 & 0,08 \\
\hline 99 & 0,01 & & 2943 & 1846 & 144654,48 & 144588,67 & 14,16 & 14,49 & 5 & 5 & 0,05 \\
\hline 100 & 0,1 & & 1974 & 7017 & 146707,30 & 146682,05 & 14,36 & 14,46 & 5 & 6 & 0,02 \\
\hline
\end{tabular}

Tabela 6.21: Comparação das soluções inteiras obtidas por HD e HA

Observando a Tabela 6.21 e as Figuras 6.10 a 6.12 , vemos que o tempo total de resolução da HA foi menor nos exemplares das demandas baixa e média e maiores para os exemplares de demanda alta. Além disso, a heurística HD não encontrou solução inteira 
factível para 5 exemplares de demanda baixa. O número de iterações da heurística residual de arredondamento gulosa foi sempre maior ou igual para a HD nas demandas baixa e média e menor para a demanda alta.

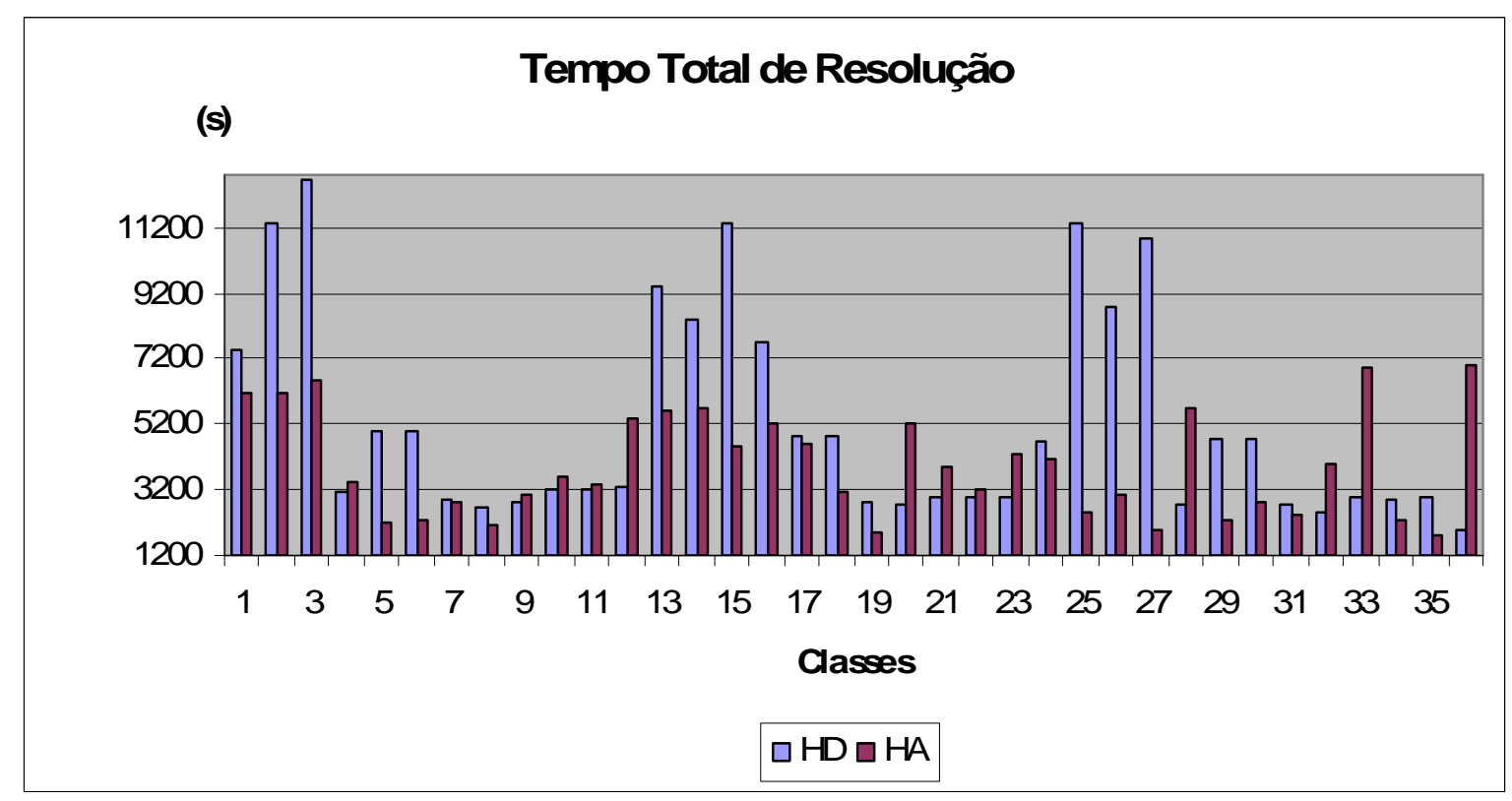

Figura 6.10: Comparação do tempo total das soluções inteiras obtidas por HD e HA.

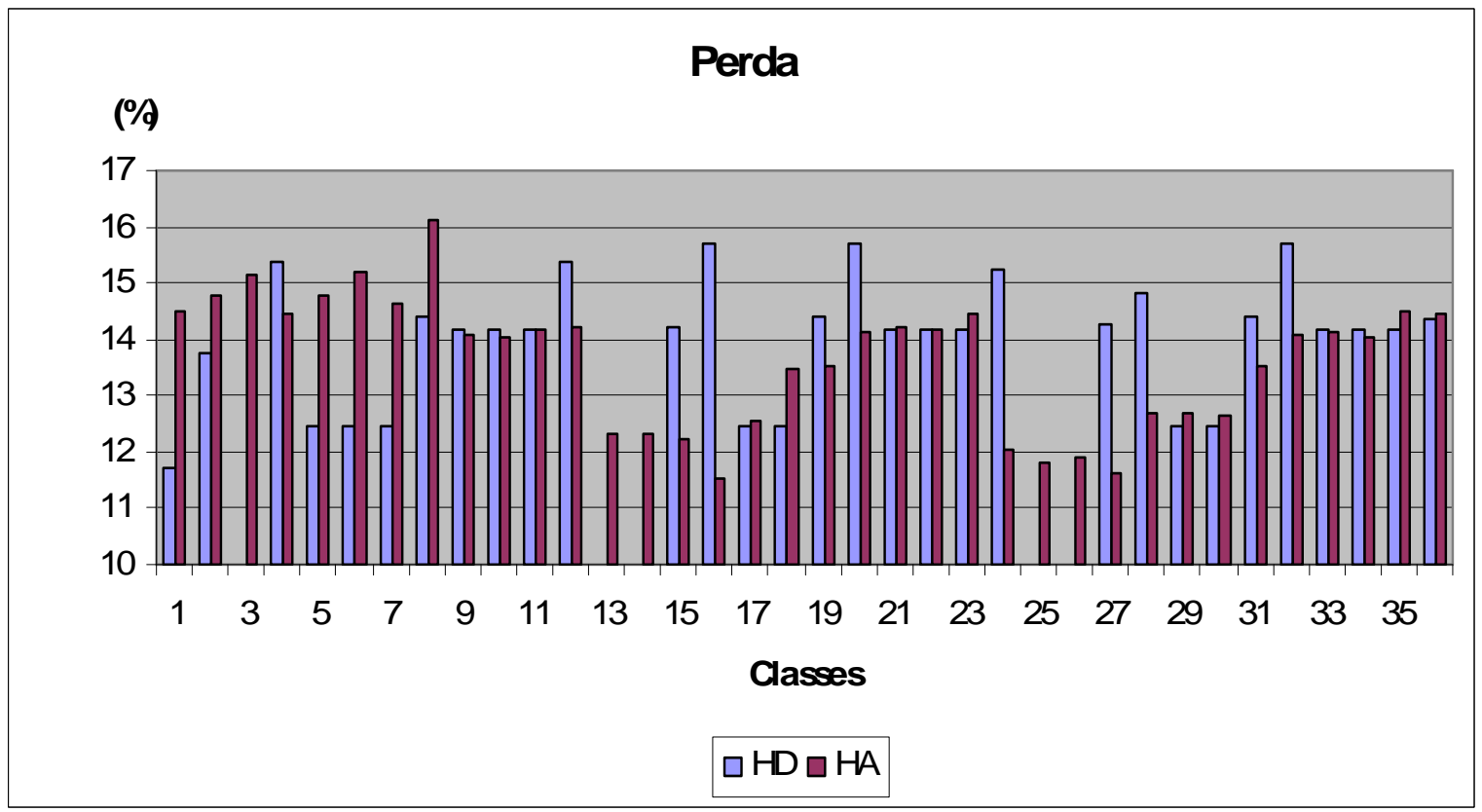

Figura 6.11: Comparação das perdas nas soluções inteiras obtidas por HD e HA. 


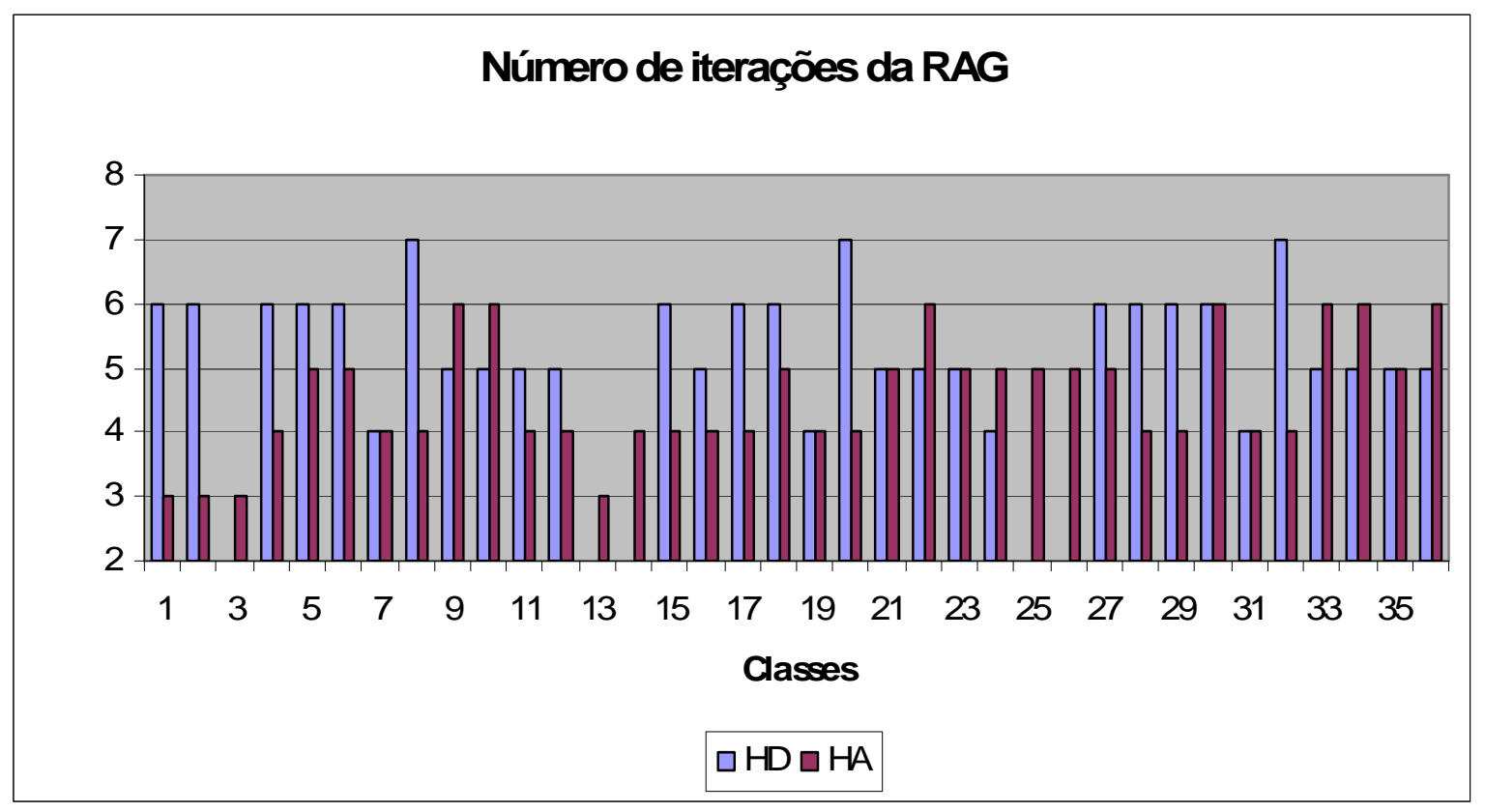

Figura 6.12: Comparação do número de iterações feito pela RAG com HD e HA.

O princípio da heurística residual de arredondamento gulosa utilizada é atender na igualdade o plano de produção do período 1, cortando exatamente a demanda de peças requeridas neste período $\left(\sum_{i=1}^{M} r_{p i} x_{i 1}\right.$, para todo $\left.p\right)$. Este fato pode explicar os valores altos obtidos para as perdas totais nos testes. Por causa das demandas baixas de peças nos problemas de corte residuais, as quais vão diminuindo conforme o número de iterações da heurística de arredondamento gulosa aumenta, piores são as combinações das peças nos padrões de corte e, consequentemente, maiores são as perdas. Por exemplo, no exemplar resolvido da classe 99 pela heurística de acoplamento, a heurística de arredondamento fez 5 iterações e teve uma perda total de $14,49 \%$, porém as perdas em cada iteração foram: $13,52 \%$, $14,22 \%, 17,49 \%, 52,84 \%, 64,37 \%$, respectivamente. Naturalmente, muitas perdas calculadas como tal, seriam retalhos a serem aproveitados pela indústria nos períodos seguintes.

A Tabela 6.22 e a Figura 6.13 mostram os desvios entre as soluções relaxada e inteira para os exemplares da Tabela 6.21 resolvidos pelas heurísticas HD e HA.

\begin{tabular}{|c|c|c|c|c|c|c|c|c|}
\hline \multicolumn{10}{|c|}{ Desvio - Solução contínua x solução inteira } \\
\hline Exemplar & $\begin{array}{c}\text { HD } \\
(\%)\end{array}$ & $\begin{array}{c}\text { HA } \\
(\%)\end{array}$ & Exemplar & $\begin{array}{c}\text { HD } \\
(\%)\end{array}$ & $\begin{array}{c}\text { HA } \\
(\%)\end{array}$ & Exemplar & $\begin{array}{c}\text { HD } \\
(\%)\end{array}$ & $\begin{array}{c}\text { HA } \\
(\%)\end{array}$ \\
\hline $\mathbf{1}$ & 0,53 & $\mathbf{0 , 4 8}$ & $\mathbf{3 7}$ & - & $\mathbf{0 , 6 7}$ & $\mathbf{7 3}$ & - & $\mathbf{0 , 5 2}$ \\
\hline $\mathbf{2}$ & 0,58 & $\mathbf{0 , 4 8}$ & $\mathbf{3 8}$ & - & $\mathbf{0 , 6 7}$ & $\mathbf{7 4}$ & - & $\mathbf{0 , 3 9}$ \\
\hline $\mathbf{3}$ & - & $\mathbf{0 , 5 1}$ & $\mathbf{3 9}$ & 0,69 & $\mathbf{0 , 6 5}$ & $\mathbf{7 5}$ & 0,57 & $\mathbf{0 , 4 6}$ \\
\hline $\mathbf{4}$ & 0,90 & $\mathbf{0 , 5 0}$ & $\mathbf{4 0}$ & 0,75 & $\mathbf{0 , 4 3}$ & $\mathbf{7 6}$ & 0,80 & $\mathbf{0 , 4 7}$ \\
\hline $\mathbf{1 3}$ & $\mathbf{0 , 6 0}$ & 0,62 & $\mathbf{4 9}$ & $\mathbf{0 , 5 8}$ & 0,70 & $\mathbf{8 5}$ & $\mathbf{0 , 5 7}$ & 0,76 \\
\hline $\mathbf{1 4}$ & $\mathbf{0 , 6 0}$ & 0,67 & $\mathbf{5 0}$ & $\mathbf{0 , 5 8}$ & 0,77 & $\mathbf{8 6}$ & $\mathbf{0 , 5 7}$ & 0,77 \\
\hline $\mathbf{1 5}$ & $\mathbf{0 , 5 2}$ & 0,55 & $\mathbf{5 1}$ & $\mathbf{0 , 5 1}$ & 0,69 & $\mathbf{8 7}$ & $\mathbf{0 , 4 9}$ & 0,78 \\
\hline $\mathbf{1 6}$ & 0,72 & $\mathbf{0 , 6 4}$ & $\mathbf{5 2}$ & 0,70 & $\mathbf{0 , 5 5}$ & $\mathbf{8 8}$ & 0,68 & $\mathbf{0 , 5 8}$ \\
\hline $\mathbf{2 5}$ & $\mathbf{0 , 6 0}$ & 0,72 & $\mathbf{6 1}$ & $\mathbf{0 , 5 9}$ & 0,69 & $\mathbf{9 7}$ & $\mathbf{0 , 5 7}$ & 0,67 \\
\hline $\mathbf{2 6}$ & $\mathbf{0 , 6 0}$ & 0,70 & $\mathbf{6 2}$ & $\mathbf{0 , 5 9}$ & 0,80 & $\mathbf{9 8}$ & $\mathbf{0 , 5 7}$ & $\mathbf{0 , 5 7}$ \\
\hline $\mathbf{2 7}$ & $\mathbf{0 , 6 0}$ & 0,62 & $\mathbf{6 3}$ & 0,59 & $\mathbf{0 , 5 8}$ & $\mathbf{9 9}$ & $\mathbf{0 , 5 7}$ & 0,61 \\
\hline $\mathbf{2 8}$ & $\mathbf{0 , 6 0}$ & 0,70 & $\mathbf{6 4}$ & $\mathbf{0 , 4 5}$ & 0,67 & $\mathbf{1 0 0}$ & $\mathbf{0 , 5 5}$ & 0,74 \\
\hline
\end{tabular}

Tabela 6.22: Desvios entre as soluções contínuas e inteiras 


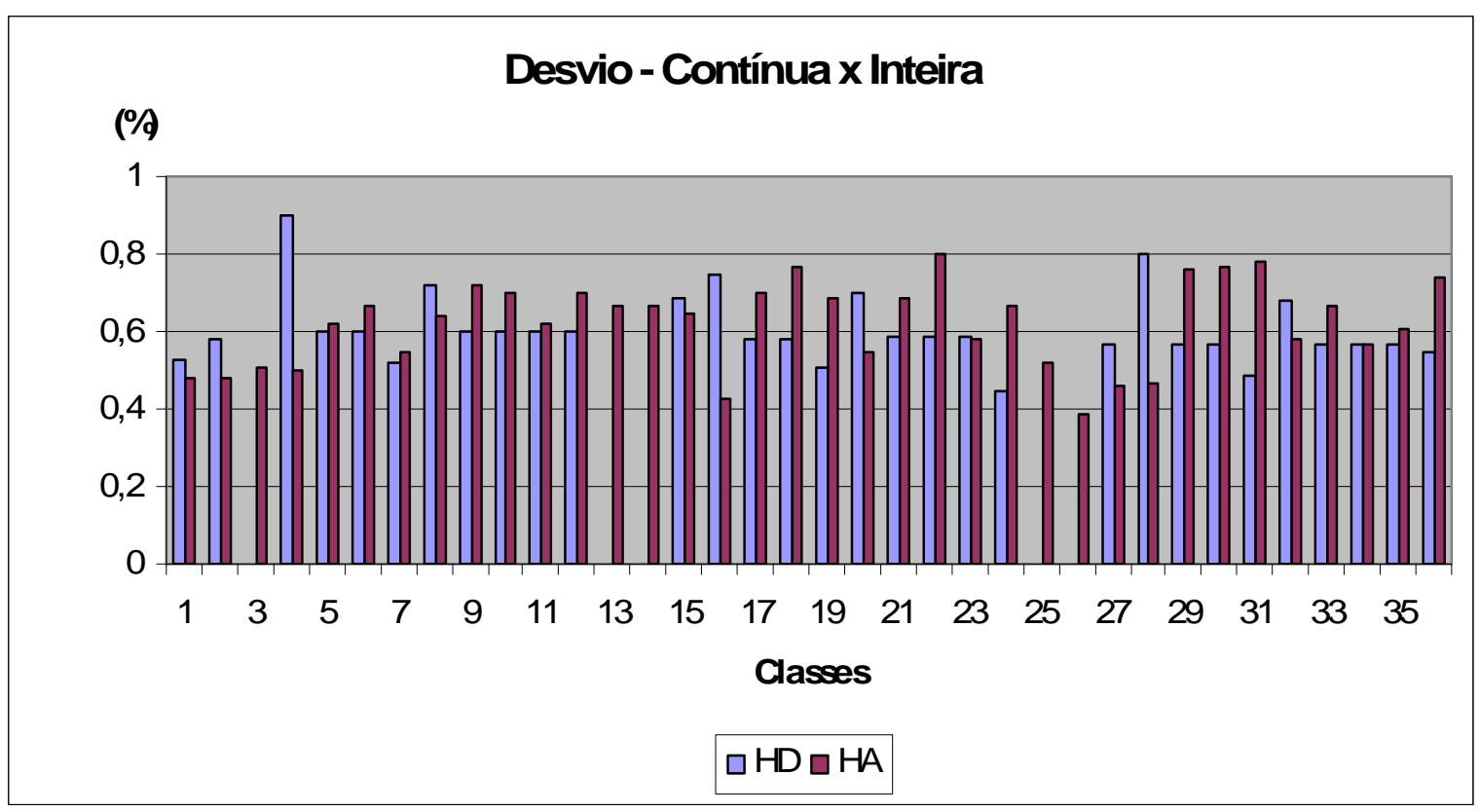

Figura 6.13: Comparação dos desvios entre as soluções contínuas e inteiras.

Analisando os desvios entre as soluções contínua e inteira, podemos dizer que as soluções inteiras obtidas pelas duas heurísticas de acoplamento e decomposição para estes exemplares são boas, pois o maior desvio obtido não chegou a $1 \%$.

\subsubsection{CPLEX 10.0 versus GLPK}

Nesta seção, comparamos o tempo total médio de resolução para obter a solução relaxada do problema acoplado quando utilizamos os softwares CPLEX 10.0 e GLPK para resolver os problemas de otimização linear e inteira a cada iteração da heurística de acoplamento.

Foram resolvidas as 108 classes de exemplares e os tempos totais médios são apresentados na Tabela 6.23 e Figura 6.14.

Conforme a Tabela 6.23, o tempo total médio de resolução dos problemas de otimização usando o CPLEX 10.0 é menor em todas as classes testadas. No pior caso, o GLPK demorou 6,2 vezes mais tempo (classe 45) para resolver o mesmo problema que o CPLEX e no melhor caso, o GLPK foi 1,7 vezes (classe 75) mais lento.

Se considerarmos o tempo total necessário para obter uma solução inteira usando a heurística residual de arredondamento gulosa, a diferença no tempo de resolução do problema relaxado torna-se bem menos significativa. Além disso, o fato de poder utilizar um software livre para resolver os problemas de otimização é mais importante que a desvantagem em relação ao tempo de resolução do problema relaxado utilizando tal software, pois isto pode viabilizar o emprego da abordagem proposta em indústrias de pequeno porte. 


\begin{tabular}{|c|c|c|c|c|c|c|c|c|c|c|c|}
\hline \multicolumn{12}{|c|}{ Tempo total médio de resolução (s) - Problema relaxado } \\
\hline \multirow{2}{*}{ Classe } & \multirow{2}{*}{$\alpha$} & \multirow{2}{*}{$\boldsymbol{h}$} & \multirow{2}{*}{ Demanda } & \multicolumn{2}{|c|}{$\gamma=0,05$} & \multirow{2}{*}{ Classe } & \multicolumn{2}{|c|}{$\gamma=0,1$} & \multirow{2}{*}{ Classe } & \multicolumn{2}{|c|}{$\gamma=\mathbf{0 , 1 5}$} \\
\hline & & & & CPLEX & GLPK & & CPLEX & GLPK & & CPLEX & GLPK \\
\hline 1 & & 0,0001 & \multirow{12}{*}{ Baixa } & 46,09 & 98,44 & 37 & 34,06 & 106,75 & 73 & 46,83 & 117,13 \\
\hline 2 & & 0,001 & & 38,09 & 102,05 & 38 & 33,97 & 107,89 & 74 & 49,13 & 110,22 \\
\hline 3 & 0,5 & $\mathbf{0 , 0 1}$ & & 34,30 & 104,66 & 39 & 34,06 & 105,30 & 75 & 49,17 & $\mathbf{8 4 , 8 0}$ \\
\hline 4 & & $\mathbf{0 , 1}$ & & 45,20 & 126,14 & 40 & 35,00 & 86,53 & 76 & 52,56 & 114,14 \\
\hline 5 & & 0,0001 & & 46,02 & 101,61 & 41 & 35,09 & 99,66 & 77 & 48,19 & 115,36 \\
\hline 6 & 1 & 0,001 & & 38,53 & 101,81 & 42 & 34,25 & 133,88 & 78 & 47,70 & 112,34 \\
\hline 7 & 1 & 0,01 & & 35,36 & 102,99 & 43 & 33,64 & 126,64 & 79 & 50,59 & 253,24 \\
\hline 8 & & 0,1 & & 45,38 & 130,39 & 44 & 34,94 & 93,92 & 80 & 56,28 & 123,53 \\
\hline 9 & \multirow{4}{*}{1,5} & 0,0001 & & 46,08 & 95,64 & 45 & 34,50 & 213,44 & 81 & 47,48 & 122,25 \\
\hline 10 & & 0,001 & & 38,36 & 100,03 & 46 & 34,27 & 128,95 & 82 & 50,06 & 126,99 \\
\hline 11 & & 0,01 & & 35,22 & 102,34 & 47 & 33,84 & 112,77 & 83 & 50,38 & 95,31 \\
\hline 12 & & 0,1 & & 46,05 & 126,84 & 48 & 34,91 & 91,13 & 84 & 53,58 & 120,02 \\
\hline 13 & \multirow{4}{*}{0,5} & 0,0001 & \multirow{12}{*}{ Média } & $\begin{array}{l}59,78 \\
\end{array}$ & 125,94 & 49 & 41,94 & 103,64 & 85 & 50,20 & 125,94 \\
\hline 14 & & 0,001 & & 58,70 & 136,94 & 50 & 42,02 & 97,27 & 86 & 50,70 & 136,94 \\
\hline 15 & & 0,01 & & 55,25 & 122,13 & 51 & 46,31 & 118,50 & 87 & 51,83 & 122,13 \\
\hline 16 & & 0,1 & & 56,63 & 110,20 & 52 & 35,75 & 111,53 & 88 & 45,48 & 110,20 \\
\hline 17 & \multirow{4}{*}{1} & 0,0001 & & 59,11 & 132,11 & 53 & 42,11 & 111,67 & 89 & 51,84 & 132,11 \\
\hline 18 & & 0,001 & & 56,41 & 123,84 & 54 & 41,11 & 108,56 & 90 & 48,89 & 123,84 \\
\hline 19 & & 0,01 & & 59,75 & 118,41 & 55 & 45,33 & 106,75 & 91 & 52,72 & 118,41 \\
\hline 20 & & 0,1 & & 57,39 & 119,24 & 56 & 36,94 & 114,28 & 92 & 44,52 & 119,24 \\
\hline 21 & \multirow{4}{*}{1,5} & 0,0001 & & $\begin{array}{l}57,70 \\
\end{array}$ & 132,86 & 57 & 44,42 & $\begin{array}{l}97,88 \\
\end{array}$ & 93 & 53,11 & 132,86 \\
\hline 22 & & 0,001 & & 58,88 & 119,30 & 58 & 44,25 & 107,63 & 94 & 50,44 & 119,30 \\
\hline 23 & & 0,01 & & 56,20 & 117,98 & 59 & 47,77 & 117,49 & 95 & 46,66 & 117,98 \\
\hline 24 & & 0,1 & & 64,42 & 120,39 & 60 & 36,25 & 115,75 & 96 & 43,80 & 120,39 \\
\hline 25 & \multirow{4}{*}{0,5} & 0,0001 & \multirow{12}{*}{ Alta } & 32,94 & 127,74 & 61 & 44,42 & 131,99 & 97 & 63,45 & 126,74 \\
\hline 26 & & 0,001 & & 40,34 & 162,08 & 62 & 44,25 & 122,88 & 98 & 62,75 & 131,78 \\
\hline 27 & & 0,01 & & 46,17 & 123,49 & 63 & 47,77 & 121,50 & 99 & 62,34 & 127,39 \\
\hline 28 & & 0,1 & & 48,33 & 124,58 & 64 & 36,25 & 118,81 & 100 & 61,61 & 113,53 \\
\hline 29 & \multirow{4}{*}{1} & 0,0001 & & 54,39 & 132,92 & 65 & 58,84 & 272,61 & 101 & 62,20 & 127,06 \\
\hline 30 & & 0,001 & & 56,50 & 131,00 & 66 & 57,23 & 126,28 & 102 & 61,53 & 128,86 \\
\hline 31 & & 0,01 & & 56,50 & 129,27 & 67 & 56,03 & 126,95 & 103 & 62,89 & 142,45 \\
\hline 32 & & 0,1 & & 56,72 & 123,30 & 68 & 49,53 & 121,38 & 104 & 57,81 & 114,30 \\
\hline 33 & \multirow{4}{*}{1,5} & 0,0001 & & $\begin{array}{l}58,92 \\
\end{array}$ & 124,31 & 69 & $\begin{array}{l}57,38 \\
\end{array}$ & 131,84 & 105 & 63,41 & 126,74 \\
\hline 34 & & 0,001 & & 51,77 & 130,67 & 70 & 58,55 & 123,91 & 106 & 57,89 & 149,41 \\
\hline 35 & & 0,01 & & 59,53 & 144,00 & 71 & 58,98 & 135,88 & 107 & 66,44 & 129,89 \\
\hline 36 & & 0,1 & & 61,00 & 113,14 & 72 & 52,84 & 131,75 & 108 & 61,36 & 115,75 \\
\hline
\end{tabular}

Tabela 6.23: Comparação do tempo total médio de resolução usando CPLEX 10.0 e GLPK 


\section{(s) \\ Tempo Total de Resolução}

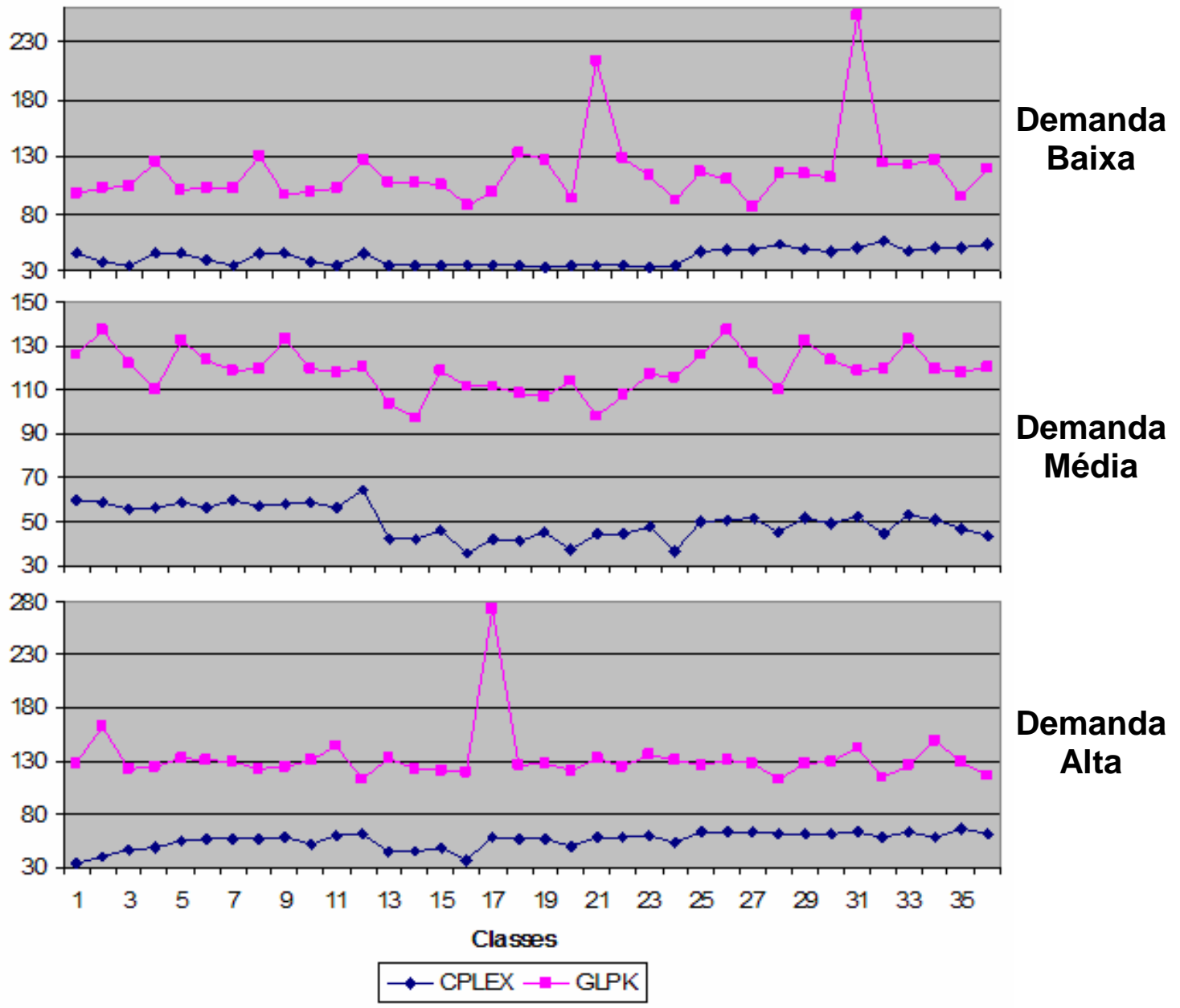

Figura 6.14: Comparação do tempo total médio de resolução usando CPLEX 10.0 e GLPK. 


\section{Capítulo 7}

\section{Conclusões e Perspectivas}

Neste capítulo, descrevemos resumidamente os principais passos realizados nesta tese, apresentamos as conclusões de acordo com os resultados dos experimentos computacionais e sugerimos algumas propostas para melhoria e continuidade deste trabalho. A Seção 7.1 referese às conclusões e a Seção 7.2 traz as perspectivas de trabalhos futuros.

\subsection{Conclusões}

Nesta tese tratamos o processo produtivo da indústria de móveis residenciais (dormitório) que consiste em: cortar placas retangulares grandes de MDF em peças menores conforme diversos padrões de corte, as quais são furadas para comporem um conjunto de produtos demandados. As placas de MDF estocadas são de tamanho único, várias espessuras e estão disponíveis em quantidades suficientes para atender as demandas dos produtos finais, as quais são estocásticas e caracterizadas pela sazonalidade. A serra e a furadeira possuem limites de capacidade e representam possíveis gargalos da produção. Em outras palavras, o processo produtivo da indústria de móveis resume-se em: resolver um problema de corte de estoque bidimensional e um problema de dimensionamento de lotes com múltiplos itens, ambos com restrições de capacidade de máquinas.

Diante deste problema, propomos um modelo acoplado de otimização linear inteiro para representá-lo, o qual acopla os problemas de dimensionamento de lotes e corte de estoque. Este modelo apresenta três principais dificuldades de resolução, além das restrições de acoplamento, que são: a integralidade das variáveis, as variáveis de preparação de máquina no processo de corte e o grande número de variáveis referentes aos padrões de corte bidimensionais.

Por causa destas dificuldades, na prática, as indústrias resolvem os problemas de dimensionamento de lotes e corte de estoque separadamente (tipicamente por métodos empíricos). Mesmo obtendo uma solução factível para os dois problemas separadamente, ao agregar suas soluções pode surgir infactibilidade. 
Um fato importante que sugere a modelagem do problema acoplado deve-se à antecipação da produção de certos produtos finais, a qual leva a um compromisso entre aumentar os custos de estoque dos produtos enquanto se diminui os custos com as placas cortadas ao reduzir a perda de matéria-prima, devido a um melhor arranjo das peças nos padrões de corte.

$\mathrm{Na}$ tentativa de contornar as dificuldades apresentadas e, consequentemente, conseguir resolver o modelo acoplado, fizemos algumas simplificações, relaxando a integralidade das variáveis e removendo as variáveis de preparação de máquina (o tempo de preparação foi incorporado nas capacidades). Assim, passamos a ter um modelo acoplado de otimização linear com um grande número de varáveis a ser resolvido. Para isto, desenvolvemos dois métodos heurísticos de solução (heurísticas de acoplamento e de decomposição) baseados no método simplex com geração de colunas, o qual permite resolver problemas com um número grande de variáveis, uma vez que relativamente poucas colunas são armazenadas e as demais são consideradas implicitamente e geradas à medida que forem necessárias.

A questão da estocasticidade da demanda dos produtos finais é tratada utilizando a estratégia de horizonte de planejamento rolante (em que as decisões do primeiro período são detalhadas nos subperíodos) e considerando a demanda esperada dos produtos formada pela soma da demanda em carteira de todos os períodos do horizonte de planejamento mais a demanda extra prevista (representada por variáveis de oportunidade) dos produtos para o horizonte inteiro.

Ambas heurísticas de acoplamento (HA) e de decomposição (HD) resolvem os problemas de dimensionamento de lotes e corte de estoque interativamente, mas de formas diferentes, conforme descrito no Capítulo 5.

Para gerar as novas colunas foram propostas duas abordagens. Resumidamente, a primeira abordagem gera, em cada iteração do método simplex, um padrão de corte para cada subperíodo e cada espessura resolvendo subproblemas de corte e, então, constrói as novas colunas a serem inseridas no problema mestre do modelo relaxado. A segunda abordagem tenta usar um mesmo padrão de corte construído para um determinado subperíodo para construir colunas para outros subperíodos e, com isso, menos subproblemas precisam ser resolvidos por iteração. Diante dos resultados obtidos nos experimentos computacionais realizados com o intuito de comparar estas duas abordagens, concluímos que a segunda abordagem é a mais eficiente, pois ao utilizá-la, é possível conseguir a mesma solução da relaxação linear do problema acoplado em um tempo total de solução menor.

Variáveis artificiais foram inseridas no modelo relaxado nas restrições de acoplamento e de capacidade da serra e furadeira dos subperíodos no problema de corte de estoque. Os valores positivos das variáveis artificiais nas restrições de acoplamento indicam a quantidade de peças que ainda precisam ser cortadas e furadas nos subperíodos para comporem os produtos demandados no primeiro período e os valores positivos nas restrições de capacidade indicam quanto tempo de máquina falta para cortar e/ou furar todas as peças requeridas no primeiro período.

Os experimentos realizados com as heurísticas de decomposição e de acoplamento inserindo variáveis artificiais ora nas restrições de acoplamento (VA) ora nas restrições de capacidade (VC) mostraram que em ambas heurísticas o tempo total médio de resolução é menor quando as variáveis artificiais estão nas restrições de acoplamento e a maior diferença no tempo entre VA e VC foi com a heurística de decomposição, a qual foi mais rápida. Porém, dependendo da informação desejada, deve-se escolher a opção adequada. 
Dando continuidade ao trabalho, fizemos uma série de experimentos para analisar o comportamento das soluções ao modificar alguns dos parâmetros do modelo e observar se uma das heurísticas (HA e HD) é mais sensível que a outra diante das variações. Os parâmetros modificados foram: demanda esperada dos produtos, quantidade de tipos de produtos finais, capacidade das máquinas e estimativa da perda usada no cálculo dos custos de produção a partir do segundo período.

Quando variamos a demanda esperada, o comportamento das soluções de ambas heurísticas (HA e HD) foi semelhante aos testes anteriores. Observando a programação da produção, é possível verificar que as pequenas modificações ocorreram somente para se adaptar aos novos valores.

Variando a quantidade de tipos de produtos, ambas heurísticas (HA e HD) obtiveram encontrar soluções factíveis para o problema acoplado para no máximo 10 tipos de produtos com demandas médias. Na prática, isto quer dizer que com a capacidade de máquina atual da fábrica de móveis é possível produzir num horizonte de planejamento com 4 períodos, no máximo 10 tipos de produtos com demandas médias.

Ao diminuir e aumentar as capacidades das máquinas nos períodos e subperíodos, as perdas percentuais de matéria-prima pouco se alteram e o número de placas cortadas reflete a variação da produção do primeiro período ao alterar as capacidades. Ambas as heurísticas (HD e HA) não encontraram solução para o caso da demanda alta, quando a capacidade foi apertada.

Quando mudamos a estimativa da perda no cálculo dos custos de produção, a partir do segundo período, por considerar as perdas da solução lote-por-lote, fica claro a influência deste parâmetro nas soluções da heurística de acoplamento, pois quando a estimativa é subestimada, ocorre pouca antecipação da produção da demanda em carteira e da parcela da demanda extra, e quando ela é mais realista acontece o inverso, que faz com que as perdas sejam reduzidas. Estas observações reforçam a capacidade do modelo em encontrar soluções de compromisso, pagando-se mais por estoque, porém reduzindo os custos com as perdas.

Depois de todos estes experimentos realizados, podemos dizer que a heurística de decomposição (HD) é menos sensível à variação dos parâmetros do problema, pois tal heurística procura sempre produzir o máximo possível no primeiro período, o que não é tão ruim, conforme mostraram os seus resultados. Já a heurística de acoplamento (HA) mostrouse mais sensível à variação dos parâmetros, principalmente, ao variar a estimativa de perda do segundo período em diante e ao aumento dos custos de estoque.

Dando continuidade aos experimentos, usando a heurística de acoplamento, determinamos algumas soluções do problema acoplado para o horizonte de planejamento inteiro, considerando a demanda esperada igual à demanda em carteira, sem adicionar novas demandas ao rolar o horizonte. Comparamos as soluções do primeiro período com as soluções lote-por-lote e os resultados mostraram que, em termos de perda, a antecipação da produção realmente, faz as perdas diminuírem.

No primeiro passo da heurística de decomposição, ao resolver o problema de dimensionamento de lotes sem se preocupar com o corte e a furação, lotes muito grandes dos produtos podem ser programados para o primeiro período, fazendo com que a capacidade das máquinas nos subperíodos não sejam suficientes para atender à demanda de peças. Surge então a necessidade de aplicar uma heurística de factibilização para eliminar tais infactibilidades. A heurística de factibilização proposta, que consiste em reduzir as dimensões dos lotes dos produtos com valores positivos, previamente ordenados, primeiro reduzindo-se 
as variáveis de oportunidade e, depois, as variáveis de estoque, conseguiu factibilizar todos os exemplares testados.

Uma vez obtida a solução do problema relaxado, o próximo passo foi determinar uma solução inteira para o problema acoplado. Para isto, implementamos uma heurística baseada na heurística residual de arredondamento gulosa proposta na literatura. Os resultados apresentados ao utilizar tal heurística não foram muito bons com relação ao tempo de resolução e também à perda de matéria-prima. Mas, ao considerar o desvio (menor que $1 \%$ no pior caso) com relação à solução contínua, vemos que suas soluções são satisfatórias.

É importante salientar que, os valores relativamente altos das perdas com matériaprima, apresentados nos experimentos, não são reais na prática, uma vez que, alguns padrões de corte gerados, principalmente, quando a demanda de peça é baixa, chegam utilizar até menos da metade da placa de MDF e o restante da placa não é considerado como perda pela indústria, pois será reaproveitado. Neste trabalho, o reaproveitamento não foi considerado e as sobras grandes foram consideradas como perdas.

Finalmente, com o intuito de não deixar o código "preso" a um software comercial de custo alto (considerando a realidade de pequenas empresas do setor) para a resolução dos problemas de otimização linear e inteira, fizemos as alterações necessárias para um software livre (GLPK). De acordo com os resultados dos experimentos, o código com o GLPK funcionou adequadamente, porém teve um maior tempo total médio de resolução, como era esperado.

\subsection{Perpectivas}

O modelo de otimização linear inteiro proposto para o problema acoplado na indústria de móveis, objeto de estudo desta tese, tem sua dificuldade de resolução aumentada devido às restrições de acoplamento (4.5.6). Um outro método de solução pode ser construído com base na relaxação Lagrangiana das restrições de acoplamento, as quais são dualizadas e incorporadas na função objetivo, penalizadas pelos multiplicadores de Lagrange. Esta relaxação permite decompor o problema em dois subproblemas, um no grupo das variáveis de produção e outro no grupo das variáveis de corte. Para atualizar os multiplicadores de Lagrange, o método do subgradiente pode ser usado.

A solução do problema Lagrangiano fornece um limitante inferior para a solução ótima do problema acoplado. Sendo assim, deve-se procurar por multiplicadores de Lagrange que forneçam o maior dos limitantes inferiores, para que se tenha uma solução mais próxima possível da solução ótima do problema acoplado (problema dual lagrangiano).

Uma sugestão para melhoria do modelo proposto seria modelar o problema de corte de estoque bidimensional como um problema multiperíodo acrescentando o estoque de peças.

Mediante aos resultados não satisfatórios, com relação ao tempo de resolução e a perda de matéria-prima, apresentados nos testes para obtenção de solução inteira do problema acoplado, em que a heurística residual de arredondamento gulosa é utilizada, ficou evidente a necessidade de uma investigação mais profunda em tal heurística para poder adequá-la ao caso de demandas baixas que precisam ser atendidas na igualdade. Uma outra alternativa, seria permitir o excesso de peças cortadas, as quais excedentes não representarão desperdício ou prejuízo para a indústria, uma vez que podem ser estocadas e, posteriormente, utilizadas como peças de reposição. Esta prática é comum em indústrias de móveis, principalmente, por causa de danos em peças que ocorrem durante o transporte e montagem dos produtos. 
Uma sugestão para melhorar a questão das perdas, seria incorporar o aproveitamento de sobras (Cherri et al., 2008, Abuabara e Morabito, 2008) durante a geração dos padrões de corte bidimensional guilhotinado 2-estágios exatos restritos na heurística residual de arredondamento para obtenção de solução inteira. 


\section{Referências Bibliográficas}

1. ABUABARA, A., MORABITO, R., Cutting optimization of structural tubes to build agricultural light aircrafts. Annals of Operations Research, (2008), doi 10.1007/s 10479008-0438-7.

2. ARBIB, C., MARINELLI, F., Integrating process optimization and inventory planning in cutting-stock with skiving option: An optimization model and its application, European Journal of Operational Research 163, 617-630, (2005).

3. ARENALES, M. N., MORABITO, R. N., An And/Or-graph approach to the solution of two-dimensional non-guillotine cutting problems. European Journal of Operational Research 84(1), 599-617, (1995).

4. BAHL, H. C., RITZMAN, L. P., GUPTA, J. N. D., Determining lot sizes and resources requirements: a review. Operations Research 35(3), 329-345, (1987).

5. BILlingtON, P. J., McClAIN, J. O., THOMAS, L. J., Mathematical programming approaches to capacity MRP systems: review, formulation and problem reduction. Management Science 29(10), 1126-1141, (1983).

6. BRAHIMI, N., DAUZERE-PERES, S., NAJID, N., NORDLI, A., Single item lot sizing problems. European Journal of Operational Research 168, 1-16, (2006).

7. BITRAN, R. G., YANASSE, H. H., Computational complexity of the capacitated lot size problem. Management Science 28(3), 1174-1186, (1982).

8. CHERRI, A. C., ARENALES, M. N., YANASSE, H. H., The one dimensional cutting stock problems with usable leftover: A heuristic approach. European Journal of Operational Research, (2008), doi10.1016/j.ejor.2008.04.039.

9. DYCKHOFF, H., A typology of cutting and packing problems. European Journal of Operational Research 44, 145-159, (1990).

10. FIGUEIREDO, A. G., Análise de produtividade de padrões de corte na indústria de móveis. Dissertação de mestrado, IBILCE - UNESP - São José do Rio Preto, (2006).

11. GILMORE, P. C., GOMORY, R. E., A linear programming approach to the cutting stock problem. Operations Research 9, 848-859, (1961).

12. GILMORE, P. C., GOMORY, R. E., A linear programming approach to the cutting stock problem - Part II. Operations Research 11, 863-888, (1963). 
13. GILMORE, P. C., GOMORY, R. E., Multi-stage cutting stock problems of two and more dimensions. Operations Research 13, 94-120, (1965).

14. GRAMANI, M. C., Otimização do processo de cortagem acoplado ao planejamento da produção. Tese de doutorado, DENSIS-UNICAMP, (2001).

15. GRAMANI, M. C. N., FRANÇA, P. M., The combined cutting stock and lot-sizing problem in industrial processes, European Journal of Operational Research 174, 509-521, (2006).

16. HAESSLER, R. W., A heuristic programming solution to a nonlinear cutting stock problem. Management Science 17(12), 793-802, (1971).

17. HENDRY, L. C., FOK, K. K., SHEK, K. W., A cutting-stock and scheduling in the cooper industry, Journal of the Operational Research Society 47, 37-48, (1996).

18. HERZ, J., Recursive computational procedure for two-dimensional stock cutting. IBM Journal on Research Development 16, 462-469, (1972).

19. HIFI, M., ZISSIMOPOULOS, V., A recursive exact algorithm for weighted twodimensional cutting. European Journal of Operational Research 91, 553-564, (1996).

20. HINXMAN A., The trim-loss and assortment problems: A survey. European Journal of Operational Research 5, 8-18, (1980).

21. KANTOROVICH, L. V., Mathematical Methods of Organizing and Planning Production. Management Science 6(4), 366-422, (1960).

22. KARIMI, B., FATEMI GHOMI, S., WILSON, J., The capacitated lot sizing problem: a review of models and algorithms. OMEGA 31, 365-378, (2003).

23. MAES, J., McClAIN, J. O., VAN WASSENHOVE, L. N., Multilevel capacitated lotsizing complexity and LP-based heuristic. European Journal of Operational Research 53, 131-148, (1991).

24. MENON, S., SCHRAGE, L., Order allocation for stock cutting in the paper industry, Operations Research 50(2), 324-332, (2002).

25. MORABITO, R., Corte de estoque bidimensional. Dissertação de Mestrado, ICMC-USP, (1989).

26. MORABITO, R., Uma abordagem em grafo-e-ou para o problema de empacotamento: Aplicação ao carregamento de paletes e contêineres. Tese de doutorado, EESC-USP, (1992).

27. MORABITO, R., ARENALES, M. N., Performance of two heuristics for solving large scale two-dimensional guillotine cutting problems. INFOR - Canadian Journal of Operational Research and Information Processing 33(2), 145-155, (1995).

28. MORABITO, R., ARENALES, M., Staged and constrained two-dimensional guillotine cutting problems - an and/or-graph approach. European Journal of Operational Research 94, 548-560, (1996).

29. MURTY, K. G., Solving the fixed charge problem by ranking the extreme points. Operations Research 16, 268-279, (1968).

30. NONAS, S. L., THORSTENSON, A., A combined cutting-stock and lot-sizing problem, European Journal of Operational Research 120, 327-342, (2000). 
31. NONAS, S. L., THORSTENSON, A., Solving a combined cutting-stock and lot-sizing problem with a column generating procedure, Computers \& Operations Research 35, 3371-3392, (2008).

32. OLIVEIRA, J., FERREIRA, J., An improved version of Wang's algorithm for two dimensional cutting problems. European Journal of Operational Research 44, 256-266, (1990).

33. PINTO, M. J., O problema de corte de estoque inteiro. Dissertação de Mestrado, ICMCUSP, (1999).

34. POLDI, K. C. Algumas extensões do problema de corte de estoque. Dissertação de mestrado, ICMC - USP, (2003).

35. POLDI, K. C., O problema de corte de estoque multiperíodo. Tese de doutorado, ICMC USP, (2007).

36. POLDI, K. C., ARENALES, M. N., Heuristics for the one-dimensional cutting stock problem with limited multiple stock lengths, Computers and Operations Research, (2008) doi.org/10.1016/j.cor.2008.07.001.

37. POltRONIERE, S. C., POLDI, K. C., TOLEDO, F. M. B., ARENAlES, M. N., A coupling cutting stock-lot sizing problem in the paper industry, Annals of Operations Research 157, 91-104, (2008).

38. REINDERS, M. P., Cutting stock optimization and integral production planning for centralized wood processing, Mathematical Computational Modeling 16(1), 37-55, (1992).

39. RESPÍCIO, A., CAPTIVO, M. E., Integrating the cutting stock problem in capacity planning, Department of Informatics and Centre of Operational Research - University of Lisbon - Portugal, 1-11, (2002).

40. SANTOS, M. O., Problemas de dimensionamento de lotes: Modelos e Métodos. Tese de doutorado, ICMC-USP, (2000).

41. STADTLER, H., A one-dimensional cutting stock problem in the aluminum industry and its solution. European Journal of Operational Research 44, 209-223, (1990).

42. VANDERBECK, F., Decomposition and column generation for integer programs. Ph.D. thesis, Université Catholique de Louvain, Belgium, (1994).

43. VIANNA, A., Problemas de corte e empacotamento: uma abordagem em grafo E/OU. Tese de doutorado, ICMC-USP, (2000).

44. WAGNER, H. M., WHITIN, T. M., Dynamic version of the economic lot size model. Management Science 5(1), 89-96, (1958).

45. WANG, P. Y., Two algorithms for constrained two-dimensional cutting stock problem. Operations Research 31(3), 573-586, (1983).

46. WÄSCHER, G., GAU, T., Heuristics for the integer one-dimensional cutting stock problem: a computational study. OR Spektrum 18, 131-144, (1996). 